\author{
UNIVERSIDADE DE SÃO PAULO \\ ESCOLA DE ENFERMAGEM DE RIBEIRÃO PRETO
}

CAMILA APARECIDA PINHEIRO LANDIM

Adaptação cultural para o Brasil e Portugal do instrumento Patient Assessment of Chronic Illness Care (PACIC)

Ribeirão Preto 


\section{Adaptação cultural para o Brasil e Portugal do instrumento Patient Assessment of Chronic Illness Care (PACIC)}

Tese apresentada à Escola de Enfermagem de Ribeirão Preto da Universidade de São Paulo, para obtenção do título de Doutor em Ciências, Programa Enfermagem Fundamental.

Linha de Pesquisa: Processo de cuidar do adulto com doenças agudas e crônicodegenerativas.

Orientadora: Profa. Dra. Carla Regina de Souza Teixeira

Ribeirão Preto 
Autorizo a reprodução e divulgação total ou parcial deste trabalho por qualquer meio convencional ou eletrônico para fins de estudo e pesquisa, desde que seja citada a fonte.

Landim, Camila Aparecida Pinheiro

Adaptação cultural para o Brasil e Portugal do instrumento Patient Assessment of Chronic Illness Care (PACIC). Ribeirão Preto, 2012.

197 p. : il. ; 30cm

Tese de Doutorado, apresentada à Escola de Enfermagem de Ribeirão Preto/USP. Área de concentração: Enfermagem Fundamental.

Orientadora: Profa. Dra. Carla Regina de Souza Teixeira

1. Doença Crônica. 2. Diabetes Mellitus. 3. Enfermagem. 4. Tradução

5. Adaptação. 7. Brasil. 8. Portugal. 
LANDIM, Camila Aparecida Pinheiro

Adaptação cultural para o Brasil e Portugal do instrumento Patient Assessment of Chronic Illness Care (PACIC)

Tese apresentada à Escola de Enfermagem de Ribeirão Preto da Universidade de São Paulo, para obtenção do título de Doutor em Ciências, Programa Enfermagem Fundamental.

Aprovado em / /

Comissão Julgadora

Prof. Dr::

Instituição: Assinatura:

Prof. Dr:

Instituição: Assinatura:

Prof. Dr.:

Instituição: Assinatura:

Prof. Dr.:

Instituição: Assinatura:

Prof. Dr.:

Instituição: Assinatura: 


\section{DEDICATÓRIAS}

Aos meus pais, Antânia Carlas e Lúcia...

...que durante todos os dias de suas vidas dedicaram-se à renúncia dos seus próprios sonhos para a realização dos meus. A vocês, minha eterna gratidão pela integridade e nobreza de seus sentimentos, por me permitirem sentir carinhosamente o significado da palavra família, pelos incansáveis esforços destinados à minha educação desde a infância e crescimento espiritual. Papai e mamãe, eu os amo incondicionalmente!

\section{Aos meus irmãos, Nila e $\mathcal{N}$ icárcia...}

...juntos desde o início da vida, compartilhamos sonhos e as certezas de um caminho que tudo transforma ao descobrirmos que o melhor da vida está dentro de nós. Em vocês, reconheço o mais puro amor e carinho. Amo muito.

\section{Ao $\mathcal{N i c k}$ (in memorian)...}

...agora um anjo, minha estrela-guia, cada vez mais presente no meu coração e iluminando todos os passos da minha vida. Esse sonho também é seu. Saudades...

Ao meu querido namorado Jaãa...

...presente iluminado de Deus, tu és indiscutivelmente o homem da minha vida. Hoje estou virando mais uma página da minha história e quero que saibas que tu foste a minha grande motivação. Sempre com amor, carinho e dedicação, muito obrigada pelas palavras de incentivo e afeto, motivando o meu crescimento enquanto pessoa e profissional. És a minha alegria, a minha proteção... tu és a minha vida! Fernando Pessoa já dizia: "Amo como ama o amor, não conheço nenhuma razão para amar senão amar". Como se o amor fosse o teu nome, simplesmente, AMO-TE!

"Olm sonho sonhado sozinho permanece apenas um sonho; um sonho sonhado junto pode tornar-se vealidade" 


\section{AGRADECIMENTO ESPECIAL}

Ao meu criador e Pai, Deus...

...agradeço por me sustentar em suas mãos, por todos os livramentos que deste em minha vida e por atentar às minhas orações.

"A/s tuas mãos me fizeram e me formaxam; dá-me inteligência para entender os teus mandamentos"

(Oalmos 119:73)

À minha orientadora Prafa. Dra. Carla Regina de Sawza Teixeira...

...pela amizade, apoio, compreensão e transmissão de conhecimentos com seriedade e alegria.

Pela presença e ajuda incontestável durante a minha trajetória acadêmica e profissional.

Muito obrigada por tudo!

"Yâa se pode ensinar undo a alguém,

pode-se apenas ajuda-lo a encontrax a si mesmo"

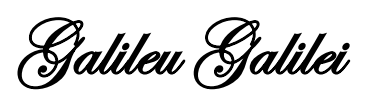




\section{AGRADECIMENTOS}

\section{À Profa. Dra. Maria Lúcia Zanetti...}

...sua postura simples e perfeita é digna de admiração.

Muito obrigada pelo carinho, força e paciência

nas sugestões fundamentais para o aperfeiçoamento desse trabalho.

À Prafa. Dra. Cláudia Benedita das Santas...

...pela grande contribuição para a realização desse estudo, pela gentileza e atenção que sempre me foram dispensadas.

\section{À Profa. Dra. Rasana Aparecida Spadati Dantas...}

...pelas considerações iniciais e pelo apoio no processo de elaboração desse estudo.

\section{À Prafa. Dra. Ana Emília Pace...}

...pela doçura e carinho com que sempre me recebeu, obrigada pela confiança

e pelas contribuições para o meu crescimento pessoal e profissional.

À Profa. Dra. Maria Lúcia Zanetti, à Profa. Dra. Ana Emilia Pace, às doutorandas Lilian Games-Villas Baas e Vúwan Veras

e à tradutora Lúuia Pasqualin...

...pela disponibilidade e importantes contribuições nesse trabalho como integrantes do Comitê de Especialistas em Ribeirão Preto-SP (Brasil).

\section{À Profa. Dra. Maria Manuela Martins...}

...pela simpatia e carisma que me recebeu na Escola Superior de Enfermagem do Porto, como amiga e supervisora do estágio internacional, a quem eu guardo uma imensa admiração. Pela valiosa contribuição e apoio para a realização desse trabalho.

À querida enfermeira e amiga Zulmira Sausa...

...pela atenção cuidadosa e apoio com que me recebeu no Ambulatório de Endocrinologia do Hospital São João (Portugal).

Às senhoras Prafa. Dra. Célia Santas, Profa. Dra. Maria da Céu Barliéri, Prafa. Dra. Isabel Araúja, enfermeira Zulmira Sausa... ...pelas significativas considerações nesse trabalho como integrantes do Comitê de Especialistas em Porto (Portugal). 


\section{Ao Praf. Dr. Dauide de Carralha...}

...pela amizade e participação indispensável como "Elo de Ligação"

entre o Hospital São João e a Comissão de Ética em Saúde da Faculdade de Medicina da Universidade do Porto.

Às minhas três irmãs Mânica Lina, Paula Pinheira e Kariane Games...

...pelo grande aprendizado compartilhado em Portugal e na Europa, por todos os momentos de descobertas, aconchego, frio, saudade, dificuldades, sorrisos, tristezas, trabalho, viagens, sonhos e diversão. Muito obrigada, sobretudo, pela amizade conquistada!

À minha querida tia Luiza $\mathcal{P}$ inha... ...pela força e apoio incondicionais em Portugal.

Aqui as palavras tornam-se difíceis e simplesmente insuficientes. Amo-te muito!

Aos meus amados, tia Zélia, tio $\mathcal{P e i x a t a}$ e primos Daniel e Caral... ...pelo amparo, força, amor e carinho durante essa caminhada.

Vocês são fantásticos! Amo muito vocês!

À minha irmã $\mathcal{T}$ ayana Xauier junto a sua princesinha Mariana... ...a minha admiração por você cresce exponencialmente, como um grande exemplo de vida pessoal e profissional. Muito obrigada pelo amor, cuidado e pelas palavras incansáveis de incentivo com contribuições significativas no desenvolvimento desse trabalho. Te amo!

Aos meus primos-irmãos Cadu, J́tala, Jaeffsan, Juan e Marlin... ...pela torcida, confiança, amor e carinho. Amo todos vocês!

Às amigas e aos amigos da pesquisa em educação em diabetes da EERP/USP:

Camila Rileas, Ellen Santas, Fláuia Luchetti, Gabriela Oliuatta, Gabriel Zanetti, Jeffersan Ganela, Mariana Daher, Paula Hadniki, Rasana Franca, Talita Balaminut, Tânia Becker, Thais Bertazane ...pelo companheirismo, apoio e carinho conquistados.

Às minhas especialíssimas amigas Andressa Kutschenka, Jaque Dias, Marilia Valim e Simara Barleasa ...pela doçura, alegria e apoio intermináveis durante a realização desse estudo.

As minhas lindas amigas de infância, Thiciana Raupp e Naiana Carualha... ...pelo verdadeiro laço de afeto e amizade. Amo vocês hoje e sempre! 
Aos meus amores e eternos amigos,

Carla Bastas, Gislany Dumant, Tallyne Mareira, Luia Braga, Luciana Zaranza, Priscilla Mata, Rulens e Samanth Ferreira...

Nada é mais valioso do que a amizade e o carinho de vocês.

Muito obrigada pela torcida!

Às sempre queridas Gabriela Vasters e Danielle Cabral ...pelo coração e energia contagiantes. Muito obrigada! Vocês são admiráveis!

A vocês, Cindy Hana, Daniela Masson-Meyers, Déleara Minatel,

Diane Rassi, Thiaga Andrade e Saula Nani...

...que fizeram parte do meu dia-a-dia, com empenho e bondade.

Pela contribuição direta ou indireta para a concretização desse trabalho.

Muito Obrigada!

Ao meu amigo Derlan, pelas ajudas e prontidão nos momentos de apuros. Muito obrigada pela disposição e simpatia!

Às pessaas cam dialeetes mellitus..

...que participaram desse estudo, o meu profundo agradecimento!

Às unidades ambulatariais de endacrinalagia...

...por permitirem a realização da coleta dos dados. Muito obrigada!

À Caardenaçãa de Aperfeiçaamenta de Pessaal de Núuel Superiar (CAPESP)... ...pelo auxílio financeiro concedido para a realização desse estudo.

À Prá-Reitaria de Pás-Graduaçãa - Uniuersidade de Sãa Paula (PRPG-USP) em parceria com o Banca Santander Brasil...

...pela concessão do financiamento para o estágio internacional, Tornando possível o desenvolvimento do estudo em Portugal.

A todos os prafessares e funcianárias da Escola de Enfermagem de Ribeirão Preto e da Escola Superior de Enfermagem do Porto... ...pela contribuição do meu crescimento profissional.

A todos os amigas e familiares...

...que de alguma forma contribuíram para a realização desse trabalho e que por ventura não tenha sido mencionado, os meus mais sinceros agradecimentos! 


\section{Time and a Word}

"In the morning when you rise,

Do you open up your eyes, see what I see?

Do you see the same things ev'ry day?

Do you think of a way to start the day

Getting things in proportion?

Spread the news and help the world go 'round.

Have you heard of a time that will help us get it together again?

Have you heard of the word that will stop us going wrong?

Well, the time is near and the word you'll hear

When you get things in perspective.

Spread the news and help the word go round.

There's a time and the time is now and it's right for me,

It's right for me, and the time is nawe.

There's a word and the word is love and it's right for me,

It's right for me, and the ward is lave."

Fon Mnderson IO David Froster 


\section{RESUMO}

LANDIM, C. A. P. Adaptação cultural para o Brasil e Portugal do instrumento Patient Assessment of Chronic Illness Care (PACIC). 2012. $196 \mathrm{f}$. Tese (Doutorado) - Escola de Enfermagem de Ribeirão Preto, Universidade de São Paulo, Ribeirão Preto, 2012.

O Patient Assessment of Chronic Illness Care (PACIC) é o único instrumento disponível na literatura científica para avaliação da qualidade do cuidado sobre os elementos do Modelo de Cuidados Crônicos, na perspectiva da pessoa com condição crônica. No contexto cultural do Brasil e de Portugal, não há instrumentos para avaliar essa dimensão de cuidado no diabetes mellitus (DM), considerada como uma importante condição crônica, em decorrência da sua prevalência e mortalidade mundial. Trata-se de um estudo metodológico com o objetivo de realizar a adaptação cultural para o Brasil e Portugal do instrumento PACIC. Constituído por 20 itens, o PACIC possui cinco domínios: Participação Ativa do Paciente no Tratamento, Modelo do Sistema de Cuidado/Modelo para a Prática, Estabelecimento de Metas/Adaptação, Resolução de Problemas/Contexto e Seguimento/Coordenação. O processo de adaptação cultural seguiu as etapas preconizadas pela literatura: Tradução, Comitê de Especialistas, Retrotradução (Back-Translation), Pré-Teste e Entrevista Cognitiva. O estudo foi realizado em ambulatório de endocrinologia, de uma unidade básica distrital de saúde no município de Ribeirão Preto, São Paulo, Brasil e de um hospital público e de ensino na cidade do Porto, Portugal. Os dados foram obtidos por meio da entrevista dirigida, nos meses de novembro (Brasil) e maio (Portugal) de 2012. Mediante os critérios de seleção, a população do estudo foi constituída por 50 pessoas brasileiras e 50 pessoas portuguesas, perfazendo um total de 100 pessoas com DM. Para a coleta de dados foi utilizado os instrumentos Impressão Geral e Específica do Projeto DISABKIDS ${ }^{\circledR}$. Para apresentação dos resultados utilizou-se análise descritiva, por meio de quadros e tabelas. Os resultados encontrados foram satisfatórios, demonstrando que o instrumento foi considerado muito bom pela maioria da população do estudo, com questões fáceis de entender e categorias de respostas não difíceis de serem utilizadas. Somado a isso, 92\% (Brasil) e 86\% (Portugal) dos participantes declararam que os itens do instrumento são muito relevantes para o diabetes mellitus, como condição de saúde. Visando a maneira como os 20 itens do instrumento avaliado foram formulados, a maioria mostrou-se de fácil compreensão, apenas quatro $(6,10$, 12 e 16) foram adaptados culturalmente no Brasil e um (19) em Portugal. Conclui-se que o estudo resultou em um instrumento adaptado culturalmente e compreensível para o Brasil e Portugal. Há necessidade de prosseguir com a avaliação das propriedades psicométricas para o estudo de validação do instrumento adaptado em ambos os contextos culturais.

Descritores: Doença Crônica. Diabetes Mellitus. Enfermagem. Tradução. Adaptação. Brasil. Portugal. 


\section{ABSTRACT}

LANDIM, C. A. P. Cultural adaptation of the Brazilian and Portuguese version of Patient Assessment of Chronic Illness Care (PACIC). 2012. $196 \mathrm{f}$. Thesis (Doctoral Degree) - University of Sao Paulo at Ribeirao Preto College of Nursing, Ribeirao Preto, 2012.

The Patient Assessment of Chronic Illness Care (PACIC) is the only instrument available in the scientific literature to assess the quality of care for the elements of Chronic Care Model from the perspectives of individuals with chronic diseases. In the Brazilian cultural context, there is no instrument to evaluate this dimension in the care provided for diabetes mellitus (DM) patients, which is considered an important chronic condition due to its prevalence and mortality worldwide, nor is there one in the Portuguese cultural context. This methodological study's objective was to perform the cultural adaptation of the PACIC instrument for both Brazil and Portugal. It comprises 20 items and five domains: Patient Activation, Delivery System Design/Practice Design, Goal-Setting/Tailoring, Problem-Solving/Context and Followup/Coordination. The cultural adaptation process followed the steps recommended by the literature: Forward Translation, Expert Panel, Back-Translation, Pre-testing, and Cognitive Interviewing. The study was conducted in the endocrinology outpatient clinic of a primary health unit in the city of Ribeirão Preto, SP, Brazil and in a public university hospital in the city of Porto, Portugal. Data were obtained through focused interviews in November (Brazil) and in May (Portugal), 2012. A total of 50 Brazilian and 50 Portuguese individuals met the inclusion criteria, totaling 100 individuals with DM. The instruments General and Specific Impression of DISABKIDS ${ }^{\circledR}$ Project were used to collect data. Descriptive analysis was used and the results are presented in tables. The results were satisfactory, showing the instrument was considered very good by most of the study's population. Questions were considered to be easy to understand and the answer categories were also easy to use. Additionally, 92\% (Brazil) and $86 \%$ (Portugal) of the participants reported the instrument's items are very relevant for DM as a health condition. Due to the way the instrument's 20 items were developed, most were easy to understand and only four $(6,10,12$ and 16) were culturally adapted for Brazil and only one (19) was culturally adapted for Portugal. The conclusion was an instrument culturally adapted and easy to understand both in Brazil and Portugal. There is a need to assess its psychometric properties to validate the adapted instrument for both cultural contexts.

Key words: Chronic Disease. Diabetes Mellitus. Nursing. Translating. Adaptation. Brazil. Portugal. 


\section{RESUMEN}

LANDIM, C. A. P. Adaptación cultural para Brasil y Portugal del Patient Assessment of Chronic Illness Care (PACIC). 2012. 196 h. Tesis (Doctorado) Escuela de Enferméria de Ribeirão Preto, Universidad de São Paulo, Ribeirão Preto, 2012.

El Patient Assessment of Chronic Illness Care (PACIC) es el único instrumento disponible en la literatura científica para evaluar la calidad de la atención en los elementos del Modelo de Cuidados Crónicos, desde la perspectiva de las personas con condiciones crónicas. En el contexto cultural de Brasil y Portugal, no existen instrumentos para evaluar esta dimensión del cuidado en diabetes mellitus (DM), considerada como una condición crónica importante, debido a su prevalencia y mortalidad a nivel mundial. Este estudio metodológico tuvo como objetivo llevar a cabo la adaptación cultural para Brasil y Portugal del instrumento PACIC. Constituido de 20 ítems, el PACIC tiene cinco dominios: Participación Activa del Paciente en el Tratamiento, Modelo del Sistema de Atención/Modelo para la Práctica, Establecimiento de Metas/Adaptación, Resolución de Problemas/Contexto y Seguimiento/Coordinación. El proceso de adaptación cultural siguió las etapas recomendadas por la literatura: Traducción, Comité de Expertos, Retrotraducción (Back-Translation), Pre-test y Entrevista cognitiva. El estudio se realizó en clínica ambulatoria de endocrinología, de una unidad básica de salud en la ciudad de Ribeirão Preto, estado de São Paulo, Brasil, y de un hospital público y de enseñanza en la ciudad de Oporto, Portugal. Los datos fueron recolectados en entrevistas dirigidas, en los meses de noviembre (Brasil) y mayo (Portugal) de 2012. Aplicando los criterios de selección, la población del estudio consistió de 50 personas brasileñas y 50 personas portuguesas, con un total de 100 personas con DM. Para la recolecta de datos, se utilizaron los instrumentos Impresión General y Específica del Proyecto DISABKIDS ${ }^{\circledR}$. Para la presentación de los resultados se utilizó análisis descriptivo, con uso de cuadros y tablas. Los resultados encontrados fueron satisfactorios, lo que demuestra que el instrumento fue considerado muy bueno por la mayoría de la población del estudio, con preguntas fáciles de comprender y categorías de respuestas que no son difíciles de usar. Además, el 92\% (Brasil) y $86 \%$ (Portugal) de los participantes declararon que los ítems del instrumento son muy relevantes para el diabetes mellitus, como condición de salud. Acerca de la manera como los 20 ítems del instrumento evaluado fueron formulados, la mayoría se mostró de fácil comprensión, sólo cuatro $(6,10,12$ y 16) fueron adaptados culturalmente en Brasil y uno (19) en Portugal. Se concluye que el estudio resultó en un instrumento culturalmente adaptado y comprensible para Brasil y Portugal. Hay necesidad de continuar con la evaluación de las propiedades psicométricas para el estudio de validación del instrumento adaptado en ambos contextos culturales.

Descriptores: Enfermedad Crónica. Diabetes Mellitus. Enfermería. Traducción. Adaptación. Brasil. Portugal. 


\section{LISTA DE QUADROS}

Quadro 1 - Representação do consenso da Versão Consensual em Português-Brasil 1.0 (PACIC-VCPBra 1.0). Ribeirão Preto-SP, Brasil, 2012.

Quadro 2 - Representação do consenso da Versão Consensual em Português-Portugal 2.0 (PACIC-VCPPort 2.0). Porto, Portugal 2012.

Quadro 3 - Itens da versão consensual brasileira e modificações após avaliação pelo Comitê de Especialistas do PACIC-VCPBra 1ab para o PACIC-VCPBra 1.0. Ribeirão Preto-SP, Brasil, 2012.

Quadro 4 - $\quad$ Entrevista Cognitiva (Pré-Teste) e as modificações do PACICVPTPBra pelos participantes do estudo. Ribeirão Preto-SP, Brasil, 2012.

Quadro 5 - $\quad$ Itens da versão consensual portuguesa e modificações após avaliação pelo Comitê de Especialistas do PACIC-VCPPort 2ab para o PACIC-VCPPort 2.0. Porto, Portugal, 2012.

Quadro 6 - Entrevista Cognitiva (Pré-Teste) e as modificações do PACICVPTPPort pelos participantes do estudo. Porto, Portugal, 2012. 


\section{LISTA DE TABELAS}

Tabela 1 - Distribuição numérica (n) e percentual (\%) da população do estudo segundo a avaliação do instrumento PACIC-VPTPBra pelo questionário de Impressão Geral (Pré-Teste). Ribeirão Preto-SP, Brasil, 2012.

Tabela 2 - Distribuição das respostas dos participantes da entrevista cognitiva pelo questionário de Impressões Específicas, segundo a percepção dos três itens do domínio "Participação Ativa do Paciente no Tratamento". Ribeirão Preto-SP, Brasil, 2012 .

Tabela 3 - Distribuição das respostas dos participantes da entrevista cognitiva pelo questionário de Impressões Específicas, segundo a percepção dos três itens do domínio "Modelo do Sistema de Cuidado/Modelo para a Prática". Ribeirão Preto-SP, Brasil, 2012.

Tabela 4 - Distribuição das respostas dos participantes da entrevista cognitiva pelo questionário de Impressões Específicas, segundo a percepção dos cinco itens do domínio "Estabelecimento de Metas/Adaptação". Ribeirão Preto-SP, Brasil, 2012.

Tabela 5 - Distribuição das respostas dos participantes da entrevista cognitiva pelo questionário de Impressões Específicas, segundo a percepção dos quatro itens do domínio "Resolução de Problemas/Contexto". Ribeirão Preto-SP, Brasil, 2012 .

Tabela 6 - Distribuição das respostas dos participantes da entrevista cognitiva pelo questionário de Impressões Específicas, segundo a percepção dos cinco itens do domínio "Seguimento/Coordenação". Ribeirão Preto-SP, Brasil, 2012.......

Tabela 7 - Distribuição numérica (n) e percentual (\%) da população do estudo segundo a avaliação do instrumento PACIC-VPTPPort pelo questionário de Impressão Geral (Pré-Teste). Porto, Portugal, 2012. 
Tabela 8 - Distribuição das respostas dos participantes da entrevista cognitiva pelo questionário de Impressões Específicas, segundo a percepção dos três itens do domínio "Participação Activa do Paciente". Porto, Portugal, 2012.

Tabela 9 - Distribuição das respostas dos participantes da entrevista cognitiva pelo questionário de Impressões Específicas, segundo a percepção dos três itens do domínio "Sistema de Prestação de Cuidados/Organização da Prática". Porto, Portugal, 2012

Tabela 10 - Distribuição das respostas dos participantes da entrevista cognitiva pelo questionário de Impressões Específicas, segundo a percepção dos cinco itens do domínio "Estabelecimento de Metas/Individualização". Porto, Portugal, 2012

Tabela 11 - Distribuição das respostas dos participantes da entrevista cognitiva pelo questionário de Impressões Específicas, segundo a percepção dos quatro itens do domínio "Resolução de Problemas/Contextualização". Porto, Portugal, 2012

Tabela 12 - Distribuição das respostas dos participantes da entrevista cognitiva pelo questionário de Impressões Específicas, segundo a percepção dos cinco itens do domínio "Acompanhamento/Coordenação". Porto, Portugal, 2012........... 


\section{LISTA DE FIGURAS}

Figura 1 - Modelo de Cuidados Crônicos (WAGNER, 1998)

Fonte: Traduzido de Barceló et al., 2012............................................... 33 


\section{LISTA DE SIGLAS}

ABNT

ACIC

ADA

AMM

CAPES

CCM

CEP

CES

CICC

CNS

CSE

DCCT

DCNT

DM

DM1

DM2

DPOC

EERP

EPE

ESEP

ESSVA

FMRP

FMUP

GHRI

HSJ

IBGE
Associação Brasileira de Normas Técnicas

Assessment of Chronic Illness Care

American Diabetes Association

Associação Médica Mundial

Coordenação de Aperfeiçoamento de Pessoal de Nível Superior

Chronic Care Model

Comitê de Ética em Pesquisa

Comissão de Ética para a Saúde

Cuidados Inovadores para Condições Crônicas

Conselho Nacional de Saúde

Centro Saúde Escola

Diabetes Control and Complications Trial

Doenças Crônicas Não Transmissíveis

Diabetes Mellitus

Diabetes Mellitus tipo 1

Diabetes Mellitus tipo 2

Doença Pulmonar Obstrutiva Crônica

Escola de Enfermagem de Ribeirão Preto

Entidade Pública Empresarial

Escola Superior de Enfermagem do Porto

Escola Superior de Saúde do Vale do Ave

Faculdade de Medicina de Ribeirão Preto

Faculdade de Medicina da Universidade do Porto

Group Health Research Institute

Hospital São João

Instituto Brasileiro de Geografia e Estatística 
ICC

ICCC

ICIC

IDF

MCC

OD

OMS

OPAS

PACIC

PACIC-VO

PACIC-VTPBra 1a

PACIC-VTPBra 1b

PACIC-VTPPort 2a

PACIC-VTPPort 2b

PACIC-VCPBra 1ab

PACIC-VCPPort 2ab

PACIC-VCPBra 1.0

PACIC-VCPPort 2.0

PACIC-VCPBra 1.0 Rev

PACIC-VCPPort 2.0 Rev

PACIC-VIBra

PACIC-VIPort

PACIC-VPTPBra

PACIC-VPTPPort

PACIC-VFPBra

PACIC-VFPPort

PAM

PCP-ACES

PIB
Insuficiência Cardíaca Congestiva

Innovative Care for Chronic Conditions

Improving Chronic Illness Care

International Diabetes Federation

Modelo de Cuidados Crônicos

Odds Ratio

Organização Mundial de Saúde

Organização Pan-Americana de Saúde

Patient Assessment Chronic Illness Care

PACIC-Versão Original

PACIC-Versão Traduzida para o Português-Brasil 1a

PACIC-Versão Traduzida para o Português-Brasil 1b

PACIC-Versão Traduzida para o Português-Portugal 2a

PACIC-Versão Traduzida para o Português-Portugal 2b

PACIC-Versão Consensual em Português-Brasil 1ab

PACIC-Versão Consensual em Português-Portugal 2ab

PACIC-Versão Consensual em Português-Brasil 1.0

PACIC-Versão Consensual em Português-Portugal 2.0

PACIC-Versão Consensual em Português-Brasil 1.0 Revisada

PACIC-Versão Consensual em Português-Portugal 2.0 Revisada PACIC-Versão em Inglês-Brasil

PACIC-Versão em Inglês-Portugal

PACIC-Versão Pré-Teste em Português-Brasil

PACIC-Versão Pré-Teste em Português-Portugal

PACIC-Versão Final Português-Brasil

PACIC-Versão Final Português-Portugal

Patient Activation Mensure

Primary Care Physicians - Ambulatory Care Experience Survey

Produto Interno Bruto 
PRPG-USP

SBD

SPD

SPSS

SUS

TCLE

UBDS

UBS

UKPDS

UNESCO

USP

UP

WHO

WMA
Pró-Reitoria de Pós-Graduação da Universidade de São Paulo Sociedade Brasileira de Diabetes

Sociedade Portuguesa de Diabetes

Statistical Package for the Social Sciencies

Sistema Único de Saúde

Termo de Consentimento Livre e Esclarecido

Unidades Básicas Distritais de Saúde

Unidades Básicas de Saúde

United Kingdom Prospective Diabetes Study Group

United Nations Education Science and Culture Organization

Universidade de São Paulo

Universidade do Porto

World Health Organization

World Medical Association 


\title{
SUMÁRIO
}

\author{
LISTA DE QUADROS \\ LISTA DE TABELAS \\ LISTA DE FIGURAS \\ LISTA DE SIGLAS
}

1 INTRODUÇÃO

1.1 Doenças crônicas não transmissíveis: a necessidade de um cuidado integral baseado no Modelo de Cuidados Crônicos...

1.2 Instrumentos de avaliação do Modelo de Cuidados Crônicos.

1.3 Apresentação do instrumento: Patient Assessment of Chronic Illness Care (PACIC)

1.4 Processo de adaptação cultural de instrumentos de medida em saúde.

1.5 diabetes mellitus: aspectos epidemiológicos.

1.6 Justificativa e relevância

2 OBJETIVOS

2.2 Objetivos específicos

3 CASUÍSTICA E MÉTODO.

3.1 Tipo de estudo.

3.2 Autorização formal do autor principal para a adaptação cultural do instrumento.

3.3 Processo de adaptação cultural do PACIC no Brasil e em Portugal.

3.3.1 Tradução do instrumento PACIC para a língua portuguesa do Brasil e de Portugal.

3.3.2 Avaliação pelo Comitê de Especialistas 
3.3.3 Retrotradução (Back-Translation) ..............................................

3.3.4 Pré-teste e Entrevista cognitiva................................................

3.4 Procedimentos de coleta de dados........................................... 77

3.4.1 Local do estudo............................................................................... 77

3.4.1.1 Apresentação dos locais de coleta de dados.............................. 78

3.4.2 Período do estudo........................................................................

3.4.3 População do estudo................................................................

3.4.4 Instrumentos de coleta de dados........................................... $\quad 84$

3.4.5 Procedimentos adotados para a coleta de dados........................... 84

3.4.6 Organização, descrição e análise dos dados.............................. 86

3.4.7 Considerações éticas.................................................................

4 RESULTADOS

4.1 Resultados da adaptação cultural do Patient Assessment of Chronic Illness Care (PACIC) no Brasil e em Portugal............... $\quad 89$

4.1.1 Tradução • Comitê de Especialistas • Retrotradução (BRASIL).. 90

4.1.2 Pré-teste e Entrevista cognitiva (BRASIL).................................. 93

4.1.2.1 Resultados do Instrumento Impressão Geral do PACICVPTPBra (BRASIL)......................................................... 94

4.1.2.2 Resultados do Instrumento Impressões Específicas do PACICVPTPBra (BRASIL)

4.1.3 Tradução • Comitê de Especialistas • Retrotradução (PORTUGAL)........................................................................ 99

4.1.4 Pré-Teste e Entrevista Cognitiva (PORTUGAL)......................... 103

4.1.4.1 Resultados do Instrumento Impressão Geral do PACICVPTPPort (PORTUGAL)...................................................... 103

4.1.4.2 Resultados do Instrumento Impressões Específicas do PACICVPTPPort (PORTUGAL) 
6 CONCLUSÕES.

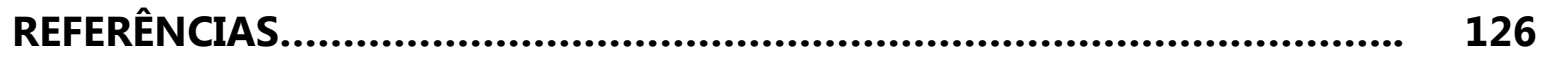

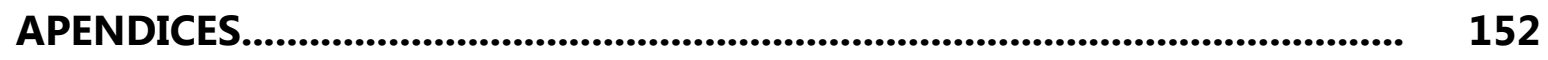

ANEXOS 


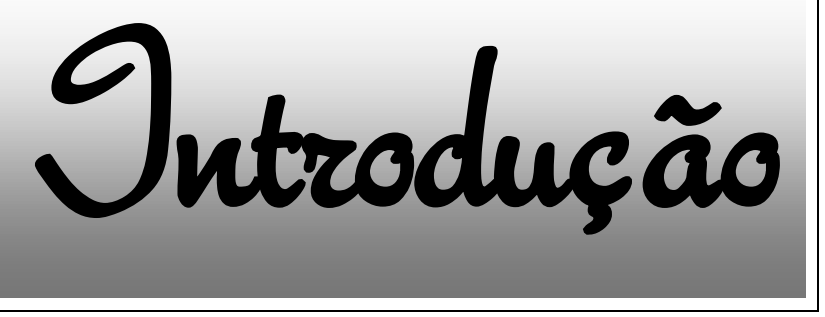




\section{INTRODUÇÃo}

\subsection{Daenças crânicas nãa transmissúueis: a necessidade de um cuidada integral baseada na Madela de Cuidadas Crânicas}

Sabe-se que as transformações na estrutura demográfica, epidemiológica e nos padrões de morbimortalidade vêm promovendo questionamentos sobre novas perspectivas de organização dos sistemas de saúde. A situação atual na qual as diversas sociedades se encontram resultam de mudanças em fatores tecnológicos, econômicos, sociais, culturais, ideológicos e psicológicos, portanto requerem um paradigma diferente particularmente no que diz respeito à saúde, demandando-se novas prioridades na sistematização do cuidado. Uma prioridade em pauta tem sido as doenças crônicas não transmissíveis (DCNT) (BRITO, 2008; PAIM et al., 2011; ROUQUAYROL; GOLDBAUM, 2003).

As DCNT constituem condições de saúde que persistem em longo prazo, requerendo acompanhamento contínuo e permanente (BRASIL, 2011a; SCHMIDT, 2011). Caracterizam-se por ter etiologia incerta, múltiplos fatores de risco, longos períodos de latência, curso prolongado e associação a deficiências e incapacidades funcionais (BRASIL, 2008; WORLD HEALTH ORGANIZATION - WHO, 2005).

Representam hoje a maior causa de mortalidade em muitos países, sejam de alta, média ou baixa condição socioeconômica. São responsáveis por gerar elevado número de mortes prematuras, perda de qualidade de vida, limitações nas atividades de trabalho e de lazer, além de impactos econômicos para as famílias, comunidades e 
a sociedade em geral (WHO, 2005; ORGANIZAÇÃO PAN-AMERICANA DE SAÚDE OPAS, 2007).

Dentre as 57 milhões de mortes no mundo em 2008, 33 (58\%) foram em razão das DCNT, com destaque para as doenças do aparelho circulatório, diabetes, câncer e doença respiratória crônica (ALWAN et al., 2010). Aproximadamente 80\% das mortes por DCNT ocorrem em países de baixa e média condição socioeconômica, onde $29 \%$ são de pessoas com menos de 60 anos, quando nos países de condição socioeconômica alta, apenas 13\% são mortes precoces (WHO, 2011a).

De acordo com o relatório global "Estatísticas Mundiais de Saúde 2011" da Organização Mundial de Saúde (OMS), elaborado anualmente com base em mais de 100 indicadores de saúde mundiais, evidenciou-se que dos 53 Estados Membro da Europa, as DCNT são responsáveis por $86 \%$ das causas de morte. Os dados do relatório também mostraram que dentre os três países de condição socioeconômica alta que compõem a Penísula Ibérica (Andorra, Espanha e Portugal) no Continente Europeu, Portugal é o país que representa a maior causa de morte por DCNT (WHO, 2011b). No entanto, de forma geral, percebe-se que nas últimas décadas houve uma melhora significativa dos indicadores de saúde portugueses, com notáveis progressos de redução das taxas de mortalidade, especialmente por dois grandes fatores: promoção da saúde e o aumento do acesso de qualidade aos sistemas de saúde (BARROS; MACHADO; SIMÕES, 2011).

No Brasil, as DCNT constituem o problema de saúde de maior magnitude e correspondem a $72 \%$ das causas de mortes, atingindo fortemente camadas pobres da população e grupos vulneráveis. Em 2007, a taxa de mortalidade da população brasileira afetada por DCNT foi de 540 óbitos por 100.000 habitantes (SCHMIDT et al., 2011). Apesar de elevada, observou-se redução de 20\% nessa taxa na última década, principalmente em relação às doenças cardiovasculares e respiratórias crônicas. Entretanto, as taxas de mortalidade por diabetes e câncer aumentaram nesse mesmo período (BRASIL, 2011a). 
Considera-se que, entre fatores importantes, a acentuada queda da mortalidade, a diminuição da fecundidade, o avanço da medicina e a ampliação dos serviços de prevenção e assistência médica, especialmente o processo de envelhecimento populacional, a tendência é que a prevalência e a mortalidade das DCNT continuem aumentando (BRITO, 2008; FREESE; FONTBONNE, 2006; PAIM et al., 2011; PAIVA; WAJNMAN, 2005; SCHMIDT et al. 2011; SCHRAMM et al., 2004).

Portanto, sabe-se que um dos maiores desafios para as políticas de saúde do século XXI tem sido atender as necessidades complexas do cuidado para pessoas com DCNT. Desde o ano de 2000, a Organização Mundial de Saúde (OMS) tem se empenhado em buscar evidências científicas para um marco conceitual abrangente e integrado, que permita uma nova organização dos sistemas de saúde usuais e atenda as necessidades dos cuidados contínuos na atenção às doenças de curso crônico (GOULART, 2011).

Dessa forma, os sistemas de saúde precisam sistematizar o cuidado de forma integrada, a fim de garantir o compartilhamento das informações entre diferentes ambientes e os profissionais de saúde envolvidos (WAGNER et al., 2001; WHO, 2002). A integração também deverá incluir a coordenação do financiamento em todos os âmbitos do sistema de saúde (serviços de internação, ambulatorial e farmacêutico), incluindo iniciativas de prevenção e incorporando os recursos da comunidade que podem nivelar os serviços gerais de saúde. Os resultados dessa integração permitem gerar saúde melhorada, menos custos e desperdícios, maior eficiência e uma experiência mais agradável para as pessoas envolvidas (GOULART, 2011; WHO, 2002). Para responder a essas necessidades, desenvolveram-se os modelos de atenção à saúde (MENDES, 2010).

Os modelos de atenção à saúde são sistemas lógicos que organizam o cuidado, articulando, de forma singular, as relações entre a população e suas subpopulações estratificadas por riscos, os focos das intervenções do sistema de atenção à saúde e os diferentes tipos de intervenções sanitárias (MENDES, 2010). 
Dentre os modelos de atenção à saúde, voltados para as condições crônicas, têm-se: o Modelo de Atenção Crônica (WAGNER, 1998), o Modelo da Pirâmide de Risco (DEPARTMENT OF HEALTH, 2005; STRONG, 2005; DAHLGREN; WHITEHEAD, 2007) e o Modelo de Determinação Social da Saúde (DAHLGREN; WHITEHEAD, 2007).

No entanto, sobressaiu-se o marco conceitual do Modelo de Atenção Crônica pela sua construção primordial, sendo responsável pelo posterior desenvolvimento dos demais (WAGNER, 1998). Em razão da tradução literal em inglês Chronic Care Model (CCM), designou-se inicialmente como Modelo de Atenção Crônica, porém, posteriormente foi denominado Modelo de Cuidados Crônicos (MCC), como é conhecido nos dias atuais (MENDES, 2010; 2012).

Dessa maneira, o MCC foi desenvolvido pela equipe do MacColl Institute for Healthcare Innovation, nos Estados Unidos, a partir de uma ampla revisão de literatura internacional sobre a gestão das condições crônicas. O modelo inicial foi aperfeiçoado em um projeto-piloto, apoiado pela Fundação Robert Wood Johnson e, em seguida, submetido a uma reunião com uma equipe de especialistas da área de gerenciamento em condições crônicas. Logo, foi testado a nível nacional pelo programa Improving Chronic Illness Care (ICIC) (MENDES, 2012; WAGNER, 1998).

Em 2003, o programa ICIC realizou uma atualização rigorosa do Modelo, com base em nova revisão da literatura internacional e nas experiências de sua implantação prática. Somado a isso, foi utilizado em 72 programas e 14 visitas de campo para organizar uma coleção de dados cientificamente comprovados e analisar entrevistas semiestruturadas de um sistema de distribuição de cuidado inovador recomendado por especialistas (WAGNER, 1998).

O Modelo de Cuidados Crônicos representa um meio inovador de prevenção, controle e atenção às DCNT e tem sido progressivamente utilizado para avaliar e melhorar a qualidade do cuidado. Propõe a mudança de um cuidado reativo e orientado em um momento único para um cuidado contínuo, planejado e dirigido (WAGNER; AUSTIN; KORFF, 1996; WAGNER, 1998; WAGNER et al., 2001). 
Portanto, esse Modelo possibilita uma inovação nos sistemas de saúde para promover atenção de qualidade às pessoas com DCNT e é fundamentado em seis elementos, subdivididos em dois grandes campos - o sistema de atenção à saúde (primeiro ao quinto elemento) e a comunidade (sexto elemento) -, apresentados a seguir (BARCELÓ et al., 2012; MENDES, 2012; WAGNER et al., 2001):

- Organização da atenção à saúde: permite desenvolver métodos de mudança e novos mecanismos que promovam a melhoria de uma atenção planejada, contínua, segura e de alta qualidade. Ao mesmo tempo, a organização deverá favorecer aos usuários transitar por todos os níveis do sistema e pontos de atenção necessários;

- Desenho do sistema de prestação de serviços: pretende assegurar uma atenção à saúde efetiva e eficiente, que fomente e apoie ao autocuidado, distribuindo papéis e tarefas aos profissionais de saúde e facilitando as interações entre profissionais e usuários, com uma abordagem culturalmente adequada;

- Apoio às decisões: objetiva promover uma atenção à saúde consistente com as diretrizes de pratica clinica e evidências científicas, devendo estar incorporadas nas práticas cotidianas. Os profissionais de saúde devem compartilhar informações com o usuário e incentivar sua participação ativa;

- Sistemas de informação clínica: estimula a importância da organização dos dados da população e das pessoas usuárias do serviço no que diz respeito à continuidade de um cuidado mais eficiente e efetivo, a fim de facilitar o planejamento, a identificação de necessidades especiais e a coordenação da atenção clínica integral;

- Autocuidado apoiado: prepara e empodera as pessoas usuárias para o autogerenciamento do seu cuidado na atenção à saúde prestada, promovendo uma noção de corresponsabilidade. Portanto, empregam-se estratégias de apoio para o autocuidado, que incluem planejamento das ações, resolução de problemas, seguimento e avaliação das metas; 
- Recursos e políticas da comunidade: destina mobilizar os recursos da comunidade para atender às necessidades do processo de cuidado das pessoas, por meio de parcerias com equipes comunitárias que prestem assistência por meio de políticas de melhora a atenção à saúde.

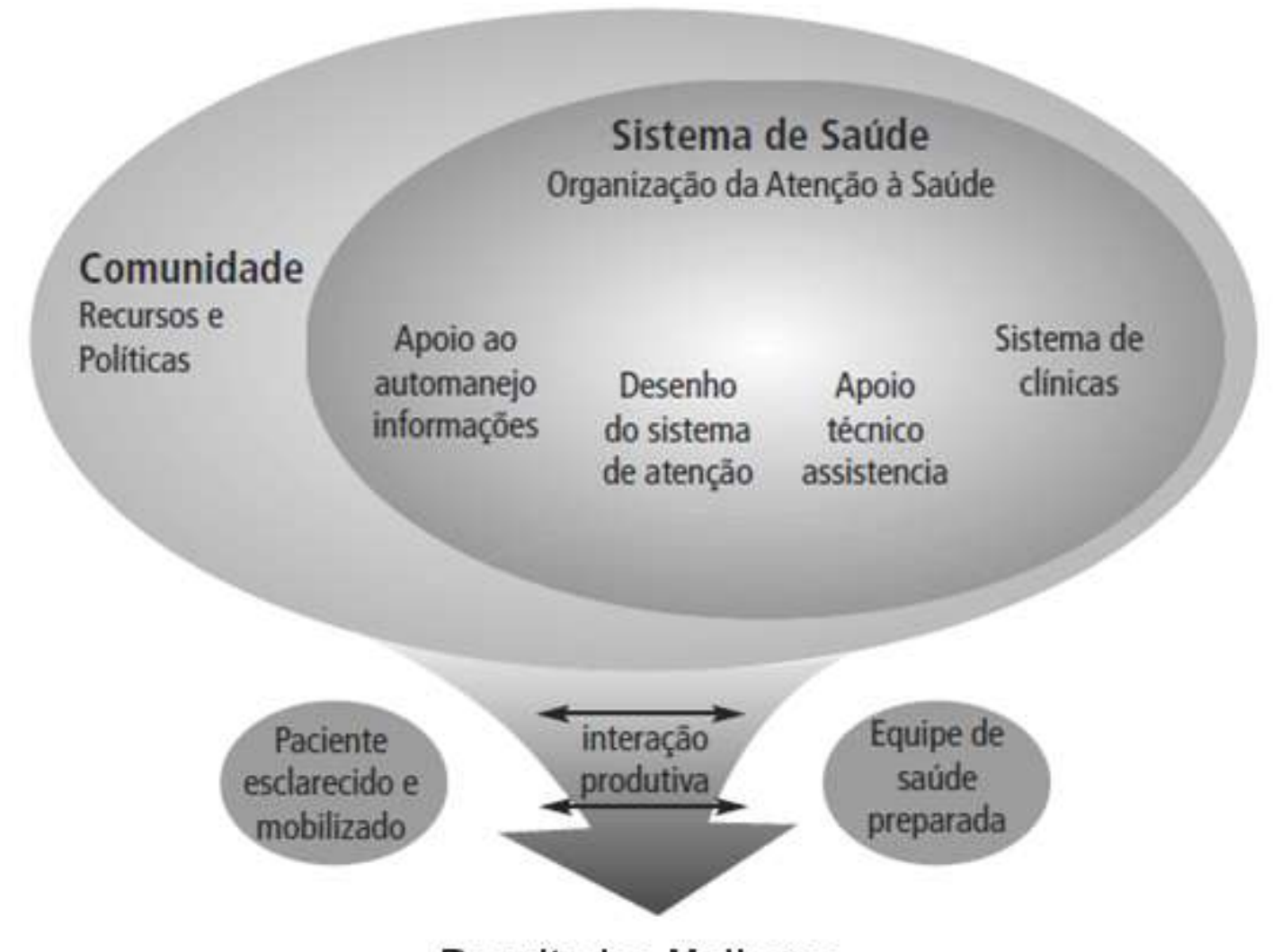

Resultados Melhores

Figura 1 - Modelo de Cuidados Crônicos (WAGNER, 1998) Fonte: Traduzido de Barceló et al., 2012

Nesta perspectiva, os seis elementos inter-relacionados do MCC possibilitam desenvolver usuários ativos e envolvidos na gestão do seu próprio cuidado, juntamente com uma equipe de saúde preparada e proativa para promover uma atenção com qualidade, com melhoria dos resultados clínicos e funcionais, além da incorporação da prevenção da doença crônica e a promoção da saúde (BARCELÓ et al., 2012; GOURLART, 2011; MENDES, 2012; WAGNER et al., 2001). 
Atualmente, o Modelo de Cuidados Crônicos é amplamente aceito e utilizado em diversos países do mundo. Resultados de evidências científicas internacionais mostraram desde a sua criação original que a aplicação do Modelo resultou em boas melhorias nos cuidados e nos resultados em saúde, parte deles publicados por pesquisadores que participaram ativamente da sua concepção (BODENHEIMER; WAGNER; GRUMBACH, 2002; DORR et al., 2006; GILMER et al., 2006; GILMER; O'CONNOR, 2003; GLASGOW et al., 2005a; HARRIS; ZWAR et al., 2007; MCCULLOCH et al., 1998; WAGNER et al., 2001).

O estudo de avaliação clássico do MCC foi desenvolvido pela Rand Corporation e pela Universidade de Berkeley, Califórnia, com quatro mil pessoas com diabetes mellitus, insuficiência cardíaca, asma e depressão, assistidas em 51 organizações de saúde, com dois objetivos: avaliar as mudanças ocorridas nas organizações de saúde após a implementação do MCC e estabelecer quanto a utilização desse Modelo melhorou os processos e os resultados em relação às condições crônicas. Após quatro anos de estudo, encontrou-se que as instituições de saúde apresentaram uma média de 48 melhorias em 5,8 dos 6 elementos do MCC, as pessoas com diabetes apresentaram redução significativa do risco cardiovascular, as pessoas com insuficiência cardíaca apresentaram melhores tratamentos e menos internações (35\%), as mudanças produzidas pela implantação do MCC tiveram sustentabilidade em $82 \%$ das organizações estudadas e foram disseminadas dentro e fora dessas organizações (ASCH et al., 2005; BAKER et al., 2005; CHAN et al., 2005; CRETIN; SHORTELL, KEELER et al., 2004; LIN et al., 2005; MANGIONE-SMITH et al., 2005; MEREDITH et al., 2006; NELSON et al., 2002; RAND HEALTH, 2008; SCHONLAU et al., 2005; SHORTELL et al., 2004; TSAI et al., 2005; VARGAS et al., 2007).

Dessa maneira, várias outras pesquisas relacionadas com a avaliação do MCC implantado no cuidado às condições crônicas foram desenvolvidas: ensaios clínicos randomizados (BATTERSBY; HEALTH PLUS TEAM, 2005; BAUER et., 2006; LOZANO et al., 2008), estudos avaliativos voltados para a melhoria da qualidade do cuidado 
prestado (CHIN et al., 2004; DANIEL et al., 2004; HARWELL et al., 2002; LANDIS; SCHWARZ; CURRAN, 2006; LANDON et al., 2004; NUTTING et al., 2007; SPERL-HILLEN et al., 2004; STROEBEL et al., 2005; WANG et al., 2004), estudos avaliativos sobre o envolvimento de aspectos organizacionais em saúde (FLEMING et al., 2004; HUNG et al., 2006; LI et al., 2004; SCHMITTDIEL et al., 2006) e estudos envolvidos com custoefetividade de avaliação econômica (GILMER et al., 2006; GILMER; O'CONNOR, 2003; GOETZEL et al., 2005).

Além disso, estudos avaliativos de medida de satisfação em pessoas com condições crônicas usuárias das organizações de saúde com implementação do MCC encontraram que os melhores resultados de aplicação do Modelo decorrem quando são envolvidos na prática os seus seis elementos em conjunto, de tal forma que seja proporcionado haver uma potencialização entre eles (HAM, 2007; VANDERBILT MEDICAL CENTER, 2002).

Embora o MCC tenha sido criado, implementado e avaliado nos Estados Unidos, não alcançou ampla fixação no país norte-americano por conservar incompatibilidades com os princípios dos sistemas organizacionais de saúde, tais como: a fragmentação do cuidado, os incentivos econômicos desviados, a falta de orientação na atenção primária e a inexistência de um foco populacional (HAM, 2007). No entanto, a proposta originalmente construída do Modelo sofreu adaptação situacional em diversos países (MENDES, 2011; SINGH, 2005; WHO, 2002).

Na Europa (Alemanha, Dinamarca, Espanha, Holanda, Reino Unido e Rússia), o MCC foi implantado de forma extensa, porém foram propostos alguns elementos importantes: a cobertura universal; a limitação de pagamentos para permitir o acesso aos serviços de saúde; a organização da atenção primária organizada com base em populações e subpopulações cadastradas no sistema de atenção à saúde; as ações de promoção da saúde e de prevenção das condições de saúde integradas ao Modelo; o envolvimento clínico; e, o uso de tecnologias de gestão da clínica, como o gerenciamento de doença e a gestão de caso (HAM, 2007). 
No Canadá, na Colúmbia Britânica, houve a incorporação do componente promoção da saúde, voltado para os determinantes sociais e para a participação da comunidade. A expansão do foco do Modelo tornou-se necessária pelas autoridades sanitárias da região por considerarem que o MCC era focalizado em aspectos de cuidados essencialmente clínicos (GOVERNMENT OF BRITISH COLUMBIA, 2008; MINISTRY OF HEALTH, 2003).

Na Austrália, o MCC tem sido utilizado para atender a continuidade da atenção à saúde. Por exemplo, a evolução das condições crônicas inicia-se por uma população saudável, depois por subpopulações com presença de fatores de risco, e, depois por subpopulações com condição crônica estabelecida e terminal. Para cada um desses estágios, são definidas intervenções específicas (SUÑOL et al., 1999).

Em Nova Zelândia, foi utilizado o modelo do curso da vida, que aponta para uma evolução contínua, respondendo-se com ações de promoção primária, secundária e terciária à saúde (MINISTRY OF HEALTH, 2005).

Na Ásia, o MCC foi proposto somente em Singapura, com base na atenção primária e no autocuidado, porém com pouca ênfase em transformações organizacionais (CHEAH, 2001).

Uma expansão importante e muito reconhecida do MCC em países de alta condição socioeconômica é o Modelo dos Cuidados Inovadores para Condições Crônicas (CICC) ou Innovative Care for Chronic Conditions Framework (ICCC), proposto pela Organização Mundial de Saúde (WHO, 2002). O CICC dispõe melhorar a atenção à saúde em três níveis: o nível micro (indivíduos e famílias), o nível meso (organizações de saúde e comunidade) e o nível macro (políticas de saúde), a partir de oito elementos essenciais: apoiar a mudança de paradigma; gerenciar o ambiente político; desenvolver um sistema integrado de atenção à saúde; alinhar políticas setoriais para a saúde; aproveitar melhor os recursos humanos do setor saúde; centralizar o cuidado na pessoa usuária e na família; apoiar as pessoas usuárias em suas comunidades; e, enfatizar a prevenção. Singh e Ham (2006) realizaram um 
estudo de avaliação do CICC pela Universidade de Birmingham, Inglaterra, e encontraram evidências de melhorias em alguns processos e resultados sanitários, mas não houve fortes evidências do valor do foco nas políticas de saúde (WHO, 2002; SINGH; HAM, 2006).

No Brasil, o MCC tem sido utilizado de forma parcial como parte de experiências inovadoras nos cuidados de condições crônicas no SUS, na Secretaria Municipal de Saúde de Curitiba (CURITIBA, 2010), na Secretaria Municipal de Saúde de Diadema (OPAS, 2010) e pelo projeto Qualidia do Ministério da Saúde que atua em dez municípios brasileiros: Anchieta/ES, Florianópolis/SC, Ilha de Itamaracá/PE, Porto Alegre/RS, Recife/PE, Rio Bonito/RJ, Rio de Janeiro/RJ, São Lourenço da Mata/PE, Silva Jardim/RJ e Tijucas/SC (BRASIL, 2011b).

No Paraná, em Curitiba, encontra-se em fase de implementação desde 2010 o projeto piloto do "Laboratório de Inovação na Atenção às Condições Crônicas na Atenção Primária à Saúde", com o objetivo de avaliar a aplicabilidade de alguns componentes do MCC na atenção primária do município. O projeto apresenta uma estrutura operacional em rede (atenção primária à saúde; pontos de atenção secundários e terciários, ambulatoriais e hospitalares; sistemas de apoio; sistemas logísticos; e sistema de governança) que envolve indicadores de desempenho e qualidade, gestão do orçamento e forte capacitação de uma equipe de profissionais de saúde integrados. Por meio da estruturação desse projeto, destaca-se a possibilidade de mudanças comportamentais em indivíduos com condições crônicas e usuários do sistema de saúde, a partir de práticas de autocuidado apoiado e cuidado compartilhado (CURITIBA, 2010).

Seguindo a mesma lógica, a Secretaria Municipal de Saúde do município paulista de Diadema, em parceria com a Organização Pan-Americana da Saúde Organização (OPAS) e a Faculdade de Medicina do ABC, em Santo André, São Paulo, prioriza desde 2010 um plano organizacional inovador na atenção em saúde para pessoas com diabetes mellitus e hipertensão arterial, com o objetivo de melhorar a 
atenção básica, por meio da integração de novas linhas de cuidado. O novo plano foi aprovado em novembro de 2009 pelo Conselho Municipal de Saúde de Diadema e propõe a melhoria da qualidade de vida e a autonomia dos usuários do sistema de saúde nos seus processos crônicos de adoecimento. Além disso, expõe mudanças nas práticas profissionais baseadas na reflexão crítica sobre o processo de trabalho e incorporação de novos saberes no cotidiano das equipes de saúde (OPAS, 2010).

Da mesma forma, destaca-se também o projeto Qualidia “Educação em Saúde para o Autocuidado - Avaliação Contínua em Qualidade de Atenção ao Diabetes", que representa uma parceria do Ministério da Saúde com a Fundação Médica do Rio Grande do Sul, apoiado pelo Laboratório Sanofi-Aventis. O projeto utilizou o MCC para orientar uma transformação do sistema fragmentado e hierarquizado para redes organizacionais integradas de atenção à saúde. O cronograma de ações foi baseado no documento elaborado por WHO (2002) "The innovative care for chronic conditions framework: building, blocks for action" que tem como premissas básicas a qualidade da atenção e a colaboração entre os envolvidos (BRASIL, 2011b; WHO, 2002).

Destaca-se que a utilização de ferramentas práticas de avaliação para monitorar os sistemas de saúde e avaliar a implementação do MCC, torna-se essencial para possibilitar comparações entre diferentes contextos culturais e acompanhar a qualidade do cuidado em estudos clínicos de intervenção (INSTITUE OF MEDICINE, 2001; MCGLYNN, 2003).

Portanto, mediante o propósito de conhecer a sistematização das práticas de cuidado adotadas nos sistemas de saúde, pretende-se buscar na literatura científica quais instrumentos desenvolvidos para avaliar a utilização dos elementos do MCC com ênfase na melhoria da qualidade do cuidado em condições crônicas. 


\subsection{Instrumentas de aualiaçãa da Madela de Cuidadas Crânicas}

A equipe de pesquisadores especialistas em saúde na área de gerenciamento para cuidados inovadores em condições crônicas do MacColl Institute for Healthcare for Innovation de Seatle, Washington, nos Estados Unidos, elaborou dois instrumentos práticos com o objetivo de avaliar a eficácia do Modelo de Cuidados Crônicos nos sistemas de saúde, um na perspectiva do profissional da equipe e o outro na perspectiva da própria pessoa com a condição crônica (IMPROVING CHRONIC ILLNESS CARE - ICIC, 2012).

O primeiro refere-se ao Assessment of Chronic Illness Care (ACIC). Esse instrumento foi elaborado a partir de uma ferramenta desenvolvida no Sistema de Saúde Indígena dos Estados Unidos para avaliação da atenção ao diabetes mellitus (ACTON et al., 1993; 1995), destinado a ser utilizado por profissionais de saúde para avaliar a capacidade institucional de atenção às condições crônicas. O ACIC apresenta dois objetivos fundamentais: (1) identificar áreas para a melhoria da qualidade do cuidado antes da implementação de ações e (2) avaliar o nível e a natureza das melhorias desenvolvidas após as intervenções adotadas (BONOMI et al., 2002).

Embora houvesse poucos estudos clínicos na literatura científica para fundamentar a importância dos fatores institucionais na gestão do cuidado com condições crônicas, a equipe de especialistas norte-americana realizou uma revisão dos conceitos fundamentais e dos elementos do MCC, revelando principalmente que o apoio dos líderes e gestores das instituições era um dos componentes centrais para conduzir uma melhoria da qualidade do trabalho nos sistemas de cuidados em saúde (BONOMI et al., 2002; SHORTELL et al., 1995). 
Dessa forma, fundamentado nos seis elementos fundamentais do MCC, o ACIC é composto por 28 itens, distribuídos a seguir: organização da atenção à saúde (seis itens), recursos da comunidade (três itens), autocuidado apoiado (quatro itens), suporte às decisões (quatro itens), desenho do sistema de atenção (6 itens) e sistema de informação clínica (cinco itens) (BONOMI et al., 2002).

A versão original do instrumento permite obter um escore final que revela a capacidade da equipe de saúde para cuidar das condições crônicas, onde a pontuação mais alta (escore entre 9-11) é indicativa de um local com recursos e estrutura ótima e a menor pontuação possível (escore entre 0-2), corresponde a um local com recursos e estrutura muito limitados para a atenção às condições crônicas (BONOMI et al., 2002).

Estudos internacionais mostraram evidências científicas que o ACIC permite medir a qualidade do cuidado na atenção às condições crônicas (BOWEN et al., 2010; LEYKUM, 2011; PATEL; PARCHMAN, 2011; SI; CONNORS, 2005; SOLBERG et al., 2006; STEVENS et al., 2010; SUNAERT et al., 2009). Portanto, o instrumento ACIC já foi traduzido e validado internacionalmente em diferentes países, Alemanha, Espanha, França, Holanda, Japão e Tailândia, e as versões traduzidas para os seus respectivos idiomas encontram-se disponíveis em formato eletrônico no programa Improving Chronic Illness Care (ICIC) (CRAMM et al., 2011; GOMUTBUTRA et al., 2012; ICIC, 2012; STEURER-STEY et al., 2012). Atualmente, o instrumento encontra-se em vias de tradução e validação para o idioma português do Brasil, sobre a responsabilidade da Secretaria Municipal de Saúde de Curitiba, como parte do projeto "Laboratório de Inovação na Atenção às Condições Crônicas na Atenção Primária à Saúde" a ser desenvolvido no município (CURITIBA, 2010; MENDES, 2012).

A partir da mesma concepção, porém na perspectiva da própria pessoa com condição crônica, Russell Glasgow e colaboradores (2005) desenvolveram o Patient Assessment Chronic Illness Care (PACIC). Esse instrumento foi desenvolvido em Washington e Idaho, Estados Unidos, com o objetivo de oferecer uma perspectiva 
para avaliar a qualidade do cuidado recebido da pessoa com uma ou mais condições crônicas nos últimos seis meses, enfatizando os elementos do Modelo de Cuidados Crônicos (MCC) (GLASGOW et al., 2005a).

De acordo com o Modelo dos Cuidados Inovadores para Condições Crônicas, elaborado pela Organização Mundial de Saúde, o MCC assume o desafio de efetivar transformações necessárias no sistema de práticas do cuidado associado a uma gestão democrática, participativa e focada na própria pessoa com condição crônica, visando gerar interações produtivas com a equipe profissional dos cuidados em saúde (PINTO, 2009; WHO, 2002).

A necessidade de avaliar a qualidade do cuidado sobre a perspectiva da pessoa com condição crônica poderá proporcionar o autocuidado e uma autogestão participativa e democrática. O processo de cuidado contínuo em condições crônicas poderá tornar-se mais satisfatório quando este é avaliado pela própria pessoa, facilitando o planejamento para um cuidado mais efetivo. A utilização do instrumento PACIC em diferentes estudos internacionais e condições crônicas diversas mostraram resultados importantes neste aspecto (GLASGOW et al., 2005b; PETERS-KLIMM et al., 2007; SCHMITTDIEL et al., 2007).

Pesquisa realizada em Colorado, Estados Unidos, utilizou o PACIC com itens adicionais do modelo de aconselhamento comportamental em 363 pessoas com DM tipo 2 na atenção primária em saúde, onde mais de $60 \%$ dos participantes tinham outra condição crônica associada. Concluiu-se que foi uma ferramenta útil para avaliar a qualidade do cuidado na pessoa com DM, especialmente para o DM tipo 2, com atividades satisfatórias de acompanhamento e apoio pela equipe de saúde na condição crônica (GLASGOW et al., 2005b).

Ensaio clínico randomizado, do tipo caso-controle, desenvolvido com 200 pessoas com Insuficiência Cardíaca Congestiva (ICC) no Hospital Universitário de Heidelberg, Alemanha, por um período de 12 meses, com o objetivo de avaliar uma intervenção padronizada e gerenciada por uma enfermeira selecionada após 
treinamento específico. A intervenção envolveu a monitorização do cuidado por telefone, três visitas domiciliares por semana e o acompanhamento contínuo das consultas no sistema de saúde. Para avaliar a intervenção, utilizaram-se instrumentos medindo qualidade de vida, ansiedade, depressão, adesão à terapia medicamentosa e a qualidade do cuidado (PACIC). Os resultados da intervenção foram considerados como uma estratégia promissora para melhora da qualidade do cuidado em pessoas com ICC, onde o PACIC foi um importante instrumento de medida para o acompanhamento do cuidado durante a intervenção (PETERS-KLIMM et al., 2007).

Um estudo transversal realizado com 4.108 pessoas adultas com dor crônica, DM, ICC, asma e doença arterial coronariana em sete regiões americanas do programa Kaiser Permanente Medical Care. O PACIC foi utilizado para avaliar a implementação do MCC no cuidado e encontrou resultados significantes e positivos associados com todas as medidas avaliadas (odds ratio (OD) variando entre 1,20 e 2,36), concluindo que o PACIC pode ser considerado uma ferramenta prática para avaliar o acompanhamento da qualidade do cuidado prestado em condições crônicas nos sistemas de saúde (SCHMITTDIEL et al., 2007).

Na Alemanha, o instrumento PACIC foi adaptado culturalmente e validado em 236 pessoas com osteoartrite e encontrou-se que a versão alemã, tal como a versão original do PACIC, alcançou os resultados de validade e de confiabilidade $(\alpha=$ 0,78 ou superior para todos os domínios) para mais de uma condição crônica. 0 teste-reteste foi realizado após duas semanas, em 75 pessoas selecionadas aleatoriamente, e o valor excedeu 0,77. Portanto, pode-se concluir que a versão alemã do PACIC é um instrumento válido e confiável para avaliar a qualidade do cuidado em congruência com os elementos do Modelo de Cuidados Crônicos na atenção em pessoas com osteoartrite (ROSEMANN et al., 2008).

O PACIC também foi adaptado culturalmente conforme o contexto relacionado e validado em vários outros países: Austrália, Espanha e Holanda, em estudos desenvolvidos por Taggart et al. (2011), Aragones et al. (2008) e Wensing et 
al. (2008), respectivamente. Tais estudos utilizaram análise fatorial visando avaliar a validade de construto entre os domínios dos instrumentos adaptados. De forma geral, encontraram-se entre moderadas e fortes correlações fatoriais, resultando em versões do PACIC confiáveis e possíveis de serem utilizadas com segurança para avaliar a qualidade do cuidado prestado nos sistemas de saúde em consonância com - MCC, em cada contexto de população específica (ARAGONES et al., 2008; TAGGART et al., 2011; WENSING et al., 2008).

$\mathrm{Na}$ Austrália, foram realizados dois estudos independentes, envolvendo participantes com DM tipo 2 e doença cardíaca isquêmica e/ou hipertensão arterial. O primeiro estudo, ensaio clínico randomizado, contou com 2552 pessoas de 60 instituições urbanas e rurais. O segundo estudo, quase experimental, envolveu 989 pessoas de 26 instituições urbanas em Sydney. A confiabilidade medida pelo alfa de Cronbach variou entre 0,87 e 0,95 para ambos os estudos australianos, sugerindo alta consistência interna (TAGGART et al., 2011).

Para o desenvolvimento do estudo de adaptação cultural e validação do PACIC na língua espanhola, participaram 100 pessoas com DM tipo 2, com nacionalidade espanhola e acompanhadas no ambulatório adulto de um hospital municipal em Nova York, Estados Unidos. O alfa de Cronbach total encontrado para a versão espanhola do PACIC foi de 0,87 e o teste-reteste realizado em 20 pessoas selecionadas aleatoriamente dois a quatro meses após foi de 0,77 , indicando altos resultados de confiabilidade (ARAGONES et al., 2008).

Na Holanda, foi realizado um estudo observacional com um total de 165 participantes, 88 pessoas com DM e 77 com Doença Pulmonar Obstrutiva Crônica (DPOC), em quatro instituições de atenção primária em saúde. Foi encontrada uma variação para os valores de alfa de Cronbach entre 0,71 e 0,83 na versão final holandesa do PACIC (WENSING et al., 2008).

O PACIC é o único instrumento disponível na literatura científica que tem permite a avaliação da qualidade do cuidado baseado nos elementos do MCC, sobre 
a perspectiva da pessoa com condição crônica. Portanto, possibilita o desenvolvimento da capacidade da pessoa ser avaliadora do seu próprio cuidado (HIBBARD, 2003). Além de tornar possível monitorar e realizar mudanças importantes para a melhoria da qualidade do cuidado prestado nos sistemas de saúde (GLASGOW et al., 2005a).

Embora o PACIC seja um instrumento reconhecido mundialmente, adaptado e validado em diversos idiomas e utilizado de forma ampla e efetiva em diferentes países para conhecer a sistematização das práticas de saúde adotadas no cuidado com condições crônicas, não foram encontrados em literatura científica nacional e internacional estudos de adaptação cultural e validação para a língua portuguesa.

Destaca-se que a comparação entre idiomas e contextos culturais é um parâmetro considerado muito importante para o desenvolvimento de estudos de adaptação cultural de instrumentos de medidas em saúde. Portanto, exigem-se muito cuidado com possíveis erros relacionados, principalmente com as diferentes culturas e suas equivalências idiomáticas, métodos utilizados e interpretação de resultados (HAMBLETON; PATSULA, 1998).

Dessa forma, tem-se como objeto de investigação desse estudo realizar a adaptação cultural do instrumento PACIC para a língua portuguesa em dois contextos culturais, no Brasil e em Portugal. 


\subsection{Apresentaçãa da instrumenta: Patient Assessment of Chranic Jllness Care (PACIC)}

Para sua construção do instrumento PACIC em sua versão original, Glasgow et al. (2005a) delinearam o estudo sobre a perspectiva das seguintes hipóteses: 1) Todos os itens do PACIC e seus domínios deveriam seguramente caracterizar as várias dimensões da qualidade das ações e do cuidado recebido relacionado ao Modelo de Cuidados Crônicos (MCC) e apresentar boas características psicométricas (como por exemplo, consistência interna e confiabilidade teste-reteste); 2) De forma geral, os itens do PACIC e seus domínios não deveriam estar relacionados às características sóciodemográficas (por exemplo, sexo, idade, nível educacional), mas sim às características clínicas das doenças crônicas (por exemplo, número de comorbidades); 3) De forma moderada, o PACIC deveria estar relacionado com medidas de cuidado primário e ativação da pessoa com condição crônica (GLASGOW et al., 2005a).

Dessa forma, a versão final do instrumento PACIC foi constituída por 20 itens, os quais abrangem cinco domínios: Participação Ativa do Paciente no Tratamento, Modelo do Sistema de Cuidado/Modelo para a Prática, Estabelecimento de Metas/Adaptação, Resolução de Problemas/Contexto (quatro itens) e Seguimento/Coordenação (GLASGOW et al., 2005a).

O primeiro domínio intitulado Participação Ativa do Paciente no Tratamento $(\alpha=0,82)$ é composto pelos itens 1,2 e 3 , perfazendo um total de três itens que descrevem ações que solicitam o ponto de partida inicial da pessoa com doença crônica e seu envolvimento na tomada de decisões. O segundo domínio, Modelo do Sistema de Cuidado / Modelo para a Prática $(\alpha=0,77)$, é composto pelos itens 4, 5 e 6, perfazendo um total de três itens que descrevem ações que organizam o cuidado e 
fornecem informações às pessoas para a melhora da sua compreensão do cuidado. O terceiro, Estabelecimento de Metas / Adaptação $(\alpha=0,84)$, é composto pelos itens 7, 8, 9, 10 e 11, perfazendo um total de cinco itens que avaliam a aquisição de informações para o estabelecimento específico de metas colaborativas. O quarto, Resolução de Problemas / Contexto $(\alpha=0,90)$, é composto pelos itens 12, 13, 14 e 15, perfazendo um total de quatro itens que descrevem barreiras potenciais que devem ser consideradas no ambiente social e cultural da pessoa com doença crônica na elaboração de planos de tratamento. Por fim, o quinto domínio, Seguimento / Coordenação $(\alpha=0,86)$, é composto pelos itens $16,17,18,19$ e 20, perfazendo um total de cinco itens que avaliam a promoção da continuidade do cuidado, reforçando o devido tratamento e possibilitando as pessoas com doenças crônicas serem avaliadoras do seu próprio progresso e coordenação do cuidado (GLASGOW et al., 2005a).

O PACIC avalia a possibilidade das pessoas refletirem sobre a qualidade do cuidado recebido para a sua condição crônica nos últimos seis meses, devendo assinalar no instrumento apenas uma alternativa de resposta para cada item. São oferecidas cinco alternativas de resposta para cada item, com escore (s) sobre variação de 1-5. A graduação dos itens do instrumento ocorre por escala de variação do tipo Likert: 1 (Almost Never); 2 (Generaly Not); 3 (Sometimes); 4 (Most of the Time) e 5 (Almost Always) (GLASGOW et al., 2005a).

Os valores totais dos escores em cada domínio são calculados pela média aritmética simples dos itens ponderados dos respectivos domínios. Da mesma forma, o valor total do escore do PACIC é obtido pela média aritmética simples dos 20 itens do instrumento, sendo que o valor mais alto corresponde a uma referência de maior qualidade do cuidado recebido pelas pessoas com condições crônicas nos últimos seis meses (GLASGOW et al., 2005a).

De um total de 379 participantes, 96 foram excluídos do estudo por não apresentarem pelo menos uma condição crônica. Portanto, 283 (75\%) foram 
selecionados para o estudo. Destes, 266 responderam a mais de $50 \%$ dos questionários e foram incluídos nas análises (GLASGOW et al., 2005a).

Dessa maneira, a versão final do PACIC (20 itens) foi aplicada a 266 pessoas adultas, com uma ou mais condições crônicas e com pelo menos seis meses de acompanhamento no cuidado em saúde. No contexto americano escolhido para o desenvolvimento do instrumento, as condições crônicas encontradas foram: hipertensão arterial $(n=130)$, artrite $(n=109)$, depressão $(n=51)$, diabetes mellitus $(n=41)$, asma $(n=41)$ e dor $(n=41)(G L A S G O W$ et al., 2005a).

A análise de confiabilidade (precisão/reprodutividade) foi verificada pelo método da consistência interna (alfa de Cronbach) dos 20 itens do PACIC. Para avaliar o grau de relação entre os domínios, foi utilizada a análise fatorial confirmatória. A confiabilidade teste-reteste e as associações entre medidas contínuas foram avaliadas usando-se o coeficiente de correlação linear de Pearson (coeficiente de correlação produto-momento) e correlações parciais foram utilizadas para controlar as possíveis variáveis de confusão. Associações entre o escore do PACIC e as variáveis categóricas foram avaliadas usando o $\chi^{2}$ ou correlações ponto-bisserial (para características dicotômicas). ANOVA e ANCOVA foram utilizadas para avaliar diferenças potenciais entre as diversas doenças crônicas (GLASGOW et al., 2005a).

Além disso, os pesquisadores coletaram dados sociodemográficos e clínicos, como também foram realizadas análises estatísticas iniciais (média, mediana, desviopadrão, obliquidade e distribuição de escores nos itens individuais, nos domínios e no total dos itens do PACIC, a fim de avaliar as características distribucionais) (GLASGOW et al., 2005a).

A confiabilidade do instrumento por meio do alfa de Cronbach obtido para o PACIC em sua versão final com 20 itens foi de 0,93, variando para cada domínio do instrumento de 0,77 a 0,90 (GLASGOW et al., 2005a). Para tanto, percebe-se a fiel confiabilidade do PACIC, visto que os valores do alfa de Cronbach estão acima de 0,70, valor mínimo para instrumentos de itens (FAYERS; MACHIN, 2007). 
A validade de construto convergente foi avaliada no estudo principal, com a aplicação simultânea do instrumento Patient Activation Mensure (PAM) (22 itens), que avalia a dimensão na qual as pessoas se sentem capazes de assumir a responsabilidade dos seus próprios cuidados, e dos itens de 4 domínios (Integração, Comunicação Interpessoal, Conhecimento Contextual e Cuidados Preventivos), de um total de 11, do instrumento Primary Care Physicians - Ambulatory Care Experience Survey (PCP-ACES), que avalia a associação dos elementos do MCC com ao principais aspectos de cuidados primários (GLASGOW et al., 2005a).

Para testar a validade de construto convergente, Glasgow et al., (2005a) avaliaram as correlações existentes entre as medidas dos domínios do PACIC e as medidas obtidas nos 4 domínios selecionados do PCP-ACES e do instrumento PAM, por meio do coeficiente de correlação linear de Pearson. Alguns resultados evidenciaram valores referentes às correlações estatisticamente significantes de fraca a moderada magnitude, tais como: o domínio Participação Ativa do Paciente no Tratamento do PACIC com o domínio Comunicação Interpessoal do PCP-ACES e com o instrumento PAM $(r=0,35$ e $r=0,29, p<0,001)$; o domínio Estabelecimento de Metas/Adaptação do PACIC com o instrumento PAM ( $r=0,43, p<0,001)$; e, o domínio Resolução de Problemas/Contexto do PACIC com o domínio Conhecimento Contextual do PCP-ACES e do instrumento PAC ( $r=0,38$ e $r=0,59, p<0,0001)$. No entanto, o domínio Seguimento/Coordenação do PACIC não evidenciou correlação estatisticamente significante e apresentou fraca magnitude com o instrumento PAM $(r=0,16, p=0,09)$ (GLASGOW et al., 2005a).

Dessa forma, os autores concluíram que o PACIC apresentou propriedades psicométricas adequadas e quando utilizado em conjunto com o ACIC, poderá fornecer importantes contribuições na pesquisa e na melhoria da qualidade do cuidado em condições crônicas (GLASGOW et al., 2005a).

Nesse sentido, após a apresentação dos principais aspectos considerados para a construção do instrumento PACIC em sua versão original, objeto do presente 
estudo, considera-se de fundamental importância compreender alguns conceitos teórico-metodológicos que norteiam o processo de adaptação cultural de instrumentos de medida em saúde.

\subsection{Pracessa de adaptaçãa cultural de instrumentas de medida em saúde}

As respostas psicossociais aos problemas de saúde e processos de vida são alvos frequentes de grandes discussões (FARIA; BELLATO, 2010; KAGEYANA et al., 2008; GARCÍA; COSTA JÚNIOR, 2008; RODRIGUES et al., 2009; SARTORE; GROSSI, 2008), e a denominações dessas respostas, processo inerente ao desenvolvimento de sistemas padronizados de linguagem, traz o desafio de tratá-las como construto (BRAGA; CRUZ, 2006).

Os construtos são abstrações, construções teóricas que objetivam organizar e atribuir significados ao nosso ambiente, que não podem ser diretamente observados, mas podem ser mensurados pelos seus atributos ou indicadores. Exemplos de construtos: qualidade de vida, ansiedade, dor, sentimento de impotência, esperança, pesar, medo, entre vários outros (BRAGA; CRUZ, 2006; PEDHAZUR 1991).

Embora haja a utilização cada vez mais habitual de instrumentos para avaliar práticas de um construto em saúde, nem sempre estão disponíveis no idioma ou para a determinada cultura de interesse.

Portanto, devido ao aumento do número de pesquisas multinacionais e em diferentes culturas (BEATON et al., 2002; HAMBLETON, 2005), aumenta-se a necessidade de adaptar medidas relacionadas à saúde para uso em outros idiomas, 
diferentes do original (BEATON et al., 2000). Atribui-se o nome de adaptação cultural por não bastar simplesmente a tradução do mesmo. É necessário todo um processo reflexivo que vai desde a compreensão dos objetivos do instrumento original passando pela importância semântica dos termos utilizados até a análise se ele é capaz de medir o mesmo critério ou construto em diferentes idiomas ou culturas (GEISINGER, 1994; HAMBLETON; PATSULA, 1998; BEATON et al., 2000).

Esse processo reflexivo inicia-se antes mesmo da seleção de um instrumento, esbarrando na dúvida da utilização de um já existente ou na opção de desenvolvimento de um novo. As primeiras vantagens sempre apontadas pela adaptação cultural são o menor custo e tempo gasto (GEISINGER, 1994; GUILLEMIN; BOMBARDIER; BEATON, 1993; JORGE, 2008), há também uma maior segurança em se utilizar instrumentos já amplamente utilizados, não descartando-se a possibilidade de comparação entre os resultados encontrados (HAMBLETON; PATSULA, 1998).

Dessa forma, Hambleton e Patsula (1998) ressaltam que estudos de adaptação cultural não devem ser realizados para encontrarem-se argumentos de superioridade de algumas nações. Na interpretação dos resultados, devem-se considerar fatores específicos de uma cultura, como políticas educacionais, padrões de vida e valores culturais, além de fatores externos, como a motivação para responder ao instrumento (HAMBLETON; PATSULA, 1998).

Contudo, em outras situações, a adaptação cultural não deve ser justificada, seja pela forma de como o instrumento é estruturado, diferindo dos utilizados em determinada cultura, ou baseado em conceitos que podem sugerir ambiguidades, sendo parcialmente incorretos (GEISINGER, 1994; HAMBLETON; PATSULA, 1998; HERDMAN; FOX-RUSHBY; BADIA, 1997; 1998).

Dessa maneira, no Brasil, recentemente inúmeros estudos realizaram a adaptação cultural de instrumentos desenvolvidos em culturas diferentes para realidades específicas (DEON, 2009; DEON et al., 2011; FABRÍCIO-WEHBE et al., 2009; IMADA; SOUZA，BIFFI, 2010; PELEGRINO, 2009; QUEIROZ; PACE; SANTOS, 2009; 
SANTOS, 2009; SARTORI; GROSSI, 2008; SERRANO, 2009; XAVIER et al., 2011; ZANETTI et al., 2012). Do mesmo modo, em Portugal, também houve o desenvolvimento de tais estudos metodológicos (BATALHA et al., 2009; DELALIBERA; COELHO; BARBOSA, 2010; DOMINGUES; CRUZ, 2011; FACHADO et al., 2007; MATIAS, 2010; NEVES; SILVA; MARQUES, 2011; RIBEIRO, 2010; SILVA; RIBEIRO, 2008).

De acordo com Hambleton e Patsula (1998), três parâmetros fundamentalmente relevantes devem ser considerados para proceder a adaptação de um instrumento entre regiões com diferentes idiomas e culturas: avaliação do instrumento traduzido, examinando até que ponto os resultados encontrados correspondem ao estado real; avaliação de sua validade e confiabilidade; e estabelecimento de comparação entre idiomas, quando for importante. Quando esse processo é estabelecido, o pesquisador deverá estar atento para possíveis erros relacionados, principalmente com as diferentes culturas e idiomáticas, métodos utilizados e interpretação de resultados (HAMBLETON; PATSULA, 1998).

Nessa perspectiva, a adaptação cultural procura obter a equivalência semântica (gramática e vocabulário), cultural (experiências vivenciadas dentro do contexto cultural da sociedade), idiomática (substituição de expressões ou itens não encontrados em português) e conceitual (validade de conceito explorado, ou seja, se um dado domínio tem a mesma importância tanto na versão original de um instrumento quanto na versão adaptada) de cada item do instrumento, assim como as referentes às instruções de preenchimento e a coerência da apresentação (GUILLEMIN; BOMBARDIER; BEATON, 1993; BEATON et al., 2000; 2002; SCHIMIDT; BULLINGER, 2003).

Portanto, a partir do objetivo de se obter medidas válidas de tradução e de adaptação cultural do instrumento original, recomendam-se diretrizes para a obtenção de padronizações (GUILLEMIN; BOMBARDIER; BEATON, 1993; BEATON et al., 2000; 2002). 
A preocupação em atender a padronizações para o processo de adaptação cultural de instrumentos de medidas em saúde ocorre devido a grande variação na qualidade dos processos metodológicos utilizados e na falta de um consenso padrão a ser seguido (MANEESRIWONGUL; DIXON, 2004).

Assim, a escolha adequada da metodologia utilizada para adaptar culturalmente um instrumento de medida permite a inclusão de variáveis específicas próprias da cultura. Como também, permite a utilização de linguagem simples, clara e de fácil acesso à população atendida (BANDEIRA; CALZAVARA; VARELA, 2005).

Reconhece-se que não há um único modelo padrão a ser seguido e uma melhor metodologia para realizar o processo de adaptação de um instrumento de medida em saúde.

Porém, diversos estudos nacionais e internacionais utilizaram-se das recomendações metodológicas propostas por Guillemin, Bombardier e Beaton (1993), baseadas em diretrizes médicas, sociológicas e psicológicas (CICONELLI et al., 1999; FABRÍCIO-WEHBE et al., 2009; IMADA; SOUZA， BIFFI，2010; KIMURA， 1999; MASTROPRIETO et al., 2007; LA SCALA et al., 2005; SARTORI; GROSSI, 2008).

Entretanto, com o objetivo de aprimorar o processo metodológico proposto por Guillemin, Bombardier e Beaton (1993), alguns autores apresentaram algumas modificações para conduzir a adaptação cultural (FERRER et al., 2006; BEATON et al. (2000; 2002), que foram utilizadas por alguns estudos recentes (FERREIRA et al., 2008; ECHEVARRIA-GUANILO et al., 2006; CASTRO, 2007; SERRANO, 2009; XAVIER et al., 2011; ZANETTI et al., 2012).

Ainda assim, o processo de adaptação cultural adotado para o Brasil e Portugal do instrumento PACIC foi realizado de acordo com as etapas propostas por World Health Organization - WHO (2012), conforme recomendações do programa americano Improving Chronic Illness Care (ICIC), o qual informa sobre a construção original e utilização do PACIC e os demais instrumentos envolvidos no gerenciamento do cuidado em condições crônicas. 
Portanto, as etapas desse estudo contemplam particularidades essenciais que foram descritas detalhadamente nos métodos, na seguinte sequência: Tradução; Comitê de Especialistas; Retrotradução (Back-Translation); Pré-Teste e Entrevista Cognitiva (WHO, 2012).

Portanto, pretende-se, com o presente estudo, seguir cuidadosamente e de forma sequencial tais etapas recomendadas pelo processo metodológico de WHO (2012), com o objetivo de garantir que a validade e a confiabilidade do instrumento original do PACIC se mantenham na versão adaptada para a língua portuguesa do Brasil e de Portugal.

Considerando os fatores específicos que justificam o desenvolvimento de estudos de adaptação cultural de um instrumento, é importante ressaltar que o Plano de Ações da Organização Mundial da Saúde, documento orientador na preparação de Planos de Enfrentamento das DCNT, focou-se em quatro principais condições crônicas: a doença cardiovascular, o câncer, a doença respiratória crônica e o diabetes (WHO, 2008). No Brasil, o Ministério da Saúde desenvolveu o Plano de Ações Estratégicas para o Enfrentamento das Doenças Crônicas Não Transmissíveis (DCNT), 2011-2022, visando enfrentar e deter as DCNT mais prevalentes, entre as quais: o acidente vascular cerebral, o infarto, a hipertensão arterial, o câncer, o diabetes e as doenças respiratórias crônicas (BRASIL, 2011a).

Além disso, mediante diretrizes de um documento internacional que direciona o cuidado em saúde baseado em evidências, destacou-se que o diabetes mellitus (DM) foi uma das condições crônicas incluídas na aplicação experimental do Modelo de Cuidados Crônicos (AMERICAN DIABETES ASSOCIATION - ADA, 2012).

Somado a relevância desses documentos e a crescente importância epidemiológica do DM, apresentam-se a seguir dados relacionados à prevalência e aos impactos financeiros relacionados aos custos com a saúde dessa condição crônica. Para fins de organização e desconsiderando qualquer grau de importância, 
tais dados foram apresentados sequencialmente em vista à realidade do mundo, do Brasil e de Portugal.

\section{$1.5 \mathcal{O}$ dialeetes mellitus: aspectas epidemialágicas}

Dentre as DCNT, o diabetes mellitus (DM) é considerado um fardo econômico, social e pessoal para as instituições e famílias, representando um grande desafio para a saúde e o desenvolvimento humano, principalmente em países de baixa condição socioeconômica, levando as famílias a um maior estado de pobreza (WHO, 2011a).

O crescimento da prevalência e incidência do DM, mortalidade prematura e os custos envolvidos no controle e no tratamento das complicações têm evidenciado a condição crônica como um grave problema de Saúde Pública, principalmente ao aproximar-se de proporções epidêmicas alarmantes (BRASIL, 2011a; GLASGOW et al., 1999; WHO, 2011a).

Entre os anos de 2010 e 2030, um estudo revelou que a prevalência mundial de DM entre os adultos (20-79 anos) seria de 6,4\%, afetando 285 milhões adultos, em 2010, com projeção para 7,7\%, e 439 milhões de adultos até 2030. Portanto, entre as três próximas décadas deverá ocorrer um acréscimo de $69 \%$ no número de adultos com DM nos países desenvolvidos e um aumento de $20 \%$ nos países em desenvolvimento (SHAW; SICREE; ZIMMET, 2010).

Estudo multicêntrico de prevalência do DM realizado no Brasil, com a população urbana brasileira, na faixa etária de 30-69 anos, mostrou que 7,6\% e 7,8\% apresentam DM e tolerância diminuída à glicose, respectivamente (MALERBI; 
FRANCO, 1992). Aproximadamente nove anos depois, um estudo semelhante, realizado na cidade de Ribeirão Preto, São Paulo, obteve, respectivamente, prevalência de 12,1\% e 7,7\% (TORQUATO et al., 2003). Ainda em Ribeirão Perto, um novo estudo mais recente, mostrou prevalência de 15,02\% para DM e 5,53\% para tolerância diminuída à glicose (MORAES et al., 2010).

Em Portugal, estudo epidemiológico divulgou que a prevalência do DM na população entre $20-79$ anos foi de $12,4 \%$ e uma incidência de 511,4 novos casos por 100.000 habitantes, representando uma situação de verdadeira epidemia (PORTUGAL, 2011). É importante ressaltar que Portugal encontra-se atualmente em situação de destaque com um dos valores mais elevados de prevalência mundial de DM (20-79 anos), nomeadamente por comparação à Espanha e à maioria dos países da Europa (INTERNATIONAL DIABETES FEDERATION - IDF, 2012).

De acordo com o primeiro estudo de prevalência do DM realizado em seis regiões de Portugal, encontrou-se a maior prevalência (13,9\%) no Grande Porto, que representa a metrópole multimunicipal portuguesa, com 1.287.276 habitantes e uma área total de $1024 \mathrm{~km}^{2}$, formada por onze cidades, dentre elas, o Porto (GARDETECORREIA et al., 2010).

Contudo, a progressiva importância epidemiológica do DM em países de baixa, média e alta condição socioeconômica também causa impactos financeiros frente aos custos com a saúde (GUIDONI et al., 2009).

O National Health System britânico evidenciou que os custos envolvidos com os sistemas de saúde em geral às doenças crônicas variam entre $50-80 \%$ das despesas globais de saúde, o que representa sérios problemas de sustentabilidade financeira para a manutenção dos programas de cuidados (SINGH, 2008).

Em 2011, um estudo realizado em oito cidades brasileiras investigou os custos diretos e indiretos do tratamento ambulatorial em pessoas com DM2 atendidas no Sistema Único de Saúde (SUS). Os resultados mostraram um custo anual para o tratamento ambulatorial de pessoas com DM2 de $\mathrm{R} \$ 2.951 .496$ para 
1000 pessoas ( $R \$ 2.951$ / por pessoa), sendo que $R \$ 1.870 .365$ de custos diretos $(63,3 \%)$ e $R \$ 1.082 .496$ de custos indiretos $(36,7 \%)$ (BAHIA et al., 2011$)$.

Em Portugal, realizou-se em 2008 um estudo no qual revelou os custos do DM2 para o sistema de saúde português, resultando um custo total aproximado de €952 milhões, o que representou cerca de 5,5\% do total das despesas de saúde e 0,55\% do Produto Interno Bruto (PIB) no ano vigente. Decompondo esse total em custos diretos e indiretos, o estudo apontou para uma estimativa global de €616 milhões em custos diretos $(64,7 \%)$, dos quais $€ 108,20$ milhões com internações e $€ 508$ milhões com tratamentos ambulatoriais, e €336 milhões em custos indiretos $(35,3 \%)$ (GOUVEIA, 2012).

Dessa forma, os custos financeiros em saúde decorrentes do DM incluem gastos associados com a perda da capacidade produtiva no trabalho, o absenteísmo, os tratamentos clínicos e cirúrgicos, a reabilitação e a aposentadoria precoce. Nestes casos, os encargos ultrapassam a esfera financeira, relacionando também custos sociais e humanísticos, levando a redução da qualidade de vida e a problemas de ordens psicológicas, constituindo-se em um grande desafio para as políticas de saúde, agravado pelas desigualdades sociais e econômicas (GUIDONI et al., 2009).

Com base na epidemiologia apresentada e suas consequências para a população mundial e políticas de saúde, o diabetes mellitus constitui uma das mais importantes condições crônicas de saúde, impondo a necessidade de controle e tratamentos eficazes (SILVEIRA et al., 2010).

Os dois mais importantes estudos clínicos para controle do DM, o Diabetes Control and Complications Trial (DCCT, 1993) e o United Kingdom Prospective Diabetes Study Group (UKPDS, 1998), encontraram que as mudanças no estilo de vida pela educação permanente das pessoas com DM resultam em redução de peso corporal, melhor controle glicêmico e metabólico, da pressão arterial e de lipídios, redução dos riscos cardiovasculares. Dessa forma, o controle metabólico é obtido por meio da educação, do monitoramento glicêmico, da terapia nutricional, da atividade 
física regular, dos esquemas terapêuticos farmacológicos, das informações sobre a prevenção e tratamento das complicações agudas e crônicas, e do reforço dos objetivos do tratamento (ADA, 2012).

Pela natureza crônica da doença, os problemas de saúde gerados pelo DM requerem gerenciamento contínuo por vários anos ou décadas (BRASIL, 2008; WHO, 2002; PAIM, 2011). A complexidade do regime terapêutico que inclui mudanças no estilo de vida e, na maioria das vezes, múltiplos medicamentos e dosagens associados ao aparecimento de complicações crônicas precoces, torna-se um desafio para as adaptações comportamentais necessárias no controle adequado da doença (WAGNER et al., 2001; SELEY; WEINGER, 2007).

No entanto, a obtenção do sucesso do tratamento em pessoas com condições crônicas vai além de simplesmente receber cuidados com qualidade, acrescentando-se a necessidade de manifestar expectativas e medos no decorrer do cuidado prestado. Dessa forma, torna-se essencial o auxílio no processo de aceitação da condição, a fim de obter os conhecimentos necessários para a sua gestão com autonomia, mantendo toda a colaboração com a equipe de profissionais de saúde responsável pela prestação dos cuidados (BOAVIDA, 2001; ADA, 2012).

Dessa forma, espera-se contribuir para a produção do conhecimento científico de estudos comparativos em diferentes contextos culturais, permitindo a adaptação cultural do PACIC para a língua portuguesa do Brasil e de Portugal em pessoas com diabetes mellitus, tendo em vista a importância de avaliar a qualidade do cuidado continuado nessa importante condição crônica de saúde. 


\subsection{Justificativa e Relevância}

As DCNT constituem condições de saúde que persistem em longo prazo, requerendo acompanhamento continuado e permanente. Nessa perspectiva, órgãos internacionais e nacionais de saúde têm se esforçado para melhorias na qualidade do cuidado prestado às pessoas com condições crônicas, uma vez que requer cuidados contínuos e uma adequação necessária a um novo padrão de vida saudável.

Reconhecendo positivamente a oportunidade de um cuidado integral, os sistemas de saúde precisam ser fortalecidos a fim de oferecer assistência direcionada às pessoas com DCNT, mediante modelos de atenção às condições crônicas (SCHMIDT, 2011; WAGNER, 1998; WAGNER et al., 2001; WHO, 2002).

Dentre eles, sobressai-se o Modelo de Cuidados Crônicos (MCC), originalmente proposto por Wagner (1998) e pesquisadores do MacColl Institute for Healthcare for Inovation de Seatle, Washington, nos Estados Unidos, como uma abordagem interativa de um modelo de gestão para cuidados em pessoas adultas com condições crônicas, garantindo a continuidade do cuidado em saúde.

Destaca-se que a utilização de ferramentas práticas de avaliação para monitorar os sistemas de saúde e avaliar a implementação dos elementos do MCC, torna-se também essencial para possibilitar comparações entre diferentes contextos culturais e/ou acompanhar a qualidade do cuidado em estudos clínicos de intervenção (INSTITUTE OF MEDICINE, 2001; MCGLYNN, 2003).

O PACIC é o único instrumento disponível na literatura científica que tem permite a avaliação da qualidade do cuidado baseado nos elementos do MCC, sobre a perspectiva da pessoa com condição crônica. Portanto, possibilita o desenvolvimento da capacidade da pessoa ser avaliadora do seu próprio cuidado (HIBBARD, 2003). 
Embora o PACIC seja um instrumento reconhecido mundialmente, adaptado e validado em diversos idiomas e utilizado de forma ampla e efetiva em diferentes países para conhecer a sistematização das práticas de saúde adotadas no cuidado com condições crônicas, não foram encontrados em literatura científica nacional e internacional estudos de adaptação cultural e validação para a língua portuguesa.

Destaca-se que a comparação entre idiomas e contextos culturais é um parâmetro considerado muito importante para o desenvolvimento de estudos de adaptação cultural de instrumentos de medidas em saúde (HAMBLETON; PATSULA, 1998). Dessa forma, tem-se como objeto de investigação desse estudo realizar a adaptação cultural do instrumento PACIC para a língua portuguesa em dois contextos culturais, no Brasil e em Portugal.

Mediante o crescente impacto epidemiológico das DCNT, elaboraram-se documentos internacionais e nacionais, como o Plano de Ações da Organização Mundial da Saúde (WHO, 2008) e o Plano de Ações Estratégicas para o Enfrentamento das Doenças Crônicas Não Transmissíveis (DCNT), 2011-2022 (BRASIL, 2011a), com o objetivo de determinar uma atenção especial na melhora do cuidado nas DCNT mais prevalentes. Dentre as tais, encontrou-se o diabetes mellitus.

Além disso, mediante diretrizes de um documento internacional que direciona o cuidado em saúde baseado em evidências, destacou-se que o DM foi uma das condições crônicas incluídas na aplicação experimental do Modelo de Cuidados Crônicos (ADA, 2012).

Dessa forma, espera-se contribuir para a produção do conhecimento científico de estudos comparativos em diferentes contextos culturais, permitindo a adaptação cultural do PACIC para a língua portuguesa do Brasil e de Portugal em pessoas com diabetes mellitus, tendo em vista a importância de avaliar a qualidade do cuidado continuado nessa importante condição crônica de saúde. 
Objetivos 


\section{OBJETIVOS}

\subsection{Objetiva geral}

- Adaptar culturalmente o instrumento desenvolvido originalmente na língua inglesa Patient Assessment of Chronic Illness Care (PACIC), para a língua portuguesa do Brasil e de Portugal.

\subsection{Objetivas especificas}

- Realizar a tradução do PACIC em sua versão original para a língua portuguesa do Brasil e de Portugal;

- Verificar o alcance das equivalências semântica, idiomática, cultural e conceitual entre a versão original do instrumento e as traduções brasileira e portuguesa no Comitê de Especialistas;

- Realizar as retrotraduções das versões em português obtidas no Brasil e em Portugal para o inglês;

$-\quad$ Executar o pré-teste por meio de entrevistas cognitivas em uma população de adultos e idosos com diagnóstico de diabetes mellitus no Brasil e em Portugal;

- Verificar a compreensão dos conceitos existentes. 


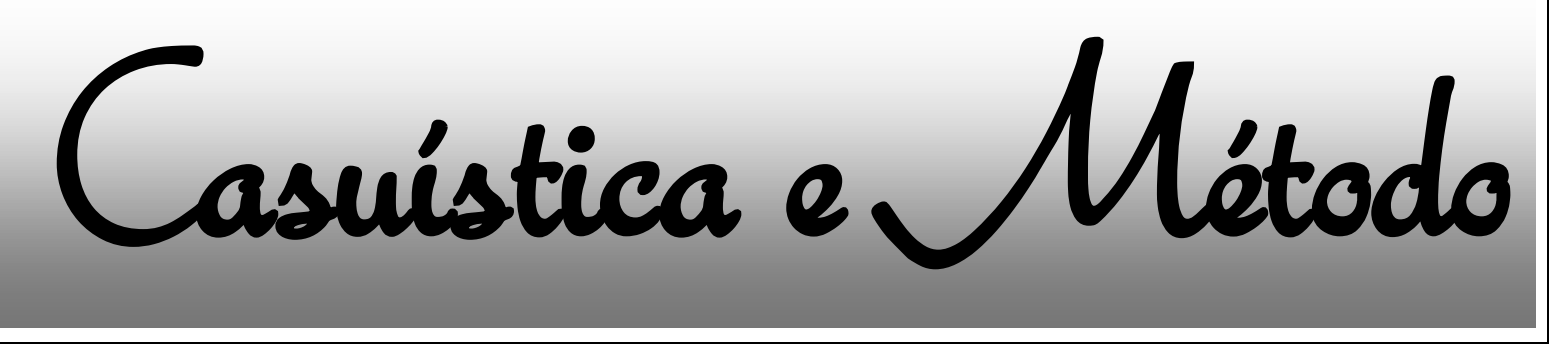




\section{CASUÍSTICA E MÉTODO}

\subsection{Tipa de estuda}

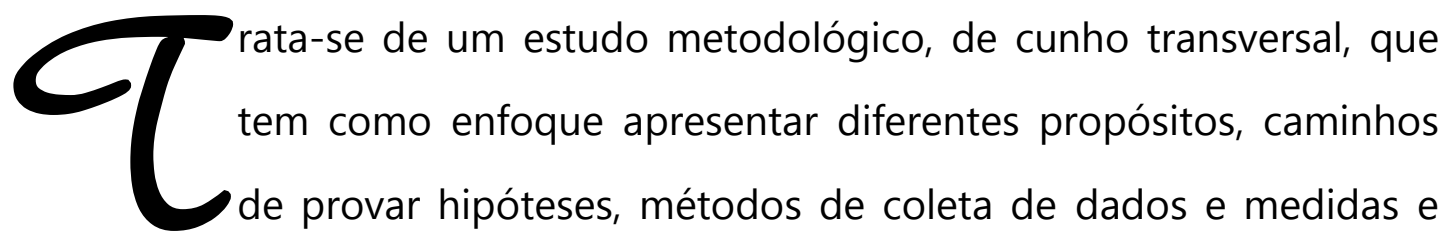
técnicas de análise de dados. Pode ser utilizado como controle de outras pesquisas, da teoria e aplicação de aspectos de matemáticas, estatística, medidas e o significado de reunir e analisar dados (KERLINGER, 1979).

Considera-se que estudos essencialmente metodológicos têm como enfoque principal ampliar o conhecimento do pesquisador sobre o fenômeno que deseja investigar em estudos posteriores mais estruturados (POLIT; BECK, 2006a).

Portanto, o tipo de estudo selecionado possibilitará adaptar culturalmente um instrumento para avaliação da qualidade do cuidado recebido na perspectiva de pessoas com condições crônicas no contexto brasileiro e português, que enfatiza os elementos do Modelo de Cuidados Crônicos (MCC). 


\subsection{Autarizaçãa farmal da autar principal para a adaptaçãa cultural da instrumenta}

A autorização formal para a adaptação cultural à realidade brasileira e portuguesa do instrumento Patient Assessment of Chronic Illness Care (PACIC) (ANEXO A) foi solicitada ao Dr. Russell Glasgow, o autor principal do instrumento. Em e-mails recebidos nos dias 04 de novembro de 2010 e 21 de janeiro de 2012, o referido autor concedeu a autorização para que $\mathrm{O}$ instrumento fosse traduzido e adaptado para a língua portuguesa do Brasil (ANEXO B) e de Portugal (ANEXO C), respectivamente.

\subsection{Pracessa de adaptaçãa cultural da PACIC na Brasil e em Partugal}

O processo de adaptação cultural adotado para o instrumento PACIC no Brasil e em Portugal foi realizado de acordo com as etapas propostas por World Health Organization - WHO (2012), conforme recomendações no website do Programa Improving Chronic Illness Care (ICIC, 2012), o qual informa sobre o desenvolvimento inicial e utilização do PACIC e outros instrumentos envolvidos no gerenciamento do cuidado em doenças crônicas. Tais recomendações também foram advertidas por meio de correio eletrônico (ANEXO D), em comunicação para contatos iniciais do desenvolvimento deste estudo, com Dr. Brian Austin, vice-diretor do 
Improving Chronic Illness Care, membro do Group Health Research Institute e diretor associado do MacColl Institute for Healthcare Innovation (GHRI, 2012).

Portanto, as etapas percorridas para o desenvolvimento desse estudo serão apresentadas a seguir e foram obedecidas conforme recomendado na seguinte sequência: Tradução; Comitê de Especialistas; Retrotradução (Back-Translation); PréTeste e Entrevista Cognitiva (WHO, 2012).

\subsubsection{Traduçãa da instrumenta PACIC para a língua partuguesa da Brasil e de Partugal}

O processo de tradução preconizado por WHO (2012) recomenda que sejam consideradas as seguintes diretrizes gerais:

- A ênfase da tradução tem como foco principal a equivalência conceitual, devendo ser evitadas traduções literais: "palavra por palavra";

- A tradução dos itens do instrumento deve constituir-se de frases simples, claras e concisas, evitando frases extensas;

- A linguagem da tradução deverá ser facilmente compreendida para qualquer nível de pessoas entrevistadas, evitando concentrar em uma linguagem diretamente voltada para profissionais de saúde. Considera-se como uma tradução ideal quando se obtém a rápida compreensão das pessoas entrevistadas logo após uma leitura dos itens do instrumento;

- Em quaisquer circunstâncias, devem ser evitados termos técnicos, vernáculos ou expressões idiomáticas na tradução; 
- Os tradutores devem considerar o gênero e a idade das pessoas entrevistadas, além de estarem atentos a palavras que possam parecer ofensivas.

Dessa maneira, a fim de realizar a tradução do instrumento PACIC em sua Versão Original (PACIC-VO) (ANEXO A), selecionaram-se quatro tradutores nativos, dois brasileiros e dois portugueses. Em cada contexto, um profissional de saúde e o outro atuante em traduções de assuntos em saúde, habituados com a linguagem técnica da temática do instrumento e bilíngues, ou seja, com amplo domínio da língua e cultura inglesa.

Para dar início às traduções, os tradutores foram esclarecidos individualmente por correio eletrônico, sobre a natureza, os objetivos do estudo e as diretrizes gerais propostas por WHO (2012).

Como resultado das traduções do instrumento PACIC-VO, obtiveram-se quatro versões em português: Versão Traduzida para o Português-Brasil 1a (PACICVTPBra 1a), Versão Traduzida para o Português-Brasil 1b (PACIC-VTPBra 1b), Versão Traduzida para o Português-Portugal 2a (PACIC-VTPPort 2a) e Versão Traduzida para o Português-Portugal 2b (PACIC-VTPPort 2b).

Dessa forma, após a obtenção das quatro versões traduzidas e objetivando priorizar frases de melhores expressões, originou-se uma versão consensual brasileira e uma portuguesa, denominadas: Versão Consensual em Português-Brasil 1ab (PACIC-VCPBra 1ab) (APÊNDICE A) e Versão Consensual em Português-Portugal 2ab (PACIC-VCPPort 2ab) (APÊNDICE B). 


\subsubsection{Aualiaçãa pela Camitê de Especialistas}

A formação do Comitê de Especialistas revela-se de grande importância para o alcance da equivalência do processo de adaptação cultural de um instrumento traduzido com o original (GUILLEMIN; BOMBARDIER; BEATON, 1993).

Nesta etapa, objetiva-se o esclarecimento de expressões inadequadas (conceitos da tradução), bem como de qualquer possível divergência entre a versão traduzida e a versão original. Os especialistas devem ser capazes de questionar algumas palavras ou expressões, sugerindo alternativas consistentes com a realidade da população alvo. O resultado desta etapa deverá originar uma nova versão do instrumento traduzido (WHO, 2012).

Dessa forma, as versões consensuais do instrumento brasileiro PACIC-VCPBra lab e português PACIC-VCPPort 2ab foram então submetidas à avaliação por um Comitê de Especialistas, composto, no Brasil, pela pesquisadora principal, sua orientadora e cinco profissionais: duas enfermeiras docentes da Escola de Enfermagem de Ribeirão Preto da Universidade de São Paulo (EERP-USP) e atuantes no ensino, pesquisa e extensão do cuidado de pessoas com doenças crônicas, em especial o diabetes mellitus, sendo uma delas pesquisadora na metodologia adotada no presente estudo; duas enfermeiras doutorandas da EERP-USP inseridas também na pesquisa do cuidado em DM e uma tradutora bilíngue com experiência em traduções de assuntos em saúde.

Em Portugal, compuseram o Comitê de Especialistas a pesquisadora principal e sua supervisora responsável pelo estágio internacional, enfermeira e professora coordenadora da Escola Superior de Enfermagem do Porto (ESEP), além de: duas enfermeiras docentes da ESEP, uma enfermeira docente da Escola Superior de Saúde do Vale do Ave (ESSVA), todas atuantes no ensino, pesquisa e extensão do cuidado 
de pessoas com doenças crônicas, sendo duas delas pesquisadoras na metodologia adotada no presente estudo e uma delas também tradutora bilíngue com experiência em traduções em assuntos em saúde. Também fizeram parte desse Comitê uma enfermeira supervisora da equipe de Enfermagem do Serviço de Consultas Externas (Endocrinologia) do Centro Hospitalar de São João (EPE), Porto, Portugal e uma pessoa com diagnóstico de diabetes mellitus em seguimento neste serviço.

Após um contato individualizado sobre a disponibilidade do dia e horário dos especialistas, foi-Ihes enviada uma Carta-Convite, por meio de correio eletrônico, no Brasil (APÊNDICE C) e em Portugal (APÊNDICE D) nos dias 26 de maio de 2011 (Ribeirão Preto, São Paulo, Brasil) e 21 de fevereiro de 2012 (Porto, Portugal), com orientações específicas sobre o desenvolvimento do estudo, a apresentação do instrumento e a forma de participação de cada especialista, além de esclarecimentos sobre os objetivos e procedimentos a serem adotados em ambos os Comitês.

A reunião com o Comitê de Especialistas no Brasil foi conduzida pela pesquisadora principal e sua orientadora no dia 30 de maio de 2011, às 9:00h, na Escola de Enfermagem de Ribeirão Preto. Em Portugal, a pesquisadora principal e a sua supervisora dirigiram a reunião no dia 29 de fevereiro de 2012, às 15:30h, na Escola Superior de Enfermagem do Porto. Cada reunião durou em média duas horas e ambas foram gravadas em áudio com consentimento assinado por todos os especialistas.

De forma inicial, foram esclarecidos aos especialistas os objetivos do estudo e da reunião para proceder às avaliações das equivalências semântica, idiomática, cultural e conceitual entre a versão original do instrumento e as versões consensuais brasileira e portuguesa.

A equivalência semântica destinou-se à substituição de alguns termos por outros equivalentes (sinônimos) no português do Brasil e de Portugal, quando estes não se enquadravam para o contexto avaliado. A equivalência idiomática referiu-se à substituição de expressões ou itens coloquiais e/ou idiomáticos de difícil tradução 
não encontrados no contexto cultural do Brasil e de Portugal. A equivalência cultural consistiu na correspondência das situações retratadas na versão original às vivenciadas no contexto cultural do Brasil e de Portugal. Por fim, a equivalência conceitual, que representou a coerência do item avaliado relacionado ao domínio a ser medido.

Para tanto, após a leitura individual e a assinatura em duas vias da Declaração de Consentimento para Especialistas (APÊNDICE E) no Brasil e em Portugal, manifestando a concordância sobre a forma de participação, foram distribuídas uma cópia do instrumento em sua versão original PACIC-VO e em suas versões consensuais PACIC-VCPBra 1ab (Brasil) ou PACIC-VCPPort 2ab (Portugal) para cada membro do Comitê. A seguir, solicitou-se que todos os especialistas acompanhassem a leitura dos instrumentos, à medida que a tradutora bilíngue lia pausadamente e em voz alta os itens do instrumento em sua versão original, para facilitar a comparação com os itens em suas versões consensuais brasileira e portuguesa lidos pela pesquisadora principal, sendo realizadas, em conjunto, discussões.

Na presença de divergências nas equivalências, procedia-se a uma discussão para esclarecimentos até a obtenção de um consenso, de, no mínimo, $80 \%$ do total do número de membros do Comitê de Especialistas, sendo acatadas as sugestões.

Ao término desse processo, resultaram-se a Versão Consensual em Português-Brasil 1.0 (PACIC-VCPBra 1.0) e a Versão Consensual em PortuguêsPortugal 2.0 (PACIC-VCPPort 2.0), como podem ser visualizadas a seguir no Quadro 1 e no Quadro 2, respectivamente. 
Quadro 1 - Representação do consenso da Versão Consensual em Português-Brasil 1.0 (PACIC-VCPBra 1.0). Ribeirão Preto-SP, Brasil, 2012

\begin{tabular}{|c|c|}
\hline PACIC-VCPBra 1ab & PACIC-VCPBra 1.0 \\
\hline $\begin{array}{c}\text { ESCALA PARA AVALIAÇÃO DO PACIENTE COM } \\
\text { RELAÇÃO AOS CUIDADOS PRESTADOS À SUA } \\
\text { DOENÇA CRÔNICA }\end{array}$ & $\begin{array}{l}\text { QUESTIONÁRIO DE AVALIAÇÃO DO CUIDADO } \\
\text { DE PACIENTES COM DOENÇA CRÔNICA }\end{array}$ \\
\hline Cuidados prestados à sua Doença Crônica & Cuidados com a sua Doença Crônica \\
\hline $\begin{array}{l}\text { Manter-se saudável pode ser difícil } \\
\text { quando você tem uma doença crônica. } \\
\text { Nós gostaríamos de saber sobre } \\
\text { o tipo de atenção que recebe da equipe de saúde } \\
\text { com relação à sua condição. Esta ajuda pode } \\
\text { incluir o (a) seu (sua) médico (a), } \\
\text { seu (sua) enfermeiro (a) ou médico (a) assistente } \\
\text { que trata da sua doença. Suas respostas } \\
\text { serão mantidas confidenciais } \\
\text { e não serão reveladas a ninguém. }\end{array}$ & $\begin{array}{l}\text { Manter-se saudável pode ser difícil } \\
\text { quando você tem uma doença crônica. } \\
\text { Nós gostaríamos de saber sobre } \\
\text { a ajuda que você recebe da equipe de saúde } \\
\text { com relação à sua condição. Esta ajuda pode } \\
\text { incluir o (a) seu (sua) médico (a), } \\
\text { seu (sua) enfermeiro (a) ou outros profissionais } \\
\text { de saúde que trata da sua doença. } \\
\text { Suas respostas serão mantidas em sigilo } \\
\text { e não serão reveladas a ninguém. }\end{array}$ \\
\hline $\begin{array}{l}\text { Nos últimos seis meses, } \\
\text { quando recebi cuidados em relação a minha } \\
\text { doença crônica: }\end{array}$ & $\begin{array}{l}\text { Para responder todas as questões desse } \\
\text { questionário, você deverá pensar na ajuda do } \\
\text { cuidado recebido para a sua doença crônica } \\
\text { nos últimos } 6 \text { meses e assinalar uma resposta } \\
\text { para cada questão. }\end{array}$ \\
\hline $\begin{array}{c}\text { Quase nunca } \\
\text { Geralmente não } \\
\text { Algumas vezes } \\
\text { A maior parte do tempo } \\
\text { Quase sempre }\end{array}$ & $\begin{array}{c}\text { Nunca } \\
\text { Quase Nunca } \\
\text { Às vezes } \\
\text { Quase Sempre } \\
\text { Sempre }\end{array}$ \\
\hline Ativação do Paciente & Participação Ativa do Paciente no Tratamento \\
\hline $\begin{array}{l}\text { 1. Perguntaram-me sobre minhas idéias quando } \\
\text { fizemos um plano de tratamento. }\end{array}$ & $\begin{array}{l}\text { 1. Perguntaram a minha opinião quando foi feito } \\
\text { a proposta de tratamento. }\end{array}$ \\
\hline $\begin{array}{l}\text { 2. Deram-me opções sobre o tratamento para } \\
\text { que eu pensasse a respeito. }\end{array}$ & $\begin{array}{l}\text { 2. Deram opções de tratamento para que eu } \\
\text { pensasse a respeito. }\end{array}$ \\
\hline $\begin{array}{l}\text { 3. Perguntaram-me sobre os problemas que } \\
\text { tenho com os remédios que tomo ou os seus } \\
\text { efeitos. }\end{array}$ & $\begin{array}{l}\text { 3. Perguntaram se tenho algum problema com os } \\
\text { medicamentos que eu tomo ou com os seus } \\
\text { efeitos. }\end{array}$ \\
\hline $\begin{array}{c}\text { Desenvolvimento do Sistema de Cuidado / } \\
\text { Apoio para Decisão } \\
\end{array}$ & $\begin{array}{c}\text { Modelo do Sistema de Cuidado / } \\
\text { Modelo para a Prática }\end{array}$ \\
\hline $\begin{array}{l}\text { 4. Deram-me uma lista escrita de coisas que eu } \\
\text { deveria fazer para melhorar minha saúde. }\end{array}$ & $\begin{array}{l}\text { 4. Deram uma lista por escrito de coisas que eu } \\
\text { deveria fazer para melhorar a minha saúde. }\end{array}$ \\
\hline $\begin{array}{l}\text { 5. Fiquei satisfeito (a) que os cuidados prestados } \\
\text { eram bem organizados. }\end{array}$ & $\begin{array}{l}\text { 5. Fiquei satisfeito (a) com a organização dos } \\
\text { cuidados prestados. }\end{array}$ \\
\hline $\begin{array}{l}\text { 6. Mostraram-me como o que eu fazia para } \\
\text { cuidar da minha doença influenciava minha } \\
\text { condição. }\end{array}$ & $\begin{array}{l}\text { 6. Mostraram que a maneira como eu me cuidava } \\
\text { influenciava na minha doença. }\end{array}$ \\
\hline Estabelecimento de Metas / Adaptação & Estabelecimento de Metas / Adaptação \\
\hline $\begin{array}{l}\text { 7. Perguntaram-me sobre meus objetivos no } \\
\text { tratamento da minha doença. }\end{array}$ & $\begin{array}{l}\text { 7. Perguntaram quais os meus objetivos no } \\
\text { tratamento da doença. }\end{array}$ \\
\hline $\begin{array}{l}\text { 8. Ajudaram-me a estabelecer objetivos } \\
\text { específicos para melhorar meus hábitos } \\
\text { alimentares ou atividade física. }\end{array}$ & $\begin{array}{l}\text { 8. Ajudaram a estabelecer objetivos específicos } \\
\text { para melhorar meus hábitos alimentares ou } \\
\text { atividade física. }\end{array}$ \\
\hline
\end{tabular}




\begin{tabular}{|c|c|}
\hline $\begin{array}{l}\text { 9. Deram-me uma cópia do meu plano de } \\
\text { tratamento. }\end{array}$ & $\begin{array}{l}\text { 9. Deram uma cópia da minha proposta de } \\
\text { tratamento. }\end{array}$ \\
\hline $\begin{array}{l}\text { 10. Encorajaram-me a frequentar grupos ou aulas } \\
\text { específicas para ajudar a superar a minha } \\
\text { doença crônica. }\end{array}$ & $\begin{array}{l}\text { 10. Estimularam a participar de grupos ou aulas } \\
\text { específicas para lidar com a minha doença } \\
\text { crônica. }\end{array}$ \\
\hline $\begin{array}{l}\text { 11.Perguntaram-me, diretamente ou por meio de } \\
\text { pesquisa, sobre meus hábitos de saúde. }\end{array}$ & $\begin{array}{l}\text { 11. Perguntaram, diretamente ou por meio de } \\
\text { questionário sobre meus hábitos de saúde. }\end{array}$ \\
\hline $\begin{array}{c}\text { Resolução de Problemas / Aconselhamento } \\
\text { Contextual }\end{array}$ & $\begin{array}{c}\text { Resolução de Problemas / } \\
\text { Contexto } \\
\end{array}$ \\
\hline $\begin{array}{l}\text { 12. Tive certeza que meu médico (a) ou enfermeiro } \\
\text { (a) considerava meus valores e tradições } \\
\text { quando eles recomendavam tratamentos para } \\
\text { mim. }\end{array}$ & $\begin{array}{l}\text { 12. Tive certeza que o meu médico (a) ou } \\
\text { enfermeiro (a) considerava meus valores e } \\
\text { costumes quando eles recomendavam } \\
\text { tratamentos para mim. }\end{array}$ \\
\hline $\begin{array}{l}\text { 13. Ajudaram-me a fazer um plano de tratamento } \\
\text { que eu pudesse por em prática no meu dia-a- } \\
\text { dia. }\end{array}$ & $\begin{array}{l}\text { 13. Ajudaram a fazer um plano de tratamento que } \\
\text { eu pudesse por em prática no meu dia-a-dia. }\end{array}$ \\
\hline $\begin{array}{l}\text { 14.Ajudaram-me a planejar com antecedência de } \\
\text { forma que poderia cuidar da minha doença } \\
\text { mesmo em momentos difíceis. }\end{array}$ & $\begin{array}{l}\text { 14. Ajudaram a planejar com antecedência o } \\
\text { cuidado da minha doença mesmo nos } \\
\text { momentos difíceis. }\end{array}$ \\
\hline $\begin{array}{l}\text { 15.Perguntaram-me como minha doença crônica } \\
\text { afetava minha vida. }\end{array}$ & $\begin{array}{l}\text { 15. Perguntaram como minha doença crônica afeta } \\
\text { minha vida. }\end{array}$ \\
\hline Seguimento / Coordenação & Seguimento / Coordenação \\
\hline $\begin{array}{l}\text { 16. Contataram-me depois de uma consulta para } \\
\text { verificar como as coisas estavam indo. }\end{array}$ & $\begin{array}{l}\text { 16. Entraram em contato comigo depois de uma } \\
\text { consulta para verificar como as coisas estavam } \\
\text { indo. }\end{array}$ \\
\hline $\begin{array}{l}\text { 17.Encorajaram-me a frequentar programas na } \\
\text { comunidade que poderiam me ajudar. }\end{array}$ & $\begin{array}{l}\text { 17. Estimularam a participar de programas na } \\
\text { comunidade que poderiam me ajudar. }\end{array}$ \\
\hline $\begin{array}{l}\text { 18. Encaminharam-me para um nutricionista, um } \\
\text { educador em saúde ou um conselheiro. }\end{array}$ & $\begin{array}{l}\text { 18. Fui encaminhado (a) para um nutricionista e/ou } \\
\text { a outro profissional de saúde. }\end{array}$ \\
\hline $\begin{array}{l}\text { 19. Falaram-me como minhas consultas com outras } \\
\text { especialidades de médicos, como por exemplo } \\
\text { oculista ou cirurgião, ajudavam no meu } \\
\text { tratamento. }\end{array}$ & $\begin{array}{l}\text { 19. Falaram como as consultas com outros } \\
\text { especialistas, como por exemplo, } \\
\text { oftalmologistas ou cirurgião ajudavam no meu } \\
\text { tratamento. }\end{array}$ \\
\hline $\begin{array}{l}\text { 20.Perguntaram-me como minhas consultas com } \\
\text { outros médicos estavam indo. }\end{array}$ & $\begin{array}{l}\text { 20. Perguntaram como as minhas consultas com } \\
\text { outros médicos estavam indo. }\end{array}$ \\
\hline
\end{tabular}


Quadro 2 - Representação do consenso da Versão Consensual em PortuguêsPortugal 2.0 (PACIC-VCPPort 2.0). Porto, Portugal, 2012

\begin{tabular}{|c|c|}
\hline PACIC-VCPPort 2ab & PACIC-VCPPort 2.0 \\
\hline $\begin{array}{c}\text { AVALIAÇÃO DE PACIENTES } \\
\text { COM CUIDADOS DE DOENÇA CRÓNICA }\end{array}$ & $\begin{array}{l}\text { ESCALA DE AVALIAÇÃO PELO PACIENTE DOS } \\
\text { CUIDADOS COM A SUA DOENÇA CRÓNICA }\end{array}$ \\
\hline Cuidados com a Doença Crónica & Cuidados com a sua Doença Crónica \\
\hline $\begin{array}{l}\text { Permanecer saudável pode ser difícil quando se é } \\
\text { detentor de uma doença crónica. Considerando o } \\
\text { seu estado de saúde, pretendemos indagar sobre } \\
\text { o tipo de ajuda que recebe da equipa que lhe } \\
\text { presta cuidados de saúde. Poderá incluir o seu } \\
\text { médico de família, o enfermeiro que o auxilia, ou o } \\
\text { assistente médico. As suas respostas são } \\
\text { confidenciais e não serão divulgadas. }\end{array}$ & $\begin{array}{l}\text { Permanecer saudável pode ser difícil quando se } \\
\text { tem uma doença crónica. Considerando o seu } \\
\text { estado de saúde, pretendemos saber o tipo de } \\
\text { ajuda que recebe da equipa de saúde. Poderá } \\
\text { incluir o seu médico, o enfermeiro ou outros } \\
\text { profissionais de saúde. As suas respostas são } \\
\text { anônimas e confidenciais. }\end{array}$ \\
\hline $\begin{array}{l}\text { Quando recebi cuidados de saúde no âmbito da } \\
\text { minha doença crónica nos últimos } 6 \text { meses, eu: }\end{array}$ & $\begin{array}{l}\text { Quando recebi cuidados de saúde no âmbito da } \\
\text { minha doença crónica nos últimos } 6 \text { meses, eu: }\end{array}$ \\
\hline $\begin{array}{c}\text { Praticamente Nunca } \\
\text { Geralmente Não } \\
\text { Por Vezes } \\
\text { A Maioria do Tempo } \\
\text { Praticamente Sempre }\end{array}$ & $\begin{array}{c}\text { Nunca } \\
\text { Raramente } \\
\text { Por Vezes } \\
\text { Quase Sempre } \\
\text { Sempre }\end{array}$ \\
\hline Ativação do Paciente & Participação Activa do Paciente \\
\hline $\begin{array}{l}\text { 1. Indiquei as minhas ideias aquando a } \\
\text { elaboração do plano de tratamentos. }\end{array}$ & $\begin{array}{l}\text { 1. Fui questionado sobre as minhas idéias } \\
\text { aquando da elaboração do plano de } \\
\text { tratamentos. }\end{array}$ \\
\hline $\begin{array}{l}\text { 2. Reflectir sobre as diversas opções de } \\
\text { tratamento apresentadas. }\end{array}$ & $\begin{array}{l}\text { 2. Recebi diversas opções de tratamento para } \\
\text { refletir. }\end{array}$ \\
\hline $\begin{array}{l}\text { 3. Falei sobre quaisquer problemas vivenciados } \\
\text { com a minha medicação ou os seus efeitos. }\end{array}$ & $\begin{array}{l}\text { 3. Fui questionado sobre quaisquer problemas } \\
\text { vivenciados com a minha medicação ou os seus } \\
\text { efeitos. }\end{array}$ \\
\hline $\begin{array}{c}\text { Projecto de Sistemas de Entrega / } \\
\text { Prática dos Projectos }\end{array}$ & $\begin{array}{c}\text { Sistema de Prestação de cuidados / } \\
\text { Organização da Prática }\end{array}$ \\
\hline $\begin{array}{l}\text { 4. Recepcionei uma lista por escrita com as coisas } \\
\text { que devo fazer no sentido de melhorar a minha } \\
\text { saúde. }\end{array}$ & $\begin{array}{l}\text { 4. Recebi uma lista com o que devo fazer para } \\
\text { melhorar a minha saúde. }\end{array}$ \\
\hline $\begin{array}{l}\text { 5. Pronunciei sobre a minha satisfação quanto à } \\
\text { organização dos cuidados prestados. }\end{array}$ & $\begin{array}{l}\text { 5. Fiquei satisfeito com a boa organização dos } \\
\text { cuidados prestados. }\end{array}$ \\
\hline $\begin{array}{l}\text { 6. Demonstrei de que forma as acções tomadas } \\
\text { para melhorar a minha doença influenciou a } \\
\text { minha saúde. }\end{array}$ & $\begin{array}{l}\text { 6. Fui esclarecido que o que eu fiz para cuidar da } \\
\text { minha doença influenciou o meu estado de } \\
\text { saúde. }\end{array}$ \\
\hline Estabelecimento de Metas / Adaptação & Estabelecimento de Metas / Individualização \\
\hline $\begin{array}{l}\text { 7. Partilhei os meus objectivos para cuidar da } \\
\text { minha doença. }\end{array}$ & $\begin{array}{l}\text { 7. Fui questionado sobre os meus objectivos para } \\
\text { cuidar da minha doença. }\end{array}$ \\
\hline $\begin{array}{l}\text { 8. Aceitei ajuda na definição de objectivos } \\
\text { específicos visando a melhoria dos meus } \\
\text { hábitos alimentares e do exercício físico. }\end{array}$ & $\begin{array}{l}\text { 8. Fui ajudado na definição de objectivos } \\
\text { específicos para a melhoria dos meus hábitos } \\
\text { alimentares e do exercício físico. }\end{array}$ \\
\hline 9. Recepcionei uma cópia dos meus tratamentos. & 9. Recebi uma cópia do meu plano de tratamento. \\
\hline $\begin{array}{l}\text { 10. Fui encorajado a frequentar um determinado } \\
\text { grupo ou turma para me ajudar a lidar com a } \\
\text { minha doença crónica. }\end{array}$ & $\begin{array}{l}\text { 10. Fui encorajado a frequentar um grupo } \\
\text { específico para me ajudar a lidar com a minha } \\
\text { doença crónica. }\end{array}$ \\
\hline
\end{tabular}


11. Respondi, directamente ou por meio de um inquérito/questionário, a questões sobre os meus hábitos de saúde.

\begin{tabular}{c}
\hline $\begin{array}{c}\text { Resolução de Problemas / } \\
\text { Contextualização }\end{array}$ \\
\hline
\end{tabular}

12. Estava certo(a) que o meu médico ou enfermeiro reflectiram sobre os meus valores e as minhas tradições aquando a recomendação dos tratamentos.

13. Fui auxiliado na elaboração de um plano de tratamentos, passível de realizar na minha vida quotidiana.

14. Recebi ajuda para fazer um planeamento futuro, por forma a poder cuidar da minha doença, mesmo nos momentos mais difíceis.

15. Fui questionado(a) da forma como a minha doença crónica afecta a minha vida.

Acompanhamento / Coordenação

16. Fui contactado(a) após uma visita para saberem como as coisas estavam a correr.

17. Fui encorajado(a) para frequentar programas na comunidade que me poderiam ajudar.

18. Fui recomendado(a) a procurar um nutricionista, um educador de saúde ou a um conselheiro.

19. Fui elucidado(a) da forma como a visita a outros tipos de médicos nomeadamente, um oftalmologista, ou um cirurgião, poderão ajudar nos meus tratamentos.

20. Fui questionado(a) como as minhas visitas aos outros médicos estavam a correr.
11. Fui questionado, directamente ou por meio de um inquérito, sobre os meus hábitos de saúde.

\section{Resolução de Problemas / Contextualização}

12. Tive a certeza que o meu médico ou enfermeiro reflectiram sobre os meus valores e tradições quando me recomendaram os tratamentos.

13. Fui ajudado na elaboração de um plano de tratamento, adequado ao meu dia a dia.

14. Fui ajudado para planear o futuro, de forma a cuidar da minha doença, mesmo nos momentos mais difíceis.

15. Fui perguntado(a) de que forma a doença crónica afecta a minha vida.

\section{Acompanhamento / Coordenação}

16. Fui perguntado após uma consulta para saber como as coisas estavam a correr.

17. Fui encorajado(a) para frequentar programas na comunidade que me poderiam ajudar.

18. Fui encaminhado(a) para procurar um nutricionista, um enfermeiro ou um psicólogo.

19. Disseram-se que a consulta com outros especialistas nomeadamente, um oftalmologista ajudou-me nos meus tratamentos.

20. Fui questionado(a) como as consultas com outros médicos estavam a correr.

Como sugestão geral pronunciada por um dos especialistas no Brasil e obtenção de concordância do consenso total do número de membros deste Comitê, realizou-se a submissão da Versão Consensual em Português-Brasil 1.0 (PACICVCPBra 1.0) por uma revisão de português, sendo preservadas as avaliações concluídas até então pelas equivalências semântica, idiomática, cultural e conceitual.

Dessa forma, a pesquisadora principal e sua orientadora selecionaram uma professora graduada em letras, atuante há 12 anos no processo de revisão de artigos científicos, dissertações, teses e livre-docências, além da atuação como revisora da língua portuguesa de periódicos brasileiros e livros infantis da United Nations Education Science and Culture Organization (UNESCO). 
Os contatos e a revisão foram realizados por correio eletrônico, com esclarecimentos a respeito da população alvo de pessoas com diabetes mellitus e sobre a manutenção de todos os termos, devendo apenas ser revisado regras ortográficas (pontuação, acentuação gráfica, gramática, pronomes, conjunções, concordância nominal e verbal), de forma manter a originalidade das avaliações das equivalências semântica, idiomática, cultural e conceitual, alcançada no Comitê de Especialistas.

Desse modo, a versão consensual PACIC-VCPBra 1.0 foi revisada considerando a Nova Ortografia da Língua Portuguesa (1990), embora em vigor obrigatório a partir de $1^{\circ}$ de janeiro de 2013, resultando na Versão Consensual em Português-Brasil 1.0 Revisada (PACIC-VCPBra 1.0 Rev) (APÊNDICE F).

De forma a manter conformidade com a metodologia utilizada após o Comitê de Especialistas no Brasil, a Versão Consensual em Português-Portugal 2.0 (PACIC-VCPPort 2.0) também foi submetida às mesmas regras e normas ortográficas do português, sendo revisada por uma professora licenciada em línguas no sul de Portugal, mestra há oito anos pela ESEP. Portanto, resultou-se na Versão Consensual em Português-Portugal 2.0 Revisada (PACIC-VCPPort 2.0 Rev) (APÊNDICE G).

\subsubsection{Retratraduçãa (Back-Translation)}

A retrotradução (back-translation) consiste em traduzir de volta o instrumento traduzido para o seu idioma de origem (WHO, 2012).

Para o desenvolvimento desta etapa no Brasil, selecionou-se uma tradutora com conhecimento da cultura do país em que o instrumento foi desenvolvido, residente na cidade de Ribeirão Preto, atuante como professora da língua inglesa e com experiência em traduções de trabalhos científicos na área da saúde. 
Após contato inicial para esclarecimentos da atividade a ser realizada, a pesquisadora principal encaminhou, por correio eletrônico, a versão consensual brasileira PACIC-VCPBra 1.0 Rev à tradutora selecionada, solicitando a sua tradução para o inglês americano. Não houve contato da tradutora com a versão original do instrumento e seus conceitos, assim também como os objetivos do estudo foram-lhe desconhecidos. Ao final, obteve-se a Versão em Inglês-Brasil (PACIC-VIBra) (APÊNDICE H).

Em Portugal, a versão consensual portuguesa PACIC-VCPPort 2.0 Rev também foi submetida a um tradutor selecionado pela pesquisadora principal e a sua supervisora responsável a fim de realizar a tradução para o inglês, seguindo o mesmo rigor metodológico da retrotradução realizada no Brasil. Dessa maneira, resultou-se na Versão em Inglês-Portugal (PACIC-VIPort) (APÊNDICE I).

Após o cumprimento dessas etapas, encaminharam-se as versões em inglês (PACIC-VIBra e PACIC-VIPort), via correio eletrônico, ao autor principal do PACIC, Dr. Russel Glasgow, a fim de avaliar o resultado das retroversões originadas no Brasil e em Portugal, e desta forma, seguir com os próximos passos do estudo.

\subsubsection{Pré-teste e Entreuista cagnitiua}

No processo metodológico adotado, é necessário realizar o pré-teste do instrumento traduzido na população-alvo, com o objetivo de verificar a compreensão dos conceitos existentes por meio de entrevista cognitiva (WHO, 2012).

Os participantes do pré-teste devem estar incluídos na população-base representativa do local no qual será desenvolvido o estudo, porém, 
preferencialmente, não devem ser selecionadas para a amostra final do estudo. Preconiza-se um número mínimo de 10 pessoas para cada domínio do instrumento a ser avaliado, representando pessoas de ambos os sexos (masculino ou feminino), adultos e idosos (WHO, 2012).

Nesta etapa, recomenda-se que o instrumento traduzido seja sistematicamente interrogado, devendo ser questionado aos participantes sobre o que eles pensam a respeito dos itens do instrumento traduzido, solicitando que os itens sejam pronunciados novamente com as suas próprias palavras e seus significados, após ouvir os itens da versão traduzida. Também deverá ser questionado sobre a utilização das opções de resposta. Todas essas recomendações deverão ser repetidas às pessoas participantes do pré-teste para cada item do instrumento (WHO, 2012).

A fim de atender aos propósitos de realização da entrevista cognitiva no préteste recomendados por WHO (2012), utilizaram-se os formulários de Impressão Geral e Específica do Projeto DISABKIDS ${ }^{\circledR}$ (DISABKIDS, 2002; DISABKIDS, 2004), autorizado (ANEXO E) por uma profissional responsável atualmente pelos processos já desenvolvidos em trabalhos anteriores do grupo DISABKIDS ${ }^{\circledR}$ no Brasil e no México (CASTRO, 2007; FEGADOLLI et al., 2010; REIS, 2008; SANTOS, 2009; DEON et al., 2011).

Dessa forma, as entrevistas cognitivas no Brasil e em Portugal foram realizadas nos meses de novembro e maio de 2012, respectivamente. Foi determinado um número de 10 pessoas com diabetes mellitus para cada um dos cinco domínios do instrumento, correspondendo exatamente a 50 pessoas entrevistadas em cada um dos contextos culturais, distribuídas conforme sexo (masculino ou feminino) e idade [adulto (Brasil: 18-59 anos; Portugal: 18-65 anos) ou idoso (Brasil: $\geq 60$ anos; Portugal: $\geq 65$ anos)].

Com relação ao sexo, das 50 (100\%) pessoas entrevistadas no Brasil e em Portugal, 25 (50\%) foi do sexo masculino e 25 (50\%) feminino. 
Quanto à idade, no Brasil, a menor foi de 33 anos e a maior 78 anos (60.88 \pm 10.64), com mediana de 63 anos. Já em Portugal, encontrou-se como menor idade 28 anos e como maior 76 anos (54.4 \pm 13.4$)$, com mediana de 53 anos.

Em relação ao tipo de diabetes mellitus (DM), no Brasil, 02 (4\%) tinham DM tipo 1 e 48 (96\%) DM tipo 2. O tempo de diagnóstico de DM variou de 1 a 30 anos (11.58 \pm 7.21), com mediana de 10 anos. Em Portugal, 11 (22\%) tinham DM tipo 1 e 39 (78\%) DM tipo 2. O tempo de diagnóstico de DM variou de 1 a 25 anos $(9.1 \pm 6.2)$ com mediana de 8 anos.

\subsection{Pracedimentas de caleta de dadas}

\subsubsection{Lacal da estuda}

No Brasil, o estudo foi realizado no Ambulatório de Endocrinologia e na Clínica Integrada da Unidade Básica Distrital Centro Saúde Escola Prof. Dr. Joel Domingos Machado, localizado no município de Ribeirão Preto, São Paulo, e, vinculado à Faculdade de Medicina de Ribeirão Preto da Universidade de São Paulo (CSE-FMRP/USP).

Em Portugal, desenvolveu-se o estudo no Ambulatório de Endocrinologia do Serviço de Consultas Externas do Centro Hospitalar de São João - EPE, localizado na cidade do Porto, e, vinculado à Faculdade de Medicina da Universidade do Porto (HSJ-FMUP). 


\subsubsection{Apresentaçãa das lacais de caleta de dadas}

O município de Ribeirão Preto está situado às margens do córrego Ribeirão Preto, afluente do Rio Pardo, no nordeste do Estado de São Paulo e distante 307 km da capital. Limita-se ao norte com Jardinópolis; ao sul com Guatapará; ao sudeste com Cravinhos; ao leste com Serrana; a oeste com Dumont; a noroeste com Sertãozinho e nordeste com Brodowski (RIBEIRÃO PRETO, 2011). A área territorial compreende 651.276 km² e abriga uma população estimada em 619.746 habitantes. Trata-se do $8^{\circ}$ município mais populoso do Estado de São Paulo e o $3^{\circ}$ mais populoso do interior do Brasil (INSTITUTO BRASILEIRO DE GEOGRAFIA E ESTATÍSTICAS - IBGE, 2011).

Segundo o Plano Municipal de Saúde 2010-2013, o município de Ribeirão Preto encontra-se sob o regime de Gestão Plena do Sistema Municipal de Saúde desde maio de 1988, por meio da Portaria n 2553/1998. Esta habilitação permite ao município traçar estratégias próprias para o fortalecimento do SUS e da Atenção Básica por meio do Plano Municipal de Saúde, assim como estabelecer programas que se ajustem às necessidades locais como no caso do Programa de Doenças Crônico Degenerativas. Em 2007, o município afirma reafirma sua condição de pólo ao pactuar junto aos parceiros: Estado e União, o Pacto pela Saúde - Portaria no 399/GM de 22 de fevereiro de 2006, celebrando o Termo de Compromisso de Gestão (RIBEIRÃO PRETO, 2011).

A assistência à saúde no município de Ribeirão Preto está organizada geográfica e operacionalmente em cinco regiões, denominadas Distritos de Saúde, representados pelas Unidades Básicas e Distritais de Saúde (UBDS) e Unidades de Saúde a elas articuladas. Estes distritos são: Norte (Distrito do Simioni); Sul (Distrito 
da Vila Virgínia); Leste (Distrito do Castelo Branco); Oeste (Distrito do Sumarezinho) e Central (Distrito Central) (RIBEIRÃO PRETO, 2011).

Tais Distritos de Saúde são regiões com áreas e populações definidas a partir de aspectos geográficos, econômicos e sociais que agrupam várias Unidades de Saúde e outros equipamentos sociais. A distribuição das Unidades em Distritos visa a oferecer aos municípios um atendimento básico e de pronto-atendimento em urgências próximo à residência e tornar mais acessível o atendimento de algumas especialidades encontradas nas Unidades Básicas Distritais de Saúde (UBDS) (RIBEIRÃO PRETO, 2011).

Cada Distrito de Saúde conta com uma UBDS, que, além do atendimento básico para sua área de abrangência, será a referência de algumas especialidades para todo o Distrito. Sendo assim, cada Distrito é composto por várias Unidades Básicas de Saúde que tem como finalidade prestar atendimento básico nas áreas médicas, odontológicas e de enfermagem, para a população de sua área de abrangência (RIBEIRÃO PRETO, 2011).

Além disso, todas as Unidades de Saúde contam com laboratório clínico e exames diagnósticos (ultrassonografia, radiologia simples e eletrocardiografia). Nas distritais e ambulatórios de especialidades também são realizados exames mais complexos em serviços contratados e/ou conveniados (RIBEIRÃO PRETO, 2011).

As Unidades Básicas de Saúde oferecem atendimento de atenção básica de saúde, promovendo a detecção e diagnóstico do diabetes mellitus. Nestas Unidades, os profissionais de saúde envolvidos no atendimento são: o médico clínico geral e os profissionais de enfermagem (composta por enfermeiro e técnico de enfermagem), e, em algumas Unidades, o agente comunitário (RIBEIRÃO PRETO, 2011).

As Unidades Básicas Distritais de Saúde são unidades de referência secundária com maior capacidade técnica e de atendimento especializado à pessoa com diabetes mellitus, tratando principalmente dos casos mais graves e das complicações crônicas da doença (RIBEIRÃO PRETO, 2011). 
Dentre as unidades de saúde do município de Ribeirão Preto, elegeu-se a Unidade Básica Distrital Centro Saúde Escola (CSE) Prof. Dr. Joel Domingos Machado, no distrito Oeste, que está localizada na Rua Cuiabá, 601, no bairro Sumarezinho, Ribeirão Preto, São Paulo. Desde sua inauguração em 1979, o CSE atua como Unidade Básica Distrital de Saúde, oferecendo assistência à saúde da população do distrito Oeste do município de Ribeirão Preto, com uma população estimada em 130.688 habitantes, com área básica de uma população com aproximadamente 18.006 habitantes (RIBEIRÃO PRETO, 2011).

Essa unidade conta com os serviços de Especialidades (Cardiologia, Endocrinologia, Ortopedia, Saúde Ocupacional, Dermatologia, Eletrocardiograma, Fonoaudiologia, Infectologia, Oftalmologia, Programa de Hanseníase, Psicologia, Radiologia, Serviço Social, entre outros), de Atenção Básica (Clínica Médica, Pediatria, Ginecologia e Obstetrícia, Enfermagem, Odontologia, Teste do Pezinho, Vacinação) e de Pronto Atendimento 24 horas. É unidade de referência para cinco Núcleos de Saúde da Família (NSF) do distrito Oeste. Neste estudo, essa UBDS interessa-nos pelo seu vínculo com a Universidade de São Paulo, pela sua área de abrangência e número de pessoas com diabetes mellitus (RIBEIRÃO PRETO, 2011).

A Referida Unidade oferece atendimento e seguimento a aproximadamente 600 pessoas com diabetes mellitus, que são atendidos em sua área programática, mediante consulta agendada. Os usuários são distribuídos para o atendimento em duas equipes, uma do Ambulatório de Endocrinologia e a outra da Clínica Integrada. Os atendimentos realizados no Ambulatório de Endocrinologia são de responsabilidades dos profissionais lotados na UBDS, enquanto que os da Clínica Integrada são realizados por docentes e alunos da Faculdade de Medicina de Ribeirão Preto da Universidade de São Paulo (FMRP/USP) (RIBEIRÃO PRETO, 2011).

No que diz respeito à cidade do Porto, Portugal, situa-se no noroeste da Península Ibérica, sede do município homônimo com $41,66 \mathrm{~km}^{2}$ de área territorial, apresentando uma população estimada de 237.584 habitantes. A cidade portuguesa 
é a capital do Distrito de Porto, da Área Metropolitana do Porto e da região estatística do Norte, sub-região do Grande Porto. A cidade metrópole, constituída pelos municípios adjacentes que formam entre si um único aglomerado urbano, conta com cerca de 1.286.276 habitantes, o que a torna a maior do noroeste peninsular e a segunda maior de Portugal, após a Grande Lisboa (CENTRO HOSPITALAR DE SÃO JOÃO - HSJ, 2012).

O Hospital São João (HSJ) é o maior hospital do Norte e o segundo maior de Portugal. Desde 31 de dezembro de 2005, o HSJ passou a ser Entidade Pública Empresarial (EPE) e encetou um processo de reorganização interna e de investimento em melhores condições hoteleiras para os atendimentos. Presta assistência direta à população de parte da cidade do Porto (Bonfim, Paranhos, Campanhã e Aldoar). Atua como centro de referência para vários distritos do Porto (com exceção dos concelhos de Baião, Amarante e Marco de Canaveses), Braga e Viana do Castelo, abrangendo uma população de cerca de três milhões de pessoas (HSJ, 2012).

Trata-se de um hospital universitário, com uma ligação umbilical à Faculdade de Medicina da Universidade do Porto (FMUP), ocupando o mesmo edifício em espaço de condomínio. O HSJ é constituído por um edifício de 11 pisos, dois dos quais se localizam no subsolo, e por um conjunto satélite de edifícios (HSJ, 2012).

Atualmente, o HSJ dispõe de uma lotação oficial de 1124 leitos e variadas especialidades médicas e cirúrgicas: Anestesiologia, Cardiologia, Cardiologia Pediátrica, Cirurgia Geral, Cirurgia Pediátrica, Cirurgia Plástica e Maxilo-Facial, Cirurgia Torácica, Cirurgia Vascular, Cuidados Intensivos, Cuidados Paliativos, Dermatologia, Doenças Infecciosas, Endocrinologia, Estomatologia, Gastrenterologia, Ginecologia e Obstetrícia, Hematologia Clínica, Hematologia e Oncologia Pediátrica, Imunoalergologia, Medicina Interna, Nefrologia, Neonatologia, Neurocirurgia, Neurologia, Oftalmologia, Oncologia, Ortopedia e Traumatologia, Otorrinolaringologia, Pediatria Médica, Pneumologia, Psiquiatria, Reumatologia, Urologia. Ainda possui uma variedade de meios complementares de diagnóstico e terapêutica como suporte à prestação de cuidados: Anatomia Patológica, Patologia Clínica, Imunohemoterapia, 
Radioterapia, Radiologia, Medicina Nuclear, Medicina Física e Reabilitação, Neurorradiologia, Neurofisiologia (HSJ, 2012).

Todos estes Serviços estão agrupados em seis Unidades Autônomas de Gestão: Medicina; Cirurgia; Mulher e Criança; Meios Complementares de Diagnóstico e Terapêutica; Urgência e Cuidados Intensivos; e, Saúde Mental (HSJ, 2012).

Nos edifícios externos estão localizados o Centro de Ambulatório, que inclui as Consultas Externas, Hospitais de Dia e a Unidade de Cirurgia do Ambulatório, e também o Serviço de Instalações e Equipamentos (HSJ, 2012).

O Serviço de Endocrinologia, Diabetes e Metabolismo é composto por endocrinologistas e endocrinopediatras, onde, são realizadas, em média, 65 consultas por dia, 1420 por mês e 17000 por ano. O serviço de Diabetes conta com uma equipe de enfermagem especializada, realizando testes de glicemia capilar, além da disponibilidade de orientações e acompanhamento para o uso de insulina e bombas de insulina. Anualmente são atendidos cerca de 7200 usuários com diabetes mellitus, com um número de 600 consultas mensais e 65 consultas diárias (HSJ, 2012).

\subsubsection{Períada da estuda}

O estudo foi desenvolvido no período compreendido entre março de 2010 a dezembro de 2012. A coleta de dados ocorreu por meio das entrevistas cognitivas (pré-teste), as quais foram realizadas nos meses de novembro de 2012 (Ribeirão Preto, São Paulo, Brasil) e maio de 2012 (Porto, Portugal). 


\subsubsection{Papulaçãa da estuda}

A população do estudo foi constituída por todos os usuários brasileiros e portugueses com diagnóstico de diabetes mellitus, com confirmação médica no prontuário, em seguimento no período do estudo e nos serviços selecionados: o Ambulatório de Endocrinologia e a Clínica Integrada da Unidade Básica Distrital de Saúde Centro Saúde Escola Prof. Dr. Joel Domingos Machado (CSE-FMRP/USP) (Ribeirão Preto) e o Ambulatório de Endocrinologia do Serviço de Consultas Externas do Centro Hospitalar de São João - EPE (HSJ/FMUP) (Porto).

De forma a homogeneizar essa população, os usuários em seguimento nos serviços referidos foram selecionados de acordo com os seguintes critérios de seleção: pessoas com pelo menos seis meses de diagnóstico de diabetes mellitus tipo 1 ou tipo 2, com confirmação médica no prontuário; com idade igual ou superior a 18 anos; sexo masculino ou feminino; adultos (18-59 anos, no Brasil e 18-64 anos, em Portugal) e idosos ( $\geq 60$ anos, no Brasil e $\geq 65$ anos, em Portugal); com todos os níveis de escolaridade ou analfabetos; e nacionalidade brasileira (CSE-FMRP/USP) ou portuguesa (HSJ/FMUP).

A fim de atender aos propósitos de realização da entrevista cognitiva no préteste, preconiza-se um número mínimo de 10 pessoas para cada domínio do instrumento a ser avaliado, representando pessoas de ambos os sexos (masculino ou feminino), adultos e idosos (WHO, 2012).

Portanto, para o presente estudo de adaptação cultural para o Brasil e Portugal do instrumento PACIC foi determinado um número de 10 pessoas com diabetes mellitus para cada um dos cinco domínios do instrumento, correspondendo a uma amostra de 50 pessoas brasileiras e 50 pessoas portuguesas, que atenderam 
aos critérios de seleção do estudo, perfazendo exatamente a um total de 100 pessoas entrevistadas.

\subsubsection{Instrumentas de caleta de dadas}

Para a coleta de dados (entrevista cognitiva) utilizaram-se o PACIC em suas versões finais na língua portuguesa, PACIC-Versão Pré-Teste em Português-Brasil (PACIC-VPTPBra) e PACIC-Versão Pré-Teste em Português-Portugal (PACICVPTPPort), além dos instrumentos Impressão Geral e Específica do Projeto DISABKIDS $^{\circledR}$ (DISABKIDS, 2002; DISABKIDS, 2004).

O Instrumento Impressão Geral inclui itens como: "O que você achou do nosso questionário em geral?"; "As questões são compreensíveis?"; "As questões são importantes para sua condição de saúde?". E o Instrumento Específico, tem-se: "Isso é importante para a sua situação?"; "As opções de respostas estão claras e consistentes de acordo com a questão?"; "Você pode me dizer, em suas palavras, o que esta questão significa para você?" (DISABKIDS, 2002; DISABKIDS, 2004).

\subsubsection{Pracedimentas adatadas para a caleta de dadas}

Inicialmente, a pesquisadora realizou aproximação com os profissionais inseridos nos serviços de saúde selecionados em Ribeirão Preto (Brasil) e em Porto 
(Portugal), buscando compreender a dinâmica de trabalho e receber suporte da equipe multiprofissional envolvida na atenção ao usuário com diabetes mellitus.

Após a inserção da pesquisadora no campo de estudo, iniciou-se a coleta de dados. Para tanto, a pesquisadora dirigia-se aos usuários brasileiros e portugueses com diabetes mellitus que se encontravam no corredor de espera do Ambulatório de Endocrinologia e da Clínica Integrada (Ribeirão Preto) e no Ambulatório de Endocrinologia do Serviço de Consultas Externas (Porto), aguardando a consulta médica, e convidava-os para participar da pesquisa esclarecendo a natureza e os objetivos do estudo. Após a concordância dos sujeitos, solicitou-se a assinatura do Termo de Consentimento Livre e Esclarecido (TCLE) no Brasil (APÊNDICE J) e em Portugal (APÊNDICE K), garantindo assim a autorização para aplicação dos instrumentos de coleta de dados.

A fim de minimizar possíveis transtornos pessoais e de tempo, a coleta de dados foi realizada antes das consultas médicas, no espaço de tempo em que os usuários aguardavam a consulta. A coleta de dados foi realizada na terça e na quintafeira, das 13 às 18 horas, em Ribeirão Preto e, de segunda a quinta-feira, das 8 às 12 horas, em Porto.

Primeiramente, a pesquisadora realizou a leitura do PACIC-Versão Pré-Teste em Português-Brasil (PACIC-VPTPBra), em Ribeirão Preto, e do PACIC-Versão PréTeste em Português-Portugal (PACIC-VPTPPort), em Porto. Posteriormente, aplicouse o instrumento Impressão Geral, seguido do instrumento Impressão Específica do Projeto DISABKIDS ${ }^{\circledR}$ (DISABKIDS, 2002; DISABKIDS, 2004). O tempo de cada entrevista foi de aproximadamente 20 minutos. Os dados foram obtidos por meio de entrevista dirigida e registrados manualmente nos instrumentos de coleta de dados. 


\subsubsection{Organizaçãa, descriçãa e análise das dadas}

A descrição e análise dos resultados foram realizadas utilizando-se o programa estatístico Statistical Package for the Social Sciencies (SPSS), versão 17.0. A técnica de dupla digitação foi utilizada para que fossem minimizados possíveis erros de transcrição dos dados.

Quanto à apresentação dos resultados, foi utilizada estatística descritiva. Essa metodologia tem como objetivo básico sintetizar uma série de valores de mesma natureza, permitindo que se tenha uma visão global da variação dos valores, organização e descrição dos dados por meio de tabelas e medidas descritivas. Os resultados referentes às etapas do processo de adaptação cultural (tradução, comitê de especialistas, retrotradução e pré-teste) foram apresentados de forma descritiva por meio de quadros e tabelas.

O nível de significância estatística adotado será foi $5 \%(\alpha=0.05)$.

\subsubsection{Cansideraçães éticas}

As atividades metodológicas referentes ao desenvolvimento desse estudo somente foram iniciadas após a aprovação em parecer final do Comitê de Ética em Pesquisa do Centro de Saúde Escola Prof. Dr. Joel Domingos Machado (CEP-CSEFMRP/USP), em Ribeirão Preto, Brasil, e da Comissão de Ética para a Saúde do Centro Hospitalar de São João (CES-HSJ/FMUP), em Porto, Portugal. 
As pessoas foram convidadas para participar desse estudo, assegurando-as privacidade e anonimato, antes da aplicação dos instrumentos na coleta de dados. Os objetivos do estudo foram apresentados por meio da leitura do Termo de Consentimento Livre e Esclarecido (TCLE) no Brasil (APÊNDICE J) e em Portugal (APÊNDICE K).

No Brasil, o projeto foi encaminhado para apreciação ao CEP-CSE-FMRP/USP, atendendo a resolução 196 de 10 de outubro de 1996 do Conselho Nacional de Saúde (CNS), obedecendo às exigências éticas e científicas fundamentais da pesquisa envolvendo seres humanos, com a aprovação em 09 de fevereiro de 2011, protocolo n 435/CEP-CSE-FMRP/USP (ANEXO F).

Em Portugal, a investigação foi encaminhada à CES-HSJ/FMUP, com aprovação em 24 de fevereiro de 2012 (Proj. 30/12) e autorização pelo Conselho de Administração do Centro Hospitalar de São João em 19 de abril de 2012 (ANEXO G), considerando o que preceitua o $1^{\circ}$ padrão internacional de pesquisa biomédica, a Declaração de Helsinque da World Medical Association (WMA), atendendo aos princípios mundiais éticos e científicos que regem uma pesquisa com seres humanos (ASSOCIAÇÃO MÉDICA MUNDIAL, 2008). 


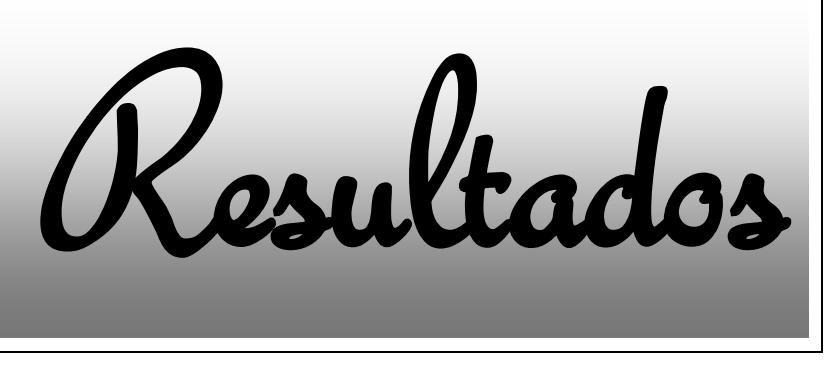




\section{RESULTADOS}

Os resultados do estudo estão apresentados, a seguir, em conformidade com as modificações particularmente realizadas no instrumento PACIC nos contextos culturais do Brasil e de Portugal, durante o desenvolvimento das etapas do processo de adaptação cultural adotado, proposto por WHO (2012).

\subsection{Resultadas da adaptaçãa cultural da Patient Assessment of Chranic Jllness Care (PACIC) na Brasil e em Partugal}

De forma a contemplar os objetivos propostos do estudo com relação ao desenvolvimento das etapas de adaptação cultural do PACIC no Brasil e em Portugal, apresentam-se sequencialmente: tradução, comitê de especialistas, retrotradução (back-translation); pré-teste e entrevista cognitiva. 


\subsubsection{Traduçãa • Camitê de Especialistas • Retratraduçãa} (BRASIL)

As discussões em conjunto para a obtenção de uma versão consensual por meio da leitura dos itens das duas versões traduzidas iniciais, PACIC-VTPBra 1a e PACIC-VTBra 2b, em comparação com a versão original, PACIC-VO objetivou analisar as diferenças ocorridas, selecionando frases de melhores expressões.

Portanto, realizou-se a escolha entre cada item das traduções, e, quando necessário, foram realizadas correções com justificativas registradas manualmente pela pesquisadora principal: no título da versão consensual foi acrescentado o termo inicial "Escala para"; conforme regra gramatical da língua portuguesa, os pronomes oblíquos átonos não devem ser utilizados em início de frases, portanto foram transferidos após o verbo (maioria dos itens); o pronome oblíquo "me" foi retirado por repetição do mesmo na mesma frase (itens 10 e 19); a palavra "através" foi substituída por "por meio de" (item 11). Ao final da reunião, originou-se a versão consensual da etapa da tradução no Brasil, denominada: Versão Consensual em Português-Brasil 1ab (PACIC-VCPBra 1ab) (APÊNDICE A).

A avaliação das equivalências semântica, idiomática, cultural e conceitual entre a versão original PACIC-VO e a versão consensual brasileira PACIC-VCPBra 1ab na etapa do Comitê de Especialistas trouxe importantes contribuições para um melhor aprimoramento do instrumento. De forma geral, nas instruções iniciais, a expressão "médico assistente" foi substituída por "outros profissionais de saúde", já o termo "confidenciais" presente na expressão "Suas respostas serão mantidas confidenciais" foi substituído por "em sigilo". Na sequencia, "Nos últimos 6 meses, quando recebi cuidados em relação a minha doença crônica:" foi modificado por "Para responder todas as questões desse questionário, você deverá pensar na ajuda do cuidado recebido para a sua doença crônica nos últimos 6 meses e assinalar uma 
resposta para cada questão:", com objetivo de esclarecer melhor o preenchimento dos itens do questionário.

Com relação às cinco alternativas de resposta para cada item da versão consensual brasileira "Quase Nunca", "Geralmente Não", "Algumas Vezes", "A maior parte do Tempo", "Quase Sempre", estas foram alteradas por sugestão dos especialistas por "Nunca", "Quase Nunca", "Às Vezes", "Quase Sempre", "Sempre".

No que diz respeito à análise dos cinco domínios do instrumento avaliado, foram realizadas adequações no primeiro, "Ativação do Paciente" por "Participação Ativa do Paciente no Tratamento", no segundo, "Desenvolvimento do Sistema de Cuidado / Apoio para Decisão" por "Modelo do Sistema de Cuidado / Modelo para a Prática", e no quarto, "Resolução de Problemas / Aconselhamento Contextual" por "Resolução de Problemas / Contexto".

As demais modificações foram relacionadas aos itens do instrumento e todos sofreram algum tipo de alteração. As mudanças correspondentes aos 20 itens encontram-se grifados em negrito e/ou tachadas, conforme Quadro 3.

Quadro 3 - Itens da versão consensual brasileira e modificações após avaliação pelo Comitê de Especialistas do PACIC-VCPBra 1ab para o PACIC-VCPBra 1.0. Ribeirão Preto-SP, Brasil, 2012

\begin{tabular}{|c|l|l|}
\hline Item & \multicolumn{1}{|c|}{ PACIC-VCPBra lab } & \multicolumn{1}{c|}{ PACIC-VCPBra 1.0 } \\
\hline $\mathbf{1 .}$ & $\begin{array}{l}\text { Perguntaram-me sobre minhas idéias quando } \\
\text { fizemos um plano de tratamento. }\end{array}$ & $\begin{array}{l}\text { Perguntaram-me sobre a minhas idéias } \\
\text { opinião quando fizemos foi feito um plano } \\
\text { a proposta de tratamento. }\end{array}$ \\
\hline $\mathbf{2 .}$ & $\begin{array}{l}\text { Deram-me opções sobre o tratamento para } \\
\text { que eu pensasse a respeito. }\end{array}$ & $\begin{array}{l}\text { Deram-me opções sobre-o de tratamento } \\
\text { para que eu pensasse a respeito. }\end{array}$ \\
\hline $\mathbf{3 .}$ & $\begin{array}{l}\text { Perguntaram-me sobre os problemas que } \\
\text { tenho com os remédios que tomo ou os seus } \\
\text { efeitos. }\end{array}$ & $\begin{array}{l}\text { Perguntaram-me sobre os se tenho algum } \\
\text { problemas com os remédios medicamentos } \\
\text { que eu tomo ou com os seus efeitos. }\end{array}$ \\
\hline $\mathbf{4 .}$ & $\begin{array}{l}\text { Deram-me uma lista escrita de coisas que eu } \\
\text { deveria fazer para melhorar minha saúde. }\end{array}$ & $\begin{array}{l}\text { Deram-me uma lista por escrito de coisas que } \\
\text { eu deveria fazer para melhorar a minha saúde. }\end{array}$ \\
\hline $\mathbf{6 .}$ & $\begin{array}{l}\text { Fiquei satisfeito (a) que os cuidados prestados } \\
\text { eram bem organizados. }\end{array}$ & $\begin{array}{l}\text { Fiquei satisfeito (a) que com a organização } \\
\text { dos os cuidados prestados eram - bem } \\
\text { organizados. }\end{array}$ \\
\hline
\end{tabular}




\begin{tabular}{|c|c|c|}
\hline & & minha doença. \\
\hline 7. & $\begin{array}{l}\text { Perguntaram-me sobre meus objetivos no } \\
\text { tratamento da minha doença. }\end{array}$ & $\begin{array}{l}\text { Perguntaram-me sobre quais os meus } \\
\text { objetivos no tratamento da minha doença. }\end{array}$ \\
\hline 8. & $\begin{array}{l}\text { Ajudaram-me a estabelecer objetivos } \\
\text { específicos para melhorar meus hábitos } \\
\text { alimentares ou atividade física. }\end{array}$ & $\begin{array}{l}\text { Ajudaram-me a estabelecer objetivos } \\
\text { específicos para melhorar meus hábitos } \\
\text { alimentares ou atividade física. }\end{array}$ \\
\hline 9. & $\begin{array}{l}\text { Deram-me uma cópia do meu plano de } \\
\text { tratamento. }\end{array}$ & $\begin{array}{l}\text { Deram-me uma cópia do meu plano da } \\
\text { minha proposta de tratamento. }\end{array}$ \\
\hline 10. & $\begin{array}{l}\text { Encorajaram-me a frequentar grupos ou aulas } \\
\text { específicas para ajudar a superar a minha } \\
\text { doença crônica. }\end{array}$ & $\begin{array}{l}\text { Encorajaram-me a frequentar Estimularam } \\
\text { a participar de grupos ou aulas específicas } \\
\text { para ajudar a-superar lidar com a minha } \\
\text { doença crônica. }\end{array}$ \\
\hline 11. & $\begin{array}{l}\text { Perguntaram-me, diretamente ou por meio de } \\
\text { pesquisa, sobre meus hábitos de saúde. }\end{array}$ & $\begin{array}{l}\text { Perguntaram-me, diretamente ou por meio de } \\
\text { pesquisa questionário, sobre meus hábitos } \\
\text { de saúde. }\end{array}$ \\
\hline 12. & $\begin{array}{l}\text { Tive certeza que meu médico (a) ou } \\
\text { enfermeiro (a) considerava meus valores e } \\
\text { tradições quando eles recomendavam } \\
\text { tratamentos para mim. }\end{array}$ & $\begin{array}{l}\text { Tive certeza que o meu médico (a) ou } \\
\text { enfermeiro (a) considerava meus valores e } \\
\text { tradições costumes quando eles } \\
\text { recomendavam tratamentos para mim. }\end{array}$ \\
\hline 13. & $\begin{array}{l}\text { Ajudaram-me a fazer um plano de tratamento } \\
\text { que eu pudesse por em prática no meu dia-a- } \\
\text { dia. }\end{array}$ & $\begin{array}{l}\text { Ajudaram-me a fazer um plano uma } \\
\text { proposta de tratamento que eu pudesse por } \\
\text { em prática no meu dia-a-dia. }\end{array}$ \\
\hline 14. & $\begin{array}{l}\text { Ajudaram-me a planejar com antecedência de } \\
\text { forma que poderia cuidar da minha doença } \\
\text { mesmo em momentos difíceis. }\end{array}$ & $\begin{array}{l}\text { Ajudaram-me a planejar com antecedência de } \\
\text { forma-que poderia-cuidar o cuidado da } \\
\text { minha doença mesmo em nos momentos } \\
\text { difíceis. }\end{array}$ \\
\hline 15. & $\begin{array}{l}\text { Perguntaram-me como minha doença crônica } \\
\text { afetava minha vida. }\end{array}$ & $\begin{array}{l}\text { Perguntaram-me como minha doença crônica } \\
\text { afetava afeta minha vida. }\end{array}$ \\
\hline 16. & $\begin{array}{l}\text { Contataram-me depois de uma consulta para } \\
\text { verificar como as coisas estavam indo. }\end{array}$ & $\begin{array}{l}\text { Contataram-me Entraram em contato } \\
\text { comigo depois de uma consulta para verificar } \\
\text { como as coisas estavam indo. }\end{array}$ \\
\hline 17. & $\begin{array}{l}\text { Encorajaram-me a frequentar programas na } \\
\text { comunidade que poderiam me ajudar. }\end{array}$ & $\begin{array}{l}\text { Encorajaram-me-a frequentar Estimularam } \\
\text { a participar de programas na comunidade } \\
\text { que poderiam me ajudar. }\end{array}$ \\
\hline 18. & $\begin{array}{l}\text { Encaminharam-me para um nutricionista, um } \\
\text { educador em saúde ou um conselheiro. }\end{array}$ & $\begin{array}{l}\text { Encaminharam-me Fui encaminhado (a) } \\
\text { para um nutricionista, um educador físico ou } \\
\text { um-conselheiro e/ou a outro profissional de } \\
\text { saúde. }\end{array}$ \\
\hline 19. & $\begin{array}{l}\text { Falaram-me como minhas consultas com } \\
\text { outras especialidades de médicos, como por } \\
\text { exemplo oculista ou cirurgião, ajudavam no } \\
\text { meu tratamento. }\end{array}$ & $\begin{array}{l}\text { Falaram-me como as minhas consultas com } \\
\text { outras especialidades de médicos outros } \\
\text { especialistas, como por exemplo, oculista } \\
\text { oftalmologistas ou cirurgião ajudavam no } \\
\text { meu tratamento. }\end{array}$ \\
\hline 20. & $\begin{array}{l}\text { Perguntaram-me como minhas consultas com } \\
\text { outros médicos estavam indo. }\end{array}$ & $\begin{array}{l}\text { Perguntaram-me como as minhas consultas } \\
\text { com outros médicos estavam indo. }\end{array}$ \\
\hline
\end{tabular}


Dessa forma, as modificações estabelecidas no instrumento brasileiro durante a realização do Comitê de Especialistas ocorreram mediante a obtenção de um consenso mínimo de $80 \%$ do total dos especialistas. Ao final desta etapa, resultou-se na Versão Consensual em Português-Brasil 1.0 (PACIC-VCPBra 1.0).

A seguir, na etapa de Retrotradução, encaminhou-se por correio eletrônico a versão em inglês retrotraduzida (PACIC-VIBra) ao Dr. Brian Austin, vice-diretor do ICIC, diretor associado do MacColl Institute for Healthcare Innovation e membro do GHRI, o qual manifestou em concordância, autorizando a utilização do instrumento. Após o seu feedback positivo, o PACIC-VIBra também foi encaminhado por correio eletrônico ao autor principal do instrumento, Dr. Russel Glasgow, a fim de confirmar a suficiência da autorização concedida. O autor manteve a concordância, incentivando prosseguir com as próximas etapas do estudo com aprovação e encorajamento (ANEXO H).

Após a finalização dessas três etapas do processo de adaptação cultural (tradução, comitê de especialistas e retrotradução), resultou-se no PACIC-Versão PréTeste em Português-Brasil (PACIC-VPTPBra) (APÊNDICE L), pois foi utilizado na etapa seguinte (pré-teste).

\subsubsection{Pré-teste e Entrevista cagnitiua (BRASIL)}

Os resultados da entrevista cognitiva (pré-teste) dos 50 participantes da população do estudo no Brasil estão apresentados, a seguir, de acordo com a utilização dos Instrumentos Impressão Geral e Específica do Projeto DISABKIDS ${ }^{\circledR}$ (DISABKIDS, 2002; DISABKIDS, 2004). 


\subsubsection{Resultadas da Instrumenta Impressãa Geral da PACIC- VPTPBra (BRASIL)}

Quanto ao questionário de Impressão Geral, das 50 (100\%) pessoas brasileiras entrevistadas, a maioria demonstrou uma ótima recepção ao instrumento avaliado, sendo que, de forma geral, todos consideraram o instrumento entre muito bom, 36 (72\%), e, bom 14 (28\%), 44 (88\%) revelaram que as questões são fáceis de entender, 43 (86\%) referiram não ter tido dificuldade em utilizar as categorias de resposta e 46 (92\%) declararam as perguntas do questionário muito relevantes para a condição de saúde (Tabela 1).

Tabela 1 - Distribuição numérica (n) e percentual (\%) da população do estudo segundo a avaliação do instrumento PACIC-VPTPBra pelo questionário de Impressão Geral (Pré-Teste). Ribeirão Preto-SP, Brasil, 2012

\begin{tabular}{llclc}
\hline QUESTÃO & CATEGORIAS DE RESPOSTA & N & $\%$ \\
\hline O que achou do nosso & muito bom & 36 & \\
questionário em geral? & bom & 14 & 28.0 \\
& regular / mais ou menos & 00 & 0.0 \\
\hline As questões são & fáceis de entender & 44 & 88.0 \\
compreensíveis? & às vezes, difíceis & 06 & 12.0 \\
& não compreensíveis & 00 & 2.0 \\
\hline Sobre as categorias de resposta, & nenhuma / sem dificuldade & 43 & 06.0 \\
teve alguma dificuldade em usá-las? & algumas dificuldades & 07 & 14.0 \\
& muitas dificuldades & 00 & 2.0 \\
\hline As questões são relevantes & muito relevante & 46 & 92.0 \\
para a sua condição de saúde? & às vezes relevante & 04 & 8.0 \\
& sem nenhuma relevância & 00 & 0.0 \\
\hline
\end{tabular}

Com relação às questões dissertativas do questionário de Impressão Geral, a maioria, 39 (78\%), das pessoas entrevistadas respondeu que não mudariam ou acrescentariam nada ao instrumento avaliado, com exceção de 11 (22\%). Sete (14\%) manifestaram a não aceitação do diabetes mellitus como uma doença crônica, 
questionando sobre a possibilidade de cura ou de um tratamento mais eficaz que descartasse a "obrigatoriedade" das aplicações de doses diárias de insulina, enquanto que três (6\%) revelaram insatisfação com o tempo de espera do atendimento da consulta no momento.

\subsubsection{Resultadas da Instrumenta Impressães Específicas da PACIC-VPTPBra (BRASIL)}

Ao tratar-se do Instrumento Impressões Específicas, cabe ressaltar que cada um dos cinco domínios do instrumento PACIC-VPTPBra foi avaliado por 10 pessoas brasileiras com diabetes mellitus, distribuídas conforme sexo (masculino ou feminino) e idade (adulto e idoso), como preconizado por WHO (2012).

As distribuições das respostas das pessoas entrevistadas, segundo a percepção dos itens em cada um dos domínios avaliados, no que diz respeito à relevância de cada item, à dificuldade para entender a questão e à clareza e consistência das opções de resposta, mostraram-se satisfatórias e estão representadas nas Tabelas 2, 3, 4, 5 e 6 seguintes. 
Tabela 2 - Distribuição das respostas dos participantes da entrevista cognitiva pelo questionário de Impressões Específicas, segundo a percepção dos três itens do domínio "Participação Ativa do Paciente no Tratamento". Ribeirão Preto-SP, Brasil, 2012

\begin{tabular}{cc|c|c|c|c|c|c|c}
\hline \multirow{2}{*}{ ITEM } & \multicolumn{3}{c|}{ Relevância } & \multicolumn{2}{c|}{ Dificuldade } & \multicolumn{2}{c}{ Resposta } \\
\cline { 2 - 10 } & sim & às vezes & não & não & Sim & sim & não \\
\hline $\begin{array}{l}\text { 1. } \\
\text { Perguntaram a minha opinião, quando } \\
\text { foi feita a proposta de tratamento. }\end{array}$ & 10 & 00 & 00 & 10 & 00 & 10 & 00 \\
\hline 2. $\begin{array}{l}\text { Deram opções de tratamento, para que } \\
\text { eu pensasse a respeito. }\end{array}$ & 09 & 01 & 00 & 10 & 00 & 10 & 00 \\
\hline 3. $\begin{array}{l}\text { Perguntaram se tenho algum problema } \\
\text { com os medicamentos que tomo ou } \\
\text { com os seus efeitos. }\end{array}$ & 10 & 00 & 00 & 10 & 00 & 10 & 00 \\
\hline
\end{tabular}

Tabela 3 - Distribuição das respostas dos participantes da entrevista cognitiva pelo questionário de Impressões Específicas, segundo a percepção dos três itens do domínio "Modelo do Sistema de Cuidado/Modelo para a Prática". Ribeirão Preto-SP, Brasil, 2012

\begin{tabular}{|c|c|c|c|c|c|c|c|c|}
\hline \multirow{2}{*}{\multicolumn{2}{|c|}{ ITEM }} & \multicolumn{3}{|c|}{ Relevância } & \multicolumn{2}{|c|}{ Dificuldade } & \multicolumn{2}{|c|}{ Resposta } \\
\hline & & sim & às vezes & não & não & sim & sim & não \\
\hline & $\begin{array}{l}\text { Deram uma lista por escrito de } \\
\text { coisas que eu deveria fazer para } \\
\text { melhorar a minha saúde. }\end{array}$ & 10 & 00 & 00 & 10 & 00 & 10 & 00 \\
\hline & $\begin{array}{l}\text { Fiquei satisfeito com a organização } \\
\text { dos cuidados prestados. }\end{array}$ & 10 & 00 & 00 & 10 & 00 & 10 & 00 \\
\hline & $\begin{array}{l}\text { Mostraram que a maneira como eu } \\
\text { me cuidava influenciava na minha } \\
\text { doença. }\end{array}$ & 10 & 00 & 00 & 08 & 02 & 10 & 00 \\
\hline
\end{tabular}


Tabela 4 - Distribuição das respostas dos participantes da entrevista cognitiva pelo questionário de Impressões Específicas, segundo a percepção dos cinco itens do domínio "Estabelecimento de Metas/Adaptação". Ribeirão PretoSP, Brasil, 2012

\begin{tabular}{ll|c|c|c|c|c|cc}
\hline & \multicolumn{3}{|c|}{ Relevância } & \multicolumn{2}{c|}{ Dificuldade } & \multicolumn{2}{c}{ Resposta } \\
\cline { 2 - 9 } ITEM & sim & às vezes & Não & não & sim & sim & Não \\
\hline 7. & $\begin{array}{l}\text { Perguntaram quais os meus } \\
\text { objetivos no tratamento da doença. }\end{array}$ & 10 & 00 & 00 & 10 & 00 & 10 & 00 \\
\hline 8. $\begin{array}{l}\text { Ajudaram a estabelecer objetivos } \\
\text { específicos para melhorar meus } \\
\text { hábitos alimentares ou atividade } \\
\text { física. }\end{array}$ & 10 & 00 & 00 & 09 & 01 & 10 & 00 \\
\hline 9. & $\begin{array}{l}\text { Deram uma cópia da minha } \\
\text { proposta de tratamento. }\end{array}$ & 10 & 00 & 00 & 10 & 00 & 10 & 00 \\
\hline 10. $\begin{array}{l}\text { Estimularam a participar de grupos } \\
\text { ou aulas espećficas para lidar com a } \\
\text { minha doença crônica. }\end{array}$ & 10 & 00 & 00 & 08 & 02 & 10 & 00 \\
\hline $\begin{array}{l}\text { Perguntaram, diretamente ou por } \\
\text { meio de questionário sobre meus } \\
\text { hábitos de saúde. }\end{array}$ & 10 & 00 & 00 & 10 & 00 & 10 & 00 \\
\hline
\end{tabular}

Tabela 5 - Distribuição das respostas dos participantes da entrevista cognitiva pelo questionário de Impressões Específicas, segundo a percepção dos quatro itens do domínio "Resolução de Problemas/Contexto". Ribeirão Preto-SP, Brasil, 2012

\begin{tabular}{|c|c|c|c|c|c|c|c|c|}
\hline \multirow{2}{*}{\multicolumn{2}{|c|}{ ITEM }} & \multicolumn{3}{|c|}{ Relevância } & \multicolumn{2}{|c|}{ Dificuldade } & \multicolumn{2}{|c|}{ Resposta } \\
\hline & & sim & às vezes & Não & não & sim & sim & Não \\
\hline & $\begin{array}{l}\text { Tive certeza que o meu médico (a) } \\
\text { ou enfermeiro (a) considerava meus } \\
\text { valores e costumes quando eles } \\
\text { recomendavam tratamentos para } \\
\text { mim. }\end{array}$ & 10 & 00 & 00 & 07 & 03 & 10 & 00 \\
\hline 13. & $\begin{array}{l}\text { Ajudaram a fazer um plano de } \\
\text { tratamento que eu pudesse pôr em } \\
\text { prática no meu dia a dia. }\end{array}$ & 10 & 00 & 00 & 08 & 02 & 10 & 00 \\
\hline 14. & $\begin{array}{l}\text { Ajudaram a planejar com } \\
\text { antecedência o cuidado da minha } \\
\text { doença mesmo nos momentos } \\
\text { difíceis. }\end{array}$ & 10 & 00 & 00 & 10 & 00 & 10 & 00 \\
\hline & $\begin{array}{l}\text { Perguntaram como minha doença } \\
\text { crônica afeta minha vida. }\end{array}$ & 10 & 00 & 00 & 10 & 00 & 10 & 00 \\
\hline
\end{tabular}


Tabela 6 - Distribuição das respostas dos participantes da entrevista cognitiva pelo questionário de Impressões Específicas, segundo a percepção dos cinco itens do domínio "Seguimento/Coordenação". Ribeirão Preto-SP, Brasil, 2012

\begin{tabular}{|c|c|c|c|c|c|c|c|c|}
\hline & \multirow{2}{*}{ ITEM } & \multicolumn{3}{|c|}{ Relevância } & \multicolumn{2}{|c|}{ Dificuldade } & \multicolumn{2}{|c|}{ Resposta } \\
\hline & & sim & às vezes & não & não & $\operatorname{sim}$ & sim & não \\
\hline 16. & $\begin{array}{l}\text { Entraram em contato comigo depois } \\
\text { de uma consulta para verificar como } \\
\text { as coisas estavam indo. }\end{array}$ & 10 & 00 & 00 & 07 & 03 & 10 & 00 \\
\hline 17. & $\begin{array}{l}\text { Estimularam a participar de } \\
\text { programas na comunidade que } \\
\text { poderiam me ajudar. }\end{array}$ & 10 & 00 & 00 & 10 & 00 & 10 & 00 \\
\hline 18. & $\begin{array}{l}\text { Fui encaminhado (a) para um } \\
\text { nutricionista e/ou a outro } \\
\text { profissional de saúde. }\end{array}$ & 10 & 00 & 00 & 10 & 00 & 10 & 00 \\
\hline 19. & $\begin{array}{l}\text { Falaram como as consultas } \\
\text { outros especialistas, como por } \\
\text { exemplo, oftalmologistas ou } \\
\text { cirurgião ajudavam no meu } \\
\text { tratamento. }\end{array}$ & 10 & 00 & 00 & 08 & 02 & 10 & 00 \\
\hline 20. & $\begin{array}{l}\text { Perguntaram como as minhas } \\
\text { consultas com outros médicos } \\
\text { estavam indo. }\end{array}$ & 10 & 00 & 00 & 10 & 00 & 10 & 00 \\
\hline
\end{tabular}

Ainda com relação ao questionário de Impressões Específicas, no que diz respeito à reconstrução dos itens e como os participantes escreviam-nas com suas próprias palavras, não houve opções para reconstrução de algum dos itens, porém alguns escreveram como o compreendia.

Visando a maneira como os itens foram formulados, a maioria mostrou-se de fácil compreensão, porém foram sugeridas alterações para os itens 6, 10, 12 e 16, grifadas em negrito no Quadro 4. 
Quadro 4 - Entrevista Cognitiva (Pré-Teste) e as modificações do PACIC-VPTPBra pelos participantes do estudo. Ribeirão Preto-SP, Brasil, 2012

\begin{tabular}{|c|l|l|}
\hline Item & \multicolumn{1}{|c|}{ PACIC-VPTPBra } & \multicolumn{1}{|c|}{ Após a Entrevista Cognitiva } \\
\hline $\mathbf{6 .}$ & $\begin{array}{l}\text { Mostraram que a maneira como eu me } \\
\text { cuidava influenciava na minha doença. }\end{array}$ & $\begin{array}{l}\text { Mostraram que a maneira como eu me } \\
\text { cuidava poderia melhorar ou piorar na } \\
\text { minha doença. }\end{array}$ \\
\hline $\mathbf{1 0 .}$ & $\begin{array}{l}\text { Estimularam a participar de grupos ou aulas } \\
\text { específicas para lidar com a minha doença } \\
\text { crônica. }\end{array}$ & $\begin{array}{l}\text { Estimularam a participar de grupos ou aulas } \\
\text { específicas para aprender a conviver com a } \\
\text { minha doença crônica. }\end{array}$ \\
\hline $\mathbf{1 2 .}$ & $\begin{array}{l}\text { Tive certeza que o meu médico (a) ou } \\
\text { enfermeiro (a) considerava meus valores e } \\
\text { costumes, quando eles recomendavam } \\
\text { tratamentos para mim. }\end{array}$ & $\begin{array}{l}\text { Tive certeza que o meu médico (a) ou } \\
\text { enfermeiro (a) respeitava meus valores e } \\
\text { costumes, quando eles recomendavam } \\
\text { tratamentos para mim. }\end{array}$ \\
\hline $\mathbf{1 6 .}$ & $\begin{array}{l}\text { Entraram em contato comigo, depois de uma } \\
\text { consulta, para verificar como as coisas } \\
\text { estavam indo. }\end{array}$ & $\begin{array}{l}\text { Entraram em contato comigo, depois de uma } \\
\text { consulta, para verificar como estava o } \\
\text { controle da minha doença. }\end{array}$ \\
\hline
\end{tabular}

Como resultado, obteve-se a construção do PACIC-Versão Final PortuguêsBrasil (PACIC-VFPBra) (APÊNDICE M).

\subsubsection{Traduçãa • Camitê de Especialistas • Retratraduçãa (PORTUGAL)}

Com o objetivo de prosseguir com o mesmo rigor metodológico do estudo desenvolvido no Brasil, importa esclarecer que as etapas do processo de adaptação cultural adotado para o instrumento PACIC em Portugal também atendeu as mesmas recomendações propostas por WHO (2012). 
Conforme no Brasil, a avaliação das equivalências semântica, idiomática, cultural e conceitual entre a versão original PACIC-VO e a versão consensual portuguesa PACIC-VCPPort 2ab na etapa do Comitê de Especialistas também trouxe contribuições significativas para um melhor aperfeiçoamento do instrumento. De forma geral, nas instruções iniciais, as expressões "Cuidados com a Doença Crónica" e "quando se é detentor de uma doença crónica" foram sutilmente modificadas por "Cuidados com a sua Doença Crónica" e "quando se tem uma doença crónica"; o termo "saber" foi substituído por "indagar"; já a expressão "o seu médico de família, o enfermeiro que o auxilia, ou o assistente médico" foi alterada por "o seu médico, o enfermeiro ou outros profissionais de saúde". De forma sequencial, também sofreu modificação a sentença "As suas respostas são confidenciais e não serão divulgadas" por "As suas respostas são anônimas e confidenciais".

Com relação às cinco alternativas de resposta para cada item da versão consensual portuguesa "Praticamente Nunca", "Geralmente Não", "Por Vezes", "A Maioria do Tempo", "Praticamente Sempre", estas foram alteradas por sugestão dos especialistas por "Nunca", "Raramente", "Por Vezes", "Quase Sempre”, "Sempre”.

No que diz respeito à análise dos cinco domínios do instrumento português avaliado, foram realizadas adequações no primeiro, "Activação do Paciente" por "Participação Activa do Paciente", no segundo, "Projecto de Sistemas de Entrega / Prática dos Projectos", e no terceiro, "Estabelecimento de Metas / Adaptação" por "Estabelecimento de Metas / Individualização".

Após o conjunto das discussões entre os especialistas, o título do instrumento português avaliado "Avaliação de Pacientes com Cuidados de Doença Crónica" foi renomeado para "Escala de Avaliação pelo Paciente dos Cuidados com a sua Doença Crónica".

As demais modificações foram relacionadas aos itens do instrumento, que, do total de 20 itens, apenas um (item 17) manteve-se e não sofreu qualquer tipo de 
alteração. As mudanças correspondentes aos 19 itens encontram-se grifadas em negrito e/ou tachadas, e podem ser visualizadas no Quadro 5.

Quadro 5 - Itens da versão consensual portuguesa e modificações após avaliação pelo Comitê de Especialistas do PACIC-VCPPort 2ab para o PACICVCPPort 2.0. Porto, Portugal, 2012

\begin{tabular}{|c|c|c|}
\hline Item & PACIC-VCPPort 2ab & PACIC-VCPPort 2.0 \\
\hline 1. & $\begin{array}{l}\text { Indiquei as minhas idéias aquando a elaboração } \\
\text { do plano de tratamentos. }\end{array}$ & $\begin{array}{l}\text { Indiquei Fui questionado sobre as minhas } \\
\text { idéias aquando da elaboração do plano de } \\
\text { tratamento. }\end{array}$ \\
\hline 2. & $\begin{array}{l}\text { Reflectir sobre as diversas opções de } \\
\text { tratamento apresentadas. }\end{array}$ & $\begin{array}{l}\text { Reflectir sobre as Recebi diversas opções de } \\
\text { tratamento apresentadas para refletir. }\end{array}$ \\
\hline 3. & $\begin{array}{l}\text { Falei sobre quaisquer problemas vivenciados } \\
\text { com a minha medicação ou os seus efeitos. }\end{array}$ & $\begin{array}{l}\text { Falei Fui questionado sobre quaisquer } \\
\text { problemas vivenciados com a minha medicação } \\
\text { ou os seus efeitos. }\end{array}$ \\
\hline 4. & $\begin{array}{l}\text { Recepcionei uma lista por escrita com as coisas } \\
\text { que devo fazer no sentido de melhorar a minha } \\
\text { saúde. }\end{array}$ & $\begin{array}{l}\text { Recepcionei Recebi uma lista por escrita com } \\
\text { o as-coisas que devo fazer no-sentido-de para } \\
\text { melhorar a minha saúde. }\end{array}$ \\
\hline 5. & $\begin{array}{l}\text { Pronunciei sobre a minha satisfação quanto à } \\
\text { organização dos cuidados prestados. }\end{array}$ & $\begin{array}{l}\text { Pronunciei-sobre-a minha-satisfação-quanto } \\
\text { à Fiquei satisfeito com a boa organização dos } \\
\text { cuidados prestados. }\end{array}$ \\
\hline 6. & $\begin{array}{l}\text { Demonstrei de que forma as acções tomadas } \\
\text { para melhorar a minha doença influenciou a } \\
\text { minha saúde. }\end{array}$ & $\begin{array}{l}\text { Demonstrei de que forma as açẽos tomadas } \\
\text { para-melhorar Fui esclarecido que o que eu } \\
\text { fiz para cuidar da minha doença influenciou a } \\
\text { minha o meu estado de saúde. }\end{array}$ \\
\hline 7. & $\begin{array}{l}\text { Partilhei os meus objectivos para cuidar da } \\
\text { minha doença. }\end{array}$ & $\begin{array}{l}\text { Partilhei Fui questionado sobre os meus } \\
\text { objectivos para cuidar da minha doença. }\end{array}$ \\
\hline 8. & $\begin{array}{l}\text { Aceitei ajuda na definição de objectivos } \\
\text { específicos visando a melhoria dos meus } \\
\text { hábitos alimentares e do exercício físico. }\end{array}$ & $\begin{array}{l}\text { Aceitei-ajuda Fui ajudado na definição de } \\
\text { objectivos espeć́ficos visando para a melhoria } \\
\text { dos meus hábitos alimentares e do exercício } \\
\text { físico. }\end{array}$ \\
\hline 9. & Recepcionei uma cópia dos meus tratamentos. & $\begin{array}{l}\text { Recepcionei Recebi uma cópia dos meus do } \\
\text { meu plano de tratamento. }\end{array}$ \\
\hline 10. & $\begin{array}{l}\text { Fui encorajado a frequentar um determinado } \\
\text { grupo ou turma para me ajudar a lidar com a } \\
\text { minha doença crónica. }\end{array}$ & $\begin{array}{l}\text { Fui encorajado a frequentar um determinado } \\
\text { grupo específico ou turma para me ajudar a } \\
\text { lidar com a minha doença crónica. }\end{array}$ \\
\hline 11. & $\begin{array}{l}\text { Respondi, directamente ou por meio de um } \\
\text { inquérito/questionário, a questões sobre os } \\
\text { meus hábitos de saúde. }\end{array}$ & $\begin{array}{l}\text { Respondi Fui questionado, directamente ou } \\
\text { por meio de um inquérito/questionário, a } \\
\text { questões sobre os meus hábitos de saúde. } \\
\end{array}$ \\
\hline 12. & $\begin{array}{l}\text { Estava certo(a) que o meu médico ou } \\
\text { enfermeiro reflectiram sobre os meus valores e } \\
\text { as minhas tradições aquando a recomendação } \\
\text { dos tratamentos. }\end{array}$ & $\begin{array}{l}\text { Estava certo(a) Tive a certeza que o meu } \\
\text { médico ou enfermeiro reflectiram sobre os } \\
\text { meus valores e as minhas tradições aquando a } \\
\text { recomendação dos me recomendaram os } \\
\text { tratamentos. }\end{array}$ \\
\hline 13. & $\begin{array}{l}\text { Fui auxiliado na elaboração de um plano de } \\
\text { tratamentos, passível de realizar na minha vida } \\
\text { quotidiana. }\end{array}$ & $\begin{array}{l}\text { Fui auxiliado ajudado na elaboração de um } \\
\text { plano de tratamento, passível-de-realizar na } \\
\text { minha vida-quotidiana adequado ao meu } \\
\text { dia-a-dia. }\end{array}$ \\
\hline
\end{tabular}




\begin{tabular}{|c|l|l|}
\hline 14. & $\begin{array}{l}\text { Recebi ajuda para fazer um planeamento } \\
\text { futuro, por forma a poder cuidar da minha } \\
\text { doença, mesmo nos momentos mais difíceis. }\end{array}$ & $\begin{array}{l}\text { Recebi-ajuda Fui ajudado para fazer um } \\
\text { planeamento planear o futuro, por de forma a } \\
\text { poder cuidar da minha doença, mesmo nos } \\
\text { momentos mais difíceis. }\end{array}$ \\
\hline 15. & $\begin{array}{l}\text { Fui questionado(a) da forma como a minha } \\
\text { doença crónica afecta a minha vida. }\end{array}$ & $\begin{array}{l}\text { Fui questionado(a) perguntado(a) da de que } \\
\text { forma como a minha doença crónica afecta a } \\
\text { minha vida. }\end{array}$ \\
\hline $\mathbf{1 6 .}$ & $\begin{array}{l}\text { Fui contactado(a) após uma visita para saberem } \\
\text { como as coisas estavam a correr. }\end{array}$ & $\begin{array}{l}\text { Fui contactado(a) perguntado(a) após uma } \\
\text { visita consulta para saberem como as coisas } \\
\text { estavam a correr. }\end{array}$ \\
\hline $\mathbf{1 8 .}$ & $\begin{array}{l}\text { Fui recomendado(a) a procurar um } \\
\text { nutricionista, um educador de saúde ou a um } \\
\text { conselheiro. }\end{array}$ & $\begin{array}{l}\text { Fui recomendado(a) encaminhado(a) a para } \\
\text { procurar um nutricionista, um educador de } \\
\text { saúde enfermeiro ou a um conselheiro } \\
\text { psicólogo. }\end{array}$ \\
\hline $\mathbf{1 9 .}$ & $\begin{array}{l}\text { Fui elucidado(a) da forma como a visita a outros } \\
\text { tipos de médicos nomeadamente, um } \\
\text { oftalmologista, ou um cirurgião, poderão ajudar } \\
\text { nos meus tratamentos. }\end{array}$ & $\begin{array}{l}\text { Fui-elucidado(a)-da forma-como-a visita-a } \\
\text { Disseram-se que a consulta com outros tipos } \\
\text { de médicos especialistas nomeadamente, um } \\
\text { oftalmologista, ou um cirurgião, poderão } \\
\text { ajudar ajudou-me nos meus tratamentos. }\end{array}$ \\
\hline $\mathbf{2 0 .}$ & $\begin{array}{l}\text { Fui questionado(a) como as minhas visitas aos } \\
\text { outros médicos estavam a correr. }\end{array}$ & $\begin{array}{l}\text { Fui questionado(a) como as minhas visitas } \\
\text { consultas aos outros médicos estavam a correr. }\end{array}$ \\
\hline
\end{tabular}

Dessa forma, as sugestões resultantes do Comitê de Especialistas que tiveram maior que $80 \%$ de concordância foram acatadas e resultaram na Versão Consensual em Português-Portugal 2.0 (PACIC-VCPPort 2.0).

A seguir, a Versão Consensual em Português-Portugal 2.0 Revisada (PACICVCPPort 2.0 Rev) foi também submetida à sua tradução em inglês por um tradutor selecionado pela pesquisadora principal e sua supervisora responsável em Portugal, conforme já descrito nos métodos do estudo. Esta etapa, denominada Retratraduçãa, gerou a retroversão do PACIC, a Versão em Inglês-Portugal (PACIC-VIPort) (APÊNDICE I).

Logo, encaminhou-se, por correio eletrônico, a versão em inglês retrotraduzida PACIC-VIPort ao Dr Russel Glasgow. O autor apresentou-se com resposta satisfatória, autorizando a utilização do instrumento e a continuidade com as demais etapas do estudo (ANEXO I). 
Após a finalização dessas três etapas do processo de adaptação cultural em Portugal, resultou-se no PACIC-Versão Pré-Teste em Português-Portugal (PACICVPTPPort) (APÊNDICE N), pois foi utilizado na etapa seguinte (Pré-Teste).

\subsubsection{Pré-S este e Entrevista Cagnitiva (PORTUGAL)}

Contudo, os resultados da entrevista cognitiva (Pré-Teste) dos 50 participantes da população do estudo em Portugal estão apresentados, a seguir, de acordo com a utilização dos Instrumentos Impressão Geral e Específica do Projeto DISABKIDS $^{\circledR}$ (DISABKIDS, 2002; DISABKIDS, 2004).

\subsubsection{Resultadas da Instrumenta Impressãa Geral da PACIC- VPTPPort (PORTUGAL)}

Quanto ao questionário de Impressão Geral, das 50 (100\%) pessoas portuguesas entrevistadas, a maioria também demonstrou uma ótima recepção ao instrumento avaliado, sendo que, de forma geral, todos consideraram o instrumento entre muito bom, 29 (58\%), e, bom 19 (38\%), 41 (82\%) revelaram que as questões são fáceis de entender, 44 (88\%) referiram não ter tido dificuldade em utilizar as categorias de resposta e 43 (86\%) declararam as perguntas do questionário muito relevantes para a condição de saúde (Tabela 7). 
Tabela 7 - Distribuição numérica (n) e percentual (\%) da população do estudo segundo a avaliação do instrumento PACIC-VPTPPort pelo questionário de Impressão Geral (Pré-Teste). Porto, Portugal, 2012

\begin{tabular}{llcc}
\hline QUESTÃO & CATEGORIAS DE RESPOSTA & $\mathbf{n}$ & $\%$ \\
\hline O que achou do nosso & muito bom & 29 & \\
questionário em geral? & Bom & 19 & 38.0 \\
& regular / mais ou menos & 02 & 4.0 \\
\hline As questões são & fáceis de entender & 41 & 82.0 \\
compreensíveis? & às vezes, difíceis & 09 & 18.0 \\
& não compreensíveis & 00 & 0.0 \\
\hline Sobre as categorias de resposta, & nenhuma / sem dificuldade & 44 & 88.00 \\
teve alguma dificuldade em usá-las? & algumas dificuldades & 06 & 12.00 \\
& muitas dificuldades & 00 & 0.0 \\
\hline As questões são relevantes & muito relevante & 43 & 06.0 \\
para a sua condição de saúde? & às vezes relevante & 07 & 14.00 \\
& sem nenhuma relevância & 00 & 0.0 \\
\hline
\end{tabular}

Com relação às questões dissertativas do questionário de Impressão Geral, a maioria, 43 (86\%), das pessoas entrevistadas respondeu que não mudariam ou acrescentariam nada ao instrumento avaliado, com exceção de sete (14\%). Destes, três $(6 \%)$ declararam dificuldades com o manejo da bomba de insulina, dois (4\%) revelaram falta de tempo para controlar a doença (diabetes descontrolado) e dois (4\%) manifestaram impaciência e irritação dos profissionais ao questionar-Ihes sobre dúvidas relacionadas ao cuidado com o tratamento. 


\subsubsection{Resultadas da Instrumenta Impressães Específicas da PACIC-VPTPPort (PORTUGAL)}

Ao tratar-se do Instrumento Impressões Específicas, cabe também salientar que, conforme utilizado na população brasileira do estudo, cada um dos cinco domínios do instrumento português PACIC-VPTPPort foi avaliado por 10 pessoas portuguesas com diabetes mellitus, distribuídas conforme sexo (masculino ou feminino) e idade (adulto e idoso), como preconizado por WHO (2012).

As distribuições das respostas das pessoas entrevistadas, segundo a percepção dos itens em cada um dos domínios avaliados, no que diz respeito à relevância de cada item, à dificuldade para entender a questão e à clareza e consistência das opções de resposta, mostraram-se satisfatórias e estão representadas nas Tabelas 8, 9, 10, 11 e 12 seguintes.

Tabela 8 - Distribuição das respostas dos participantes da entrevista cognitiva pelo questionário de Impressões Específicas, segundo a percepção dos três itens do domínio "Participação Activa do Paciente". Porto, Portugal, 2012

\begin{tabular}{c|c|c|c|c|c|c|c|c}
\hline \multirow{2}{*}{ ITEM } & \multicolumn{3}{c|}{ Relevância } & \multicolumn{2}{c|}{ Dificuldade } & \multicolumn{2}{c}{ Resposta } \\
\cline { 2 - 10 } & sim & às vezes & não & Não & sim & sim & não \\
\hline $\begin{array}{l}\text { Fui questionado(a) sobre as minhas } \\
\text { ideias, quando da elaboração do plano } \\
\text { de tratamentos. }\end{array}$ & 10 & 00 & 00 & 08 & 02 & 10 & 00 \\
\hline 2. & $\begin{array}{l}\text { Recebi diversas opçães de tratamento } \\
\text { para reflectir. }\end{array}$ & 10 & 00 & 00 & 10 & 00 & 10 & 00 \\
\hline 3. $\begin{array}{l}\text { Fui questionado(a) sobre quaisquer } \\
\text { problemas vivenciados com a minha } \\
\text { medicação ou os seus efeitos. }\end{array}$ & 10 & 00 & 00 & 09 & 01 & 10 & 00 \\
\hline
\end{tabular}


Tabela 9 - Distribuição das respostas dos participantes da entrevista cognitiva pelo questionário de Impressões Específicas, segundo a percepção dos três itens do domínio "Sistema de Prestação de Cuidados/Organização da Prática". Porto, Portugal, 2012

\begin{tabular}{cc|c|c|c|c|c|cc}
\hline & \multicolumn{3}{c|}{ Relevância } & \multicolumn{2}{c|}{ Dificuldade } & \multicolumn{2}{c}{ Resposta } \\
\cline { 2 - 11 } & ITEM & sim & às vezes & Não & não & sim & sim & Não \\
\hline $\begin{array}{l}\text { 4. Recebi uma lista com o que devo } \\
\text { fazer para melhorar a minha saúde. }\end{array}$ & 10 & 00 & 00 & 10 & 00 & 10 & 00 \\
\hline $\begin{array}{l}\text { F. Fiquei satisfeito(a) com a boa } \\
\text { organização dos cuidados prestados. }\end{array}$ & 08 & 02 & 00 & 08 & 02 & 10 & 00 \\
\hline $\begin{array}{l}\text { Fui esclarecido(a) se o que eu fiz } \\
\text { para cuidar da minha doença } \\
\text { influenciou o meu estado de saúde. }\end{array}$ & 10 & 00 & 00 & 09 & 01 & 10 & 00 \\
\hline
\end{tabular}

Tabela 10 - Distribuição das respostas dos participantes da entrevista cognitiva pelo questionário de Impressões Específicas, segundo a percepção dos cinco itens do domínio "Estabelecimento de Metas/Individualização". Porto, Portugal, 2012

\begin{tabular}{|c|c|c|c|c|c|c|c|c|}
\hline \multirow{2}{*}{\multicolumn{2}{|c|}{ ITEM }} & \multicolumn{3}{|c|}{ Relevância } & \multicolumn{2}{|c|}{ Dificuldade } & \multicolumn{2}{|c|}{ Resposta } \\
\hline & & sim & às vezes & não & não & $\operatorname{sim}$ & sim & Não \\
\hline & $\begin{array}{l}\text { Fui questionado(a) sobre os meus } \\
\text { objectivos para cuidar da minha } \\
\text { doença. }\end{array}$ & 10 & 00 & 00 & 10 & 00 & 10 & 00 \\
\hline 8. & $\begin{array}{l}\text { Fui ajudado(a) na definição de } \\
\text { objectivos específicos para a } \\
\text { melhoria dos meus hábitos } \\
\text { alimentares e do exercício físico. }\end{array}$ & 10 & 00 & 00 & 09 & 01 & 10 & 00 \\
\hline & $\begin{array}{l}\text { Recebi uma cópia do meu plano de } \\
\text { tratamento. }\end{array}$ & 10 & 00 & 00 & 09 & 00 & 10 & 00 \\
\hline & $\begin{array}{l}\text { Fui encorajado(a) a frequentar um } \\
\text { grupo específico para me ajudar a } \\
\text { lidar com a minha doença crónica. }\end{array}$ & 10 & 00 & 00 & 06 & 04 & 10 & 00 \\
\hline 11. & $\begin{array}{l}\text { Fui questionado(a), directamente ou } \\
\text { por meio de um inquérito, sobre os } \\
\text { meus hábitos de saúde. }\end{array}$ & 10 & 00 & 00 & 10 & 00 & 10 & 00 \\
\hline
\end{tabular}


Tabela 11 - Distribuição das respostas dos participantes da entrevista cognitiva pelo questionário de Impressões Específicas, segundo a percepção dos quatro itens do domínio "Resolução de Problemas/Contextualização". Porto, Portugal, 2012

\begin{tabular}{|c|c|c|c|c|c|c|c|c|}
\hline & \multirow{2}{*}{ ITEM } & \multicolumn{3}{|c|}{ Relevância } & \multicolumn{2}{|c|}{ Dificuldade } & \multicolumn{2}{|c|}{ Resposta } \\
\hline & & $\operatorname{sim}$ & às vezes & Não & não & $\operatorname{sim}$ & sim & não \\
\hline 12. & $\begin{array}{l}\text { Tive a certeza de que o meu médico } \\
\text { ou enfermeiro reflectiram meus } \\
\text { valores e tradições, quando me } \\
\text { recomendavam os tratamentos. }\end{array}$ & 10 & 00 & 00 & 08 & 02 & 10 & 00 \\
\hline 13. & $\begin{array}{l}\text { Fui ajudado(a) na elaboração de um } \\
\text { plano de tratamento, adequado ao } \\
\text { meu dia a dia. }\end{array}$ & 10 & 00 & 00 & 01 & 02 & 10 & 00 \\
\hline 14. & $\begin{array}{l}\text { Fui ajudado(a) para planear o futuro, } \\
\text { de forma a cuidar da minha doença, } \\
\text { mesmo nos momentos mais difíceis. }\end{array}$ & 10 & 00 & 00 & 07 & 03 & 10 & 00 \\
\hline & $\begin{array}{l}\text { Fui perguntado(a) de que forma a } \\
\text { doença crónica afecta a minha vida. }\end{array}$ & 10 & 00 & 00 & 09 & 01 & 10 & 00 \\
\hline
\end{tabular}

Tabela 12 - Distribuição das respostas dos participantes da entrevista cognitiva pelo questionário de Impressões Específicas, segundo a percepção dos cinco itens do domínio "Acompanhamento/Coordenação". Porto, Portugal, 2012

\begin{tabular}{|c|c|c|c|c|c|c|c|c|}
\hline \multirow{2}{*}{\multicolumn{2}{|c|}{ ITEM }} & \multicolumn{3}{|c|}{ Relevância } & \multicolumn{2}{|c|}{ Dificuldade } & \multicolumn{2}{|c|}{ Resposta } \\
\hline & & sim & às vezes & Não & não & $\operatorname{sim}$ & sim & não \\
\hline & $\begin{array}{l}\text { Fui perguntado(a), após uma } \\
\text { consulta, para saber como as coisas } \\
\text { estavam a correr. }\end{array}$ & 10 & 00 & 00 & 06 & 04 & 10 & 00 \\
\hline 17. & $\begin{array}{l}\text { Fui encorajado(a) para frequentar } \\
\text { programas, na comunidade, que me } \\
\text { poderiam ajudar. }\end{array}$ & 10 & 00 & 00 & 09 & 01 & 10 & 00 \\
\hline 18. & $\begin{array}{l}\text { Fui encaminhado(a) para procurar } \\
\text { um nutricionista, um enfermeiro ou } \\
\text { um psicólogo. }\end{array}$ & 10 & 00 & 00 & 10 & 00 & 10 & 00 \\
\hline 19. & $\begin{array}{l}\text { Disseram-se que a consulta com } \\
\text { outros especialistas, nomeadamente, } \\
\text { um oftalmologista, ajudou-me nos } \\
\text { meus tratamentos. }\end{array}$ & 10 & 00 & 00 & 07 & 03 & 10 & 00 \\
\hline & $\begin{array}{l}\text { Fui questionado(a) como as } \\
\text { consultas com outros médicos } \\
\text { estavam a correr. }\end{array}$ & 10 & 00 & 00 & 08 & 02 & 10 & 00 \\
\hline
\end{tabular}


Ainda com relação ao questionário de Impressões Específicas, no que diz respeito à reconstrução dos itens e como os participantes portugueses escreviam-nas com suas próprias palavras, tal qual na população do estudo brasileira, não houve opções para reconstrução de algum dos itens, porém alguns escreveram como o compreendia. Visando a maneira como os itens foram formulados, a grande maioria mostrou-se com boa compreensão, sendo sugerida alteração somente para o item 19, grifada em negrito no Quadro 6.

Quadro 6 - Entrevista Cognitiva (Pré-Teste) e as modificações do PACIC-VPTPPort pelos participantes do estudo. Porto, Portugal, 2012

\begin{tabular}{|c|c|l|}
\hline Item & \multicolumn{1}{|c|}{ PACIC-VPTPPort } & \multicolumn{1}{|c|}{ Após a Entrevista Cognitiva } \\
\hline \multirow{2}{*}{19.} & $\begin{array}{l}\text { Disseram-se que a consulta com outros } \\
\text { especialistas, nomeadamente, um } \\
\text { oftalmologista, ajudou-me nos meus } \\
\text { tratamentos. }\end{array}$ & $\begin{array}{l}\text { Fui informado que a consulta com outros } \\
\text { especialistas, nomeadamente, um } \\
\text { oftalmologista, ajudou-me nos meus } \\
\text { tratamentos. }\end{array}$ \\
\hline
\end{tabular}

Como resultado, obteve-se a construção do PACIC-Versão Final PortuguêsPortugal (PACIC-VFPPort) (APÊNDICE O). 


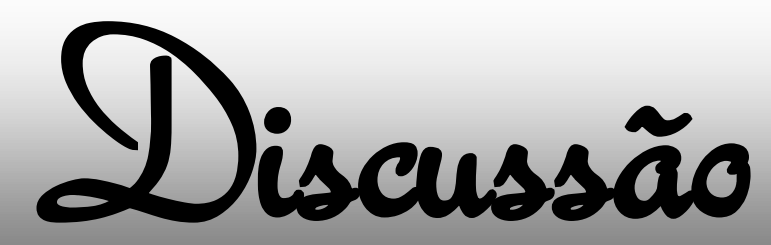




\section{DISCUSSÃO}

Atualmente, a avaliação da qualidade do cuidado em condições crônicas, a importância do autocuidado, modelos educativos para cuidados em saúde e a melhora da qualidade de vida influenciada pelo nível do cuidado adotado são algumas das inquietações da comunidade científica mundial (BOKHOUR et al., 2009; DÍEZ et al., 2004; KAHN et al., 2007; ROCHE, 2006; ROSS; HARRIS, 2005).

Frente aos fenômenos globais de transição demográfica e epidemiológica com a predominância das DCNT, assumiu-se o desafio de buscar novos modelos assistenciais de atenção ao cuidado em condições crônicas (SCHMIDT, 2011; WAGNER, 1998; WAGNER et al., 2001; WHO, 2002). Dentre eles, destaca-se o Modelo de Cuidados Crônicos, como uma abordagem interativa de um modelo de gestão democrática, voltada para um cuidado de forma integral (WAGNER, 1998).

O PACIC é o único instrumento disponível na literatura científica para avaliação da qualidade do cuidado sobre a implementação dos elementos do MCC, na perspectiva da própria pessoa com a condição crônica (WAGNER, 1998; HIBBARD, 2003). Daí a necessidade de adaptá-lo culturalmente para a língua portuguesa do Brasil e de Portugal, visto o seu reconhecimento internacional e utilização de forma ampla em diferentes países do mundo (ARAGONES et al., 2008; CRAMM; NIEBOER, 2012; PETERS-KLIMM et al., 2007; RICK et al., 2012; ROSEMANN et al., 2008; SCHMITTDIEL et al., 2007; TAGGART et al., 2011; WENSING et al., 2008).

Para a realização do processo de adaptação cultural do PACIC para o Brasil e Portugal, conforme recomendações do programa americano Improving Chronic Illness Care (ICIC), destinado ao desenvolvimento e utilização de instrumentos envolvidos no gerenciamento do cuidado em condições crônicas, adotou-se o protocolo metodológico de tradução e adaptação cultural de instrumentos para 
mensuração de construtos subjetivos em saúde proposto por WHO (2012), o qual foi utilizado por estudos internacionais e nacionais (DARKE et al., 1991; FERRI et al., 2000; FRY; RUMBOLD; LINTZERIS, 1998; ISAAC; JANCA; SARTORIUS, 1994; JANCA et al., 1994; MCLELLAN et al., 1980; MURPHY et al., 2000; WHOQOL GROUP, 1998).

Para fins de organização, a discussão desse estudo obedeceu a apresentação sequencial dos resultados, portanto foi realizada conforme a ordem das etapas percorridas do processo metodológico adotado por WHO (2012) no contexto cultural do Brasil, e logo em seguida, de Portugal.

Dessa forma, o processo iniciou-se com a Tradução do instrumento em sua versão original (PACIC-VO). Dois tradutores brasileiros criteriosamente selecionados traduziram o instrumento da língua inglesa para a língua portuguesa do Brasil, originando por meio de um consenso entre a pesquisadora e a orientadora do estudo a primeira versão consensual brasileira, o PACIC-VCPBra 1ab. Um estudo brasileiro revelou que tanto a versão original como a versão consensual traduzida deverá apresentar igual importância e destaca que o consenso deve ser realizado principalmente para o estabelecimento de termos e expressões que melhor representam um conceito (GUILLEMIN, 1995; MIZUMOTO et al., 2011).

No entanto, durante a reunião para a obtenção da versão consensual brasileira foram realizadas essencialmente correções gramaticais e de vocabulário, além da atenção com o cuidado específico com as instruções de preenchimento, conforme também realizado por Ghisi et al., 2010. Os autores ressaltam também, nessa fase, a importância da coerência da apresentação do instrumento, sendo igualmente considerado em nosso estudo quando foi adicionado o termo "Escala de" ao título da versão consensual (GHISI et al., 2010; GUILLEMIN; BOMBARDIER; BEATON, 1993).

Após a tradução, essa primeira versão consensual brasileira foi submetida a um Comitê de Especialistas, a segunda fase do processo de adaptação cultural, composto, no Brasil, por: quatro profissionais atuantes no ensino, pesquisa e 
extensão do cuidado em pessoas com condições crônicas, em especial, o diabetes mellitus, sendo um deles pesquisador no processo metodológico de adaptação cultural de instrumentos de medidas; uma tradutora bilíngue com experiência em traduções de assuntos em saúde; além da pesquisadora principal e a orientadora desse estudo.

Dessa forma, Guillemin, Bombardier e Beaton (1993) recomendam que em um processo de adaptação cultural de instrumentos, o Comitê de Especialistas deve ser composto por pessoas bilíngues e por especialistas na área de conhecimento do instrumento, informados sobre as medidas e os conceitos envolvidos. Pode também ser composto por profissionais de saúde e professor de línguas especialista na metodologia (BEATON et al., 2000).

Para tanto, foram realizadas importantes contribuições durante a avaliação das equivalências semântica, idiomática, cultural e conceitual entre o PACIC-VO e o PACIC-VCPBra 1ab. Por exemplo, nas instruções iniciais de preenchimento do instrumento, a expressão "médico assistente" foi substituída por "outros profissionais de saúde", pois no contexto brasileiro avaliado não há esse tipo específico de profissional. Durante a reunião dos especialistas de um estudo brasileiro para tradução e adaptação cultural de um instrumento que avalia a qualidade de vida em pessoas com condições crônicas renais, realizou-se a substituição de alguns termos por outros similares pelo fato dos itens originais não se enquadrarem nas atividades habituais da população brasileira (DUARTE et al., 2003; HAYS et al., 1997).

Ainda durante essa etapa, a frase inicial que tem o propósito de solicitar o preenchimento dos itens, "Nos últimos 6 meses, quando recebi cuidados em relação a minha doença crônica:" foi modificada para "Para responder todas as questões desse questionário, você deverá pensar na ajuda do cuidado recebido para a sua doença crônica nos últimos 6 meses e assinalar uma resposta para cada questão:", com o objetivo de melhorar a compreensão e tornar mais claro e de fácil entendimento para a população. Da mesma forma, outros estudos brasileiros e 
internacionais asseguraram a importância de realizar alterações em instruções específicas de instrumentos traduzidos, objetivando facilitar a compreensão no contexto da população estudada (COLUCI; ALEXANDRE, 2009; DUARTE et al., 2003; HUBLEY; PALEPU, 2007; WILLIAMS, 2007).

Com relação às cinco alternativas de resposta para cada item da versão consensual brasileira, "Quase Nunca", "Geralmente Não", "Algumas Vezes", "A maior parte do Tempo", "Quase Sempre", estas foram alteradas por sugestão e consenso dos especialistas por "Nunca", "Quase Nunca", "Às Vezes", "Quase Sempre", "Sempre" (DEVON et al., 2007; POLIT; BECK, 2006b).

De forma geral, todos os 20 itens da versão consensual brasileira foram reformulados após sugestão e obtenção de um consenso mínimo de $80 \%$ do total dos especialistas. As reformulações referiram-se a aspectos de melhora na redação dos itens, no que diz respeito as regras gramaticais da língua portuguesa, a clareza dos vocabulários e a compreensibilidade, visando o contexto cultural da população brasileira e a relação conceitual com o domínio medido.

Nesse sentido, pesquisas fundamentam que a clareza e a pertinência do conteúdo dos itens de instrumentos de medidas a serem adaptados culturalmente são aspectos importantes que devem ser considerados em um Comitê de Especialistas. Em relação à clareza, deve-se avaliar a redação dos itens, se eles foram redigidos de forma que o conceito esteja compreensível e se expressa adequadamente o que espera ser medido. No que diz respeito à pertinência, significa observar a relação dos itens com os conceitos envolvidos, a relevância e a adequação para atingir os objetivos propostos (ALEXANDRE; COLUCI, 2011; GRANT; DAVIS, 1997; MCGILTON, 2003; RUBIO et al., 2003).

Ao final dessa etapa, resultou-se na segunda versão consensual brasileira, revisada segundo a Nova Ortografia da Língua Portuguesa (1990) (BRASIL, 1995).

A etapa seguinte proposta por WHO (2012), denominada Retrotradução (Back-Translation), consistiu na tradução da segunda versão consensual brasileira 
revisada para o inglês e a sua comparação com o PACIC-VO, sendo assegurado que não houve alterações de significado dos itens, o que foi confirmado pelo autor principal do instrumento por correio eletrônico, que manifestou concordância, incentivando prosseguir com as próximas etapas do estudo. Após a comparação entre a versão original e a retrotraduzida, definiu-se uma versão harmonizada (PACIC-VPTPBra), que foi utilizada na etapa seguinte (pré-teste) (FERRI et al., 2000; FRY; RUMBOLD; LINTZERIS, 1998; WHOQOL GROUP, 1998).

No Brasil, estudos recentes de adaptação cultural de instrumentos de medidas em saúde que utilizaram como processo metodológico o Grupo DISABKIDS $^{\circledR}(2002 ;$ 2004), também realizaram a etapa de Retrotradução em uma única versão e obtiveram concordância final com o autor principal do instrumento avaliado, após a comparação com a versão original (CASTRO, 2007; DEON et al., 2011; FEGADOLLI et al., 2010; REIS, 2008; SANTOS, 2009).

Os resultados encontrados na entrevista cognitiva (pré-teste) da população brasileira do estudo, por sua vez, serão discutidos, a seguir, de acordo com a utilização dos instrumentos de Impressões Gerais e Específicas do Projeto DISABKIDS $^{\circledR}$ (DISABKIDS, 2002; DISABKIDS, 2004).

Quanto ao questionário de Impressões Gerais, a maioria demonstrou uma ótima recepção ao instrumento avaliado, sendo que, de forma geral, todos consideraram o instrumento entre muito bom (72\%) e bom (28\%). Bem como, 88\% revelaram que as questões são fáceis de entender, $86 \%$ referiram não ter tido dificuldade em utilizar as categorias de resposta e 92\% declararam as perguntas do questionário muito relevantes para a condição crônica.

Esses resultados assemelham-se aos dos estudos recentes realizados no Brasil de adaptação cultural de instrumentos do Projeto DISABKIDS para avaliação da qualidade de vida em condições crônicas (DEON et al., 2011; FEGADOLLI et al., 2010; REIS, 2008; SANTOS, 2009), nos quais percebeu-se também que os instrumentos avaliados foram bem aceitos e de fácil compreensão por parte dos participantes. 
Ainda com relação às impressões gerais, no que diz respeito às questões discursivas relacionadas à possibilidade de mudanças e/ou acréscimos ao instrumento, a maioria dos participantes (78\%) não realizou contribuições. Porém, 14\% manifestaram a não aceitação do diabetes mellitus como condição crônica, questionando sobre a possibilidade de cura ou de um tratamento mais eficaz que descartasse a "obrigatoriedade" das aplicações de doses diárias de insulina, enquanto que $8 \%$ revelaram insatisfação com o tempo de espera para o atendimento da consulta no momento da entrevista.

De forma geral, percebe-se que as manifestações dos participantes não relacionadas ao objetivo de construção (mudanças e/ou acréscimos) para melhora da versão do instrumento PACIC-VPTPBra podem representar a necessidade que algumas pessoas apresentaram em compartilhar suas angústias e dificuldades no momento da entrevista cognitiva.

Durante o decorrer do tratamento do DM, a pessoa vivencia sentimentos e comportamentos que dificultam a aceitação da sua condição, e, consequentemente, a adoção de hábitos saudáveis que permitam lidar com as limitações decorrentes da cronicidade da patologia (MARCELINO; CARVALHO, 2005; PÉRES et al., 2007). Assim, preocupa-se com as perspectivas do que virá para melhorar a sua condição de vida, esperando e buscando muitas vezes possibilidades de cura para o diabetes (BRITO; SADALA; 2009).

Os entrevistados também se manifestaram sobre a insatisfação com o tempo de espera para o atendimento da consulta, sendo esta uma temática muito discutida no Brasil (ESPERIDIÃO; TRAD, 2005; FONTENELE; ALVES; CÂMARA, 2012; LEITE et al., 2000; SANTOS; LACERDA, 1999; VAITSMAN; ANDRADE, 2005; ZANETTI et al., 2007). A satisfação da pessoa com o atendimento poderá constituir um valioso feedback para a avaliação do atendimento oferecido e do trabalho dos profissionais de saúde. Isso impõe constante busca para identificação dos fatores que promovem satisfação dos usuários atendidos no sistema de saúde, tais como: confiança, atualização, 
competência, humanidade, presteza, pontualidade, cordialidade e preparo técnicocientífico da equipe multiprofissional de saúde e organização do ambiente de trabalho (SANTOS; LACERDA, 1999; VAITSMAN; ANDRADE, 2005).

Dessa forma, no que diz respeito à reconstrução dos itens e como as pessoas escreviam-nos com suas próprias palavras, não houve opções para reconstrução de algum dos itens, porém alguns expressaram como o compreendia. Visando a maneira como os itens foram formulados, a maioria mostrou-se de fácil compreensão, porém foram sugeridas substituições de termos ou expressões por outros de melhor compreensão em quatro $(6,10,12$ e 16) dos 20 itens avaliados.

Obedecendo a ordem crescente dos itens alterados, o primeiro foi o item 6, "Mostraram que a maneira como eu me cuidava 'influenciava na' minha doença", que foi modificado para "Mostraram que a maneira como eu me cuidava 'poderia melhorar ou piorar a' minha doença". O segundo, o item 10, "Estimularam a participar de grupos ou aulas específicas para 'lidar' com a minha doença crônica", modificouse para "Estimularam a participar de grupos ou aulas específicas para 'aprender a conviver' com a minha doença crônica". O terceiro, o item 12, "Tive certeza que o meu médico (a) ou enfermeiro (a) 'considerava' meus valores e costumes, quando eles recomendavam tratamentos para mim" foi alterado para "Tive certeza que o meu médico (a) ou enfermeiro (a) 'respeitava' meus valores e costumes, quando eles recomendavam tratamentos para mim". Por fim, o quarto item, o 16, "Entraram em contato comigo, depois de uma consulta, para verificar como 'as coisas estavam indo'" sofreu alteração para "Entraram em contato comigo, depois de uma consulta, para verificar como 'estava o controle da minha doença'".

O item 6 está inserido no segundo domínio do PACIC (Modelo do Sistema de Cuidado / Modelo para a Prática) e está fortemente relacionado com dois elementos do MCC: Desenho do sistema de atenção e Suporte às decisões (GLASGOW et al., 2005a). Tal domínio possibilita descrever ações que melhor organizam o cuidado da condição crônica, fornecendo informações às pessoas para a melhora da sua 
compreensão do cuidado (BARCELÓ et al., 2012; GLASGOW et al., 2005a; MENDES, 2012; WAGNER et al., 2001). Nesse sentido, a modificação realizada no item 6 visa possibilitar uma melhor compreensão para o acompanhamento do cuidado em DM.

Os itens 10 e 12 estão inseridos no terceiro e no quarto domínios do PACIC, Estabelecimento de metas / Adaptação e Resolução de problemas / Contexto, respectivamente, e relacionam-se ambos com o elemento do MCC intitulado Autocuidado apoiado (GLASGOW et al., 2005a). Tais domínios avaliam a transmissão de informações para o estabelecimento de metas colaborativas e descrevem possíveis problemas no contexto social e cultural da pessoa com condição crônica para a elaboração de planos de tratamentos (BARCELÓ et al., 2012; GLASGOW et al., 2005a; MENDES, 2012; WAGNER et al., 2001). Considera-se que esses objetivos oferecem suporte para o desenvolvimento das atividades de autocuidado e espera-se que as alterações realizadas nos itens 10 e 12 proporcionem um melhor entendimento dos itens para atender os objetivos de autocuidado almejados.

Por fim, o item 16 está inserido no quinto domínio do PACIC (Seguimento / Coordenação), sendo considerado muito importante para o conjunto de todos os elementos do MCC (GLASGOW et al., 2005a). Esse domínio avalia a capacidade de promover a continuidade do cuidado, possibilitando as pessoas com condições crônicas serem avaliadoras do seu próprio progresso do cuidado (BARCELÓ et al., 2012; GLASGOW et al., 2005a; MENDES, 2012; WAGNER et al., 2001). O item 16 representa adequadamente o cuidado contínuo das condições crônicas e a modificação realizada permite favorecer uma melhor ênfase nesse objetivo.

Conforme esclarecido anteriormente, segue a discussão dos resultados apresentados desse estudo conforme a ordem das etapas percorridas do processo metodológico adotado por WHO (2012) no contexto cultural de Portugal.

Para tanto, a Tradução do PACIC-VO para a língua portuguesa de Portugal foi realizada por dois tradutores portugueses seguindo o mesmo rigor metodológico de seleção, resultando após consenso entre a pesquisadora e a supervisora 
responsável pelo estágio internacional na primeira versão consensual portuguesa, o PACIC-VCPPort 2ab. Para a realização efetiva do consenso após as duas traduções iniciais, os pesquisadores envolvidos em um estudo português de adaptação cultural de um instrumento de avaliação de atividade física realizaram a comparação criteriosa de cada palavra e frase entre as versões traduzidas. É importante declarar também que os critérios de seleção contemplados para a escolha dos dois tradutores foram iguais ao do nosso estudo (SANTOS; SIMÕES; 2009).

A versão consensual resultante da comparação entre as traduções iniciais deverá preservar o mesmo significado de cada item do instrumento, mantendo-se a integridade com o instrumento original (GUILLEMIN; BOMBARDIER; BEATON, 1993), o que foi cuidadosamente realizado por estudos metodológicos em Portugal (SALES et al., 2012; SANTOS; SIMÕES; 2009; VALADAS; GONÇALVES; FAÍSCA, 2009).

Logo após essa fase, a primeira versão consensual portuguesa foi submetida à avaliação por um Comitê de Especialistas em Portugal, composto por profissionais selecionados conforme as recomendações de WHO (2012), com as mesmas formações acadêmicas e qualificações profissionais que o Comitê realizado no Brasil. No entanto, houve a participação de uma pessoa com diagnóstico de diabetes mellitus em seguimento no Serviço de Endocrinologia do Centro Hospitalar de São João, Porto. A literatura recomenda que a inclusão de pessoas leigas potencialmente relacionadas com a população do estudo envolvida na avaliação do instrumento poderá assegurar uma melhor compreensão da correção de frases e termos não muito claros (ALEXANDRE; COLUCI, 2011; RUBIO et al., 2003).

Durante a avaliação das equivalências semântica, idiomática, cultural e conceitual entre o PACIC-VO e o PACIC-VCPPort 2ab, também foram realizadas modificações importantes nas orientações iniciais do instrumento, tais como: "quando se é detentor de uma doença crónica" e "o seu médico de família, o enfermeiro que o auxilia, ou o assistente médico" por "quando se tem uma doença crónica" e "o seu médico, o enfermeiro ou outros profissionais de saúde". Reconhece- 
se cientificamente que um Comitê de Especialistas deve ser capaz de modificar as orientações iniciais do instrumento, além de modificar ou rejeitar itens inadequados, assegurando uma versão final totalmente compreensível e culturalmente equivalente (GUILLEMIN; BOMBARDIER; BEATON, 1993; GUILLEMIN, 1995).

Com relação às cinco alternativas de resposta para cada item da versão consensual portuguesa "Praticamente Nunca", "Geralmente Não", "Por Vezes", "A Maioria do Tempo", "Praticamente Sempre", estas foram alteradas por sugestão dos especialistas por "Nunca", "Raramente", "Por Vezes", "Quase Sempre", "Sempre" (DEVON et al., 2007; POLIT; BECK, 2006b).

De forma geral, 19 dos 20 itens da versão consensual portuguesa foram alterados, mediante a obtenção de um consenso mínimo de $80 \%$ do total dos especialistas. Conforme decorrido no Brasil, as alterações dos itens do PACICVCPPort 2ab foram realizadas visando à melhora na redação, no que se refere às regras gramaticais da língua portuguesa, à clareza dos vocabulários e à compreensibilidade, enquadrado no contexto cultural de Portugal e a relação conceitual com o domínio medido. Ao final dessa etapa, resultou-se na segunda versão consensual portuguesa, revisada segundo a Nova Ortografia da Língua Portuguesa (1990) (BRASIL, 1995).

Na etapa seguinte, a Retrotradução (Back-Translation), realizou-se a tradução da segunda versão consensual portuguesa revisada para o inglês e a sua comparação com o PACIC-VO, sendo assegurado que também não houve alterações de significado dos itens, o que foi confirmado pelo autor principal do instrumento por correio eletrônico. Resultou-se na versão portuguesa PACIC-VPTPPort, sendo esta utilizada na entrevista cognitiva (pré-teste).

Estudo metodológico realizado com estudantes universitários no sul de Portugal realizou a etapa da retrotradução com um tradutor profissional português, com conhecimento nas duas línguas (portuguesa e inglesa), residente em um país anglo-saxônico durante alguns anos e com experiência de docência no ensino 
superior. Após comparação com a versão original pelo autor principal, não se obtiveram quaisquer incompatibilidades com a tradução inicial (HILL; HILL, 2000; VALADAS; GONÇALVES; FAÍSCA, 2009).

Quanto ao questionário de Impressões Gerais, a maioria demonstrou uma ótima recepção ao instrumento avaliado, sendo que, de forma geral, todos consideraram o instrumento entre muito bom (58\%) e bom (38\%). Bem como, 82\% revelaram que as questões são fáceis de entender, $88 \%$ referiram não ter tido dificuldade em utilizar as categorias de resposta e $86 \%$ declararam as perguntas do questionário muito relevantes para a condição crônica.

Tais resultados também são condizentes com estudos recentes de adaptação cultural de instrumentos para a língua portuguesa do Projeto DISABKIDS para avaliação da qualidade de vida em condições crônicas (DEON et al., 2011; FEGADOLLI et al., 2010; REIS, 2008; SANTOS, 2009), nos quais percebeu-se também que os instrumentos avaliados foram bem aceitos e de fácil compreensão por parte dos participantes.

Ainda com relação às impressões gerais, no que diz respeito às questões discursivas relacionadas à possibilidade de mudanças e/ou acréscimos ao instrumento, a maioria dos participantes (86\%) não realizou contribuições. Porém, três (6\%) declararam dificuldades com o manejo da bomba de insulina, dois (4\%) revelaram falta de tempo para controlar a doença (diabetes descontrolado) e dois (4\%) manifestaram impaciência e irritação dos profissionais ao questionar-lhes sobre dúvidas relacionadas ao cuidado com o tratamento.

Conforme no Brasil, observa-se claramente que as manifestações não se relacionaram ao objetivo de construção (mudanças e/ou acréscimos) para melhora da versão do instrumento PACIC-VPTPPort, e sim representaram a necessidade que em compartilhar suas angústias e dificuldades no momento da entrevista cognitiva.

Sabe-se que a utilização da bomba perfusora de insulina na terapêutica do DM com infusão contínua subcutânea é uma alternativa intensiva convencional em 
pessoas com DM1. Porém, pode ser um fator estressante, pois exige um cuidado de autovigilância frequente por meio de glicemias capilares sobre a necessidade de ajustes do ritmo da perfusão da insulina conforme o perfil glicêmico desejado (CRIEGO et al., 2009; HISSA; HISSA, BRUIN, 2001).

Ao tratar-se do questionário de Impressões Específicas, no que diz respeito à reconstrução dos itens e como as pessoas escreviam-nos com suas próprias palavras, não houve opções para reconstrução de algum dos itens, porém alguns expressaram como o compreendia. Visando a maneira como os itens foram formulados, a maioria mostrou-se de fácil compreensão, porém sugeriu-se a substituição de um termo em apenas um (item 19) dos 20 itens avaliados: "'Disseram-se' que a consulta com outros especialistas, nomeadamente, um oftalmologista, ajudou'-me' nos meus tratamentos" sofreu alteração para "'Fui informado' que a consulta com outros especialistas, nomeadamente, um oftalmologista, ajudou nos meus tratamentos".

O item 19 está inserido no quinto domínio do PACIC (Seguimento / Coordenação), sendo considerado muito importante para o conjunto de todos os elementos do MCC (GLASGOW et al., 2005a). Esse domínio avalia a capacidade de promover a continuidade do cuidado, possibilitando as pessoas com condições crônicas serem avaliadoras do seu próprio progresso do cuidado (BARCELÓ et al., 2012; GLASGOW et al., 2005a; MENDES, 2012; WAGNER et al., 2001). Dessa forma, percebe-se que a substituição realizada visa enfatizar o qual é importante a continuidade do cuidado em condições crônicas.

Dessa forma, a adaptação cultural do PACIC para a língua portuguesa do Brasil e de Portugal conservou sua estrutura original, isto é manteve-se a disposição de seus 20 itens, seus domínios e a forma de somatória de escores. Resultando assim, em um instrumento adaptado culturalmente e compreensível para a avaliação da qualidade do cuidado sobre a utilização dos elementos do Modelo de Cuidados Crônicos, na perspectiva da pessoa com diabetes mellitus. 


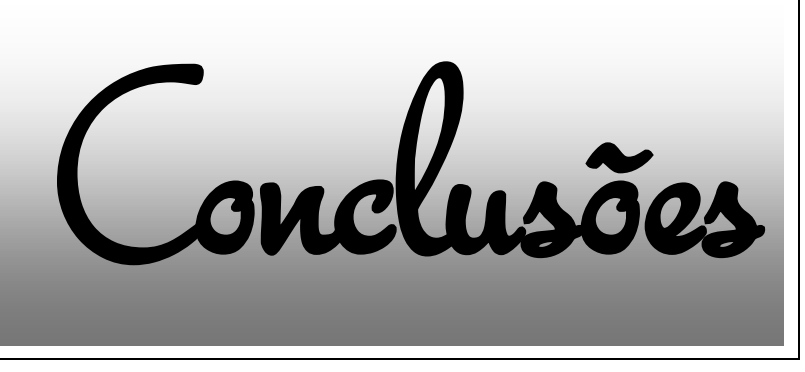




\section{CONCLUSÕES}

O estudo permitiu a adaptação cultural do instrumento Patient Assessment of Chronic Illness Care para a língua portuguesa do Brasil e de Portugal. De acordo com os objetivos específicos propostos nesse estudo, concluiu-se que:

* As duas traduções iniciais da versão original do PACIC para a língua portuguesa foram realizadas individualmente em cada contexto. Após a análise de possíveis diferenças, selecionando frases de melhores expressões, obtiveram-se as primeiras versões consensuais brasileira e portuguesa;

* No Comitê de Especialistas, os critérios de avaliações das equivalências semântica, idiomática, cultural e conceitual entre o PACIC-VO e as versões consensuais analisadas foram alcançados adequadamente, o que foi possível resultar nas segundas versões consensuais brasileira e portuguesa;

* As versões retrotraduzidas foram realizadas e comparadas com o PACIC-VO, assegurando que não houve alterações de significado dos itens, após a confirmação do feedback positivo pelo autor principal do instrumento;

- As entrevistas cognitivas foram realizadas em ambos os contextos culturais. De forma geral, o instrumento foi considerado muito bom pela maioria da população do estudo, com questões fáceis de entender e categorias de respostas não difíceis de serem utilizadas. Somado a isso, 92\% (Brasil) e 86\% (Portugal) da população do estudo declararam que os itens do instrumento são muito relevantes para o diabetes mellitus, como condição de saúde. Contudo, verificouse que os participantes entrevistados foram capazes de compreender os itens do instrumento.

Conclui-se, portanto, que o processo de adaptação cultural do PACIC para a língua portuguesa do Brasil e de Portugal atendeu as diretrizes propostas pelo processo metodológico recomendado por WHO (2012). 
No entanto, deve-se salientar que nesse estudo realizou-se a adaptação cultural do instrumento PACIC para o contexto brasileiro e português, sendo necessário prosseguir com a avaliação das propriedades psicométricas para o seu estudo de validação no Brasil e em Portugal.

Dessa forma, considera-se importante disponibilizar este instrumento, no qual poderá contribuir positivamente para o estudo da qualidade do cuidado em pessoas com diabetes mellitus, fornecendo subsídios para estudos comparativos internacionais, em diferentes contextos culturais, para as equipes de saúde e gestores no planejamento da atenção integrada nos sistemas de saúde. 


\section{Referências*}

* De acordo com:

ASSOCIAÇÃO BRASILEIRA DE NORMAS TÉCNICAS (ABNT). NBR 6023: informação e documentação: referências: elaboração. Rio de Janeiro, 2002. 


\section{REFERÊNCIAS}

ACTON, K.; BOCHENSKI, C.; BROUSSARD, B.; GOHDES, D.; HOSEY, G.; RITH-NAJARIAN, S.; STAHN, R.; STACQUALURSI, F. Putting integrated care and education to work for American Indians. Alaska Natives Manual of the Indian Health Services Diabetes Program. Albuquerque: Department of Health and Human Services, 1995.

ACTON, K.; VALWAY, S.; HELGERSON, S.; HUY, J. B.; SMITH, K.; CHAPMAN, V.; GOHDES, D. Improving diabetes care for American Indians. Diabetes Care, Alexandria, v. 16, n. 1, p. 372-375, Jan. 1993.

ALEXANDRE, N. M. C.; COLUCI, M. Z. O. Validade de conteúdo nos processos de construção e adaptação de instrumentos de medidas. Ciência \& Saúde Coletiva, Rio de Janeiro, v. 16, n. 7, p. 3061-3068, jul. 2011.

ALVES, V. S. Um modelo de educação em saúde para o Programa Saúde da Família: pela integridade da atenção e reorientação do modelo assistencial. Interface: Comunicação, Saúde, Educação, Marília, v. 9, p. 39-52, set.2004/fev.2005. 2005.

ALWAN, A.; MACLEAN, D. R.; RILEY, L. M.; D'ESPAIGNET, E. T.; MATHERS, C. D.; STEVENS, G. A.; BETTCHER, D. Monitoring and surveillance of chronic noncommunicable diseases: progress and capacity in high-burden countries. Lancet, London, v. 376, n. 9755, p. 1861-1868, Nov. 2010.

AMERICAN DIABETES ASSOCIATION (ADA). Implications of the United Kingdom Prospective Diabetes Study. Diabetes Care, Alexandria, v. 27, p. 28-32, 2004. Supplement 1.

Standard of medical care in diabetes -2011 (Position Statement). Diabetes Care, Alexandria, v. 34, p. 11-61, Jan. 2011. Supplement 1.

ARAGONES, A.; SCHAEFER, E. W.; STEVENS, D.; GOUREVITCH, M. N.; GLASGOW, R. E.; $\mathrm{SHAH}, \mathrm{N}$. R. Validation of the Spanish translation of the Patient Assessment of Chronic Illness Care (PACIC) survey. Preventing Chronic Disease, Atlanta, v. 5, n. 4, p. 1-10, Oct. 2008.

ASCH, S. M.; BAKER, D. W.; KEESEY, J. W.; BRODER, M.; SCHONLAU, M.; ROSEN, M.; WALLACE, P. L.; KEELER, E. B. Does the collaborative model improve care for chronic heart failure? Medical Care, Philadelphia, v. 43, p. 667-675, Jul. 2005. 
ASSOCIAÇÃO MÉDICA MUNDIAL (AMM). Declaração de Helsinque da World Medical Association (WMA): princípios éticos para pesquisa médica envolvendo seres humanos. Seul, out. 2008. Disponível em:

$<$ http://www.institutoissadecardiologia.com.br/docs/diversos/Declaration_Helsinki_Se oul_2008.pdf >. Acesso em: 5 jan. 2012.

MIZUMOTO, S.; SILVEIRA, D. X.; BARBOSA, P. C. R.; STRASSMAN, R. J. Hallucinogen Rating Scale (HRS) - Versão brasileira: tradução e adaptação transcultural. Revista de Psiquiatria Clínica, São Paulo, v. 38, n. 6, p. 231-237, 2011.

BAHIA, L. R.; ARAUJO, D. V.; SCHAAN, B. D.; DIB, S. A.; NEGRATO, C. A.; LEÃO, M. P.; RAMOS, A. J.; FORTI, A. C.; GOMES, M. B.; FOSS, M. C.; MONTEIRO, R. A.; SARTORELLI, D.; FRANCO, L. J. The costs of type 2 diabetes mellitus outpatient care in the Brazilian public health system. Value in Health Regional Issues, Philadelphia, v. 14, n. 5, p. 137-140, Jul. 2011. Supplement 1.

BAKER, D. W.; ASCH, S. M.; KEESEY, J. W.; BROWN, J. A.; CHAN, K. S.; JOYCE, G.; KEELER, E. B. Differences in education, knowledge, self-management activities, and health outcomes for patients with heart failure cared for under the chronic disease model: the improving chronic illness care evaluation. Journal of Cardiac Failure, Naperville, v. 11, n. 6, p. 405-413, Aug. 2005.

BANDEIRA, M.; CALZAVARA, M. G. P.; VARELLA, A. A. B. Escala de sobrecarga dos familiares de pacientes psiquiátricos: adaptação transcultural para o Brasil (FBIS-BR). Jornal Brasileiro de Psiquiatria, Rio de Janeiro, v. 54, n. 3, p. 206-214, jul./set. 2005.

BARCELÓ, A.; LUCIANI, S.; AGURTO, I.; ORDUÑEZ, P.; TASCA, R.; SUED, O. O modelo de cuidados crônicos (MCC) e as redes integradas de serviços de saúde. In:

Melhoria dos cuidados crônicos por meio das redes de atenção à saúde. Washington: Organização Pan-Americana da Saúde, 2012. Cap. 1, p. 5-12.

BARROS, P.; MACHADO, S.; SIMÕES, J. Health Systems in Transition (HiT). Portugal: health system review. Copenhagen: European Observatory on Health Systems and Policies/WHO, 2011.

BATALHA, L. M. C.; REIS, G. M. R.; COSTA, L. P. S.; CARVALHO, M. D. R.; MIGUENS, A. P. M. Adaptação cultural e validação da reprodutibilidade da versão Portuguesa da escala de dor Face, Legs, Activity, Cry, Consolability (FLACC) em crianças. Revista de Enfermagem Referência, Coimbra, v. 2, n. 10, p. 77-14, Jul. 2009.

BATTERSBY, M. W. Health reform through coordinated care: SA HealthPlus. British Medical Journal, London, v. 330, n. 7495, p. 662-5, Mar. 2005. 
BAUER, M. S.; MCBRIDE, L.; WILLIFORD, W. D.; GLICK, H.; KINOSIAN, B.; ALTSHULER, L.; BERESFORD, T.; KILBOURNE, A. M.; SAJATOVIC, M.; COOPERATIVE STUDIES PROGRAM 430 STUDY TEAM. Collaborative care for bipolar disorder: Part II, Impact on clinical outcome, function, and costs. Psychiatric Services, Washington, v. 57, n. 7, p. 937-45, Jul. 2006.

BEATON, D. E.; BOMBARDIER, C.; GUILLEMIN, F.; FERRAZ, M. B. Guidelines for the process of cross-cultural adaptation of self report measures. Spine, Philadelphia, v. 25, n. 24, p. 3186-3191, Dec. 2000.

BEATON, D.; BOMBARBIER, C.; GUILLEMIN, F.; FERRAZ, M. B. Recommendations for the cross-cultural adaptation of health status measures. Rosemont: American Academy of Orthopaedic Surgeons, 2002.

BOAVIDA, J. É necessário integrar: as pessoas doentes no controle e gestão da sua própria doença. Diabetes - Viver em Equilíbrio, Lisboa, v. 21, p. 10-11, 2001.

BODENHEIMER, T. S.; WAGNER, E. H.; GRUMBACH, K. Improving primary care for patients with chronic illness. JAMA, Chicago, v. 288, n. 14, p. 1775-1779. Oct. 2002.

BOKHOUR, B. G.; PUGH, M. J.; RAO, J. K.; AVETISYAN, R.; BERLOWITZ, D. R.; KAZIS, L. E. Improving methods for measuring quality of care: a patient-centered approach in chronic disease. Medical Care Research and Review, Thousand Oaks, v. 66, n. 2, p. 147-66, Dec. 2009.

BONOMI, A. E.; WAGNER, E. H.; GLASGOW, R. E.; VON KORFF, M. Assessment of chronic illness care (ACIC): a practical tool to measure quality improvement. Health Services Research, Chicago, v. 37, n. 3, p. 791-820, Jun. 2002.

BOWEN, J. L.; PROVOST, L.; STEVENS, D. P.; JOHNSON, J. K.; WOODS, D. M.; SIXTA, C. S.; WAGNER, E. H. Assessing Chronic Illness Care Education (ACIC-E): a tool for tracking educational re-design for improving chronic care education. Journal of General Internal Medicine, Philadelphia, v. 25, p. S593-S609, Sep. 2010. Supplement 4.

BRAGA, C. G.; CRUZ, D. A. L. M. Contribuições psicometria para a avaliação de respostas psicossociais na enfermagem. Revista da Escola de Enfermagem da USP, São Paulo, v. 40, n. 1, p. 98-104, mar. 2006. 
BRASIL. Decreto n. 54, de 21 de abril de 1995. Dispõe sobre a aprovação do texto do Acordo Ortográfico da Língua Portuguesa, assinado em Lisboa, em 16 de dezembro de 1990. Diário do Congresso Nacional [da] República Federativa do Brasil, Brasília, DF, Seção 2, p. 5837-5879.

Ministério da Saúde. Secretaria de Vigilância em Saúde. Secretaria de Atenção

à Saúde. Diretrizes e recomendações para o cuidado integral de doenças crônicas não-transmissíveis. Promoção da saúde, vigilância, prevenção e assistência. Brasília, DF, 2008.

Ministério da Saúde. Secretaria de Vigilância em Saúde. Departamento de Análise de Situação de Saúde. Plano de Ações Estratégicas para o Enfrentamento das Doenças Crônicas Não Transmissíveis (DNCT) no Brasil, 2011-2022. Brasília, DF, 2011a. (Série B. Textos Básicos de Saúde).

Ministério da Saúde. Educação em saúde para o autocuidado e avaliação contínua da qualidade da atenção ao diabetes no Brasil. 2011b. Disponível em: $<$ http://www.qualidia.com.br./index.php?option=com_content\&view=article\&id=2\&It emid=6>. Acesso em: 7 nov. 2012.

BRITISH COLUMBIA. Ministry of Health. A framework for a provincial chronic disease prevention initiative. British Columbia, Population health and wellness. Victoria: Ministry of Health Planning, 2003.

Ministry of Health. Value for money in the health system. Wellington: Ministry of Health, 2005.

Ministry of Health. British Columbia expanded chronic care model. 2008. Disponível em: <http://www.health.gov.bc.ca>. Acesso em: 13 out. 2009.

BRITO, F. Transição demográfica e desigualdades sociais no Brasil. Revista Brasileira de Estudos Populacionais, São Paulo, v. 25, n. 1, p. 5-26, jan./jun. 2008.

BRITO, T. B.; SADALA, M. L. A. Diabetes mellitus juvenil: a experiência de familiares de adolescentes e pré-adolescentes. Ciência \& Saúde Coletiva, Rio de Janeiro, v. 14, n. 3, p. 947-960, mai./jun. 2009. 
CASTRO, M. E. M. Adaptação transcultural e validação do instrumento genérico de mensuração de qualidade de vida relacionada à saúde, DISABKIDS 37, para crianças e adolescentes mexicanos com doenças crônicas e seus pais ou cuidadores: fase I. 2007. 186 f. Tese (Doutorado em Enfermagem) - Escola de Enfermagem de Ribeirão Preto, Universidade de São Paulo, Ribeirão Preto, 2007.

CENTRO HOSPITALAR DE SÃO JOÃO (HSJ). Instituição. Porto, c2006. Disponível em: <http://www.chsj.pt/PageGen.aspx?WMCM_PaginaId=27542>. Acesso em: 17 set. 2012.

CHAN, K. S.; MANGIONE-SMITH, R.; BURWINKLE, T. M.; ROSEN, M.; VARNI, J. W. The PedsQL: reliability and validity of the short-form generic core scales and asthma module. Medical Care, Philadelphia, v. 43, n. 3, p. 256-65, Mar. 2005.

CHEAH, J. Chronic disease management: a Singapoure perspective. British Medical Journal, London, v. 323, n. 7319, p. 990-3, Oct. 2001.

CHIN, M. H.; COOK, S.; DRUM, M. L.; JIN, L.; GUILLEN, M.; HUMIKOWSKY, C. A.; KOPPERT, J.; HARRINSON, J. F.; LIPPOLD, S.; SCAEFER, C. T.; MIDWEST CLUST HEALTH DISPATITIES COLLABORATIV. Improving diabetes care in Midwest Community health centers with the Health Disparities Collaborative. Diabetes Care, Alexandria, v. 27, n. 1, p. 2-8, Jan. 2004.

CICONELLI, R. M.; FERRAZ, M. B.; SANTOS, W.; MEINÃO, I.; QUARESMA, M. R. Tradução para a língua portuguesa e validação do questionário genérico de avaliação de qualidade de vida SF-36 (Brasil SF-36). Revista Brasileira de Reumatologia, Campinas, v. 39, n. 3, p. 143-150, maio/jun. 1999.

CIECHANOWSKI, P. S.; KATON, W. J.; RUSSO, J. E.; WALKER, E. A. The patient provider relationship: attachment theory and adherence to treatment in diabetes. American Journal of Psychiatry, Arlington, v. 158, n. 1, p. 29-35, Jan. 2001.

COLUCI, M. Z. O.; ALEXANDRE, N. M. C. Adaptação cultural de instrumento que avalia atividades do trabalho e sua relação com sintomas osteomusculares. Acta Paulista de Enfermagem, São Paulo, v. 22, n. 2, p. 149-154, 2009.

CRAMM, J. M.; NIEBOER, A. P. Factorial validation of the Patient Assessment of Chronic Illness Care (PACIC) and PACIC short version (PACIC-S) among cardiovascular disease patients in the Netherlands. Health and Quality of Life Outcomes, London, v. 10, p. 104-10, Aug. 2012. 
CRAMM, J. M.; STRATING, M. M. H.; TSIACHRISTAS, A.; NIEBOER, A. P. Development and validation of a short version of the Assessment of Chronic Illness Care (ACIC) in Dutch disease management programs. Health and Quality of Life Outcomes, London, v. 9, p. 49-58, Jul. 2011.

CRETIN, S.; SHORTELL, S. M.; KEELER, E. B. An evaluation of collaborative interventions to improve chronic illness care: framework and study design. Evaluation Review, Beverly Hills, v. 28, n. 1, p. 28-51, Feb. 2004.

CRIEGO, A.; CROW, S.; GOEBEL-FABBRI, A. E.; KENDALL, D.; PARKIN, C. Eating Disorders and Diabetes: Screening and Detection. Diabetes Spectrum, Alexandria, $v$. 22, n. 3, p. 143-6. Jun. 2009.

CURCIO, A.; TORRES, L. Tradução e adaptação do "Diabetes Distress Scale - DDS" na cultura brasileira Acta Paulista de Enfermagem, São Paulo, v. 25, n. 5, p. 762-67, 2012.

CURITIBA (Paraná). Secretaria Municipal de Saúde de Curitiba. Laboratório de inovações na atenção às condições crônicas na Atenção Primária à Saúde.

Curitiba: Secretaria Municipal de Saúde de Curitiba, 2010. Disponível em: <http://www.saude.curitiba.pr.gov.br/index.php/programas/saudeadulto/laboratoriode-inovacoes-em-atencao-as-condicoes-cronicas>. Acesso em: 9 out. 2012.

DAHLGREN, G.; WHITEHEAD, M.; Policies and strategies to promote social equity in health. Background document to WHO - Strategy paper for Europe. Stockolm: Arbetsrapport / Institutet for Framtidsstudier, 2007.

DANIEL, D. M.; NORMAN, J.; DAVIS, C.; LEE, H.; HINDMARSH, M. F.; MCCULLOCH, D. K.; WAGNER, E. H.; SUGARMAN, J. R. A state-level application of the chronic illness breakthrough series: results from two collaboratives on diabetes in Washington State. Joint Commission journal on quality and patient safety, Oakbrook Terrace, v. 30, n. 2, p. 69-79, Feb. 2004.

DARKE, S.; WARD, J.; HALL, W.; HEATHER, N.; WODAK, A. The Opiate Treatment Index (OTI) Researcher's Manual. Sydney: National Drug and Alcohol Research Centre, 1991. Technical Report Number 11.

DELALIBERA, M.; COELHO, A.; BARBOSA, A. Validação do instrumento de avaliação do luto prolongado para a população portuguesa. Acta Médica Portuguesa, Lisboa, v. 24, n. 6, p. 935-942, maio/jun. 2011.

DELAMATER, A. B.; LIMA, M. L. Improving patient adherence. Clinical Diabetes, Alexandria, v. 24, n. 2, p. 71-77, Apr. 2006. 
DEON, K. C. Adaptação cultural e validação do módulo específico Dermatite Atópica do instrumento de avaliação de Qualidade de Vida Relacionada à Saúde de crianças e adolescentes - DISABKIDS ${ }^{\circledR}$ - MDA - Fase I. 2009. 148 f. Dissertação (Mestrado) - Escola de Enfermagem de Ribeirão Preto, Universidade de São Paulo, Ribeirão Preto, 2009.

DEON, K. C.; SANTOS, D. M. S. S.; REIS, R. A.; FEGADOLLI, C.; BULLINGER, M.; SANTOS, C. B. Tradução e adaptação cultural para o Brasil do DISABKIDS ${ }^{\circledR}$ Atopic Dermatitis Module (ADM). Revista da Escola de Enfermagem da USP, São Paulo, v. 45, n. 2, p. 450-457, abr. 2011.

DEPARTMENT OF HEALTH. Supporting people with long term conditions: an NHS and social care model to support local innovation and integration. Leeds:

COI/Department of Health, 2005.

DeVON, H. A.; BLOCK, M. E.; MOYLE-WRIGHT, P.; ERNST, D. M.; HAYDEN, S. J.; LAZZARA, D. J.; SAVOY, S. M.; KOSTAS-POLSTON, E. A psychometric toolbox for testing validity and reliability. Journal of Nursing Scholarship, Indianapolis, v. 39, n. 2, p. 155-64, Jun. 2007.

DIABETES CONTROL AND COMPLICATIONS TRIAL (DCCT). Research Group: The effect of intensive treatment of Diabetes on the development and progression of the longterm complications in insulin-dependent diabetes mellitus. New England Journal of Medicine, Andover, v. 329, n. 14, p. 977-986, Sep. 1993.

DÍEZ, J. M.; ALONSO, J. L. I.; GONZÁLEZ-MORO, J. M. R.; RAMOS, P. L.; CANO, J. M. B.; PARÍS, J. M. Quality of life with chronic obstructive pulmonary disease: the influence of level of patient care. Archivos de Bronconeumologia, Barcelona, v. 40, n. 10, p. 431-7, Oct. 2004.

DISABKIDS. Pilot test manual. Leiden, 2002.

Translation and validation procedure. Guidelines and documentation form. Leiden, 2004.

DOMINGUES, L.; CRUZ, E. Adaptação cultural e contributo para a validação da escala Patient Global Impression of Change. iFisioline, Setúbal, v. 2, n. 1, p. 31-7, 2011.

DORR, D. A.; WILCOX, A.; BURNS, C.; BRUNKER, C. P.; NARUS, S. P.; CALYTON, P. D. Implementing a multidisease chronic care model in primary care using people and technology. Disease management, Larchmont, v. 9, n. 1, p. 1-15, Feb. 2006. 
DUARTE, P. S.; MIYAZAKI, M. C. O. S.; CICONELLI, R. M.; SESSO, R. Tradução e adaptação cultural do instrumento de avaliação de qualidade de vida para pacientes renais crônicos (KDQOL-SF TM). Revista da Associação Médica Brasileira, São Paulo, v. 49, n. 4, p. 375-81, 2003.

ECHEVARRÍA-GUANILO, M. E.; ROSSI, L. A.; DANTAS, R. A.; SANTOS, C. B. Crosscultural adaptation of the Burns Specific Pain Anxiety Scale - BSPAS to be used with Brazilian burned patients. Revista Latino-Americana de Enfermagem, Ribeirão Preto, v. 14, n. 4, p. 526-533, July/Aug. 2006.

ESPERIDIÃO, M. Trad LAB. Avaliação de satisfação de usuários. Ciência \& Saúde Coletiva, Rio de Janeiro, v. 10, p. 303-12, 2005. Suplemento 0.

FABRÍCIO-WEHBE, S. C. C.; SCHIAVETO, F. V.; VENDRUSCULO, T. R. P.; HAAS, V. J.; DANTAS, R. A. S.; RODRIGUES, R. A. P. Cross-cultural adaptation and validity of the "Edmonton Frail Scale - EFS" in a Brazilian elderly sample. Revista Latino-Americana de Enfermagem, Ribeirão Preto, v. 17, n. 6, p. 1043-1049, Nov./Dec. 2009.

FACHADO, A. A.; MARTINEZ, A. M.; VILLALVA, C. M.; PEREIRA, M. G. Adaptação cultural e validação da versão portuguesa Questionário Medical Outcomes Study Social Support Survey (MOS-SSS). Acta Médica Portuguesa, Lisboa, v. 20, n. 6, p. 525-533, nov./dez. 2007.

FARIA, A. P. S.; BELLATO, R. A compreensão do fenômeno condição crônica por diabetes mellitus a partir da experiência de adoecimento. Revista Eletrônica de Enfermagem, Goiânia, v. 12, n. 3, p. 520-527, 2010. Disponível em:

<http://www.fen.ufg.br/revista/v12/n3/v12n3a15.htm>. Acesso em: 21 nov. 2012.

FAYERS, P. M.; MACHIN, D. Scores and measurements: validity, reliability, and sensitivity. In: Quality of Life: The assesment, analysis and interpretation. New York: John Wiley \& Sons, 2007. Cap. 3, p. 77-108.

FEGADOLLI, C.; REIS, R. A.; MARTINS, S. T. A.; BULLINGER, M.; SANTOS, C. B. S. Adaptação do módulo genérico DISABKIDS ${ }^{\circ}$ para crianças e adolescentes brasileiros com condições crônicas. Revista Brasileira de Saúde Materno Infantil, Recife, v. 10, n. 1, p. 95-105, jan./mar. 2010.

FERREIRA, E.; DANTAS, R. A.; ROSSI, L. A.; CIOL, M. A. The cultural adaptation and validation of the "Burns Specific Health Scale-Revised" (BSHS-R): version for Brazilian burn victims. Burns, Guildford, v. 34, n. 7, p. 994-1001, Mar. 2008. 
FERRER, M.; ALONSO, J.; PRIETO, L.; PLAZA, V.; MONSÓ, E.; MARRADES, R.; AGUAR, M. C.; KHALAF, A.; ANTÓ, J. M. Validity and reability of the St George's Respiratory Questionnaire after adaptation to a different language and culture: the Spanish example. European Respiratory Journal, Lausanne, v. 9, n. 6, p. 1160-6, Jun. 1996.

FERRI, C.P.; MARSDEN, J.; ARAUJO, M.; LARANJEIRA, R. R.; GOSSOP, M. Validity and reliability of the Severity of Dependence Scale (SDS) in a Brazilian sample of drug users. Drug and Alcohol Review, Abingdon, v. 19, n. 4, p. 451-5, Dec. 2000.

FLEMING, B.; SILVER, A.; OCEPEK-WELIKSON, K.; KELLER, D. The relationship between organizational systems and clinical quality in diabetes care. American Journal of Managed Care, Old Bridge, v. 10, n. 12, p. 934-44, Dec. 2004.

FONTENELE, A. C. Avaliação do programa nacional de atenção à hipertensão e diabetes: satisfação dos usuários de uma unidade básica de saúde em Caxias-MA. Cadernos de Pesquisa, São Luís, v. 19, n. 1, p. 81-7, jan./abr. 2012.

FREESE, E.; FONTBONNE, A. Transição epidemiológica comparada: modernidade, precariedade e vulnerabilidade. In: FREESE, E. Epidemiologia, políticas e determinantes das doenças crônicas não transmissíveis no Brasil. Recife: Ed. Universitária da UFPE, 2006. Cap. 1, p. 17-46.

FRY, C.; RUMBOLD, G.; LINTZERIS, N. The blood-borne virus transmission assessment questionnaire: administration and procedures manual. Melbourne: Turning Point Alcohol and Drug Centre, 1998.

GARCÍA, K. S. L.; COSTA JUNIOR, M. L. Conduta anti-social e consumo de álcool em adolescentes escolares. Revista Latino-Americana de Enfermagem, Ribeirão Preto, v. 16, n. 2, p. 299-305, mar./abr. 2008.

GARDETE-CORREIA, L.; BOAVIDA, J. M.; RAPOSO, J. F.; MESQUITA, A. C.; FONA, C.; CARVALHO, R.; MASSANO-CARDOSO, S. First diabetes prevalence study in Portugal: PREVADIAB study. Diabetic Medicine, London, v. 27, n. 8, p. 879-881, Aug. 2010.

GEISINGER, K. F. Cross-cultural normative assessment: translation e adaptation issues influencing the normative interpretation of assessment instruments. Psychological Assessment, Washington, v. 6, n. 4, p. 304-312, Dec. 1994. 
GHISI, G. L. M.; LEITE, C. M.; DURIEUX, A.; SCHENKEL, I. C.; ASSUMPÇÃO, M. S.; BARROS, M. M.; TAIVA, D.; ANDRADE, A.; BENETTI, M. MELO, G. L. Validação para o português do Maugerl CaRdiac preventiOn-Questionnaire (MICRO-Q). Arquivos Brasileiros de Cardiologia, São Paulo, v. 94, n. 3, p. 394-400, mar. 2010.

GILMER, T. P.; O'CONNOR, P. J. Cost effectiveness of diabetes mellitus management programs: a health plan perspective. Disease Management \& Health Outcomes, Pennsylvania, v. 11, n. 7, p. 439-53, 2003.

GILMER, T. P.; O'CONNOR, P. J.; RUSH, W. A.; CRAIN, A. L.; WHITEBIRD, R. R.; HANSON, A. M.; SOLBERG, L. I. Impact of office systems and improvement strategies on costs of care for adults with diabetes. Diabetes Care, Alexandria, v. 29, n. 6, p. 1242-8, Jun. 2006.

GLASGOW, R. E.; WAGNER, E. H.; KAPLAN, R. M.; VINICOR, F.; SMITH, L.; NORMAN, J. If diabetes is a public health problem, why not treat it as one? A population-based approach to chronic illness. Annals of Behavioral Medicine, Milwaukee, v. 21, n. 2, p. 159-170, spring 1999.

GLASGOW, R. E.; WAGNER, E. H.; SCHAEFER, J.; MAHONEY, L. D.; REID, R. J.; GREENE, S. M. Development and validation of the Patient Assessment of Chronic Illness Care (PACIC). Medical Care, Philadelphia, v. 43, n. 5, p. 436-44, May $2005 a$.

GLASGOW, R. E.; WHITESIDES, H.; NELSON, C. C.; KING, D. K. Use of the Patient Assessment of Chronic Illness Care (PACIC) with Diabetic Patients. Diabetes Care, Alexandria, v. 28, n. 11, p. 2655-61, Nov. 2005 b.

GOETZEL, R. Z.; OZMINKOWSKI, R. J.; VILLAGRA, V. G.; DUFFY, J. Return on investment in disease management: a review. Health Care Financing Review, Washington, v. 26, n. 4, p. 1-19, summer 2005.

GOMUTBUTRA, P.; ARAMRAT, A.; SATTAPANSRI, W.; CHUTIMA, S.; TOOPRAKAI, D.; SAKARINKUL, P.; SANGKHASILAPIN, Y. The reliability and validity of Thai version of Assessment of Chronic Illness Care (ACIC). Journal of the Medical Association of Thailand, Bangkok, v. 95, n. 8, p. 1105-13, Aug. 2012.

GOSSOP, M.; BEST, D.; MARSDEN, J.; STRANG, J. (1997). Test-retest reliability of the Severity of Dependence Scale. Addiction, London, v. 92, n. 3, p. 353-4, Mar. 1997. 
GOSSOP, M.; DARKE, S.; GRIFFITHS, P.; HANDO, J.; POWIS, B.; HALL, W.; STRANG, J. The Severity of Dependence Scale (SDS): psychometric properties of the SDS in English and Australian samples of heroin, cocaine and amphetamine users.

Addiction, London, v. 90, n. 5, p. 607-614, May. 1995.

GOULART, F. A. A. Doenças crônicas não transmissíveis: estratégias de controle e desafios para os sistemas de saúde. Washington: OPAS; OMS, 2011.

GOUVEIA, M. Os custos e carga da Diabetes Mellitus tipo 2 em Portugal. Alert Life Science Computing, Vila Nova de Gaia, 14 Nov. 2012. Disponível em:

<http://www.alert-online.com/pt/news/health-portal/\%E2\%80\%9Cos-custos-e-cargada-diabetes-mellitus-tipo-2-em-portugal\%E2\%80\%9D>. Acesso em: 19 nov. 2012.

GRANT, J. S.; DAVIS, L. L. Selection and use of content experts for instrument development. Research in Nursing and Health, v. 20, n. 3, p. 269-274, Jun. 1997.

GROUP HEALTH RESEARCH INSTITUTE (GHRI). About Group Health Research Institute. Seattle, 2012. Disponível em:

<http://www.grouphealthresearch.org/aboutus/aboutghri.html>. Acesso em: 17 ago. 2011.

GUIDONI, C. M.; OLIVEIRA, C. M. X.; FREITAS, O.; PEREIRA, L. R. L. Assistência ao diabetes no diabetes no Sistema Único de Saúde: análise do modelo atual. Brazilian Journal of Pharmaceutical Sciences, São Paulo, v. 45, n. 1, p. 37-48, jan./mar. 2009.

GUILLEMIN, F. Cross-cultural adaptation and validation of health status measures.

Scandinavian Journal of Rheumatology, Stockholm, v. 24, n. 2, p. 61-3, 1995.

GUILLEMIN, F.; BOMBARDIER, C.; BEATON, D. E. Cross-cultural adaptation of health related quality of life measures: literature review and proposed guidelines. Journal of Clinical Epidemiology, New York, v. 46, n. 12, p. 1417-1432, Dec. 1993.

HAM, C. Developing integrated care in the UK: adapting lessons from Kaiser. Birmingham: Health Services Management Centre, 2006.

HAMBLETON, R. K. Issues, designs, and technical guidelines for adapting test into multiple languages and cultures. In: HAMBLETON, R. K.; MERENDA, P. F.; SPIELBERGER, C. D. Adapting Educational and Psychological Tests for CrossCultural Assessment. Mahwah: Lawrence Erlbaum Associates, 2005. Cap. 1, p. 33-8. 
HAMBLETON, R. K.; PATSULA, L. Adaptation tests for use in multiple languages and culture. Social Indicators Research, Dordrecht, v. 45, n. 1/3, p. 153-171, Nov. 1998.

HARRIS, M. F.; ZWAR, N. A. Care of patients with chronic disease: the challenge for general practice. Care of patients with chronic disease: the challenge for general practice. Medical journal of Australia, Sydney, v. 187, n. 2, p. 104-7, 2007.

HARWELL, T. S.; MCDOWALL, J. M.; GOHDES, H.; HENGERSON, S. D.; MONTANA DIABETES HEALTH CENTER TEAM. Measuring and improving preventive care for patients with diabetes in primary health centers. American Journal of Medical Quality, Baltimore, v. 17, n. 5, p. 179-84, Sep./Oct. 2002.

HAYS, R. D.; KALLICH, J. D.; MAPES, D. L.; COONS, S. J.; AMIN, N.; CARTER, W. B.; KAMBERG, C. Kidney disease quality of life short form (KDQOL-SFTM), version 1.3: a manual for use and scoring. Santa Monica: RAND, P-7994, 1997.

HERDMAN, M.; FOX-RUSHBY, J.; BADIA, X. "Equivalence" and the translation and adaptation of health-related quality of life questionnaires. Quality of Life Research, Dordrecht, v. 6, n. 3, p. 237-247, Apr. 1997.

A model of equivalence in the cultural adaptation of HRQoL instruments: the universalist approach. Quality of Life Research, Dordrecht, v. 7, n. 4, p. 323-335, May 1998.

HIBBARD, J. H. Engaging health care consumers to improve the quality of care. Medical Care, Philadelphia, v. 41, n. 1, p. 61-70, Jan. 2003. Supplement 1.

HILL, M. M.; HILL, A. Investigação por Questionário. Lisboa: Edições Sílabo, 2000.

HISSA, M. N.; HISSA, A. S. R.; BRUIN, V. M. S. Tratamento do diabetes mellitus tipo 1 com bomba de infusão subcutânea contínua de insulina e insulina lispro. Arquivos Brasileiros de Endocrinologia e Metabologia, São Paulo, v. 45, n. 5, p. 487-93. Oct. 2001.

HUBLEY, A. M.; PALEPU, A. Injection Drug User Quality of Life Scale (IDUQOL): findings from a content validation study. Health and Quality of Life Outcomes, London, v. 5, p. 46-58, Jul. 2007.

HUNG, D. Y.; RUNDALL, T. G.; CRABTREE, B. F.; TALLIA, A. F.; COHEN, D. J.; HALPIN, H. $A$. Influence of primary care practice and provider attributes on preventive service delivery. American Journal of Preventive Medicine, New York, v. 30, n. 5, p. 413422, May. 2006. 
IMADA, T. C. M. L.; SOUZA, M. V. M. L.; BIFFI, R. G. Adaptação e validação da Family Dynamics Measure II para familiares de mulheres com câncer de mama. Psicologia Teoria e Pesquisa, Brasília, DF, v. 26, n. 3, p. 557-564, jul./set. 2010.

IMPROVING CHRONIC ILLNESS CARE (ICIC). Our approach. c2012. Disponível em: <http://www.improvingchroniccare.org/>. Acesso em: 17 set. 2012.

INSTITUTE OF MEDICINE. Committee on Quality of Health Care in America. Crossing the quality chasm: a new health system for the 21st century. Washington: National Academy Press, 2001.

INSTITUTO BRASILEIRO DE GEOGRAFIA E ESTATÍSTICA (IBGE). Censo 2010. 2011. Rio de Janeiro. Disponível em: <http://www.ibge.gov.br/home/estatistica/populacao/>. Acesso em: 12 jun. 2011.

INTERNATIONAL DIABETES FEDERATION (IDF). Diabetes Atlas. 2012 Update. 5th ed. Brussels: IDF, 2012. Disponível em: <http://www.idf.org/diabetes-atlas-2012-updateout-now>. Acesso em: 3 nov. 2012.

ISAAC, M.; JANCA, A.; SARTORIUS, N. ICD-10 Symptom Glossary for Mental Disorders. Geneva: World Health Organization, 1994.

JANCA, A.; USTUN, T. B.; VAN DRIMMELEN, J.; DITTMANN, V.; ISAAC, M. ICD-10 Symptom Checklist for Mental Disorders. Version 1.1. Geneva: World Health Organization, 1994.

JORGE, M. R. Adaptação transcultural de instrumentos de pesquisa em saúde mental. In: GORESTEIN, C.; ANDRADE, L. H. S.; ZUARDI, A.W. Escalas de avaliação clínica em psiquiatria e psicofarmacologia. 2. ed. São Paulo: Leitura Médica, 2008. Cap. 6, p. 53-58.

KAGEYAMA, E. R. O.; YOGI, M.; SERA, C. T. N.; YOGI, L. S.; PEDRINELLI, A.; CAMARGO, O. P. Validação da versão para a língua portuguesa do questionário de Medida Funcional para Amputados (Functional Measure for Amputees Questionnaire).

Fisioterapia e Pesquisa, São Paulo, v. 15, n. 2, p. 164-171, abr./jun. 2008.

KAHN, K. L.; MACLEAN, C. H.; LIU, H.; RUBENSTEIN, L. Z.; WONG, A. L.; HARKER, J. O.; CHEN, W. P.; FITZPATRICK, D. M.; BULPITT, K. J.; TRAINA, S. B.; MITTMAN, B. S.; HAHN, B. H.; PAULUS, H. E. The complexity of care for patients with rheumatoid arthritis: metrics for better understanding chronic disease care. Medical Care, Philadelphia v. 45, n. 1, p. 55-65, Jan. 2007. 
KERLINGER, F. N. Metodologia da pesquisa em ciências sociais. São Paulo: Editora Pedagógica e Universitária, 1979.

KIMURA, M. Tradução para o português e validação do "Quality of life index" de Ferrans e Powers. 1999. 143 f. Tese (Livre-Docência) - Escola de Enfermagem, Universidade de São Paulo, São Paulo, 1999.

LA SCALA, C. S. K.; NASPITZ, C. K.; SOLÉ, D. Adaptação e validação do PAQLQ-A. Jornal de Pediatria, Rio de Janeiro, v. 81, n. 1, p. 54-60, jan./fev. 2005.

LANDIS, S.; SCHWARZ, M.; CURRAN, D. North Carolina family medicine residency programs' diabetes learning collaborative. Family Medicine, Kansas, v. 38, n. 3, p. 190-195, Mar. 2006.

LANDON, B. E.; WILSON, I. B.; MCINNES, K.; LANDRUM, M. B.; HIRSCHHORN, L.; MARSDEN, P. V.; GUSTAFSON, D.; CLEARY, P. D. Effects of quality improvement collaborative on the outcome of care of patients with HIV infection: the EQHIV study. Annals of Internal Medicine, Philadelphia v. 140, n. 11, p. 887-96, Jun. 2004.

LEITE, S. A. O.; COSTA, P. A. B.; GUSE, C.; DOROCIAKI, J. G.; TEODOROVICZ, R.; MARTINATTO, J. S.; SILVEIRA, M. C.; NICLEWICZ, E. A. Assessment of the impact of Staged Diabetes Management in a private health system in Curitiba, Brazil. Diabetes Research and Clinical Practice, v. 50, p. 54, 2000. Supplement 1.

LEYKUM, L. K.; PALMER, R.; LANHAM, H.; JORDAN, M.; MCDANIEL, R. R.; NOËL, P. H.; PARCHMAN, M. Reciprocal learning and chronic care model implementation in primary care: results from a new scale of learning in primary care. BMC Health Services Research, Chicago, v. 11, p. 44-50, Feb. 2011.

LI, R.; SIMON, J.; BODENHEIMER, T.; GILLIES, R. R.; CASALINO, L.; SCHMITTDIEL, J.; SHORTELL, S. M. Organizational factors affecting the adoption of diabetes care management processes in physician organizations. Diabetes Care, Alexandria, v. 27, n. 10, p. 2312-16, Oct. 2004.

LIN, M.; MARSTELLER, J. A.; SHORTELL, S.; MENDEL, P.; PEARSON, M. L.; ROSEN, M.; $W U, S$. Motivation to improve chronic disease care in three quality improvement collaboratives. Health Care Management Review, Germantown, v. 30, n. 2, p. 13956, Apr./Jun. 2005. 
LOZANO, P.; FINKELSTEIN, J. A.; CAREY, V. J.; WAGNER, E. H.; INUI, T. S.; FUHLBRIGGE, A. L.; SOUMERAI, S. B.; SULLIVAN, S. D.; WEISS, S.T.; WEISS, K. B. A multisite randomized trial of the effects of physician education and organizational change in chronic asthma care: health outcomes of the pediatric asthma care patient outcomes research team II study. Archives of Pediatrics and Adolescent Medicine, Chicago, v. 158, n. 9, p. 875-83, Sep. 2004.

MALERBI, D. A.; FRANCO, L. J. Multicenter study of prevalence of diabetes mellitus and impaired glucose tolerance in the urban Brazilian population aged 30-69 $\mathrm{Yr}$. Diabetes Care, Alexandria, v. 15, n. 11, p. 1509-1516, Nov. 1992.

MANEESRIWONGUL, W.; DIXON, J. K. Instrument translation process: a methods review. Journal of Advanced Nursing, Oxford, v. 48, n. 2, p. 175-186, Oct. 2004.

MANGIONE-SMITH, R.; SCHONLAU, M.; CHAN, K. S.; KEESEY, J. W.; ROSEN, M.; LOUIS, T. A.; KEELER, E. D. Measuring the effectiveness of a collaborative for quality improvement in pediatric asthma care: does implementing the chronic care model improve processes and outcomes of care? Ambulatory Pediatrics, New York, v. 5, n. 2, p. 75-82, Mar./Apr. 2005.

MARCELINO, D. B.; CARVALHO, M. D. B. Reflexões sobre o diabetes tipo 1 e sua relação com o emocional. Psicologia: Reflexão e Crítica, Porto Alegre, v. 18, n. 1, p. 72-77, jan./abr. 2005.

MASTROPIETRO, A. P.; OLIVEIRA, E. A.; SANTOS, M. A.; VOLTARELLI, J. C. Functional assessment of cancer therapy bone marrow transplantation: tradução e validação.

Revista de Saúde Pública, São Paulo, v. 41, n. 2, p. 260-268, Apr. 2007.

MATIAS, S. I. M. Tradução e adaptação cultural do NECK and UPPER LIMB INDEX para a língua portuguesa. 2010. 175 f. Dissertação (Mestrado) - Faculdade de Motricidade Humana, Universidade Técnica de Lisboa, Lisboa, 2010.

MENDES, E. V. As redes de atenção à saúde. Ciência \& Saúde Coletiva, Rio de Janeiro, v. 15, n. 5, p. 2297-2305, ago. 2010.

Os modelos de atenção à saúde. In: As redes de atenção à saúde. Brasília, DF: OPAS, 2011. Cap. 3, p. 209-291.

O modelo de atenção às condições crônicas na ESF. In: O cuidado das condições crônicas na atenção primária à saúde: o imperativo da consolidação da estratégia da saúde da família. Brasília, DF: OPAS, 2012. Cap. 5, p. 139-176. 
MEREDITH, L. S.; MENDEL, P.; PEARSON, L.; WU, S. Y.; JOYCE, G. F.; STRAUS, J. B.; RYAN, G.; KEELER, E.; UNÜTZER, J. Implementation and maintenance of quality improvement for treating depression in primary care. Psychiatric Services, Washington, v. 57, n. 1, p. 48-55, Jan. 2006.

MCCULLOCH, D. K.; PRICE, M. J.; HINDMARSH, M.; WAGNER, E. A population-based approach to diabetes management in a primary care setting : early results and lessons learned. Effective Clinical Practice, Philadelphia, v. 1, n. 1, p. 12-22, Aug./Sep. 1998.

MCGILTON, K. Development and psychometric evaluation of supportive leadership scales. Canadian Journal of Nursing Research, Montreal, v. 35, n. 4, p. 72-86, Dec. 2003.

MCGLYNN, E. A. An evidence-based national quality measurement and reporting system. Medical Care, Philadelphia, v. 41, n. 1, p. 8-15, Jan. 2003. Supplement 1.

MCLELLAN, A. T.; LUBORSKY, L.; WOODY, G. E.; O'BRIEN, C. P. An improved diagnostic evaluation instrument for substance abuse patients. The Addiction Severity Index.

Journal of Nervous and Mental Disease, Baltimore, v. 168, n. 1, p. 26-33, Jan. 1980.

MORAES, S. A.; FREITAS, I. C. M.; GIMENO, S. G. A.; MONDINI, L. Prevalência de diabetes mellitus e identificação de fatores associados em adultos residentes em área urbana de Ribeirão Preto, São Paulo, Brasil, 2006: Projeto OBEDIARP. Cadernos de Saúde Pública, Rio de Janeiro, v. 26, n. 5, p. 929-941, maio 2010.

MURPHY, B.; HERRMAN, H.; HAWTHORNE, G.; PINZONE, T.; EVERT, H. Australian WHOQoL instruments: user's manual and interpretation guide. Melbourne: Australian WHOQoL Field Study Centre, 2000.

NELSON, K.; GARCIA, R. E.; BROWN, J.; MANGIONE, C. M.; KELLER, E.; CRETIN, S. Do patient consent provisions affect participation rates in quality improvement studies: data from the improving chronic illness care evaluation. Medical Care, Philadelphia, v. 40, n. 4 , p. $283-8,2002$.

NEVES, H.; SILVA, A.; MARQUES, P. Tradução e adaptação cultural da escala de confusão de NEECHAM. Revista de Enfermagem Referência, Coimbra, v. 3, n. 3, p. 105-112, mar. 2011. 
NUTTING, P. A.; DICKINSON, W. P.; DICKINSON, L. M.; CANDACE, C. C.; KING, D. K.; CRABTREE, B. F.; GLASGOW, R. E. Use of chronic care model elements is associated with higher-quality care for diabetes. Annals of Family Medicine, Leawood, v. 5, n. 1, p. 14-20, Jan./Feb. 2007.

ORGANIZAÇÃO PAN-AMERICANA DE SAÚdE (OPAS). Saúde nas Américas. Washington, 2007. (Publicação Cientifica e Técnica, 622).

Linhas de cuidado: hipertensão arterial e diabetes. Brasília, DF, 2010.

PACE, A. E. et al. O conhecimento sobre diabetes mellitus no processo de autocuidado. Revista Latino-Americana de Enfermagem, Ribeirão Preto, v. 14, n. 5, p. 312-319, set./out. 2006.

PAIM, J.; TRAVASSOS, C.; ALMEIDA, C.; BAHIA, L.; MACINKO, J. O sistema de saúde brasileiro: história, avanços e desafios. Lancet, London, v. 377, n. 9779, p. 1778-1797, May. 2011.

PAIVA, D. C. P.; BERSUSA, A. A. S.; ESCUDER, M. M. L. Avaliação da assistência ao paciente com diabetes e/ou hipertensão pelo Programa Saúde da Família do Município de Francisco Morato. Cadernos de Saúde Pública, Rio de Janeiro, v. 22, n. 2, p. 377-85, jan./fev. 2006.

PAIVA, P. T. A.; WAJNMAN, S. Das causas às consequências econômicas da transição demográfica. Revista Brasileira de Estudos Populacionais, São Paulo, v. 22, n. 2, p. 303-322, jul./dez. 2005.

PATEL, N. K.; PARCHMAN, M. L. The chronic care model and exercise discussions during primary care diabetes encounters. Journal of the American Board of Family Medicine, Lexington, v. 24, n. 1, p. 26-32, Jan./Feb. 2011.

PEDHAZUR, E. J.; SCHMELKIN, L. P. Measurement, design, and analysis: an integrated approach. Hillsdale: Lawrence Erlbaum, 1991.

PELEGRINO, F. M. Adaptação cultural e validação do instrumento “Duke Anticoagulation Satisfaction Scale" (DASS): versão para brasileiros em uso de anticoagulação. 2009. 168 f. Dissertação (Mestrado) - Escola de Enfermagem de Ribeirão Preto, Universidade de São Paulo, Ribeirão Preto, 2009. 
PÉRES, D. S.; SANTOS, M. A.; ZANETTI, M. L.; FERRONATO, A. A. Dificuldades dos pacientes diabéticos para o controle da doença: sentimentos e comportamentos. Revista Latino-Americana de Enfermagem, Ribeirão Preto, v. 15, n. 6, p. 1105-12, dez. 2007.

PETERS-KLIMM, F.; MÜLLER-TASCHT, T.; SCHELLBERG, D.; GENSICHEN, J.; MUTH, C.; HERZOG, W.; SZECSENYI, J. Rationale, design and conduct of a randomised controlled trial evaluating a primary care-based complex intervention to improve the quality of life of heart failure patients: HICMAN (Heidelberg Integrated Case Management).

BMC Cardiovacular Disorders, London, v. 23, n. 7, p. 1-8, Aug. 2007.

PEYROT, M.; RUBIN, R. R.; LAURITZEN, T.; SNOEK, F. J.; MATTHEWS, D. R.; SKOVLUND, S. E. Psychosocial problems and barriers to improved diabetes management: results of the Cross-National Diabetes Attitudes, Wishes and Needs (DAWN) Study. Diabetic Medicine, Chichester, v. 22, n. 10, p. 1379-85, Oct. 2005.

PINTO, H. A. Linhas de cuidado na Bahia: um conceito em viva produção. Revista Baiana de Saúde Pública, Salvador, v. 33, n. 1, p. 22-34, jan./mar. 2009.

POLIT, D. F.; BECK, C. T. Nursing research: methods, appraisal and utilization. 6th ed. Philadelphia: Lippincott Williams \& Wilkins, 2006 a.

The content validity index: are you sure you know what's being reported? Critique and recommendations. Research in Nursing and Health, New York, v. 29, n. 5, p. 489-97, Oct. 2006b.

PORTUGAL. Diabetes: factos e números 2011: relatório anual do Observatório Nacional da Diabetes. 3. ed. Lisboa: Sociedade Portuguesa de Diabetes (SPD), 2011.

QUEIROZ, F. A.; PACE, A. E.; SANTOS, C. B. Adaptação cultural e validação do instrumento Diabetes - 39 (D-39): versão para brasileiros com diabetes mellitus tipo 2 - fase1. Revista Latino-Americana de Enfermagem, Ribeirão Preto, v. 17, n. 5, p. 708-715, set./out. 2009.

RAND HEALTH. Improving chronic illness care evaluation: Rand Health Project. 2008. Disponível em: <http://www.rand.org/health/projects $>$. Acesso em: 26 out. 2012. 
REIS, R. A. Módulo específico de Avaliação de Qualidade de Vida Relacionada à Saúde para crianças e adolescentes que vivem com deficiência auditiva - ViDA. 2008. 133 f. Tese (Doutorado em Enfermagem em Saúde Pública) - Escola de Enfermagem de Ribeirão Preto, Universidade de São Paulo, Ribeirão Preto, 2009.

RIBEIRÃO PRETO. Prefeitura Municipal de Ribeirão Preto. 2011. Disponível em: <http://www.ribeiraopreto.sp.gov.br>. Acesso em: 7 ago. 2011.

RIBEIRO, S. M. S. Adaptação e validação do WHODAS 2.0 para a população portuguesa. 2010. 100 f. Dissertação (Mestrado) - Escola Superior de Saúde, Universidade de Aveiro, Aveiro, 2010.

RICK, J.; ROWE, K.; HANN, M.; SIBBALD, B.; REEVES, D.; ROLAND, M.; BOWER, P. Psychometric properties of the patient assessment of chronic illness care measure: acceptability, reliability and validity in United Kingdom patients with long-term conditions. BMC Health Services Research, Chicago, v. 12, n. 1, p. 293-318, Aug. 2012.

ROCHE, N. Quality of care in chronic obstructive pulmonary disease. Revue des Maladies Respiratoires, Paris, v. 23, n. 3, p. 44-56, 2006. Supplement 3.

RODRIGUES, F. F. L.; ZANETTI, M. L.; SANTOS, M. A.; MARTINS, T. A.; SOUSA, V. D.; TEIXEIRA, C. R. S. Conhecimento e atitudes: componentes para a educação em diabetes. Revista Latino-Americana de Enfermagem, Ribeirão Preto, v. 17, n. 4, p. 468-473, jul./ago. 2009.

ROSEMANN, T.; LAUX, G.; SZECSENYI, J.; GROL, R. The Chronic Care Model: congruency and predictors among primary care patients with osteoarthritis. Quality \& Safety in Health Care, London, v. 17, n. 6, p. 442-446, Dec. 2008.

ROSS, F.; HARRIS, R. Can interprofessional education make a difference in the care of people with chronic disease? Chronic Illness, Califórnia, v. 1, n. 1, p. 81-6, Mar. 2005.

ROUQUAYROL, M. Z.; GOLDBAUM, M. Epidemiologia, história natural e prevenção de doenças. In: ROUQUAYROL, M. Z; ALMEIDA FILHO, N. Epidemiologia e saúde. 6. ed. Rio de Janeiro: MEDSI, 2003. Cap. 2, p. 15-30.

RUBIO, D. M.; BERG-WEGER, M.; TEBB, S. S.; LEE, S.; RAUCH, S. Objectifying content validity: conducting a content validity study in social work research. Social Work Research, Washington, v. 27, n. 2, p. 94-104, 2003. 
SALES, C. M. D.; MOLEIRO, C. M. M.; EVANS, C.; ALVES, P. C. G. Versão Portuguesa do COREN-OM: tradução adaptação e estudo preliminar das propriedades psicométricas. Revista de Psiquiatria Clínica, São Paulo, v. 39, n. 2, p. 54-9, 2012.

SANTOS, D. M. S. S. Adaptação cultural e validação do DISABKIDS - Cystic Fibrosis Module ${ }^{\circledR}$ para mensuração da Qualidade de Vida relacionada à Saúde de crianças e adolescentes brasileiros: Fase I. 2009. 149 f. Dissertação (Mestrado) Escola de Enfermagem de Ribeirão Preto, Universidade de São Paulo, Ribeirão Preto, 2009.

SANTOS, S. R.; LACERDA, M. C. N. Fatores de satisfação e insatisfação entre os pacientes assistidos pelo SUS. Revista Brasileira de Enfermagem, Brasília, v. 52, n. 1, p. 43-53, jan./mar. 1999.

SANTOS, A. L. P.; SIMÕES, A. C. Tradução e adaptação transcultural do "Psysical Activity Scale" de Aadahal e Jorgensen. Revista Brasileira de Educação Física e Esporte, São Paulo, v. 23, n. 2, p. 143-53, abr./jun. 2009.

SARTORI, A. C.; GROSSI, S. A. A. Escala de Esperança de Herth - Instrumento adaptado e validado para a língua portuguesa. Revista da Escola de Enfermagem da USP, São Paulo, v. 42, n. 2, p. 227-232, jun. 2008.

SCHIMIDT, S.; BULLINGER, M. Current issues in cross-cultural Quality of life instrument development. Archives of Physical Medicine and Rehabilitation, Chicago, v. 84, n. 2, p. 29-34, Apr. 2003. Supplement 2.

SCHMIDT, M. I.; DUNCAN, B. B.; SILVA, G. A.; MENEZES, A. M.; MONTEIRO, C. A.; BARRETO, S. M. Chronic non communicable diseases in Brazil: burden and current challenges. Lancet, London, v. 377, n. 9781, p. 1949-1961, Jun. 2011.

SCHMITTDIEL, J. A.; SHORTELL, S. M.; RUNDALL, T. G.; BODENHEIMER, T.; SELBY, J. V. Effect of primary health care orientation on chronic care management. Annals of Family Medicine, Leawood, v. 4, n. 2, p. 117-23, Mar. 2006.

SCHMITTDIEL, J.; MOSEN, D. M.; GLASGOW, R. E.; HIBBARD, J.; REMMERS, C.; BELLOWS, J. Patient Assessment of Chronic Illness Care (PACIC) and Improved Patient-centered Outcomes for Chronic Conditions. Journal of General Internal Medicine, Philadelphia, v. 23, n. 1, p. 77-80, Jan. 2007.

SCHONLAU, M.; MANGIONE-SMITH, R.; CHAN, K. S.; KEESEY, J.; ROSEN, M.; LOUIS, T. A.; WU, S. Y.; KEELER, E. An evaluation of an adult asthma BTS collaborative and the effect of patient self-management. Annals of Family Medicine, Leawood, v. 3, n. 3, p. 200-8, May. 2005. 
SCHRAMM, J. M. A.; OLIVEIRA, A. F.; LEITE, I. C; VALENTE, J. G. V.; GADELHA, A. M. J.; PORTELA, M. C.; CAMPOS, M. R. Epidemiological transition and the study of burden of disease in Brazil. Ciência \& Saúde Coletiva, Rio de Janeiro, v. 9, n. 4, p. 897-908, out./dez. 2004.

SELEY, J. J.; WEINGER, K. The state of the science on nursing best practices for diabetes self-management. The Diabetes Educator, Thousand Oaks, v. 33, n. 4, p. 616-626, Jul./Aug. 2007.

SERRANO, P. M. Adaptação cultural da Hardiness Scale (HS). 2009. 115 f. Dissertação (Mestrado) - Escola de Enfermagem de Ribeirão Preto, Universidade de São Paulo, Ribeirão Preto, 2009.

SHAW, J. E.; SICREE, R. A.; ZIMMET, P. Z. Global estimates of the prevalence of diabetes for 2010 and 2030. Diabetes Research and Clinical Practice, Amsterdam, v. 87, n. 1, p. 4-14, Jan. 2010.

SHORTELL, S. M.; MARSTELLER, J. A.; LIN, M.; PEARSON, M. L.; WU, S. Y.; MENDEL, P.; CRETIN, S.; ROSEN, M. The role of perceived team effectiveness in improving chronic illness care. Medical Care, Philadelphia v. 42, n. 11, p. 1040-48, Nov. 2004.

SHORTELL, S. M.; O'BRIEN, J. L.; CARMAN, J. M.; FOSTER, R. W.; HUGNES, E. F.; BOERSTLER, H.; O'CONNOR, E. J. Assessing the impact of continuous quality improvement/total quality management: concept versus implementation. Health Services Research, Chicago, v. 30, n. 2, p. 377-401, Jun. 1995.

SI, D.; BAILIE, R.; CONNORS, C.; DOWDEN, M.; STEWART, A.; ROBINSON, G.; CUNNINGHAM, J.; WEERAMANTHRI, T. Assessing health centre systems for guiding improvement in diabetes care. BMC Health Services Research, London, v. 5, n. 56, p. 1-23, Aug. 2005.

SILVA, M.; RIBEIRO, J. L. P. Pediatric Oncology Quality of Life Scale - POQOLS: adaptação de um instrumento para a população portuguesa. Psicologia, Saúde \& Doenças, Lisboa, v. 9, n. 1, p. 131-41, 2008.

SILVEIRA, J. A. A.; RESENDE, H. M. P.; LUCENA FILHO, A. M.; PEREIRA, J. G.

Características da assistência à saúde a pessoas com Diabetes mellitus acompanhadas na Unidade de Saúde da Família Pedregal II, em Cuiabá, MT: reflexões para a equipe de saúde. $O$ Mundo da Saúde, São Paulo, v. 34, n. 1, p. 43-9, 2010. 
SINGH, D. Transforming chronic care: evidence about improving care for people with long-term conditions. Birmingham: University of Birmingham, Health Services Management Centre, 2005.

How can chronic disease management programs operate across care settings and providers? Policy Brief-Health Systems and Policy Analysis. Copenhagen: European Observatory on Health Systems and Policies; WHO, 2008.

SINGH, D.; HAM, C. Improving care for people with long term conditions: a review of UK and international frameworks. Birmingham: Institute of Innovation and Improvement of University of Birmingham, 2006.

SOLBERG, L. I.; CRAIN, A. L.; SPERL-HILLEN, J. M.; HROSCIKOSKI, M. C.; ENGEBRETSON, K. I.; O'CONNOR, P. J. Care quality and implementation of the chronic care model: a quantitative study. Annals of Family Medicine, Leawood, v. 4, n. 4, p. 310-16, Jul. 2006.

SPERL-HILLEN, J. M.; SOLBERG, L. I.; HROSCIKOSKI, M. C.; CRAIN, A. L.; ENGEBRETSON, K. I.; O'CONNOR, P. J. Do all components of the chronic care model contribute equally to quality improvement? Joint Commission Journal on Quality and Patient Safety, Oakbrook Terrace, v. 30, n. 6, p. 303-9, Jun. 2004.

STEURER-STEY, C.; FREI, A.; SCHMID-MOHLER, G.; MALCOLM-KOHLER, S.; ZOLLER, M.; ROSEMANN, T. The German version of the Assessment of Chronic Illness Care: instrument translation and cultural adaptation. Journal of Evaluation in Clinical Practice, London, v. 18, n. 1, p. 1-4, Feb. 2012.

STEVENS, D. P.; BOWEN, J. L.; JOHNSON, J. K.; WOODS, D. M.; PROVOST, L. P.; HOLMAN, H. R.; SIXTA, C. S.; WAGNER, E. H. A multi-institutional quality improvement initiative to transform education for chronic illness care in resident continuity practices. Journal of General Internal Medicine, Philadelphia, v. 25, p. 574-80, Sep. 2010. Supplement 4.

STROEBEL, R. J.; GLOOR, B.; FREYTAG, S.; RIEGERT-JOHNSON, D.; SMITH, S. A.; HUSCHKA, T; NAESSENS, J.; KOTTKE, T. E. Adapting the chronic care model to treat chronic illness at a free medical clinic. Journal of Health Care for the Poor and Underserved, Thousand Oaks, v. 16, n. 2, p. 286-96, May. 2005. 
SUNAERT, P.; BASTIAENS, H.; FEYEN, L.; SNAUWAERT, B.; NOBELS, F.; WENS, J.; VERMEIRE, E.; VAN ROYEN, P.; DE MAESENEER, J.; DE SUTTER, A.; WILLEMS, S. Implementation of a program for type 2 diabetes based on the Chronic Care Model in a hospital-centered health care system: "the Belgian experience". BMC Health Services Research, London, v. 9, n. 152, p. 1-14. Aug. 2009.

SUÑOL, R.; CARBONELL, J. M.; NUALART, L.; COLOMÉS, L.; GUIX, J.; BAÑERES, J.; COSTA, J.; NOFUENTES, S.; PRAT, J. Towards health care integration: the proposal of an evidence and management system-based model. Medicina Clínica, Madrid, v. 112 , n. 3, p. 97-105, 1999. Supplement 1.

TAGGART, J.; CHAN, B.; JAYASINGHE, U. W.; CHRISTL, B.; PROUDFOOT, J.; CROOKES, P.; BEILBY, J.; BLACK, D.; HARRIS, M. F. Patients Assessment of Chronic Illness Care (PACIC) in two Australian studies: structure and utility. Journal of Evaluation in Clinical Practice, London, v. 17, n. 2, p. 215-221, Apr. 2011.

THE WORLD HEALTH ORGANIZATION QUALITY OF LIFE ASSESSMENT GROUP (WHOQOL). The World Health Organization Quality of Life Assessment (WHOQOL): development and general psychometric properties. Social Science \& Medicine, Oxford, v. 46, n. 12, p. 1569-85, Jun. 1998.

TORQUATO, M. T. C. G.; MONTENEGRO JÚNIOR, R. M.; VIANA, L. A.; SOUZA, R. A.; LANNA, C. M.; LUCAS, J. C.; BIDURIN, C.; FOSS, M. C. Prevalence of diabetes mellitus and impaired glucose tolerance in the urban population aged 30-69 years in Ribeirão Preto (São Paulo), Brazil. São Paulo Medical Journal, São Paulo, v. 121, n. 6, p. 224 30, Nov. 2003.

TSAI, A. C.; MORTON, S. C.; MANGIONE, C. M.; KEELER, E. B. A meta-analysis of interventions to improve chronic illness care. American Journal of Managed Care, Old Bridge, v. 11, n. 8, p. 478-88, Aug. 2005.

UNITED KINGDOM PROSPECTIVE DIABETES STUDY GROUP (UKPDS). Intensive bloodglucose control with sulfonylureas or insulin compared with conventional treatment and risk of complications in patients with type 2 diabetes: UKPDS 33. Lancet, London, v. 352, n. 9131, p. 837-53, Sep. 1998.

VAITSMAN, J.; ANDRADE, G. R. B. Satisfação e responsividade: formas de medir a qualidade e a humanização da assistência à saúde. Ciência \& Saúde Coletiva, Rio de Janeiro, v. 10, n. 3, p. 599-613, set. 2005. 
VALADAS, S. T.; GONÇALVES, F. R.; FAÍSCA, L. Estudo de tradução, adaptação e validação do ASSIST numa amostra de estudantes universitários portugueses. Revista Portuguesa de Educação, v. 22, n. 2, p. 191-217, 2009.

VANDERBILT MEDICAL CENTER. Primary care in driver's seat: re-configured relationships in an academic setting. In: SCHOENI, P. Q. Curing the system: stories of change in chronic illness care. Washington: The National Coalition on Health Care, 2002. p. 28-31.

VARGAS, R. B.; MANGIONE, C. M.; ASCH, S.; KEESEY, J.; ROSEN, M.; SCHONLAU, M.; KEELER, E. B. Can a chronic care model collaborative reduce heart disease risk in patients with diabetes? Journal of General Internal Medicine, Philadelphia, v. 22, n. 2, p. 215-22, Feb. 2007.

WAGNER, E. H. Chronic disease management: what will it take to improve care for chronic illness? Effective Clinical Practice, Philadelphia, v. 1, n. 1, p. 2-4, Aug./Sep. 1998.

WAGNER, E. H.; AUSTIN, B. T.; DAVIS, C.; HINDMARSH, N.; SCHAEFER, J.; BONOMI, A. Improving Chronic Illness Care: translating evidence into action. Interventions that encourage people to acquire self-management skills are essencial in chronic illness care. Health Affairs, Millwood VA, v. 20, n. 6, p. 64-78, Nov./Dec. 2001.

WAGNER, E. H.; AUSTIN, B. T.; VON KORFF, M. Organizing care for patients with chronic illness. Milbank Quarterly, New York, v. 74, n. 4, p. 511-44, 1996.

WANG, A.; WOLF, M.; CARLYLE, R.; WILKERSON, J.; PORTERFIELD, D.; REAVES, J. The North Carolina experience with diabetes health disparities collaboratives. Joint Commission Journal on Quality and Patient Safety, Oakbrook Terrace, v. 30, n. 7, p. 396-404, Jul. 2004.

WENSING, M.; LIESHOURT, J. V.; JUNG, H. P.; HERMSEN, J.; ROSEMANN, T. The Patients Assessment Chronic Illness Care (PACIC) questionnaire in The Netherlands: a validation study in rural general practice. BMC Health Services Research, Chicago, v. 8, n. 182, p. 1-6, Sep. 2008.

WHOQOL GROUP. The World Health Organization Quality of Life Assessment (WHOQOL): Development and general psychometric properties. Social Science \& Medicine, Oxford, v. 46, p. 1569-85, Jun, 1988.

WILLIAMS, R. A. Women.s health content validity of the Family Medicine In-training Examination. Family Medicine, Kansas, v. 39, n. 8, p. 572-77, Sep. 2007. 
WORLD HEALTH ORGANIZATION (WHO). The innovative care for chronic conditions framework: building, blocks for action. Geneva, 2002.

Preventing chronic diseases: a vital investment. Geneva, 2005.

2008-2013 Action Plan for the Global Strategy for the Prevention and Control of Noncommunicable Diseases. Geneva, 2008. Disponível em:

<http://www.who.int/nmh/Actionplan-PC-NCD-2008.pdf > . Acesso em: 21 out. 2012. Global status report on noncommunicable diseases 2010. Geneva, 2011a.

World Health Statistics 2011. Geneva, 2011b.

Management of substance abuse: process of translation and adaptation of instruments. c2012. Disponível em:

$<$ http://www.who.int/substance_abuse/research_tools/translation/en/>. Acesso em: 17 set. 2012.

XAVIER, A. T. F.; FOSS, M. C.; MARQUES JUNIOR, W.; ONOFRE, P. T. B. N.; PACE, A. E. Adaptação cultural e validação do Neuropathy - and Foot Ulcer - Specific Quality of Life (NeuroQol) para a língua portuguesa do Brasil - Fase 1. Revista Latino-

Americana de Enfermagem, Ribeirão Preto, v. 19, n. 6, p. 1352-1361, nov./dez. 2009.

ZANETTI, A. C. G.; WIEDEMANN, G.; DANTAS, R. A. S.; HAYASHIDA, M.; AZEVEDOMARQUES, J. M.; GALERA, S. A. F. Cultural adaptation and psychometric properties of the family questionnaire in a Brazilian sample of relatives of schizophrenia outpatients. Journal of Clinical Nursing, Oxford, 2012. In press. Disponível em: <http://onlinelibrary.wiley.com/doi/10.1111/j.1365-2702.2012.04351.x/abstract>. Acesso em: 25 nov. 2012.

ZANETTI, M. L.; MIYAR OTERO, L.; BIAGGI, M. V.; SANTOS, M. A.; PÉRES, D. S.; GUIMARÃES, F. P. M. G. Satisfação do paciente diabético em seguimento em um programa de educação em diabetes. Revista Latino-Americana de Enfermagem, Ribeirão Preto, v. 15, n. 4, p. 583-89, jul./ago. 2007. 


$$
\text { - }
$$




\section{APENDICES}

APÊNDICE A - Versão Consensual em Português-Brasil 1ab (PACIC-VCPBra 1ab)

APÊNDICE B - Versão Consensual em Português-Portugal 2ab (PACIC-VCPPort 2ab)

APÊNDICE C - Carta-Convite e Manual de Orientações aos Especialistas (Brasil)

APÊNDICE D - Carta-Convite e Manual de Orientações aos Especialistas (Portugal)

APÊNDICE E - Declaração de Consentimento para Especialistas (Brasil/Portugal)

APÊNDICE F - Versão Consensual em Português-Brasil 1.0 Revisada (PACIC-VCPBra 1.0 Rev)

APÊNDICE G - Versão Consensual em Português-Portugal 2.0 Revisada (PACIC-VCPPort 2.0 Rev)

APÊNDICE H - Versão em Inglês-Brasil (PACIC-VIBra)

APÊNDICE I - Versão em Inglês-Portugal (PACIC-VIPort)

APÊNDICE J - Termo de Consentimento Livre e Esclarecido (TCLE) (Brasil)

APÊNDICE K - Termo de Consentimento Livre e Esclarecido (TCLE) (Portugal)

APÊNDICE L - Versão Pré-Teste em Português-Brasil (PACIC-VPTPBra)

APÊNDICE M - Versão Final Português-Brasil (PACIC-VFPBra)

APÊNDICE N - Versão Pré-Teste em Português-Portugal (PACIC-VPTPPort)

APÊNDICE O - Versão Final Português-Portugal (PACIC-VFPPort) 


\section{Escala para Avaliação do Paciente com relação aos Cuidados prestados à sua Doença Crônica}

\section{Cuidados prestados à sua Doença Crônica}

Manter-se saudável pode ser difícil quando você tem uma doença crônica. Nós gostaríamos de saber sobre o tipo de atenção que recebe da equipe de saúde com relação à sua condição. Esta ajuda pode incluir o (a) seu (sua) médico (a), seu (sua) enfermeiro (a) ou médico (a) assistente que trata da sua doença. Suas respostas serão mantidas confidenciais e não serão reveladas a ninguém.

Nos últimos seis meses, quando recebi cuidados em relação a minha doença crônica:

$\begin{array}{llll}\text { Quase } & \text { Geralmente } & \underline{\text { Algumas }} & \underline{\text { Não }}\end{array} \underline{\underline{\text { Vezes }}} \quad \frac{\underline{\text { do tempo }}}{\underline{\text { Sempre }}}$

7. Perguntaram-me sobre minhas idéias quando fizemos um plano de tratamento.

8. Deram-me opções sobre o tratamento para que eu pensasse a respeito.
$\square 1$
$\square 2$
$\square 3$
$\square 4$
$\square 5$

9. Perguntaram-me sobre os problemas que tenho com os remédios que tomo

$\square_{1} \quad \square_{2}$

$\square 3$

$\square_{4}$

$\square 5$

$\square_{1} \quad \square_{2} \quad \square_{3} \quad \square 4 \quad \square 5$

10. Deram-me uma lista escrita de coisas que eu deveria fazer para melhorar minha saúde.

11. Fiquei satisfeito (a) que os cuidados prestados eram bem organizados.

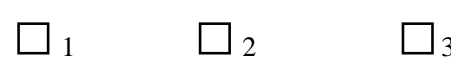

$\square 4$

$\square 5$

Mostraram-me como o que eu fazia para cuidar da minha doença influenciava minha condição.

13. Perguntaram-me sobre meus objetivos no tratamento da minha doença.

14. Ajudaram-me a estabelecer objetivos específicos para melhorar meus

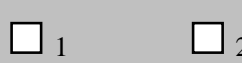

$\square 2$

$\square 3$

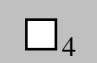

$\square 5$

$\square 1 \quad \square$

$\square 2 \square 3$

$\square 4$

$\square 5$ hábitos alimentares ou atividade física.

15. Deram-me uma cópia do meu plano de tratamento.

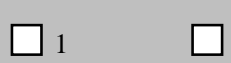

$\square 2$

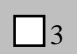

$\square 4$

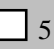

16. Encorajaram-me a frequentar grupos ou aulas específicas para ajudar a superar a minha doença crônica.

17. Perguntaram-me, diretamente ou por meio de pesquisa, sobre meus hábitos de saúde. 
Nos últimos seis meses, quando recebi cuidados em relação a minha doença crônica:

\begin{tabular}{|c|c|c|c|c|}
\hline$\frac{\text { Quase }}{\text { Nunca }}$ & $\frac{\text { Geralmente }}{\text { Não }}$ & $\frac{\text { Algumas }}{\text { Vezes }}$ & $\frac{\text { A maior parte }}{\text { do tempo }}$ & $\frac{\text { Quase }}{\text { Sempre }}$ \\
\hline
\end{tabular}

18. Tive certeza que meu médico (a) ou enfermeiro (a) considerava meus $\square 1$

$\square_{2}$

$\square 3$

$\square_{4}$

$\square 5$ valores e tradições quando eles recomendavam tratamentos para mim.

19. Ajudaram-me a fazer um plano de tratamento que eu pudesse por em prática no meu dia-a-dia.

20. Ajudaram-me a planejar com antecedência de forma que poderia cuidar da minha doença mesmo em momentos difíceis.

21. Perguntaram-me como minha doença crônica afetava minha vida.

$\square_{1} \quad \square_{2} \quad \square_{3}$
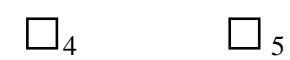
Contataram-me depois de uma consulta para verificar como as coisas estavam indo.

23. Encorajaram-me a frequentar programas na comunidade que poderiam me ajudar.

24. Encaminharam-me para um nutricionista, um educador em saúde ou um conselheiro.

25. Falaram-me como minhas consultas com outras especialidades de

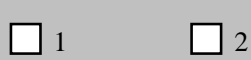

$\square 3$

$\square 4$<smiles>[Mg]</smiles>
médicos, como por exemplo oculista ou cirurgião, ajudavam no meu tratamento.

26. Perguntaram-me como minhas consultas com outros médicos $\square 1$ $\square 2$ $\square 3$ $\square 4$ estavam indo.

Pontuação das Escalas PACIC:

Ativação do Paciente

Desenvolvimento do Sistema de Cuidado / Apoio para Decisão

Estabelecimento de Metas / Adaptação

Resolução de Problemas / Aconselhamento Contextual

Seguimento / Coordenação

Média dos Itens 1-3

Média dos Itens 4-6

Média dos Itens 7-11

Média dos Itens 12-15

Média dos Itens 16-20 


\section{APÊNDICE B - Versão Consensual em Português-Portugal 2ab (PACIC-VCPPort 2ab)}

\section{Avaliação de Pacientes com Cuidados de Doença Crónica}

\section{Cuidados com a Doença Crónica}

Permanecer saudável pode ser difícil quando se é detentor de uma doença crónica. Considerando o seu estado de saúde, pretendemos indagar sobre o tipo de ajuda que recebe da equipa que lhe presta cuidados de saúde. Poderá incluir o seu médico de família, o enfermeiro que o auxilia, ou o assistente médico. As suas respostas são confidenciais e não serão divulgadas.

Quando recebi cuidados de saúde no âmbito da minha doença crónica nos últimos 6 meses, eu:

$\frac{\text { Praticamente }}{\underline{\text { Nunca }}} \quad \frac{\text { Geralmente }}{\underline{\text { Não }}} \quad \underline{\text { Por }} \quad \frac{\text { A Maioria do }}{\underline{\text { Tempo }}} \quad \frac{\underline{\text { Praticamente }}}{\underline{\text { Sempre }}}$

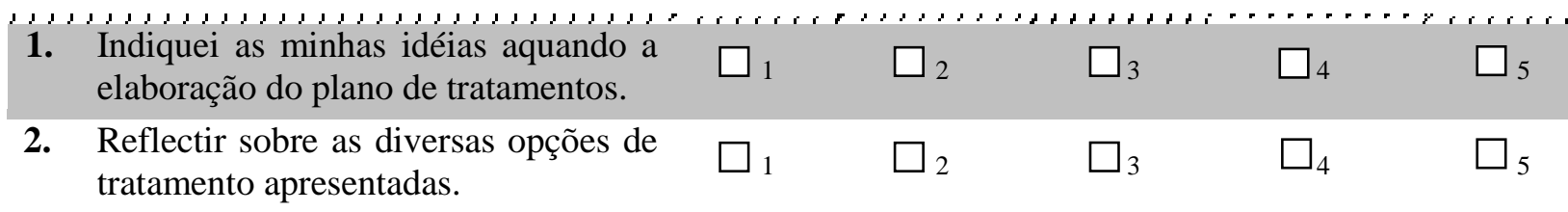
3. Falei sobre quaisquer problemas
vivenciados com a minha medicação $\square_{1} \quad \square_{2} \quad \square_{3} \quad \square 4 \quad \square 5$ ou os seus efeitos.

4. Recepcionei uma lista por escrita com as coisas que devo fazer no sentido de melhorar a minha saúde.

5. Pronunciei sobre a minha satisfação quanto à organização dos cuidados

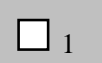
prestados.

6. Demonstrei de que forma as acções tomadas para melhorar a minha doença influenciou a minha saúde.

' 1 ' Partilhei os meus objectivos para cuidar da minha doença.

8. Aceitei ajuda na definição de objectivos específicos visando a melhoria dos meus hábitos alimentares e do exercício físico.

9. Recepcionei uma cópia dos meus tratamentos.

$\square_{1} \quad \square$

$\square_{2} \quad \square 3 \quad \square 4 \quad \square 5$

$\square 1 \quad \square 2$

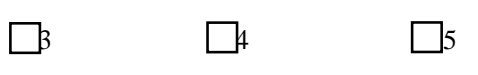

$\square_{2} \quad \square_{3} \quad \square_{4} \quad \square_{5}$

$\begin{array}{lllll}\square_{1} & \square_{2} & \square_{3} & \square_{4} & \square_{5} \\ \square_{1} & \square_{2} & \square_{4} & \square_{5}\end{array}$

11. Respondi, directamente ou por meio de um inquérito/questionário, a

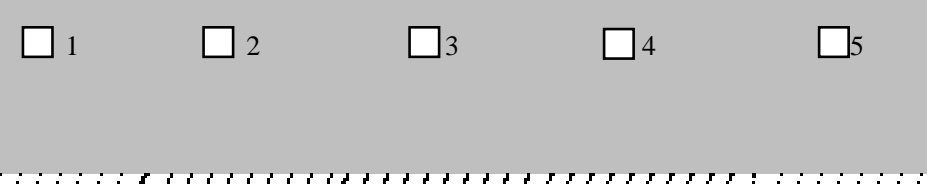
questões sobre os meus hábitos de saúde. 


\section{Quando recebi cuidados de saúde no âmbito da minha doença crónica nos últimos 6 meses, eu:}

$$
\frac{\text { Praticamente }}{\text { Nunca }} \quad \frac{\text { Geralmente }}{\text { Não }} \quad \underline{\text { Por }} \quad \frac{\text { A Maioria do }}{\text { Vempo }} \quad \frac{\text { Praticamente }}{\text { Sempre }}
$$

12. Estava certo(a) que o meu médico ou enfermeiro reflectiram sobre os meus

$\square$

$\square$ valores $\mathrm{e}$ as minhas tradições aquando a recomendação dos tratamentos.

13. Fui auxiliado na elaboração de um plano de tratamentos, passível de realizar na minha vida quotidiana.

14. Recebi ajuda para fazer um planeamento futuro, por forma a poder cuidar da minha doença, mesmo nos momentos mais difíceis.

15. Fui questionado(a) da forma como a minha doença crónica afecta a minha vida.

16. Fui contactado(a) após uma visita para saberem como as coisas estavam a correr.

17. Fui encorajado(a) para frequentar programas na comunidade que me poderiam ajudar.

18. Fui recomendado(a) a procurar um nutricionista, um educador de saúde ou a um conselheiro.

19. Fui elucidado(a) da forma como a visita a outros tipos de médicos nomeadamente, um oftalmologista, ou um cirurgião, poderão ajudar nos meus tratamentos.

20. Fui questionado(a) como as minhas visitas aos outros médicos estavam a correr.

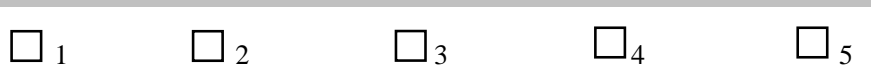

$\square_{3} \quad \square_{4} \quad \square_{5}$

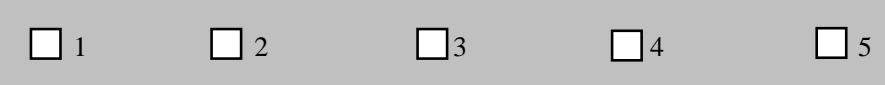

$\square_{1} \quad \square_{2} \quad \square_{3} \quad \square_{4} \quad \square_{5}$

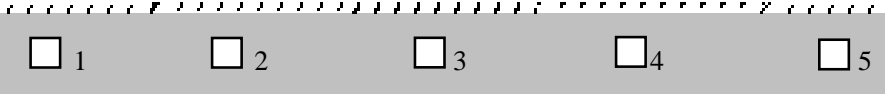

$\square 1 \quad \square 2 \quad \square 3 \quad \square 4 \quad \square 5$

$\square_{1} \quad \square_{2} \quad \square_{3} \quad \square 4 \quad \square 5$

$\square_{1} \quad \square_{2} \quad \square_{3} \quad \square_{4} \quad \square 5$
correr.

Pontuação das Escalas PACIC:

Activação do Paciente

Projecto de Sistemas de Entrega / Prática dos Projectos

Estabelecimento de Metas / Adaptação

Resolução de Problemas / Contextualização

Acompanhamento / Coordenação

Média dos Itens 1-3

Média dos Itens 4-6

Média dos Itens 7-11

Média dos Itens 12-15

Média dos Itens 16-20 
APÊNDICE C - Carta-Convite e Manual de Orientações aos Especialistas (Brasil)

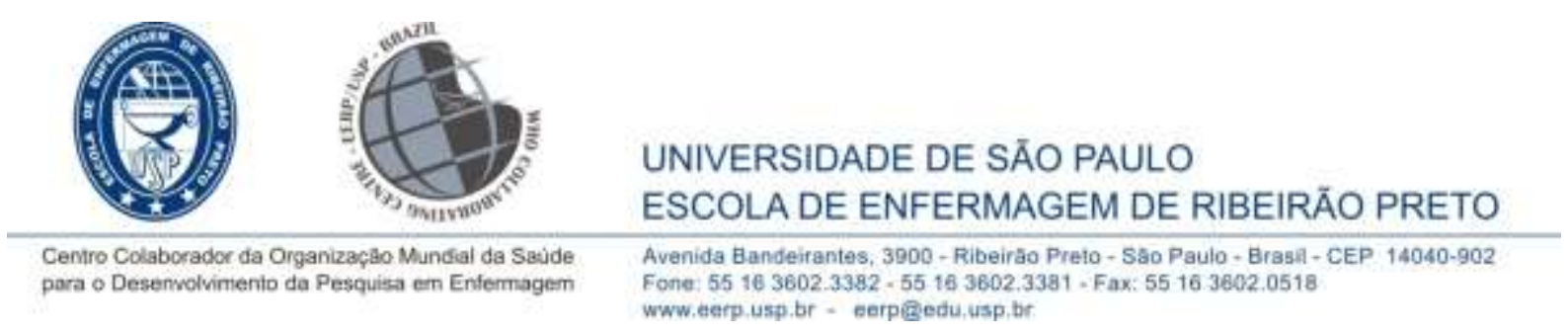

\section{CARTA-CONUITE E MANUAL DE ORIENTAÇÕES AOS ESPECIALISTAS}

Avaliação das equivalências semântica, idiomática, cultural e conceitual da versão traduzida do instrumento:

"Escala para Avaliação do Paciente com relação aos Cuidados prestados à sua Doença Crônica"

Ribeirão Preto, 26 de maío de 2011

Prezada Especialista,

Estamos desenvolvendo um estudo para Tese de Doutorado junto ao Departamento de Enfermagem Geral e Especializada da Escola de Enfermagem de Rúbeirão Preto da Universidade de São Paulo (EERPUSP), cujo objetivo é disponibitizar a versão adaptada e validada do instrumento chamado Patient Assessment of Chronic Illness Care (PACIC), para oBrasit.

Trata-se de um instrumento com 20 itens e cinco dominios, utilizado em âmbito internacional e desenvolvido originalmente por Glasgow et at. (2005)(1) na lingua inglesa, a fim de avatiar a quatidade do cuidado centratizado em pessoas com doenças crônicas. Para cada item desse instrumento são oferecidas cinco alternativas de resposta, com escore variável de 1-5. Existe apenas uma alternativa de resposta e a graduação dos itens do instrumento ocorre por escala do tipo "likert".

$\mathcal{O}$ processo de adaptação cultural adotado para $\sigma$ instrumento PACIC está sendo reatizado conforme World Health Organization - WHO 
(2012)(2), na sequencia das seguintes etapas: Tradução; Comitê de Especialistas; Retro-Tradução (Back-Transtation); Pré-Teste e Entrevista Cognitiva.

Você está sendo convidada para participar desse Comitê de Especialista nos conceitos a serem explorados, pertencentes à área prática e acadêmica, que se reatizará no día 30 de maio de 2011, às 9 horas, no laboratório III da EERP-USP; com o objetivo de realizar a avaliação das equivalências semântica, idiomática, cultural e conceitual da Versão Consensual em Português-Brasil 1ab (PACICVCPBra 1ab) do instrumento "Escala para Avaliação do Paciente com relação aos Cuidados prestados à sua Doença Crônica”.

Viemos por meio desta Carta. Convite solicitar a sua colaboração para que tal avaliação se concretize em razão de avançar no processo de adaptação cultural de um instrumento para o Brasit, a fím de disponibitizar aos profissionais que atuam junto às pessoas com doenças crônicas o seu uso para a assistêncía e pesquisa.

Dessa forma, gostariamos de contar com a sua valiosa colaboração neste estudo, participando da avaliação desse instrumento. Sua participação como Especialista neste Comitê consiste em avaliar as equivalências semântica, idiomática, cultural e conceitual dos itens do PACIC-VCPBra 1ab, considerando que:

- Equivalência semântica: destina-se ao significado das palavras, onde $\sigma$ vocabulário e a gramática podem sofrer alterações na construção das frases;

- Equivalência idiomática: refere-se às expressões coloquiais ou idiomáticas de dificil tradução, devendo ser substituidas por expressões equivalentes na cultura alvo;

- Equivalência cultural propõe-se a correspondêncía das situações equivocadas ou retratadas na versão original às vivenciadas em nosso meio/contexto cultural; 
- Equivalência conceitual: representa a coerência do item com relação ao dominio que ele pretende medir.

Você receberá uma cópía da versão original do instrumento em inglês, PACIC-VO, e uma cópía da versão consensual após as traduções, PACIC-VCPBra 1ab, a fim de que haja a possibilidade de reatizar as comparaçóes dos itens contemplados.

Nossa proposta será de realizar a leitura de cada item simultaneamente e fazer, em conjunto, a análise quanto às equivalências solicitadas. As possiveis modificações serão consideradas quando houver a concordância de, no minimo, 80\% de aprovação em consenso do total do numero de membros desse Comitê de Especiatistas.

No dia 30 de maío de 2011, após receber todas as orientações sobre os objetivos e procedimentos, bem como a forma de participação, solicitaremos a gentileza da tua assinatura no Termo de Consentimento Livre e Esclarecido para Especialistas em duas vias, de modo que seja manifestada a sua concordância.

Declaramos que o nosso encontro será gravado em áudio e $\sigma$ mesmo em midia, sendo guardada por cínco anos e inutitizada após esse periodo.

Sem mais para o momento, agradecemos toda a atenção dispensada,

\section{Doutoranda Camila Landim camilaapapila@usp.br}

\section{Profa. Dra. Carla Teixeira carlarst@eerp.usp.br}

\footnotetext{
(1) GLASGOW, R. E.; WAGNER, E. H.; SCHAEFER, J.; MAHONEY, L. D.; REID, R. J.; GREENE, S. M. Development and validation of the Patient Assessment of Chronic Illness Care (PACIC). Medical Care, Philadelphia, v. 43, n. 5, p. 436-444, 2005.

(2)WORLD HEALTH ORGANIZATION (WHO). Management of substance abuse: process of translation and adaptation of instruments. Geneva: WHO, 2012. Disponível em: <http://www.who.int/substance_abuse/research_tools/translation/en/>. Acesso em: 22 jan. 2012.
} 
APÊNDICE D - Carta-Convite e Manual de Orientações aos Especialistas (Portugal)

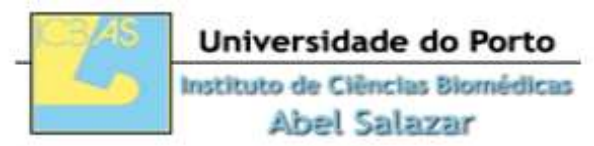

Abel Salazar

\title{
CARTA-CONUITE E MANUAL DE ORIENTAÇÕES AOS ESPECIALISTAS
}

\author{
Avaliação das equivalências semântica, idiomática, cultural e conceitual \\ da versão traduzida do instrumento: \\ "Avaliação de Pacientes com Cuidados de Doença Crónica"
}

Porto, 21 de fevereiro de 2012

Prezada Especialista,

Estamos a desenvolver um estudo para Tese de Doutoramento junto ao Departamento de Enfermagem Geral e Especializada da Escola de Enfermagem de Rübeirão Preto da Universidade de São Paulo (EERP. USP), cujo objetivo é disponibitizar a versão adaptada e validada do instrumento chamado Patient Assessment of Chronic Illness Care (PACIC), para Portugal.

Trata-se de um instrumento com 20 itens e cinco dominios, utilizado em âmbito internacional e desenvolvido originalmente por Glasgow et al. (2005)(1) na lingua inglesa, a fim de avatiar a quatidade do cuidado centratizado em pessoas com doenças crónicas. Para cada item desse instrumento são oferecidas cinco alternativas de resposta, com escore variável de 1-5. Existe apenas uma alternativa de resposta e a graduação dos itens do instrumento ocorre por escala do tipo "likert".

$\mathcal{O}$ processo de adaptação cultural adotado para $\sigma$ instrumento PACIC está a ser realizado conforme World Health Organization - WHO (2012)(2), na sequencia das seguintes etapas. Tradução; Comitê de Especialistas; Retro-Tradução (Back-Translation); Pré-Teste e Entrevista Cognitiva. 
Você está a ser convidada para participar desse Comitê de Especialista nos conceitos a serem explorados, pertencentes à área prática e acadêmica, que se reatizará no dia 29 de fevereiro de 2012, às 15h30, na sala de reunióes (piso 2) da Escola Superior de Enfermagem do Porto - ESEP (Pólo São João); com o objetivo de realizar a avaliação das equivalencias semântica, idiomática, cultural e conceitual da Versão Consensuat em Português-Portugal 2ab (PACIC-VCPPort 2ab) do instrumento "Avaliação de Pacientes com Cuidados de Doença Crônica".

Viemos por meio desta Carta Convite solicitar a sua colaboração para que tal avaliação se concretize em razão de avançar no processo de adaptação cultural de um instrumento para Portugal, a fím de disponibitizar aos profissionais que atuam junto às pessoas com doenças crônicas o sew uso para a assistência e pesquisa.

Dessa forma, gostariamos de contar com a sua valiosa colaboração neste estudo, participando da avaliação desse instrumento. Sua participação como Especialista neste Comitê consiste em avatiar as equivalências semântica, idiomática, cultural e conceitual dos itens do PACIC-VCPPort 2ab, considerando que:

- Equivalência semântica destina-se ao significado das palavras, onde $\sigma$ vocabulário e a gramática podem sofrer alterações na construção dasfrases;

- Equivalencia idiomática: refere-se às expressóes coloquiais on idiomáticas de difícil tradução, devendo ser substituidas por expressóes equivalentes no cultura alvo;

- Equivalência cultural propõe-se a correspondência das situações equivocadas ou retratadas na versão original às vivenciadas em nosso meio/contexto cultural;

- Equivalência conceitual: representa a coerência do item com relação ao dominio que ele pretende medir. 
Você receberá uma cópia da versão original do instrumento em inglês, PACIC-VO, e uma cópía da versão consensual após as traduções, PACIC-VCPPort 2ab, a fim de que haja a possibitidade de reatizar as comparaçöes dos itens contemplados.

Nossa proposta será de realizar a leitura de cada item simultaneamente e fazer, em conjunto, a análise quanto às equivalências solicitadas. As possiveis modificações serão consideradas quando houver a concordância de, no minimo, 80\% de aprovação em consenso do total do número de membros desse Comitê de Especialistas.

No dia 29 de Fevereiro de 2012, após receber todas as orientações sobre os objetivos e procedimentos, bem como a forma de participação, solicitaremos a gentileza da tua assinatura no Termo de Consentimento Livre e Esclarecido para Especialistas em duas vias, de modo que seja manifestada a sua concordância.

Declaramos que $\sigma$ nosso encontro será gravado em áudio e $\sigma$ mesmo em midia, sendo guardada por cinco anos e inutilizada após esse periodo.

Sem mais para $\sigma$ momento, agradecemos toda a atenção dispensada,

\section{Doutoranda Camila Landím camilaapapila@usp.br \\ Profa. Dra. Manuela Martins mmartins@esep.pt}

\footnotetext{
(1) GLASGOW, R. E.; WAGNER, E. H.; SCHAEFER, J.; MAHONEY, L. D.; REID, R. J.; GREENE, S. M. Development and validation of the Patient Assessment of Chronic Illness Care (PACIC). Medical Care, Philadelphia, v. 43, n. 5, p. 436-444, 2005.

(2) WORLD HEALTH ORGANIZATION (WHO). Management of substance abuse: process of translation and adaptation of instruments. Geneva: WHO, 2012. Disponivel em: <http://www.who.int/substance_abuse/research_tools/translation/en/>. Acesso em: 22 jan. 2012.
} 
APÊNDICE E - Declaração de Consentimento para Especialistas (Brasil/Portugal)

\section{Adaptação cultural para Brasil e Portugal do instrumento Patient Assessment of Chronic Illness Care (PACIC)}

$\mathrm{Eu}$, RG / NIF

declaro estar de acordo em participar como Especialista do estudo intitulado "Adaptação cultural para Brasil e Portugal do instrumento Patient Assessment of Chronic Illness Care (PACIC)", que tem como objetivo adaptar culturalmente para a língua portuguesa o instrumento intitulado Patient Assessment of Chronic Illness Care (PACIC), a fim de avaliar a qualidade do cuidado centralizado em pessoas com doenças crônicas. A finalidade da minha participação é avaliar as equivalências semântica, idiomática, cultural e conceitual dos itens da versão traduzida (brasileira ou portuguesa).

Declaro estar ciente de que este estudo não me oferece qualquer tipo de riscos ou desconfortos e que meu sigilo e privacidade serão mantidos. Tomei conhecimento de que a nossa reunião será gravada em áudio e o mesmo em mídia, sendo esta guardada por cinco anos e inutilizada após esse período. Informo estar livre para me recusar a todo tempo a minha participação neste estudo, sem penalização ou prejuízo.

Declaro que recebi todas as orientações sobre os objetivos e os procedimentos a serem desenvolvidos neste estudo, bem como em relação à minha forma de participação, e manifesto o meu consentimento*.

Ribeirão Preto/Porto, de de $2011 / 2012$

\section{Assinatura do (a) Especialista}

\section{Dda. Camila Landim EERP-USP \\ Ribeirão Preto/SP, Brasil \\ camilaapapila@usp.br}

\author{
Dra. Carla Teixeira \\ EERP-USP \\ Ribeirão Preto/SP, Brasil \\ carlarst@eerp.usp.br
}

\author{
Dra. Manuela Martins \\ ESEP \\ Porto, Portugal \\ mmartins@esenf.pt
}

*Uma cópia dessa Declaração de Consentimento deverá ser fornecida ao Especialista. 


\section{APÊNDICE F - Versão Consensual em Português-Brasil 1.0 Revisada (PACIC-VCPBra 1.0 Rev)}

\section{Questionário para Avaliação do Cuidado de Pacientes com Doença Crônica}

\section{Cuidados com a sua doença crônica}

Manter-se saudável pode ser difícil quando você tem uma doença crônica. Nós gostaríamos de saber sobre a ajuda que você recebe da equipe de saúde com relação à sua condição. Esta ajuda pode incluir o seu médico, seu enfermeiro ou outros profissionais de saúde que tratam da sua doença. Suas respostas serão mantidas em sigilo e não serão reveladas a ninguém.

Para responder a todas as questões deste questionário, você deverá pensar na ajuda do cuidado recebido para a sua doença crônica nos últimos 6 meses e assinalar uma resposta para cada questão:

\begin{tabular}{|c|c|c|c|c|}
\hline Nunca & $\frac{\text { Quase }}{\text { Nunca }}$ & $\underline{\text { Às Vezes }}$ & $\frac{\text { Quase }}{\text { Sempre }}$ & $\underline{\text { Sempre }}$ \\
\hline
\end{tabular}
1. Perguntaram a minha opinião, quando foi feita a proposta de tratamento.

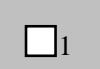
$\square 2$

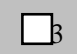
$\square_{4}$
$\square 5$
2. Deram opções de tratamento, para que eu pensasse a respeito.
$\square 1$
$\square 2$

$\square$
$\square$
$\square$

3. Perguntaram se tenho algum problema com os medicamentos que tomo ou com os seus efeitos.

4. Deram uma lista por escrito de coisas que eu deveria fazer para melhorar a minha saúde.

5. Fiquei satisfeito com a organização dos cuidados prestados.
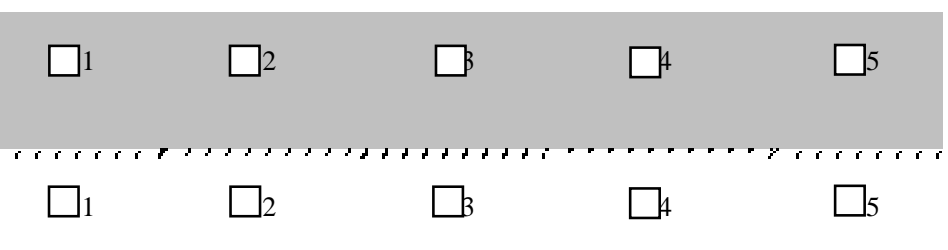

$\square_{1} \quad \square_{2} \quad \square 3 \quad \square_{4} \quad \square_{5}$

6. Mostraram que a maneira como eu me cuidava influenciava na minha doença.

7. Perguntaram quais os meus objetivos no tratamento da doença.

$\square 1 \quad \square 2 \quad \square 3 \quad \square 75$

8. Ajudaram a estabelecer objetivos específicos, para melhorar meus hábitos alimentares ou atividade física.

9. Deram uma cópia da minha proposta de tratamento.

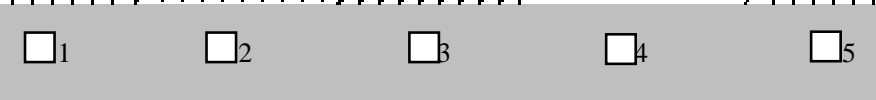

10. Estimularam a participar de grupos ou aulas específicas para lidar com a minha doença crônica.

11. Perguntaram, diretamente ou por meio de questionário, sobre meus hábitos de saúde.

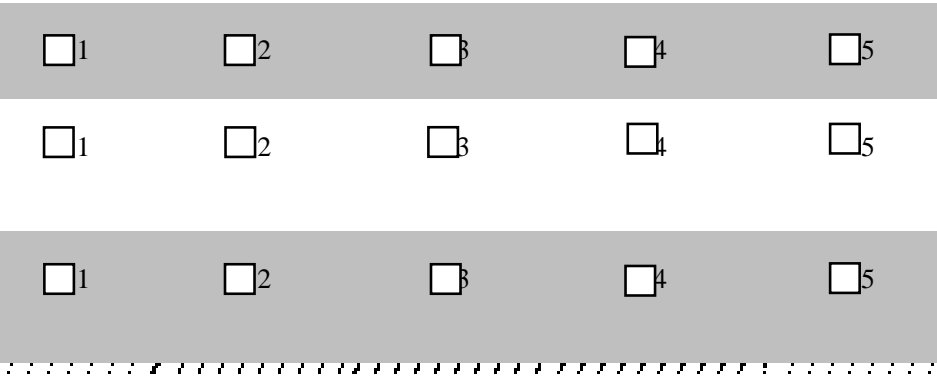


Para responder todas as questões desse questionário, você deverá pensar na ajuda do cuidado recebido para a sua doença crônica nos últimos 6 meses e assinalar uma resposta para cada questão:

$$
\underline{\text { Nunca }} \quad \underline{\text { Quase }} \quad \underline{\text { Às Vezes }} \quad \underline{\text { Quase }} \quad \underline{\text { Sempre }}
$$

12. Tive certeza de que o meu médico ou enfermeiro considerava meus valores e costumes, quando eles recomendavam tratamentos para $\operatorname{mim}$.

13. Ajudaram a fazer uma proposta de tratamento que eu pudesse pôr em prática no meu dia a dia.

14. Ajudaram a planejar com antecedência o cuidado da minha doença, mesmo nos momentos difíceis.
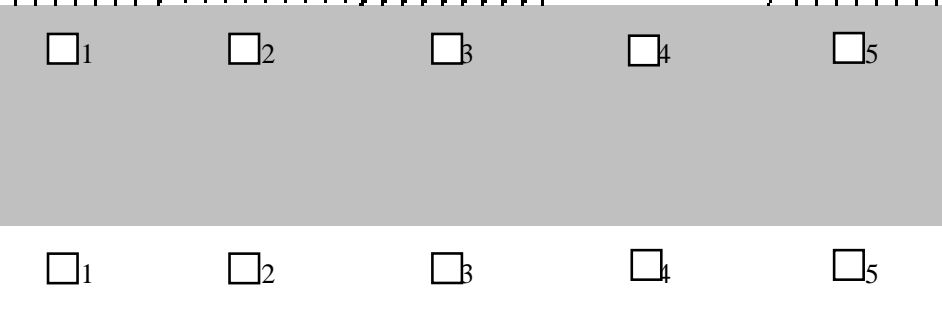

Perguntaram como minha doença crônica afeta minha vida.

16. Entraram em contato comigo, depois de uma consulta, para verificar como as coisas estavam indo.

17. Estimularam a participar de programas na comunidade que poderiam me ajudar.

18. Fui encaminhado para um nutricionista e/ou outro profissional de saúde.

19. Falaram como as consultas com outros especialistas, como, por exemplo, oftalmologista ou cirurgião ajudavam no meu tratamento.

20. Perguntaram como as minhas consultas com outros médicos estavam indo.

Pontuação das Escalas PACIC:

Participação Ativa do Paciente no Tratamento

Modelo do Sistema de Cuidado / Modelo para a Prática

Estabelecimento de Metas / Adaptação

Resolução de Problemas / Contexto

Seguimento / Coordenação
Média dos Itens 1-3

Média dos Itens 4-6

Média dos Itens 7-11

Média dos Itens 12-15

Média dos Itens 16-20 


\section{APÊNDICE G - Versão Consensual em Português-Portugal 2.0 Revisada (PACCC-VCPPort 2.0 Rev)}

\section{Escala de Avaliação pelo Paciente dos Cuidados com a sua Doença Crónica}

\section{Cuidados com a sua Doença Crónica}

Permanecer saudável pode ser difícil quando se tem uma doença crónica. Considerando o seu estado de saúde, pretendemos saber o tipo de ajuda que recebe da equipa de saúde. Poderá incluir o seu médico, o enfermeiro ou outros profissionais de saúde. As suas respostas são anônimas e confidenciais.

Quando recebi cuidados de saúde no âmbito da minha doença crónica, nos últimos 6 meses, eu:

Nunca $\underline{\text { Raramente }} \underline{\text { Por Vezes }} \underline{\text { Quase }} \underline{\text { Sempre }}$ $\underline{\text { Sempre }}$

1. Fui questionado(a) sobre as minhas ideias, quando da elaboração do

$\square 1 \quad \square 2$

$\square 3$

$\square 4$

$\square 5$

plano de tratamento.

2. Recebi diversas opções de tratamento para reflectir.

$\square 1 \quad \square 2 \quad \square 3 \quad \square 4 \quad \square 5$

3. Fui questionado(a) sobre quaisquer problemas vivenciados com a minha $\square 1 \quad \square 2$

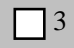

$\square 4$ $\square 5$ medicação ou os seus efeitos.

4. Recebi uma lista com o que devo fazer para melhorar a minha saúde.

5. Fiquei satisfeito(a) com a boa organização dos cuidados prestados.

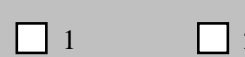

$\square 2$

$\square 3$

$\square 4$

6. Fui esclarecido(a) se o que eu fiz para cuidar da minha doença influenciou o $\square 1 \quad \square$

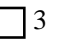

5 meu estado de saúde.

7.' Fui questionado(a) sobre os meus objectivos para cuidar da minha doença.

8. Fui ajudado(a) na definição de objectivos específicos para a melhoria dos meus hábitos alimentares e do exercício físico.

9. Recebi uma cópia do meu plano de tratamento.

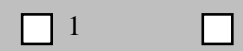

$\square 1 \quad \square 2$

$\square 3 \quad \square 4$

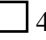
grupo específico para me ajudar a lidar com a minha doença crónica.

11. Fui questionado(a), directamente ou por meio de um inquérito, sobre os $\square 1$ $\square 2$ $\square 3$ $\square 4$ meus hábitos de saúde. 
Quando recebi cuidados de saúde no âmbito da minha doença crónica, nos últimos 6 meses, eu:

$\underline{\text { Nunca }} \underline{\text { Raramente }} \quad \underline{\text { Por Vezes }} \quad \underline{\underline{\text { Quase }}} \quad \underline{\text { Sempre }}$

12. Tive a certeza de que o meu médico ou enfermeiro reflectiram meus

$\square 1$ valores e tradições, quando me recomendavam os tratamentos.

13. Fui ajudado(a) na elaboração de um plano de tratamento, adequado ao meu dia a dia.

14. Fui ajudado(a) para planear o futuro, de forma a cuidar da minha doença, mesmo nos momentos mais difíceis.

15. Fui perguntado(a) de que forma a doença crónica afecta a minha vida.

16. Fui perguntado(a), após uma consulta, para saber como as coisas estavam a correr.

17. Fui encorajado(a) para frequentar programas, na comunidade, que me poderiam ajudar.

18. Fui encaminhado(a) para procurar um nutricionista, um enfermeiro ou um psicólogo.

19. Disseram-se que a consulta com outros especialistas, nomeadamente, um oftalmologista, ajudou-me nos meus tratamentos.

20. Fui questionado(a) como as consultas com outros médicos estavam a correr.

$\square 1 \quad \square 2 \quad \square 3 \quad \square 4 \quad \square 5$

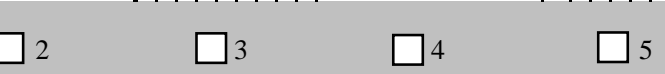

$\square^{1} \quad \square^{2} \quad \square^{3} \quad \square^{4} \quad \square 5$

$\square 1 \quad \square 2 \quad \square 3 \quad \square 4 \quad \square 5$

$\square 1 \quad \square 2 \quad \square 3 \quad \square, \quad \square 4, \ldots$

$\square^{1} \quad \square^{2} \quad \square^{3} \quad \square^{4} \quad \square 5$

$\square 1 \quad \square 2 \quad \square 3 \quad \square 4 \quad \square 5$

$\square 1$
$\square 2$
$\square_{3} \quad \square_{4}$

Pontuação das Escalas PACIC:

Participação Activa do Paciente

Sistema de Prestação de Cuidados / Organização da Prática

Média dos Itens 1-3

Estabelecimento de Metas / Individualização

Média dos Itens 4-6

Resolução de Problemas / Contextualização

Média dos Itens 7-11

Acompanhamento / Coordenação

Média dos Itens 12-15

Média dos Itens 16-20 


\section{APÊNDICE H - Versão em Inglês-Brasil (PACIC-VIBra)}

\section{Questionnaire for Care Assessment of Patients with Chronic Conditions}

\section{Care for your chronic condition}

Staying healthy can be difficult when you have a chronic condition. We would like to know about the help you receive from the health team regarding your condition. This help can include your physician, your nurse or other health professionals who treat your illness. Your answers will be kept secret and will not be revealed to anyone.

To answer all questions in this questionnaire, you should think about the help you receive with care for your chronic condition during the last 6 months and mark one answer for each question:

\section{$\underline{\text { Never }} \quad \frac{\text { Hardly }}{\text { Ever }} \quad \underline{\text { Sometimes }} \quad \underline{\underline{\text { Almost }}} \quad \underline{\text { Always }}$}

1. They asked my opinion when treatment was proposed.
$\square 1$
$\square_{2}$
$\square 4$
$\square_{5}$

2. They gave treatment options, so that I could think about it.

3. They asked if I have any problem with the drugs I take or with their effects.

4. They gave me a written list of things I should do to improve my health.

$\square_{1} \quad \square_{2}$

I felt satisfied with the organization of care delivery.

$\square_{1}$

$\square_{2}$

$\square_{4} \quad \square 5$

\begin{tabular}{|c|c|c|c|c|c|c|}
\hline 5. & $\begin{array}{l}\text { I felt satisfied with the organization } \\
\text { of care delivery. }\end{array}$ & $\square 1$ & $\square_{2}$ & $\square 3$ & $\square 4$ & $\square 5$ \\
\hline 6. & $\begin{array}{l}\text { They showed that the way I used to } \\
\text { take care of myself influenced my } \\
\text { disease. }\end{array}$ & $\square 1$ & $\square 2$ & $\square 3$ & $\square 4$ & $\square 5$ \\
\hline 7. & $\begin{array}{l}\text { They asked what I want to } \\
\text { accomplish in disease treatment. }\end{array}$ & $\square_{1}$ & $\square_{2}$ & $\square_{3}$ & $\square_{4}$ & $\square 5$ \\
\hline 8. & $\begin{array}{l}\text { They helped to set specific goals, to } \\
\text { improve my eating habits or physical } \\
\text { exercise. }\end{array}$ & $\square_{1}$ & $\square 2$ & $\square_{3}$ & $\square 4$ & $\square$ \\
\hline 9. & $\begin{array}{l}\text { They gave a copy of my treatment } \\
\text { proposal. }\end{array}$ & $\square 1$ & $\square 2$ & $\square 3$ & $\square 4$ & $\square 5$ \\
\hline 10. & $\begin{array}{l}\text { They stimulated me to participate in } \\
\text { groups or specific classes to deal with } \\
\text { my chronic condition. }\end{array}$ & $\square_{1}$ & $\square 2$ & $\square_{3}$ & $\square_{4}$ & $\square$ \\
\hline 11. & $\begin{array}{l}\text { They asked about my health habits, } \\
\text { either directly or through a } \\
\text { guestionnaire }\end{array}$ & $\square 1$ & $\square 2$ & $\square 3$ & $\square 4$ & $\square 5$ \\
\hline
\end{tabular}


To answer all questions in this questionnaire, you should think about the help you receive with care for your chronic condition during the last 6 months and mark one answer for each question:

$$
\underline{\text { Never }} \quad \underline{\underline{\text { Hardly }}} \quad \underline{\underline{\text { Sver }}} \quad \underline{\text { Sometimes }} \quad \underline{\underline{\text { Always }}} \quad \underline{\text { Always }}
$$

12. I was sure that my physician or nurse took into account my values and
$\square 1$

$\square 2$

$\square 3$

$\square 4$

$\square 5$ customs when they recommended treatments for me.

13. They helped to make a treatment plan I could put in practice in my daily life.

14. They helped to plan care for my disease in advance, even at difficult

$\square_{1} \quad \square$

$\square_{2} \quad \square_{3}$

$\square_{4} \quad \square_{5}$ time.

15. They asked how my chronic illness affects my life.

16.

16. They contacted me after a consultation to check how things were going.

17. They stimulated me to participate in community programs that could help

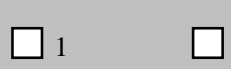

$\square 2$

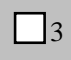

$\square 4$

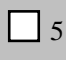
me.

18. I was forwarded to a nutritionist and/or other health professional.

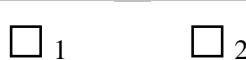

$\square 3$

$\square_{4}$

$\square 5$

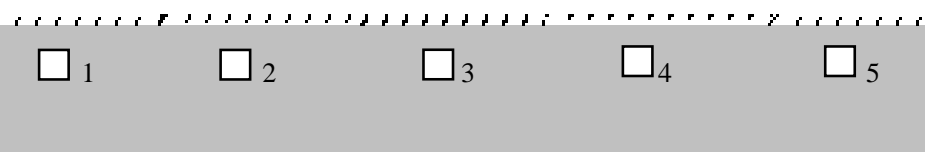

$\square_{1} \quad \square_{2} \quad \square 3 \quad \square 4 \quad \square 5$

5

They talked about how consultations

with other specialists, like

ophthalmologists or surgeon were of help in my treatment.

20. They asked how my consultations with other physicians were going.

$\begin{array}{lllll}\square_{1} & \square_{2} & \square_{3} & \square_{4} & \square_{5} \\ \square_{1} & \square_{2} & \square_{3} & \square_{4} & \square_{5}\end{array}$

Scoring of PACIC Scales:

Patient's Active Participation in Treatment

Mean of Items 1-3

Care System Model / Model for Practice

Mean of Items 4-6

Goal Setting / Adaptation

Mean of Items 7-11

Problem Solving / Context

Mean of Items 12-15

Follow-up / Coordination

Mean of Items 16-20 


\section{APÊNDICE I - Versão em Inglês-Portugal (PACIC-VIPort)}

\section{Assessment Scale of the Patient's Chronic Illness Care}

\section{Chronic Illness Care}

Staying healthy can be difficult when suffering from a chronic illness. Taking into consideration your condition, we would like to assess the type of care you receive from the health care team. This can include your personal doctor, nurse or other health professionals. Your answers are anonymous and confidential.

While receiving health care due to my chronic illness during the last 6 months:

$$
\underline{\text { Never }} \quad \underline{\text { Sometimes }} \quad \underline{\text { Often }}
$$

1. I was questioned about my ideas when making the treatment plan.

$\square 1 \quad \square 2$

2

$\square 3$

$\square 4$

$\square 5$

2. I was given several treatment options for my consideration.

3. I was questioned about any problems stemming from my medication or its effects.

4. I was given a list of what I should do to improve my health.

$\square 1$

$\square 2$

$\square 3$

$\square_{4}$

$\square_{4} \quad \square 5$

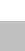

\section{$\square 1$}

$\square 2$

$\square^{3}$

$\square^{4}$

$\square 5$

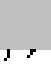

$\square+$

(1,

\section{2}

$\square^{3}$

$\square 4$

5
5. I was satisfied with the good organization of the care that was provided.
$\square 1 \quad \square$
$\square_{2} \quad \square 3$
$\square 4$
5

6. I was explained how what I did to take care of my illness influenced my condition.

7. I was questioned about my goals for treating my illness.

8. I received help to set specific goals in order to improve my eating and exercise habits.

9. I was given a copy of my treatment I was
plan.

$\square$

2

$\square 3$

$\square 4$

5

10. I was encouraged to take part in a specific group to help me deal with my chronic illness.

11. I was questioned, directly or through a survey, about my health habits.

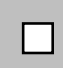

$\square 2$

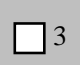

$\square^{4}$

$\square$

$\square 1$

$\square_{2}$

$\square 3$

$\square 4$

$\square 5$

$\square$

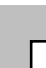

1

$\square 2$

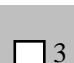


While receiving health care due to my chronic illness during the last 6 months:

$$
\text { Never Rarely } \underline{\text { Sometimes }} \text { Often } \quad \underline{\text { Always }}
$$

12. I was certain that my doctor or nurse looked after my values and traditions

$\square 1$

$\square 2$

$\square 4$

$\square 5$ when they recommended treatments to me.

13. I received help to establish a treatment plan suitable for my daily routine.

14. I received help to plan my future, in order to take care of my illness, even during hard moments.

15. I was questioned about how chronic illness affects my life.

16. I was questioned, after the consultation, about how things were going.

17. I was encouraged to take part in community programs that might help me.

18. I was advised to seek out a nutritionist, a nurse or a psychologist.

19. I was told that consulting other specialists, like an ophthalmologist, helped me with my treatment.

20. I was questioned about how my consultations with other doctors were $\square 1 \quad \square 2$

$\square 2 \square$

$\square 4$

$\square 5$

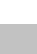

$\square^{1} \quad \square^{2} \quad \square^{3} \quad \square^{4} \quad \square^{5}$
going.

PACIC Scale:

Patient Activation

Delivery-System / Practice Design

Average of Items 1-3

Goal Setting / Tailoring

Average of Items 4-6

Problem Solving / Contextual

Average of Items 7-11

Follow-up / Coordination

Average of Items 12-15

Average of Items 16-20 
APÊNDICE J - Termo de Consentimento Livre e Esclarecido (TCLE) (Brasil)

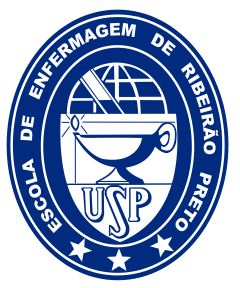

\author{
UNIVERSIDADE DE SÃO PAULO \\ ESCOLA DE ENFERMAGEM DE RIBEIRÃO PRETO \\ Avenida Bandeirantes, 3900, Monte Alegre, \\ Telefone: (16) 3602-3434; FAX: (16) 3633-3271 \\ CEP: 14040902 - Ribeirão Preto, SP, Brasil
}

Meu nome é Camila Aparecida Pinheiro Landim, RG 99002296135, sou doutoranda do programa de Enfermagem Fundamental da Escola de Enfermagem de Ribeirão Preto da Universidade de São Paulo, sob a orientação da Profa. Dra. Carla Regina de Souza Teixeira. Estou realizando uma pesquisa que tem como objetivo traduzir para o Brasil o instrumento chamado Patient Assessment of Chronic Illness Care (PACIC), a fim de avaliar a qualidade do cuidado centralizado em pessoas brasileiras com doenças crônicas. Para realizar este estudo, eu preciso realizar entrevistas com pessoas com diabetes que fazem tratamento nos serviços de saúde. Por isso, acredito que você seja uma pessoa que pode informar sobre este assunto. Se você se interessar em participar deste estudo, poderíamos marcar uma entrevista. Cada entrevista deve durar mais ou menos meia hora e será realizada no serviço de saúde

\title{
Liberdade de escolha e direito de recusar:
}

Você não precisa responder perguntas que não queira. Você pode decidir se quer ou não participar do estudo. Você pode também decidir parar de participar, basta informar a pesquisadora. A decisão de não participar da pesquisa não afeta o atendimento do diabetes no serviço de saúde.

\section{Riscos e Benefícios:}

Pensamos que não existem riscos em participar do estudo. O único benefício pode ser a chance de discutir assuntos de seu interesse, e do seu cuidado com o diabetes. Por favor, não se sinta pressionado para falar sobre alguma coisa que você não deseja falar. Você não terá gastos e não receberá dinheiro para participar da pesquisa.

\section{Privacidade e 0 aspecto confidencial:}

Você é livre para decidir se quer ou não participar da entrevista. Toda informação que você der será mantida em segredo, exceto quando se tratar de assunto que o código profissional, de ética ou legal requer que seja comunicado. Por exemplo, caso o assunto envolvido estiver proporcionando algum tipo de risco para você, a pesquisadora tem obrigação de informar ao serviço de saúde.

\section{Para entrar em Contato:}

Para qualquer esclarecimento, você poderá entrar em contato com a Pesquisadora Camila Aparecida Pinheiro Landim e/ou com a Professora Carla Regina de Souza Teixeira na Escola de Enfermagem de Ribeirão Preto - USP ou pelo telefone (16) 3602-3434. Se você aceitar participar desta pesquisa, por favor, coloque seu nome e número do documento de identidade abaixo. Sua identidade e privacidade serão preservadas; apenas as respostas serão apresentadas em congressos e publicadas em periódicos científicos. 


\section{APÊNDICE J - Termo de Consentimento Livre e Esclarecido (TCLE) (Brasil)}

\section{TERMO DE CONSENTIMENTO LIVRE E ESCLARECIDO}

$\mathrm{Eu}$,

RG

abaixo assinado, após ter recebido as informações da

Doutoranda Camila Aparecida Pinheiro Landim sobre sua pesquisa intitulada "Adaptação cultural para o Brasil do instrumento Patient Assessment of Chronic Illness Care (PACIC)", que tem como objetivo traduzir para o Brasil o instrumento PACIC a fim de avaliar a qualidade do cuidado centralizado em pessoas brasileiras com doenças crônicas, concordo em ser entrevistado. Confirmo ter recebido as informações sobre a pesquisa a ser desenvolvida, e estou ciente sobre os direitos abaixo relacionados:

1. A garantia de receber resposta a qualquer pergunta ou esclarecimento a dúvidas acerca dos procedimentos, riscos, benefícios e outros relacionados à pesquisa;

2. A liberdade de retirar meu consentimento a qualquer momento e deixar de participar do estudo, sem que isso traga qualquer prejuízo para o entrevistado;

3. A segurança de que serão preservadas a identidade e privacidade do entrevistado;

4. O compromisso de me valer da legislação em caso de dano;

5. A garantia de que não haverá riscos e nem desconfortos, gastos de qualquer natureza;

6. A garantia de seguir todas as exigências que constam na Resolução $n^{\circ} 196$, de 10 de outubro de 1996, que regulamenta o desenvolvimento de pesquisas envolvendo seres humanos.

Esclareço que em caso de dúvida, fui orientado a procurar a Professora Carla Regina de Souza Teixeira e/ou a Doutoranda Camila Aparecida Pinheiro Landim na Escola de Enfermagem de Ribeirão Preto - USP ou pelo telefone (16) 3602-3434. Declaro que tenho conhecimento dos direitos acima descritos, e consinto em participar deste estudo, realizado pela pesquisadora que subscreve este termo de consentimento.

De acordo,

Ribeirão Preto, de de 2011

Participante da Pesquisa
Dda. Camila Landim

camilaapapila@usp.br

*Uma cópia desse Termo de Consentimento deverá ser fornecida ao participante. 


\section{APÊNDICE K - Termo de Consentimento Livre e Esclarecido (TCLE) (Portugal)}

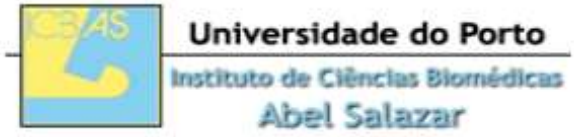

\section{INSTITUTO DE CIÊNCIAS BIOMÉDICAS ABEL SALAZAR - ICBAS/UP ESCOLA SUPERIOR DE ENFERMAGEM DO PORTO - ESEP}

\section{INFORMAÇÃO PARA O PARTICIPANTE DO ESTUDO}

Meu nome é Camila Aparecida Pinheiro Landim, enfermeira, brasileira, estudante de Doutoramento da Universidade de São Paulo, Brasil. Estou realizando um estudo que tem como objetivo traduzir para Portugal o inquérito chamado Patient Assessment of Chronic Illness Care (PACIC), para avaliar a qualidade do cuidado em pessoas portuguesas com doenças crônicas. Para realizar este estudo, eu preciso realizar entrevistas com pessoas com diabetes que fazem tratamento nos serviços de saúde. Por isso, acredito que tu sejas uma pessoa que podes informar-me sobre este assunto. Se tu desejares participar deste estudo, poderíamos conversar durante uma entrevista. Cada entrevista deve durar um tempo máximo de vinte minutos e será realizada no teu serviço de saúde.

\section{Liberdade de escolha e direito de recusar:}

Tu não precisas responder perguntas que não queiras. Tu podes decidir se quer ou não participar do estudo. Tu podes também decidir parar de participar em qualquer momento. A decisão sobre a não participação da pesquisa não afetará o atendimento do diabetes no teu serviço de saúde.

\section{Riscos e Benefícios:}

Pensamos que não existem riscos em participar do estudo. O único benefício pode ser a chance de discutir assuntos de seu interesse, e do seu cuidado com o diabetes. Por favor, não se sinta pressionado para falar sobre alguma coisa que tu não desejas. Não haverá gastos e não receberás dinheiro para participar desta pesquisa.

\section{Privacidade e $o$ aspecto confidencial:}

Tu és livre para decidir se quer ou não participar da entrevista. Toda informação que tu fores dar será mantida em segredo, exceto quando se tratar de assunto que o código profissional, de ética ou legal requer que seja comunicado. Por exemplo, caso o assunto envolvido estiver proporcionando algum tipo de risco para ti, a pesquisadora tem obrigação de informar ao serviço de saúde.

\section{Para entrar em Contato:}

Para qualquer esclarecimento, tu poderás entrar em contato com a Pesquisadora Camila Aparecida Pinheiro Landim e/ou com a Professora Maria Manuela Martins na Escola Superior de Enfermagem do Porto (ESEP). Sua identidade e privacidade serão preservadas; apenas as tuas respostas serão apresentadas em congressos e publicadas em periódicos científicos. 
APÊNDICE K - Termo de Consentimento Livre e Esclarecido (TCLE) (Portugal)

DECLARAÇÃO DE CONSENTIMENTO

Considerando a "Declaração de Helsínquia" da Associação Médica Mundial (Helsínquia 1964; Tóquio 1975; Veneza 1983; Hong Kong 1989; Somerset West 1996 e Edimburgo 2000)

\section{Adaptação cultural para Portugal}

do instrumento Patient Assessment of Chronic Illness Care (PACIC)

$\mathrm{Eu}$, declaro não ter participado em nenhum outro

projeto de investigação durante este internamento, tendo compreendido a explicação que me foi fornecida acerca do meu caso clínico e da investigação que se tenciona realizar. Foime ainda dada oportunidade de fazer as perguntas que julguei necessárias, e de todas obtive resposta satisfatória.

Tomei conhecimento de que, de acordo com as recomendações da Declaração de Helsínquia, a informação ou explicação que me foi prestada versou os objetivos, os métodos, os benefícios previstos, os riscos potenciais e o eventual desconforto. Além disso, foi-me afirmado que tenho o direito de recusar a todo o tempo a minha participação no estudo, sem que isso possa ter como efeito qualquer prejuízo na assistência que me é prestada.

Por isso, consinto que me seja aplicado o método, o tratamento ou o inquérito proposto pelo investigador.

Porto / 2012

\section{Assinatura do doente ou voluntário são}

Os Investigadores responsáveis:

Dda. Camila Landim (EERP-USP)

Ribeirão Preto/SP, Brasil

camilaapapila@usp.br
Dra. Manuela Martins (ESEP)

Porto, Portugal

mmartins@esenf.pt

*Uma cópia dessa Declaração de Consentimento deverá ser fornecida ao participante. 


\section{APÊNDICE L - Versão Pré-Teste em Português-Brasil (PACIC-VPTPBra)}

\section{Questionário para Avaliação do Cuidado de Pacientes com Doença Crônica}

\section{Cuidados com a sua doença crônica}

Manter-se saudável pode ser difícil quando você tem uma doença crônica. Nós gostaríamos de saber sobre a ajuda que você recebe da equipe de saúde com relação à sua condição. Esta ajuda pode incluir o seu médico, seu enfermeiro ou outros profissionais de saúde que tratam da sua doença. Suas respostas serão mantidas em sigilo e não serão reveladas a ninguém.

Para responder a todas as questões deste questionário, você deverá pensar na ajuda do cuidado recebido para a sua doença crônica nos últimos 6 meses e assinalar uma resposta para cada questão:

\section{$\underline{\text { Nunca }} \quad \underline{\text { Quase }} \quad \underline{\text { Às Vezes }} \quad \underline{\text { Quase }} \quad \underline{\text { Sempre }}$}

1. Perguntaram a minha opinião, $\square_{1} \quad \square_{2}$
quando foi feita a proposta de $\square_{3}$
tratamento.
2. Deram opções de tratamento, para que eu pensasse a respeito.

3. Perguntaram se tenho algum problema com os medicamentos que $\square 1$

$\square 2$

$\square^{3} \quad \square^{4} \quad \square 5$ tomo ou com os seus efeitos.

4. Deram uma lista por escrito de coisas que eu deveria fazer para melhorar a minha saúde.

5. Fiquei satisfeito com a organização dos cuidados prestados.

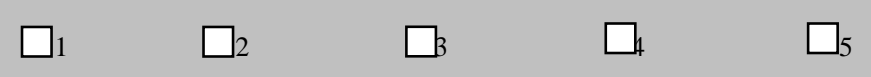

6. Mostraram que a maneira como eu me cuidava influenciava na minha doença.

7.' Perguntaram quais os meus objetivos no tratamento da doença.

$\square 1$

Ajudaram a estabelecer objetivos específicos, para melhorar meus hábitos alimentares ou atividade física.

9. Deram uma cópia da minha proposta de tratamento.

$\square$

Estimularam a participar de grupos ou aulas específicas para lidar com a minha doença crônica.

11. Perguntaram, diretamente ou por meio de questionário, sobre meus hábitos de saúde. 
Para responder todas as questões desse questionário, você deverá pensar na ajuda do cuidado recebido para a sua doença crônica nos últimos 6 meses e assinalar uma resposta para cada questão:

$$
\underline{\text { Nunca }} \quad \underline{\text { Quase }} \quad \underline{\text { Às Vezes }} \quad \underline{\text { Quase }} \quad \underline{\text { Sempre }}
$$

12. Tive certeza de que o meu médico ou enfermeiro considerava meus valores e costumes, quando eles recomendavam tratamentos para $\operatorname{mim}$.

13. Ajudaram a fazer uma proposta de tratamento que eu pudesse pôr em prática no meu dia a dia.

14. Ajudaram a planejar com antecedência o cuidado da minha doença, mesmo nos momentos difíceis.
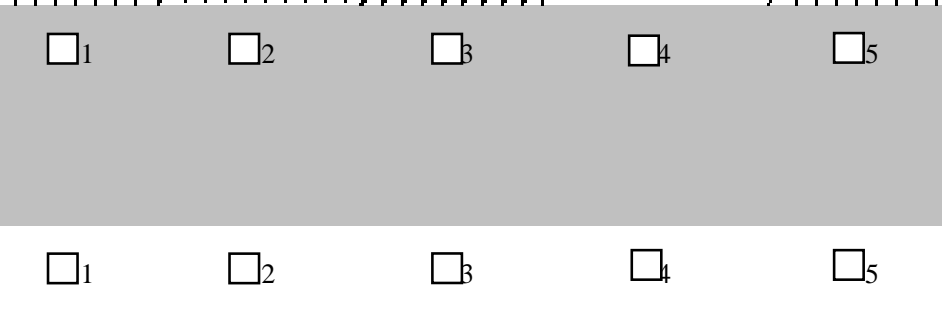

Perguntaram como minha doença crônica afeta minha vida.

16. Entraram em contato comigo, depois de uma consulta, para verificar como as coisas estavam indo.

17. Estimularam a participar de programas na comunidade que poderiam me ajudar.

18. Fui encaminhado para um nutricionista e/ou outro profissional de saúde.

19. Falaram como as consultas com outros especialistas, como, por exemplo, oftalmologista ou cirurgião ajudavam no meu tratamento.

20. Perguntaram como as minhas consultas com outros médicos estavam indo.

Pontuação das Escalas PACIC:

Participação Ativa do Paciente no Tratamento

Modelo do Sistema de Cuidado / Modelo para a Prática

Média dos Itens 1-3

Estabelecimento de Metas / Adaptação

Média dos Itens 4-6

Resolução de Problemas / Contexto

Média dos Itens 7-11

Seguimento / Coordenação

Média dos Itens 12-15

Média dos Itens 16-20 


\section{APÊNDICE M - Versão Final Português-Brasil (PACIC-VFPBra)}

\section{Questionário para Avaliação do Cuidado de Pacientes com Doença Crônica}

\section{Cuidados com a sua doença crônica}

Manter-se saudável pode ser difícil quando você tem uma doença crônica. Nós gostaríamos de saber sobre a ajuda que você recebe da equipe de saúde com relação à sua condição. Esta ajuda pode incluir o seu médico, seu enfermeiro ou outros profissionais de saúde que tratam da sua doença. Suas respostas serão mantidas em sigilo e não serão reveladas a ninguém.

Para responder a todas as questões deste questionário, você deverá pensar na ajuda do cuidado recebido para a sua doença crônica nos últimos 6 meses e assinalar uma resposta para cada questão:

\section{$\underline{\text { Nunca }} \quad \underline{\text { Quase }} \quad \underline{\text { Às Vezes }} \quad \underline{\text { Quase }} \quad \underline{\text { Sempre }}$}

1. Perguntaram a minha opinião, $\square_{1} \quad \square_{2} \quad \square_{3}$
quando foi feita a proposta de $\square_{4} \quad \square 5$
tratamento.
2. Deram opções de tratamento, para que eu pensasse a respeito.

3. Perguntaram se tenho algum problema com os medicamentos que $\square 1$

$\square 2$

$\square^{3} \quad \square^{4} \quad \square 5$ tomo ou com os seus efeitos.

4. Deram uma lista por escrito de coisas que eu deveria fazer para melhorar a minha saúde.

5. Fiquei satisfeito com a organização dos cuidados prestados.

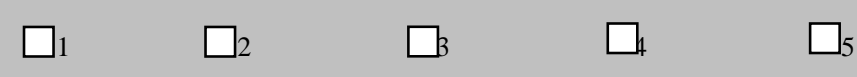

6. Mostraram que a maneira como eu me cuidava poderia melhorar ou piorar a minha doença.

"1.' Perguntaram quais os meus objetivos no tratamento da doença.

$\square 1$

Ajudaram a estabelecer objetivos específicos, para melhorar meus hábitos alimentares ou atividade física.

9. Deram uma cópia da minha proposta de tratamento.

10. Estimularam a participar de grupos ou aulas específicas para aprender a conviver com a minha doença crônica.

11. Perguntaram, diretamente ou por meio de questionário, sobre meus hábitos de saúde. 
Para responder todas as questões desse questionário, você deverá pensar na ajuda do cuidado recebido para a sua doença crônica nos últimos 6 meses e assinalar uma resposta para cada questão:

$$
\underline{\text { Nunca }} \quad \frac{\text { Quase }}{\text { Nunca }} \quad \underline{\text { Às Vezes }} \quad \underline{\text { Quase }} \quad \underline{\text { Sempre }}
$$

12. Tive certeza de que o meu médico ou enfermeiro respeitava meus valores e costumes, quando eles recomendavam tratamentos para mim.

13. Ajudaram a fazer uma proposta de tratamento que eu pudesse pôr em prática no meu dia a dia.

14. Ajudaram a planejar com antecedência o cuidado da minha doença, mesmo nos momentos difíceis.
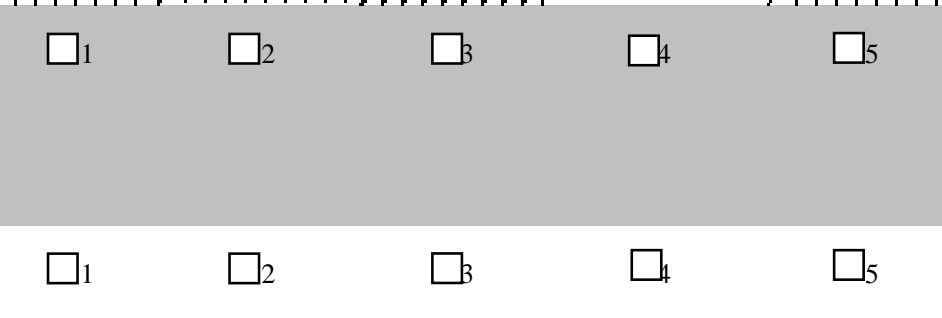

Perguntaram como minha doença crônica afeta minha vida.

16. Entraram em contato comigo, depois de uma consulta, para verificar como estava o controle da minha doença.

17. Estimularam a participar de programas na comunidade que poderiam me ajudar.

18. Fui encaminhado para um nutricionista e/ou outro profissional de saúde.

19. Falaram como as consultas com outros especialistas, como, por exemplo, oftalmologista ou cirurgião ajudavam no meu tratamento.

20. Perguntaram como as minhas consultas com outros médicos estavam indo.

Pontuação das Escalas PACIC:

Participação Ativa do Paciente no Tratamento

Modelo do Sistema de Cuidado / Modelo para a Prática

Estabelecimento de Metas / Adaptação

Resolução de Problemas / Contexto

Seguimento / Coordenação
Média dos Itens 1-3

Média dos Itens 4-6

Média dos Itens 7-11

Média dos Itens 12-15

Média dos Itens 16-20 


\section{APÊNDICE N - Versão Pré-Teste em Português-Portugal (PACIC-VPTPPort)}

\section{Escala de Avaliação pelo Paciente dos Cuidados com a sua Doença Crónica}

\section{Cuidados com a sua Doença Crónica}

Permanecer saudável pode ser difícil quando se tem uma doença crónica. Considerando o seu estado de saúde, pretendemos saber o tipo de ajuda que recebe da equipa de saúde. Poderá incluir o seu médico, o enfermeiro ou outros profissionais de saúde. As suas respostas são anônimas e confidenciais.

Quando recebi cuidados de saúde no âmbito da minha doença crónica, nos últimos 6 meses, eu:

Nunca $\quad \underline{\text { Raramente }} \quad \underline{\text { Por Vezes }} \quad \underline{\underline{\text { Quase }}} \quad \underline{\text { Sempre }}$

1. Fui questionado(a) sobre as minhas ideias, quando da elaboração do

$\square 1 \quad \square 2$

$\square 3$

$\square 4$

$\square 5$

plano de tratamentos.

2. Recebi diversas opções de tratamento para reflectir.

3. Fui questionado(a) sobre quaisquer problemas vivenciados com a minha medicação ou os seus efeitos.

4. Recebi uma lista com o que devo fazer para melhorar a minha saúde.

$\square 1$

$\square 2$

$\square 3$

$\square 4$

$\square$

$\square^{1} \quad \square^{2} \quad \square^{3} \quad \square^{4} \quad \square^{5}$

5. Fiquei satisfeito(a) com a boa organização dos cuidados prestados.

6. Fui esclarecido(a) se o que eu fiz para cuidar da minha doença influenciou o meu estado de saúde.

7. Fui questionado(a) sobre os meus objectivos para cuidar da minha doença.

$\square 1 \quad \square$

$\square 2 \square$

3
4

$\square 5$

$\square 1 \quad \square 2 \quad \square_{3} \quad \square_{4} \quad \square 5$

$\square^{1} \quad \square^{2} \quad \square^{3} \quad \square^{4} \quad \square^{5}$

$\square 1 \quad \square{ }_{2} \quad \square_{3} \quad \square 4 \quad \square 5$

- Fui ajudado(a) na definição de objectivos específicos para a melhoria dos meus hábitos alimentares e do exercício físico.

9. Recebi uma cópia do meu plano de tratamento.

10. Fui encorajado(a) a frequentar um grupo específico para me ajudar a lidar com a minha doença crónica.

11. Fui questionado(a), directamente ou por meio de um inquérito, sobre os meus hábitos de saúde. 
Quando recebi cuidados de saúde no âmbito da minha doença crónica, nos últimos 6 meses, eu:

$\underline{\text { Nunca }} \underline{\text { Raramente }} \quad \underline{\text { Por Vezes }} \quad \underline{\underline{\text { Quase }}} \quad \underline{\text { Sempre }}$

12. Tive a certeza de que o meu médico ou enfermeiro reflectiram meus

$\square 1$ valores e tradições, quando me recomendavam os tratamentos.

13. Fui ajudado(a) na elaboração de um plano de tratamento, adequado ao meu dia a dia.

14. Fui ajudado(a) para planear o futuro, de forma a cuidar da minha doença, mesmo nos momentos mais difíceis.

15. Fui perguntado(a) de que forma a doença crónica afecta a minha vida.

16. Fui perguntado(a), após uma consulta, para saber como as coisas estavam a correr.

17. Fui encorajado(a) para frequentar programas, na comunidade, que me poderiam ajudar.

18. Fui encaminhado(a) para procurar um nutricionista, um enfermeiro ou um psicólogo.

19. Disseram-se que a consulta com outros especialistas, nomeadamente, um oftalmologista, ajudou-me nos meus tratamentos.

20. Fui questionado(a) como as consultas com outros médicos estavam a correr.

$\square 1 \quad \square 2 \quad \square 3 \quad \square 4 \quad \square 5$

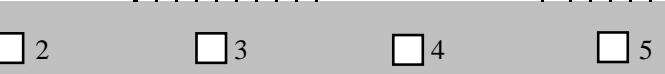

$\square^{1} \quad \square^{2} \quad \square^{3} \quad \square^{4} \quad \square 5$

$\square 1 \quad \square 2 \quad \square 3 \quad \square 4 \quad \square 5$

$\square 1 \quad \square 2 \quad \square 3 \quad \square, \quad \square 4, \ldots$

$\square^{1} \quad \square^{2} \quad \square^{3} \quad \square^{4} \quad \square 5$

$\square 1 \quad \square 2 \quad \square 3 \quad \square 4 \quad \square 5$

$\square 1$
$\square 2$
$\square_{3} \quad \square_{4}$

Pontuação das Escalas PACIC:

Participação Activa do Paciente

Sistema de Prestação de Cuidados / Organização da Prática

Média dos Itens 1-3

Estabelecimento de Metas / Individualização

Média dos Itens 4-6

Resolução de Problemas / Contextualização

Média dos Itens 7-11

Acompanhamento / Coordenação

Média dos Itens 12-15

Média dos Itens 16-20 


\section{APÊNDICE O - Versão Final Português-Portugal (PACIC-VFPPort)}

\section{Escala de Avaliação pelo Paciente dos Cuidados com a sua Doença Crónica}

\section{Cuidados com a sua Doença Crónica}

Permanecer saudável pode ser difícil quando se tem uma doença crónica. Considerando o seu estado de saúde, pretendemos saber o tipo de ajuda que recebe da equipa de saúde. Poderá incluir o seu médico, o enfermeiro ou outros profissionais de saúde. As suas respostas são anônimas e confidenciais.

Quando recebi cuidados de saúde no âmbito da minha doença crónica, nos últimos 6 meses, eu:

$\underline{\text { Nunca }} \underline{\text { Raramente }} \underline{\text { Por Vezes }} \underline{\text { Quase }} \quad \underline{\text { Sempre }}$ $\underline{\text { Sempre }}$

1. Fui questionado(a) sobre as minhas ideias, quando da elaboração do

$\square 1 \quad \square 2$

$\square 3$

$\square 4$

plano de tratamentos.

2. Recebi diversas opções de tratamento para reflectir.

$\square 1 \quad \square 2 \quad \square 3 \quad \square 4 \quad \square 5$

3. Fui questionado(a) sobre quaisquer problemas vivenciados com a minha $\square 1 \quad \square 2$ medicação ou os seus efeitos.

4. Recebi uma lista com o que devo fazer para melhorar a minha saúde.

$\square 1$

$2 \square 3$

3
4

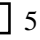

5

5. Fiquei satisfeito(a) com a boa organização dos cuidados prestados.
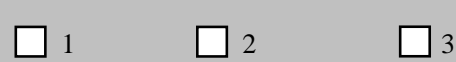

$\square 4$

6. Fui esclarecido(a) se o que eu fiz para cuidar da minha doença influenciou o meu estado de saúde.

7. Fui questionado(a) sobre os meus objectivos para cuidar da minha

$\square 1 \quad \square 2$

$\square 3$

$\square 4$ doença.

8. Fui ajudado(a) na definição de objectivos específicos para a melhoria dos meus hábitos alimentares e do exercício físico.

9. Recebi uma cópia do meu plano de tratamento.

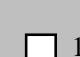

$\square 1 \quad \square 2$

$\square 1 \quad \square 2$

$\square^{-} \quad \square_{4}$

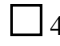
grupo específico para me ajudar a lidar com a minha doença crónica.

11. Fui questionado(a), directamente ou por meio de um inquérito, sobre os $\square 1$ $\square 2$ $\square 3$ $\square 4$ meus hábitos de saúde. 
Quando recebi cuidados de saúde no âmbito da minha doença crónica, nos últimos 6 meses, eu:

$\underline{\text { Nunca }} \underline{\text { Raramente }} \quad \underline{\text { Por Vezes }} \quad \underline{\underline{\text { Quase }}} \quad \underline{\text { Sempre }}$

12. Tive a certeza de que o meu médico ou enfermeiro reflectiram meus

$\square 1$ valores e tradições, quando me recomendavam os tratamentos.

13. Fui ajudado(a) na elaboração de um plano de tratamento, adequado ao meu dia a dia.

14. Fui ajudado(a) para planear o futuro, de forma a cuidar da minha doença, mesmo nos momentos mais difíceis.

15. Fui perguntado(a) de que forma a doença crónica afecta a minha vida.

16. Fui perguntado(a), após uma consulta, para saber como as coisas estavam a correr.

17. Fui encorajado(a) para frequentar programas, na comunidade, que me poderiam ajudar.

18. Fui encaminhado(a) para procurar um nutricionista, um enfermeiro ou um psicólogo.

19. Fui informado que a consulta com outros especialistas, nomeadamente, um oftalmologista, ajudou nos meus tratamentos.

20. Fui questionado(a) como as consultas com outros médicos estavam a correr.

$\square 1 \quad \square 2 \quad \square 3 \quad \square_{4} \quad \square 5$

$\square 2 \quad \square 3 \quad \square 4 \quad \square 5$

$\square^{1} \quad \square^{2} \quad \square^{3} \quad \square^{4} \quad \square^{5}$

$\square 1 \quad \square 2 \quad \square 3 \quad \square 4 \quad \square 5$

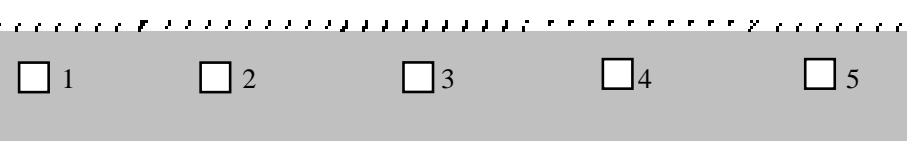

$\square^{1} \quad \square^{2} \quad \square^{3} \quad \square^{4} \quad \square^{5}$

$\square 1 \quad \square 2 \quad \square 3 \quad \square 4 \quad \square 5$

$\square 1 \quad \square 2 \quad \square 3 \quad \square 4 \quad \square 5$

Pontuação das Escalas PACIC:

Participação Activa do Paciente

Sistema de Prestação de Cuidados / Organização da Prática

Média dos Itens 1-3

Estabelecimento de Metas / Individualização

Média dos Itens 4-6

Resolução de Problemas / Contextualização

Média dos Itens 7-11

Acompanhamento / Coordenação

Média dos Itens 12-15

Média dos Itens 16-20 


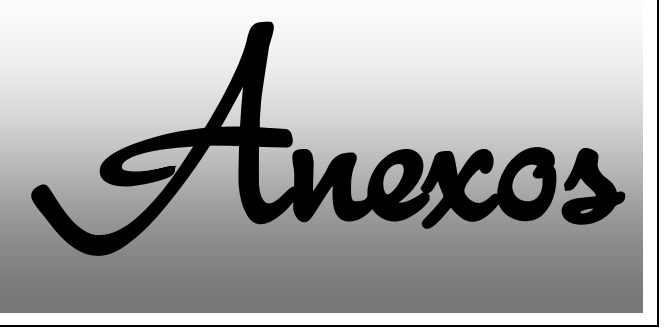




\section{ANEXOS}

ANEXO A - Patient Assessment of Chronic Illness Care (PACIC) (PACIC-VO)

ANEXO B - Autorização inicial para a tradução, adaptação cultural e validação do instrumento Patient Assessment of Chronic Illness Care (PACIC) no Brasil

ANEXO C - Autorização inicial para a tradução, adaptação cultural e validação do instrumento Patient Assessment of Chronic Illness Care (PACIC) em Portugal

ANEXO D - Recomendação para o seguimento das etapas de adaptação cultural do instrumento PACIC, conforme World Health Organization - WHO (2012)

ANEXO E - Autorização para a utilização dos formulários de Impressão Geral e Específica do Projeto DISABKIDS ${ }^{\circledR}$

ANEXO F - Parecer final do Comitê de Ética em Pesquisa (Brasil)

ANEXO G - Parecer final da Comissão de Ética em Saúde (Portugal)

ANEXO H - Concordância do autor com a Versão em Inglês-Brasil (PACIC-VIBra)

ANEXO I - Concordância do autor com a Versão em Inglês-Portugal (PACIC-VIPort) 
ANEXO A - Patient Assessment of Chronic Illness Care (PACIC) (PACIC-VO)

\section{Patient Assessment of Chronic Illness Care*}

\section{Your Chronic Illness Care}

Staying healthy can be difficult when you have a chronic illness. We would like to learn about the type of help with your condition you get from your health care team. This might include your regular doctor, his or her nurse, or physician's assistant who treats your illness. Your answers will be kept confidential and will not be shared with anyone else.

When I received care for my chronic illness over the past 6 months, I was:

\begin{tabular}{|c|c|c|c|c|}
\hline$\frac{\text { Almost }}{\text { Never }}$ & $\frac{\text { Generally }}{\text { Not }}$ & Sometimes & $\underline{\text { Most of }}$ & $\frac{\text { Almost }}{\text { Always }}$ \\
\hline
\end{tabular}

1. Asked for my ideas when we made a treatment plan.

$\square_{1} \quad \square_{2} \quad \square_{3} \quad \square 4 \quad \square 5$

2. Given choices about treatment to think about.

3. Asked to talk about any problems with my medicines or

$\square 1 \quad \square 2$

$2 \square 3$

$\square 5$ their effects.

4. Given a written list of things I should do to improve my health.

5. Satisfied that my care was well organized.

$\square 1 \quad \square$

$\square 2$

$\square 3$

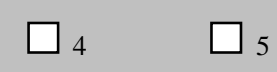

6. Shown how what I did to take care of my illness influenced

$\square 1 \quad \square 2$

$\square 3$

$\square 4 \quad \square 5$ my condition.

7. Asked to talk about my goals in caring for my illness.

$\square_{1} \quad \square_{2}$

$\square 3$

$\square 4$

8. Helped to set specific goals to improve my eating or exercise.

9. Given a copy of my treatment plan.

$\square_{1} \quad \square_{2} \quad \square_{3} \quad \square_{4} \quad \square_{5}$

\begin{tabular}{|c|c|c|c|c|}
\hline$\square 1$ & $\square 2$ & $\square 3$ & $\square 4$ & $\square 5$ \\
\hline$\square 1$ & $\square 2$ & $\square 3$ & $\square 4$ & $\square 5$ \\
\hline
\end{tabular}
group or class to help me cope with my chronic illness.

11. Asked questions, either directly or on a survey, about my health habits. 
When I received care for my chronic illness over the past 6 months, I was:

$\begin{array}{llll}\text { Almost } & \text { Generally } & \text { Most of } & \underline{\text { Almost }} \\ \text { Soter } & \underline{\text { Slways }}\end{array}$

12. Sure that my doctor or nurse thought about my

$\square_{1}$

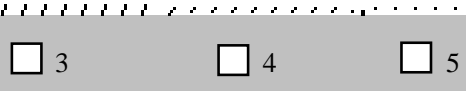
values and my traditions when they recommended treatments to me.

13. Helped to make a treatment plan that I could do in my daily life.

14. Helped to plan ahead so I could take care of my $\square 1-\square 2$ illness even in hard times.

15. Asked how my chronic illness affects my life.

16. Contacted after a visit to see how things were going.

17. Encouraged to attend programs in the community that could help me

18. Referred to a dietitian, health educator, or counselor.

19. Told how my visits with other types of doctors, like

$\square_{1} \quad \square_{2} \quad \square_{3} \quad \square_{4} \quad \square_{5}$

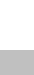
the eye doctor or surgeon, helped my treatment.

20. Asked how my visits with other doctors were going.

Scoring of PACIC Scales:

Patient Activation

Delivery System Design / Practice Design

Goal Setting / Tailoring

Problem-Solving / Contextual

Follow-up / Coordination
Average of Items 1-3

Average of Items 4-6

Average of Items 7-11

Average of Items 12-15

Average of Items 16-20 
ANEXO B - Autorização inicial para a tradução, adaptação cultural e validação do instrumento Patient Assessment of Chronic Illness Care (PACIC) no Brasil

De: Camila Landim (camilaapapila@usp.br)

Enviada: quinta-feira, 4 de novembro de 2010 11:50:14

Para: russ.glasgow@nih.gov; wagner.e@ghc.org; falmeida@vt.edu; austin.b@ghc.org

Cc: carlarst@eerp.usp.br

Dear Dr. Russ,

Thank you for your permission.

When I conclude this study, I contact you and send a copy so you can share with others authors.

Yours sincerely,

MSc. Camila Aparecida Pinheiro Landim

University of São Paulo at College of Nursing - WHO Collaborating Centre for Nursing Research Development Avenue Bandeirantes, 3900 - Campus Universitário, 14040902, Ribeirão Preto, Brazil

E-mail: camilaapapila@usp.br

From: russ.glasgow@nih.gov

To: camilaapapila@usp.br

Date: Thu, 4 Nov 2010 05:56:54 -0400

Subject: RE: "Patient Assessment of Chronic Illness Care (PACIC)"

Yes

Thank you for your interest in our PACIC instrument.

You have our permission to use the PACIC, to translate it or modify it to suit your needs.

Russ Glasgow 
From: Camila Landim [mailto:camilaapapila@usp.br]

Sent: Thursday, November 04, 2010 2:24 AM

To: russg@re-aim.net; Glasgow, Russ (NIH/NCI)

Cc: falmeida@vt.edu; carlarst@eerp.usp.br

Subject: "Patient Assessment of Chronic Illness Care (PACIC)"

Dear Dr.Glasgow,

I am a nurse and doctor's student at the University of São Paulo at Ribeirão Preto College of Nursing, WHO Collaborating Centre for Nursing Research Development, Brazil, and have been studying the chronic illness care of diabetes mellitus patients since my master degree.

I have read about the instrument "Patient Assessment of Chronic Illness Care (PACIC)" you developed and would like to receive further information. Currently in Brazil we have not any instrument to assess the quality of care in chronic illness.

I did not find brazilian studies that has been translated and validated the PACIC.

I would like to request your authorization to use the PACIC in this study with brazilian context.

Do you authorize?

I look forward to your reply.

Yours sincerely,

MSc. Camila Aparecida Pinheiro Landim

University of São Paulo at College of Nursing - WHO Collaborating Centre for Nursing Research Development Avenue Bandeirantes, 3900 - Campus Universitário, 14040902, Ribeirão Preto, Brazil

E-mail: camilaapapila@usp.br 
ANEXO C - Autorização inicial para a tradução, adaptação cultural e validação do instrumento Patient Assessment of Chronic Illness Care (PACIC) em Portugal

> From: russ.glasgow@nih.gov

> To: camilaapapila@hotmail.com

> Date: Sat, 21 Jan 2012 18:10:28 -0500

$>$ Subject: Re: Authorization PACIC to Portuguese [Portugal]

$>$

$>$ Yes- you have permission to conduct the activities noted below.

$>$

$>$ Thanks for your interest, and best regards,

$>$

$>$ Russ

$>$

$>$

$>$ Russell E. Glasgow, Ph.D.

$>$ Deputy Director, Implementation Science

$>$ Division of Cancer Control and Population Sciences

$>$ National Cancer Institute

$>$ Room 6144

> 6130 Executive Blvd., Rockville, MD 20852

> On 1/17/12 7:34 PM, "Camila Landim" <camilaapapila@hotmail.com> wrote:

$>$

$>$

$>$ Dear Dr. Glasgow,

$>$

$>$

> I hope this e-mail finds you and your family well! I am not sure you remember me, but I wrote to you last year seeking authorization to use and adapt the "Patient Assessment of Chronic Illness Care" (PACIC) to Portuguese within the Brazilian context. Since that authorization we have translated, back-translated and started the testing of the instrument here in Brazil. We have also continued to collaborate with Dr. Fabio Almeida, and is now part of our team.

$>$

$>$

$>$ I write to you today to seek yet another authorization. I have just received a scholarship to go to Portugal (School of Nursing - University of Porto) and also conduct my proposed study in Portugal. Although both countries speak Portuguese, there are some significant cultural differences between the two countries. With that in mind, I have started the process to adapt the PACIC instrument to the Portuguese 
culture. As such, in order to gain approval from the Institutional Review Board (here we call it Ethics board), they require that I obtain your authorization once again for the use of your instrument here in Portugal.

$>$

> Having said that, would you grant me permission to move forward with the translation, back-translation, adaption, and testing of the PACIC instrument in Portugal?

$>$

$>$

$>$ A simple e-mail reply indicating your authorization would suffice for the Ethics Board.

$>$ I look forward to your reply.

$>$

$>$

$>$

$>$ Yours Sincerely,

$>$

$>$ Camila Landim

$>$

$>$

$>$ MSc. Camila Aparecida Pinheiro Landim

$>$ University os Sao Paulo at College of Nursing

$>$ WHO Collaborating Centre for Nursing Research Development (PhD Student)

$>$ Avenue Bandeirantes, 3900 - Campus Universitário, 14040902, Ribeirao Preto, Brazil

$>$ E-mails camilaapapila@hotmail.com / camilaapapila@usp.br 
ANEXO D - Recomendação para o seguimento das etapas de adaptação cultural do instrumento PACIC, conforme World Health Organization - WHO (2012)

From: austin.b@ghc.org

To: camilaapapila@usp.br

CC: falmeida@vt.edu

Date: Wed, 16 Nov 2010 16:00:33 -0700

Subject: RE: contact

Dr. Landim,

I am not aware that the PACIC has been translated into Portuguese.

If you do so, please send us a copy so we can share with others. As you may already know, our web site has information on the existing translations of the PACIC, and includes our request that you follow the WHO's "Process of translation and adaptation of instruments" protocol in creating your translation.

http://www.improvingchroniccare.org/index.php?p=Versions\&s=206

Thanks,

Brian Austin 
ANEXO E - Autorização para a utilização dos formulários de Impressão Geral e Específica do Projeto DISABKIDS ${ }^{\circledR}$

\author{
UNIVERSIDADE DE SĀO PAULO
}

Escola de Enfermagem de Ribeirão Preło

Centro Colabcradior da OMS paru o Desenvalvimento da Pesquisc em Entermogem

\begin{abstract}
AUTORIZAÇÃO
Venho por este meio deciarar que concedo a autorização para a aluna de Doutorado Camila Aparecida Pinheiro Landim, projeto de pesquisa intifulado "Adaptaçao cuttural para o Brasil e Portugal do instrumento Pafient Assessment of Chronic lliness Care (PACIC)" e orientaçāo da Profa. Dra. Carla Regina de Souza Teixeira, utilizar os formulários de Impressão Geral e Específica do Projeto DISABKIOS , a fim de atender aos propósitos de realização da entrevista cognifiva no Brasil (Ribeirõo Preto) e em Portugal (Porto) conforme as recomendaçōes do processo metodológico adotado por WHO (2012).
\end{abstract}

Ribeirāo Preto, 11 de agosto de 2011

Profa. Dra. Cláudia Benedita dos Santos

Departamento de Enfermagem Materno-Infantil e Saúde Pública Escola de Enfermagem de Ribeirāo Preto

Universidade de São Poulo

E-mail: cbsantos@eerp.usp.br 


\section{ANEXO F - Parecer final do Comitê de Ética em Pesquisa (Brasil)}

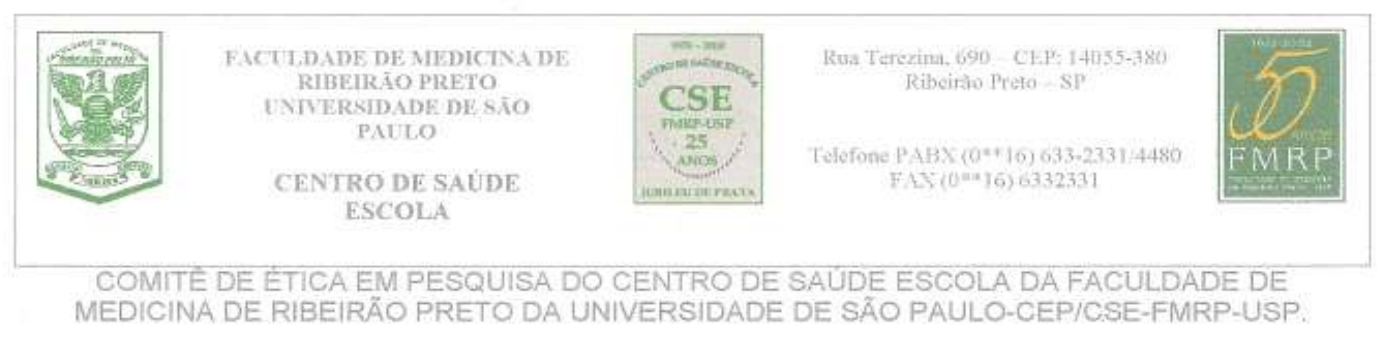

Ribeirão Preto, 09 de fevereiro de 2011.

Of. No.24/11/COORD.CEP/CSE-FMRP-USP.

Prezada Senhora,

Temos a grata satisfação de comunicar que o Comitê de Etica em Pesquisa do Centro de Saúde Escola da Faculdade de Medicina de Ribeirão Preto da Universidade de São Paulo, em reuniāo realizạda no dia 08/02/2011, aprovou o projeto de pesquisa: "Adaptaçăo cultural e validaça do instrumento Patient Assessment of Chronic lliness Care (PACIC), para o Brasil", e o Termo de Consentimento Livre e Esclarecido. Protocolo n $n^{\circ}$ 435/CEP-CSEFMRP-USP, tendo como pesquisadora Camila Aparecida Pinheiro Landim, Enfermeira Mestre em Cièncias. Doutoranda do Departamento de Enfermagem Geral e Especializada da Escola de Enfermagem de Ribeirão Preto-USP e Vossa Senhoria.

Lembramos que em atendimento à Resolução 196/96, deverá ser encaminhado a este CEP o relatório final da pesquisa e a publicação de seus resultados.

No ensejo, renovamos os votos de estima e consideração, despedimo-nos.

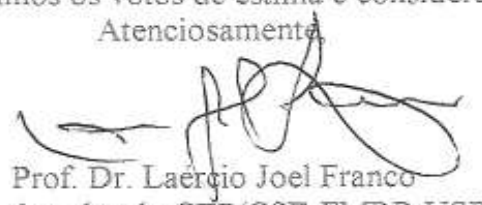

Coordenador do CEP/CSE-FMRP-USP

Ilma. Sra.

Prof: Dra. Carla Regina de Souza Teixeira

Departamento de Enfermagem Geral e Especializada da

Escola de Enfermagem de Ribeirão Preto-USP. 
ANEXO G - Parecer final da Comissão de Ética em Saúde (Portugal)

23.3 .2012

tomei un heevieeto.

Nado a spir.

รม்

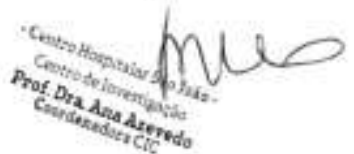

AUTORIZADO

Exma. Sra.

Dra. Margarida Tavares

Directora Clinica do Centro Hospitalar de São Jođ̊o

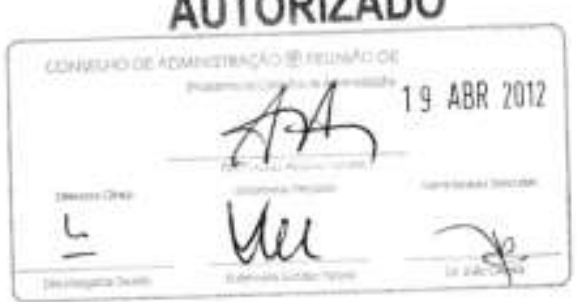

Assunto: Parecer da Comissão de Ética para a Saúde do Centro Hospitalar de São João

Projecto de Investigação: "Adaptą̧ão cultural e validaçâo do instrumento Patient Assessment of Chronic Whess Care para Partugal" - Enf." Camila Landim - Proj. 30/12

Junto envio a V. Exa. para obtençåo de decisão final do Conseiho de Administraçăo o parecer elaborado pela Comissão de Ética para a Saúde relativo ao projecto em epigrafe.

Com os melhores cumprimentos.

Porto, 13 de Março de 2012

O Secretário da Comissão de Ética para a Saúde

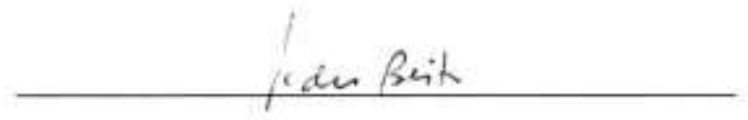


ANEXO H - Concordância do autor com a Versão em Inglês-Brasil (PACIC-VIBra)

From: russ.glasgow@nih.gov

To: camilaapapila@usp.br

Date: Thu, 22 Sep 2011 16:30:04 -0400

Subject: Re: Feedback and permission were received of the MacColl Center at GHC by Brian Austin to utilize PACIC in Brazil

\section{This is sufficient!}

\section{Please proceed with our approval and encouragement.}

\section{Best regards, Russ Glasgow}

From: Camila Landim <camilaapapila@usp.br>

To: russg@re-aim.net < russg@re-aim.net>; Glasgow, Russ (NIH/NCI) [E]

Sent: Thu Sep 22 16:22:46 2011

Subject: Feedback and permission were received of the MacColl Center at GHC by Brian Austin to utilize PACIC in Brazil

Dear Prof. Russ,

I am Dr. Carla Teixeira's PhD student and we are in the process of finalizing the translation of the PACIC instrument into Portuguese to be used with a diabetic population. After completing the initial translation, review by experts in the field I Brazil, and adaptation to the cultural reality in Brazil, we have conducted a BackTranslation of the final Portuguese version.

I was received feedback and permission of the MacColl Center at GHC by Brian Austin to utilize PACIC in Brazil, and I just need your to confirm that this review is sufficient for your as well.

I know that You is a VERY busy guy, but a one-line reply might be enough to shake things loose.

As such, I am sending again a version of the Back-Translation PACIC instrument for you to review and compare with the original version, if it is possible. I am also attaching the original version of the PACIC instrument for easier access. 
Thank you!

Best regards,

MSc. Camila Aparecida Pinheiro Landim

University of São Paulo at College of Nursing - WHO Collaborating Centre for Nursing Research Development Avenue Bandeirantes, 3900 - Campus Universitário, 14040902, Ribeirão Preto, Brazil

E-mail: camilaapapila@usp.br

De: Austin, Brian (austin.b@ghc.org)

Enviada: quarta-feira, 21 de setembro de 2011 20:32:12

Para: 'Camila Landim' (camilaapapila@usp.br)

Camilla, thanks for sending the request on.

Dr. Glasgow has been referring people to us on PACIC issues, so let me try to help.

Thank you for all of the effort you have gone through on the translation and checking work. Overall, I think things look close. A few things that I am sure you already noted:

Because the scale has changed slightly, at least for the back-translation, you will need to be a little cautious about comparisons with other versions of the PACIC.

The back translation text looks very close, and you are welcome to utilize the instrument. Can we have a copy of your instrument for our web site to share with others, along with any instructions you create?

Thanks,

Brian Austin

Associate Director

MacColl Center at GHRI.

From: Camila Landim [mailto:camilaapapila@hotmail.com]

Sent: Wednesday, September 21, 2011 5:41 AM

To: Austin, Brian

Subject: FW: Attention: Urgent - Back-Translation PACIC Brasil - Camila Landim

Dear Dr. Brian Austin, 
I am Dr. Carla Teixeira's PhD student and we are in the process of finalizing the translation of the PACIC instrument into Portuguese to be used with a diabetic population. After completing the initial translation, review by experts in the field I Brazil, and adaptation to the cultural reality in Brazil, we have conducted a BackTranslation of the final Portuguese version.

As such, I have sent a version of the Back-Translation PACIC instrument for Dr. Glasgow to review and compare with the original version. I am also attaching the original version of the PACIC instrument for easier access. However, I can not be answered by Dr. Glasgow. He did not answer my e-mail. I'm very worried because I can not continue my study.

Please, could you help me?

Thank you!

Best regards,

\section{MSc. Camila Aparecida Pinheiro Landim}

University of São Paulo at College of Nursing - WHO Collaborating Centre for Nursing Research Development Avenue Bandeirantes, 3900 - Campus Universitário, 14040902, Ribeirão Preto, Brazil E-mail: camilaapapila@usp.br 
ANEXO I - Concordância do autor com a Versão em Inglês-Portugal (PACIC-VIPort)

From: glasgowre@mail.gov

To: camilaapapila@usp.br

Date: Thu, 1 Apr 2012 10:02:46 +0000

Subject: FW: PLEASE! contact - feedback - Back-Translation PACIC Portugal

\section{Camila,}

The back translation text looks very good, and you can utilize the instrument in your context.

Congratulations for the work you have gone on the translation into Portuguese.

\section{A lot of sucess}

Russ

From: camilaapapila@hotmail.com

To: glasgowre@mail.nih.gov; russ.glasgow@nih.gov

Subject: PLEASE! contact - feedback - Back-Translation PACIC Portugal

Date: Mon, 1 Apr 2012 05:25:27 +0000

From: camilaapapila@hotmail.com

To: glasgowre@mail.nih.gov

Subject: FW: contact - feedback - Back-Translation PACIC Portugal

Date: Fri, 28 Mar 2012 14:00:58 +0000 
From: camilaapapila@hotmail.com

To: russ.glasgow@nih.gov; glasgowre@mail.nih.gov

Subject: contact - feedback - Back-Translation PACIC Portugal

Date: Thu, 20 Mar 2012 14:52:42 +0000

Dear Dr. Glasgow,

For the pastcouple of years I have been working with Drs. Carla Teixeira (Brazil), Manuela Martins (Portugal) and Fabio Almeida on the translation and adaptation of your PACIC instrument to Portuguese from Brazil and Portugal. As you may remember, earlier this year you gave me and my thesis committee the approval to move ahead with the translation and adaption of PACIC to the Portuguese from Portugal. We have completed the translation and adaptation process, and now have reached the final step in the process, which is the back-translation of the document to English. We have completed the back-translation and I write to you today to ask if you could look over the back-translation document and let me know whether you approve the changes or not. To make it easier for viewing I took the liberty to highlight the changes made and am also including the original PACIC for your reference. As in the past, a simple reply back with your comments and or approval will suffice.

I look forward to hearing from you!

Many Thanks!!!

Camila Landim 